\author{
ZENTRUM \\ FÜR BIODIVERSITÄT UND NACHHALTIGE LANDNUTZUNG \\ SEKTION \\ BIOdIVERSITÄT, ÖKOLOGIE UND NATURSCHUTZ \\ - Centre of Biodiversity ANd Sustainable LAND USE - \\ SECTION: BIODIVERSITY, ECOLOGY AND NATURE CONSERVATION
}

\title{
Pollinator biodiversity, functional complementarity and dynamic plant-pollinator interaction networks
}

\author{
Dissertation zur Erlangung des Doktorgrades der \\ Mathematisch-Naturwissenschaftlichen Fakultäten der \\ Georg-August-Universität Göttingen
}

\author{
vorgelegt von \\ Diplom-Biologe \\ Jochen Fründ
}

aus

Schweinfurt

Göttingen, September 2011 
Referent:

Korreferent:

Tag der mündlichen Prüfung:
Prof. Dr. Teja Tscharntke

Prof. Dr. Stefan Vidal

08. November 2011 


\section{Contents}

Deutsche Zusammenfassung und Schlussfolgerungen 5

$\begin{array}{ll}\text { English Summary } & 8\end{array}$

Chapter 1: General Introduction 11

$\begin{array}{ll}\text { General Introduction } & 12\end{array}$

Box 1: Uniting functional complementarity and insurance effects of biodiversity on $\begin{array}{ll}\text { ecosystem processes and services } & 18\end{array}$

Research objectives $\quad 20$

$\begin{array}{ll}\text { Chapter outline } & 20\end{array}$

$\begin{array}{ll}\text { Study organisms and systems } & 22\end{array}$

$\begin{array}{ll}\text { References } & 28\end{array}$

Chapter 2: Bee diversity effect on pollination depends on functional complementarity $\begin{array}{ll}\text { and niche shifts } & 37\end{array}$

$\begin{array}{ll}\text { Abstract } & 38\end{array}$

$\begin{array}{ll}\text { Introduction } & 39\end{array}$

$\begin{array}{ll}\text { Methods } & 40\end{array}$

Results $\quad 46$

Discussion $\quad 52$

Acknowledgments $\quad 56$

$\begin{array}{ll}\text { Literature cited } & 57\end{array}$

Supporting Information for Chapter $2 \quad 62$

Chapter 3: Linné's floral clock is slow without pollinators - flower closure and plantpollinator interaction webs $\quad \mathbf{7 6}$

$\begin{array}{ll}\text { Abstract } & 77\end{array}$

Chapter 3 published Article $\quad 78$

$\begin{array}{ll}\text { Chapter } 3 \text { Supplementary Material } & 87\end{array}$

Chapter 4: Specialization of mutualistic interaction networks decreases towards $\begin{array}{ll}\text { tropical latitudes } & 102\end{array}$

$\begin{array}{ll}\text { Abstract } & 103\end{array}$ 
$\begin{array}{ll}\text { Chapter } 4 \text { published Article } & 104\end{array}$

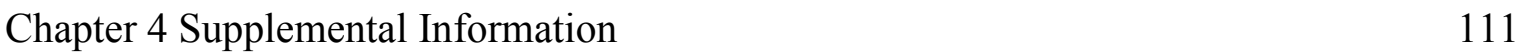

Chapter 5: Experimental environmental change and mutualistic vs. antagonistic $\begin{array}{ll}\text { plant flower-visitor interactions } & 127\end{array}$

$\begin{array}{ll}\text { Abstract } & 128\end{array}$

Chapter 5 published Article 129

Chapter 5 Appendix 135

Chapter 6: Response diversity of solitary bees to overwintering temperatures $\quad 138$

$\begin{array}{ll}\text { Abstract } & 139\end{array}$

$\begin{array}{ll}\text { Introduction } & 140\end{array}$

Materials and methods 141

$\begin{array}{ll}\text { Results } & 144\end{array}$

$\begin{array}{ll}\text { Discussion } & 147\end{array}$

$\begin{array}{ll}\text { Acknowledgements } & 151\end{array}$

$\begin{array}{ll}\text { References } & 151\end{array}$

$\begin{array}{ll}\text { Supplemental Material for Chapter } 6 & 156\end{array}$

$\begin{array}{ll}\text { Chapter 7: Synthesis } & 157\end{array}$

$\begin{array}{ll}\text { General Discussion } & 158\end{array}$

$\begin{array}{ll}\text { General Conclusions } & 161\end{array}$

$\begin{array}{ll}\text { References } & 162\end{array}$

$\begin{array}{ll}\text { Acknowledgments } & 164\end{array}$

Declaration: contribution of the author to multi-authored manuscripts 166

$\begin{array}{ll}\text { Curriculum Vitae } & 167\end{array}$ 


\section{Deutsche Zusammenfassung und Schlussfolgerungen}

Der weltweit $\mathrm{zu}$ beobachtende Rückgang der biologischen Vielfalt ist Besorgnis erregend und kann gravierende Konsequenzen für die Funktionsfähigkeit natürlicher Ökosysteme haben. Unter anderem könnte sich ein Rückgang der Artenvielfalt der bestäubenden Insekten negativ auswirken, da die Bestäubung für die Reproduktion und damit das langfristige Überleben der meisten Pflanzenarten essentiell und auch bei vielen der landwirtschaftlich genutzten Pflanzenarten ein wesentlicher Ertragsfaktor ist. Bestäubung durch Insekten stellt damit sowohl einen wichtigen Prozess innerhalb der Ökosysteme als auch eine wichtige ökosystemare Dienstleistung für den Menschen dar.

In Anbetracht des Rückgangs und der Gefährdung vieler Bienenarten wird in dieser Arbeit untersucht, welche funktionelle Bedeutung die Artenvielfalt von Bestäubern, insbesondere von Wildbienen, in der Natur hat. In Fortsetzung der funktionellen Biodiversitätsforschung, die sich bisher besonders auf die Artenvielfalt von Pflanzen konzentriert hat, werden verschiedenste Facetten der funktionellen Bedeutung von Wildbienendiversität in fünf Studien (Kapitel 2-6) mit überwiegend experimentellem Schwerpunkt untersucht. Weil in dieser Arbeit die Bedeutung der Bestäubung für Pflanzengemeinschaften im Mittelpunkt stehen soll, werden wiederholt die Netzwerke der Interaktionen zwischen verschiedenen Bestäuber- und Pflanzenarten betrachtet. Während in Kapitel 2 vor allem der direkte Effekt der Bienendiversität auf die Bestäubung von Wildpflanzen experimentell überprüft wird, werden in den übrigen Kapitel andere Aspekte der Bestäuberdiversität und damit verbundener Themen beleuchtet.

Kapitel 2 stellt die wichtigsten Ergebnisse eines umfangreichen Flugkäfigexperiments vor. In 55 Käfigen mit einer Fläche von $8 \mathrm{~m}^{2}$ wurde eine Gemeinschaft von 14 Pflanzenarten etabliert und eine bis fünf Bienenarten in unterschiedlichen Kombinationen eingesetzt, die angebotene Nistmöglichkeiten besiedelten. Mit diesem Versuch konnte erstmals experimentell nachgewiesen werden, dass Bienendiversität einen positiven Effekt auf die Bestäubung und den Samenertrag wildlebender Pflanzengemeinschaften hat. Allerdings hat die Artenzahl allein einen relativ geringen Erklärungswert im Vergleich zu mechanistischen Variablen, die den Komplementaritätseffekt einer Bienengemeinschaft vorhersagen. Als besonders wichtig zeigte sich dabei, wie gut die Bienenarten sich in Bezug auf die von ihnen besuchten Pflanzenarten und die von ihnen bevorzugten Witterungsbedingungen ergänzen. Hummeln scheinen dabei zwar eine Schlüsselrolle für die Bestäubung einzunehmen, aber diese kann nur in Kombination mit anderen 
Bienenarten voll zur Geltung kommen. Einige Pflanzenarten wurden nur besucht, wenn mehrere Bienenarten gemeinsam vorkamen - ein Verlust von Bienendiversität könnte sich also besonders auf artenreiche Pflanzengemeinschaften und die Bestäubung seltener Pflanzenarten auswirken.

Kapitel 3 befasst sich mit der tageszeitlichen Dynamik der Blüte-BestäuberInteraktionen. Es wird experimentell nachgewiesen, dass bestimmte Pflanzen ihre Blütenköpfe innerhalb von kurzer Zeit nach der Bestäubung schließen, aber ohne Bestäubung bis zum Abend geöffnet bleiben. Diese Reaktion verläuft so schnell, dass sie das tageszeitliche Muster der Blütenöffnung erklären kann, welches unter dem Namen „Linné's Blumenuhr“ bekannt ist und für das traditionell abiotische Faktoren und endogene Rhythmen verantwortlich gemacht wurde. Es wird gezeigt, dass die tageszeitliche Dynamik von Interaktionsnetzwerken stark vom Vorkommen von Pflanzen aus der entsprechenden Gruppe innerhalb der Korbblütler geprägt wird. Die tageszeitliche Veränderung des Blütenangebots und zeitliche Einnischung ist vermutlich auch für die Koexistenz von Arten von Bedeutung und sollte in zukünftigen Untersuchungen von Pflanze-Bestäuber-Interaktionen berücksichtigt werden. Der Zeitpunkt des Schließens der Blüten könnte möglicherweise auch zur effizienten Abschätzung des Bestäubungserfolgs genutzt werden.

Kapitel 4 präsentiert eine Studie, die die Spezialisierung in Interaktionsnetzwerken auf einer globalen Skala vergleicht. Entgegen der häufigen Annahme, Interaktionen in den Tropen seien besonders spezialisiert und Teil der Erklärung für die hohe tropische Artenvielfalt, zeigt diese Studie, dass komplementäre Spezialisierung mutualistischer Interaktionen (Bestäubung durch Blütenbesucher und Samenausbreitung durch Fruchtfresser) von gemäßigten Breiten zu den Tropen hin abnimmt. Stärker spezialisierte Interaktionen sind v.a. in Gebieten mit kälterem Klima $\mathrm{zu}$ finden. Bei den Samenausbreitungsnetzwerken scheint auch klimatische Stabilität und der Anteil von obligaten Fruchtfressern eine Rolle zu spielen. Diese Ergebnisse zeigen, dass Spezialisierung kein zwangsläufiges Produkt langer Ko-Evolution ist, und in Gebieten mit geringer Pflanzendiversität vermutlich begünstigt ist. Die komplementäre Spezialisierung bildet wiederum eine Grundlage für Bestäuberdiversitätseffekte auf Pflanzengemeinschaften.

In Kapitel 5 wird gezeigt, dass die Wirkungen unterschiedlicher Umweltveränderungen auf die Bestäubung nicht additiv sind, sondern voneinander abhängen, wodurch Vorhersagen über zukünftige Veränderungen erschwert werden. Mit einer experimentellen 
Feldstudie wurde der gemeinsame Einfluss von drei Umweltveränderungen auf Blütenbesuch und Samenansatz bei Ackersenf untersucht. Die Ergebnisse legen nahe, dass unterschiedliche Sensitivität verschiedener Bestäubergruppen gegenüber verschiedenen Umweltveränderungen zu einer Absicherung der Bestäubungsfunktion führt, obwohl die Anzahl und Diversität der blütenbesuchenden Bienen unter den natürlichsten Bedingungen (bei Kalk-Magerrasen zur natürlichen Blütezeit) mit Abstand am höchsten war. Außerdem zeigt diese Studie, dass Verschiebungen in der Blühphase, die durch Klimaerwärmung verursacht werden können, nicht unbedingt zu negativen Konsequenzen für die Pflanze führen müssen, da ein Verlust von Bestäuberinteraktionen durch eine Befreiung von Gegenspielern ausgeglichen werden kann.

In Kapitel 6 wird schließlich gezeigt, dass verschiedene Bienenarten unterschiedlich auf die Erhöhung der Überwinterungstemperaturen reagieren, und Bienendiversität daher response diversity beinhaltet, die eine Voraussetzung für Versicherungseffekte der Biodiversität ist. Neun verschiedene Bienenarten wurden in Klimaschränken bei Temperaturen von 1.5 bis $9.5{ }^{\circ} \mathrm{C}$ überwintert. Höhere Temperaturen während der Überwinterung wirkten sich auf das Gewicht der Bienen und den Schlupfzeitpunkt aus, wobei die Artunterschiede teilweise durch das Entwicklungsstadium während der Überwinterung und damit den natürlichen Flugzeitraum erklärt werden können. Dies zeigt, dass die Vorhersage von Effekten des Klimawandels genaueres Wissen über die Biologie unterschiedlicher Arten erfordert.

Abschließend lässt sich sagen, dass die fünf hier vorgestellten Studien neue Einblicke in die Funktionsweise von Pflanze-Bestäuber-Interaktionen auf ökosystemarer Ebene ermöglichen. Die verschiedenen Kapitel verdeutlichen, dass diese Interaktionen auf vielen Ebenen stark dynamisch sind. Die intermediär und variabel ausgeprägte Spezialisierung spielt dabei eine wesentliche Rolle für den Zusammenhang zwischen Bestäuberdiversität und Bestäubungsfunktion, der tendenziell positiv ist. Die Kenntnis artspezifischer biologischer Eigenschaften ist essentiell, um den ,Bestäubungswert ${ }^{\star}$ einer Bienengemeinschaft vorherzusagen, da die funktionelle Bedeutung nicht nur von der Artenvielfalt an sich bestimmt wird, sondern auch entscheidend durch Artidentität, funktionelle Komplementarität und response diversity. 


\section{English Summary}

Worldwide declines in biodiversity have prompted concerns about the functioning of ecosystems that may rely on it. This is also true for the pollination of plants, which is essential for the reproduction and thus long-term survival of most species and also an important ecosystem service essential for the production of many agricultural products. Animal species providing this service, particularly bees, are experiencing severe declines. In this thesis, I address the multifaceted aspects of the functional relevance of wild bee diversity, in the context of biodiversity-ecosystem functioning research that so far has primarily focused on primary productivity and consumptive interactions. The scientific background and important concepts are reviewed in chapter 1.

With a biodiversity experiment establishing caged communities of one to five bee species, chapter 2 shows that multiple bee species provide greater pollination services to a plant community than one bee species alone, and that the mechanism of this pollinator diversity effect is functional complementarity. Functional complementarity in the pollination of plant communities was determined by flower preferences that are partly a consequence of interspecific competition leading to increased visitation to poorly visited plant species. Furthermore, bumble bees are particularly important pollinators because they forage under weather conditions when most solitary bees are inactive. These differences explain why multiple species are needed to pollinate a plant community completely.

Chapter 3 focuses on within-day temporal patterns of plant-pollinator interactions. In a first step, the influence of pollination on the daily pattern of flower opening and closure known as "Linné's floral clock" is tested for a group of Asteraceae in a set of experiments. Flower heads closed rapidly in response to pollination, but were open until late afternoon otherwise. This finding contrasts to previous work attributing the time of flower closure to abiotic or endogenous factors only. In a second step, the consequences of this pattern for plant-pollinator networks are examined. Depending on plant species composition, early flower closure drives strong temporal dynamics in plant-pollinator interactions. This chapter suggests that flower closure may be used as an efficient proxy for pollination in the taxa showing such a response, and it reveals a possible mechanism enhancing coexistence and temporal specialization.

Chapter 4 presents a global study on mutualistic interaction networks that focused on complementarity specialization, which is important for ecosystem functioning such as 
pollination (as shown in chapter 2). The study revealed that, in contrast to traditional thinking, plant - flower visitor and plant - seed disperser interactions in tropical latitudes are less specialized than those in temperate regions. Strong complementary specialization, which is a precondition for strong complementarity effects regarding the relationship between pollinator diversity and pollination of plant communities, is probably more constrained in tropical regions with lower relative density of plant species, and favoured in regions with colder climate.

In chapter 5 the possibility of interactions among environmental change drivers is addressed, confirming that they cause high uncertainty in predictions. Consequences of three drivers for flower visitation and seed set of phytometer plants were studied in a fullfactorial field experiment: the loss of calcareous grasslands caused by land use change, phenological shifts due to climate change and increased plant height as a response to increasing nutrient levels. In contrast to concerns about synergistic interactions among environmental change drivers, bee visitation dropped strongest already after a single change. Results on seed set indicate that complementarity among different pollinator groups likely provides insurance against exacerbating consequences of global change, and shifts in flowering phenology may disrupt interactions not only with mutualists but also antagonists.

Chapter 6 experimentally shows that bee diversity provides response diversity to winter climate warming, confirming the precondition for an insurance effect of biodiversity for pollination. Nine species of solitary bees were overwintered in climate chambers presenting a finely resolved temperature gradient spanning the range of climate change predictions. Overwintering temperatures affected weight loss during winter and the time of emergence of bees, but the differences can be partly attributed to differences in life history (life stage during winter). This highlights the need for deeper biological knowledge on the species level for accurately predicting consequences of climate change, such as increased energy expenditure during diapause and possible mismatches between interaction partners in consequence of phenological shifts.

Taken together, the five chapters confirm that bee diversity is relevant for pollination and that diversity effects cannot be solely attributed to identity effects (driven by the most efficient pollinator). The underlying mechanisms are likely based on functional complementarity due to dynamic niche partitioning and physiological or life-history constraints. The dynamic and flexible nature of community-wide interactions among plants and pollinators is highlighted. The need for more detailed biological trait 
information of multiple species is shown, as a prerequisite for reliably estimating the pollination function of bee communities. The intermediate and variable degree of specialization of plant-pollinator interactions and of individual pollinator species is important in mediating pollinator diversity effects on various scales. The "pollination value' of bee communities is determined by functional complementarity, response diversity and species identity. 


\section{Chapter 1}

\section{General Introduction}

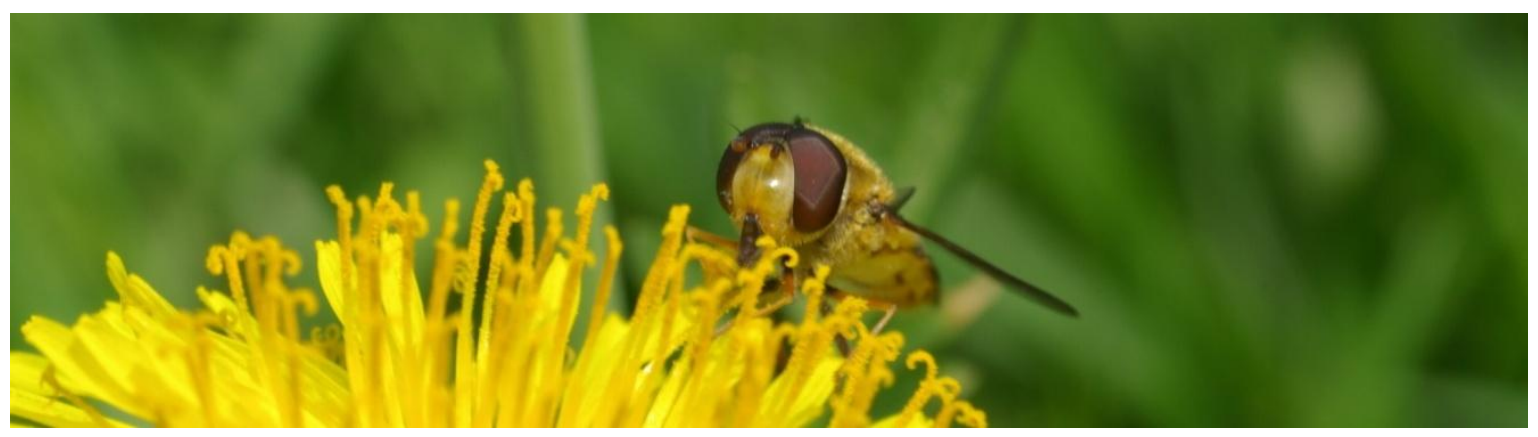

Photo by René Capell 


\section{General Introduction}

\section{Threatened Biodiversity}

Biological diversity is currently experiencing strong declines and is further threatened by global environmental change caused by humankind (Sala et al. 2000). Biodiversity refers to the diversity of biological forms at different levels of organisation, including genetic diversity, species diversity and ecosystem diversity (WRI et al. 1992). While some of the concepts may apply to different levels of biodiversity, this thesis focuses on species diversity, for which threats are best known. For example, one fifth of vertebrate species is considered as currently threatened by extinction in the IUCN Red List and the status of threat increases despite conservation effort (Hoffmann et al. 2010). One of the main reasons for current biodiversity declines is the intensification of land use, which involves destruction of natural or semi-natural habitats, increasing chemical inputs and simplification of landscape structure (Tscharntke et al. 2005). In central Europe, extensively used semi-natural grasslands are particularly rich in biodiversity, but changing and disappearing (WallisDeVries et al. 2002). Other drivers of biodiversity loss include invasive alien species introduced due to increased global exchange and climate change caused by greenhouse gas emissions (Sala et al. 2000). Concerns about biodiversity declines have reached out to politicians and policy-makers, who are trying to develop counteractions (United Nations 1992).

\section{Biodiversity and ecosystem functioning}

A common argument for the conservation of biodiversity is that it is important for the functioning of natural ecosystems and ecosystem services provided to humankind, such as air and water purification, nutrient retention, and pollination of crop plants (Kremen 2005). Other arguments may also be important, including ethical concerns about the intrinsic value, but may be less accessible to scientific testing. Numerous studies have shown that species diversity can positively affect ecosystem processes such as primary productivity and trophic interactions (Loreau et al. 2001; Balvanera et al. 2006; Cardinale et al. 2006; Duffy et al. 2007; Scherber et al. 2010), but this effect is far from universal (Bengtsson et al. 2002). Much of the previous research on biodiversity - ecosystem functioning relationships has focused on experimental manipulation of grassland plant species richness (Tilman \& Downing 1994; Hector et al. 1999; Scherber et al. 2010), and to a minor extent on aquatic systems (e. g. Emmerson et al. 2001), often in microcosms (e. 
g. Cardinale et al. 2002). Studies focusing on the diversity of higher trophic levels in terrestrial systems have emerged more recently (e. g. Tylianakis et al. 2006; Finke \& Snyder 2008). Still, most studies focus on processes related to biomass turnover (Duffy et al. 2007), and many other types of processes remain poorly addressed (but see Scherber et al. 2010).

Positive effects of biodiversity on ecosystem functioning can be explained by different mechanisms, which can be conceptionally divided into selection (or sampling or identity) effects and complementarity effects. In selection effects, the most effective species determines the community effect and the probability for its presence increases with diversity. In complementarity effects, the combination of functionally different species is responsible for the community effect and the functional performance of the community can be higher than for any individual species (Loreau \& Hector 2001; Loreau et al. 2001). Both groups of mechanisms have been shown to be relevant in some cases, but their general relevance is still under debate (Cardinale et al. 2006; Blüthgen \& Klein 2011). Complementarity effects in this general definition can be caused by different ecological processes, including resource partitioning of species with different niches (Finke \& Snyder 2008; Cardinale 2011) and interspecific interactions such as facilitation (Cardinale et al. 2002; Greenleaf \& Kremen 2006). On larger scales, biodiversity can also be functionally important by providing an insurance against environmental changes and fluctuations (Naeem \& Li 1997; Yachi \& Loreau 1999; Box 1).

\section{Pollination and diversity}

Pollination by insects or other animals is essential for a majority of plant species, including crops (Klein et al. 2007) and wild plants (Kearns et al. 1998; Ollerton et al. 2011). Reproduction of many wild plants has been found to be limited by pollination under multiple conditions (Ashman et al. 2004; Knight et al. 2005). The ultimate reason for (cross) pollination is genetic exchange, but this is difficult to consider on ecological scales. In most cases, pollinators visit the flowers for floral rewards including nectar, pollen, oil or scent (Pellmyr 2002). Pollinators comprise bees and other insects, mainly flies, beetles, butterflies and moths (Pellmyr 2002). In tropical regions, highly eusocial bees (honeybees and stingless bees) often play a dominant role (Klein et al. 2008). Outside Europe, vertebrates can also be important pollinators (Pellmyr 2002). Flowers of most plants are visited by different species of animals (Waser et al. 1996), but not all visitors are good pollinators and they can strongly vary in effectiveness (Herrera 1987). 
Measuring actual pollination success is often a challenging task (Dafni 1993). Bees are generally the most important group of pollinators and their life cycles are closely tied to flowers (Kearns et al. 1998). As bees need multiple habitats, they are also particularly vulnerable to land use change (Westrich 1996). In consequence, population declines and local extinctions of bee species have been reported repeatedly (Allen-Wardell et al. 1998; Biesmeijer et al. 2006; Brown \& Paxton 2009; Potts et al. 2010; Cameron et al. 2011). In Germany, $52 \%$ of the 560 bee species are included in the Red List of threatened species (Westrich et al. 2008). The importance of wild bees (referring to all bees except managed honeybees) as crop pollinators may increase in the face of declines of honeybee (Winfree et al. 2007), which are threatened by several factors (De la Rúa et al. 2009).

Positive correlations between floral diversity and pollinator or bee diversity have been found in several cases (Steffan-Dewenter \& Tscharntke 2001; Potts et al. 2003), which may often be explained by a bottom-up effect of plant diversity (Ebeling et al. 2008; Fründ et al. 2010). Diverse floral communities provide resources for more pollinator species and enhance coexistence. However, whether the diversity of pollinators has a positive effect on pollination function has rarely been tested, partly because it is often confounded with pollinator abundance (Steffan-Dewenter \& Tscharntke 1999; e. g. Kremen et al. 2002; Potts et al. 2006). In real-world scenarios, pollinator diversity loss may also be coupled with declining pollinator abundance when there is no density compensation (Larsen et al. 2005; Winfree \& Kremen 2009). Klein et al. (2003) and Hoehn et al. (2008) found a positive relationship between bee species richness and pollination service to crops (coffee and pumpkin) in Indonesian agroforests. In both cases, complementarity effects caused by niche partitioning among bee species may have been responsible (Hoehn et al. 2008; Tylianakis et al. 2008b).

The first step towards a pollinator diversity experiment was done by Fontaine et al. (2006), who compared two levels of pollinator group diversity (bumblebees, hoverflies and their combination). They found highest reproduction of a plant community when both groups were present, and that functional complementarity may be involved in the underlying mechanisms. However, experimental conditions were fairly restricted: pollinators were introduced into cages for only a few hours, no nests were present, and abundance and species composition were not completely controlled for. Therefore, it is difficult to relate these first experimental results to observed declines in bee diversity. In the context of pollinator declines, it is further relevant whether some pollinator species are more important than others and play key roles for providing the pollination function 
(Ghazoul 2005). This was found in a few studies on pollination of individual plant species, leading to species identity effects strongly influencing the relationship between pollinator diversity and pollination (Larsen et al. 2005; Gómez et al. 2007; Perfectti et al. 2009). Strong variation in the importance of pollinator species has also been suggested for plant communities, highlighting the key function of highly generalist pollinators (Bascompte et al. 2003; Guimarães Jr et al. 2011). This would mean that pollinator diversity 'per se' may not be the best predictor of functional importance of bee communities.

\section{Networks and specialization}

Patterns of interactions among entire communities of plants and pollinators (or other mutualists such as seed-dispersers) are usually described as interaction networks (Bascompte \& Jordano 2007; Blüthgen 2010). The understanding of interactions at the network or community level is essential to understand the relevance of pollinator diversity for the pollination of plant communities. A common effort in research on ecological interaction networks aims on identifying the degree of specialization in the interactions (Blüthgen 2010). The traditional view of highly specialized adaptations in pollination systems ('syndromes') has been challenged by emphasizing generalization in plantpollinator interactions (Waser et al. 1996; Ollerton et al. 2009), but quantification of specialization on the network level and comparing it among communities remains a challenge (Ollerton \& Cranmer 2002; Blüthgen et al. 2008). This is also true for global scales: while it is known that abiotic pollination is more important in tropical than in temperate regions (Ollerton et al. 2011) and tropical plant-pollinator interactions are often perceived as highly specialized (Bawa 1990), latitudinal gradients in pollination specialization were not found by studies with a community perspective (Ollerton \& Cranmer 2002; Dupont et al. 2009).

It is generally unknown to what extent the structure of interaction networks is determined by invariable species properties (Santamaria \& Rodriguez-Girones 2007; Stang et al. 2009), and to what extent it is the outcome of possible interspecific competition among pollinators (Palmer et al. 2003; Vazquez et al. 2009; Fründ et al. 2010). Dynamics in plant-pollinator interaction networks are beginning to be recognized: link structure may be flexible after species loss (Kaiser-Bunbury et al. 2010) and temporal dynamics within and between years are now realized (Alarcón et al. 2008; Olesen et al. 2008; Petanidou et al. 2008; Dupont et al. 2009; Burkle \& Alarcón 2011). Temporal patterns within a day are known for flower opening and closure (van Doorn \& van 
Meeteren 2003) and for bee activity (Stone et al. 1999), but have not been considered in the network context (but see Baldock et al. 2011; Fründ et al. 2011 this thesis).

Specialization should also be of particular importance for the relationship between biodiversity and ecosystem functioning: complementarity effects are expected for communities with high specialization and niche partitioning, but not for communities with many redundant generalists (Finke \& Snyder 2008; Blüthgen \& Klein 2011). Most previous studies on pollinator diversity effects have focused on pollination of individual plant species. In this case, spatio-temporal niche partitioning may be of particular importance in determining the functional value of specific bee communities (Hoehn et al. 2008; Blüthgen \& Klein 2011). However, when the focus is on pollination of plant communities leading to a network perspective, niche partitioning according to plant species or floral traits gains importance (Blüthgen \& Klein 2011).

\section{Biodiversity effects in the face of global change}

The main drivers of biodiversity change include habitat destruction, climate change and enrichment of nutrients such as $\mathrm{CO}_{2}$, nitrogen and phosphorous (Sala et al. 2000). When multiple drivers act simultaneously, there is also concern about interactive and possibly synergistic effects that amplify the negative effects of single drivers (Brook et al. 2008; Tylianakis et al. 2008a). This multitude of environmental changes is the basis for an additional value of biodiversity (Box 1). The insurance hypothesis says that biodiversity is important for functioning because it sustains functioning under variable conditions and confers resilience and stability to ecosystems (Yachi \& Loreau 1999; Bengtsson et al. 2003). This can happen if species react differently to different changes ("response diversity": Elmqvist et al. 2003) and are functionally redundant, such that new species can take over functions if previously important species are declining or get extinct. This is one aspect of the generally positive relationship between diversity and stability (Doak et al. 1998; Ives \& Carpenter 2007). Indices of functional diversity should help to get closer to mechanistic explanations of biodiversity effects and make accurate predictions in the face of environmental change, but there is ongoing discussion about which methods are most appropriate (Petchey \& Gaston 2006; Villéger et al. 2008; Laliberté \& Legendre 2010).

With respect to pollinator diversity, functional redundancy as a prerequisite for insurance effects is generally assumed as most pollinator species are generalised to some extent and most plant species can be pollinated by different plant species (Waser et al. 1996; Memmott et al. 2004; Vazquez et al. 2005), although the extent of functional 
redundancy is controversial (Blüthgen \& Klein 2011). Whether pollinator or bee diversity also implies response diversity is largely unknown, but it was found that different pollinator guilds respond differently to land use patterns at the landscape scale (SteffanDewenter et al. 2002; Jauker et al. 2009) and one study has shown response diversity among bee species to the amount of native vegetation (Winfree \& Kremen 2009). 


\section{Box 1: Uniting functional complementarity and insurance effects of biodiversity on ecosystem processes and services}

The concepts of complementarity and insurance effects of biodiversity are related. For clear conclusions, both require to define a focal function (i.e. a process or service of interest). Different views on these concepts fall into three categories.

\section{The effect vs. response diversity view}

This view (Fig. B1) is based on a concept separating functional traits into response and effect traits (Naeem \& Wright 2003; Hooper et al. 2005): response traits determine how a species responds to environmental change, while effect traits determine the ecological function performed by the species. If species differ in effect traits, they are functionally complementary and complementarity effects lead to a positive relationship between biodiversity and ecosystem functioning. If species are similar in effect traits, they are functionally redundant and no immediate positive effect of biodiversity is expected. However, if redundant species differ in response traits, an insurance effect of biodiversity (Yachi \& Loreau 1999) is expected: these species buffer the function against environmental fluctuation or future threats. Therefore, the precondition for insurance effects is response diversity (Bengtsson et al. 2003; Elmqvist et al. 2003; Laliberte et al. 2010) in addition to redundancy.
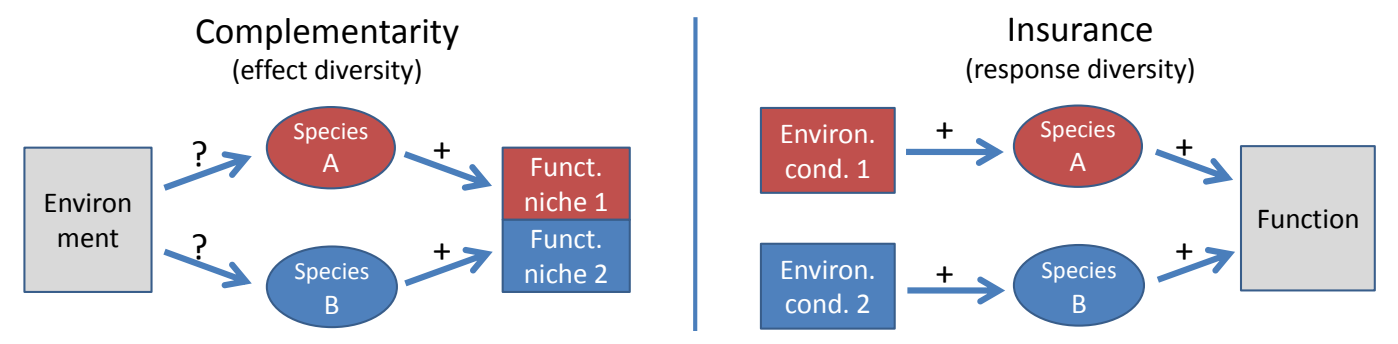

Figure B1: insurance and complementarity effects are separate things in the 'effect vs. response diversity view'. Abbreviations: Environ. cond. 1 = environmental condition 1; Funct. niche 1 = functional niche 1.

\section{The mean vs. variability view}

The relationship between biodiversity and stability has been a focus of ecology for much longer than the insurance hypothesis (MacArthur 1955; Ives \& Carpenter 2007). Based on this tradition, many studies separate the two concepts by either focusing on the mean functional performance (complementarity) or its variability (insurance) (Tylianakis et al. 2006; Ebeling et al. 2008). According to this view (Fig. B2), complementarity effects may be an explanation for increasing mean function with biodiversity, while insurance effects refer to the increasing stability of the function (irrespective of changes in mean function). The decreased variability of function is mainly interesting when it translates into mean changes of a derived function, e.g. reducing the chance of exceeding thresholds with drastic consequences. As this view does not explicitly consider species traits, this type of insurance effects can also be caused by stochastic fluctuations (Doak et al. 1998). However, insurance is not always equated with reduced variability: major proponents of the insurance hypothesis consider both a decrease in variance and an increase in mean as insurance effects of biodiversity (Yachi \& Loreau 1999; Loreau et al. 2003). 


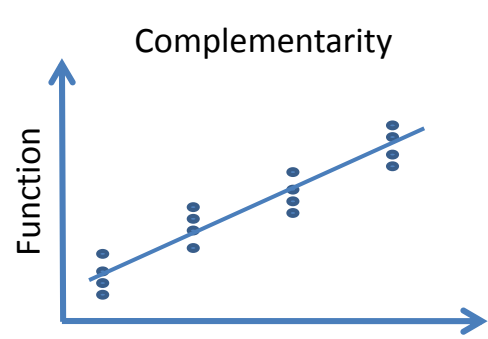

Number of Species

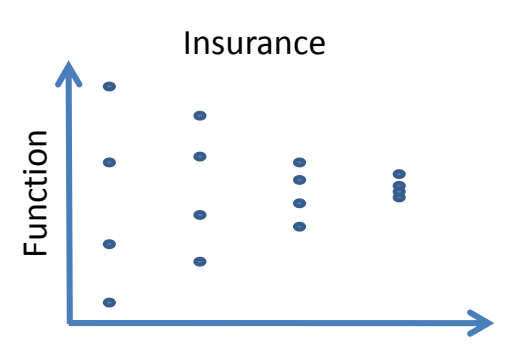

Number of Species

Figure B2: insurance and complementarity effects in the 'mean vs. variability view'. 'Function' here refers to the value of a predefined variable being influenced by the species. Points indicate repeated measurements of the same function, e.g. at different points in time.

\section{The multiple scales view}

The separation of functional traits into response and effect may not always be as clear-cut as implied by the response diversity - redundancy concept. Especially when the focal function and the scale of interest are not precisely defined (which may be easier for applied problems than for general theory), complementarity and insurance can refer to the same effect (Fig. B3). The term insurance may then best be used for future option values or for temporal complementarity effects in general. However, also spatial insurance effects have been identified (Loreau et al. 2003; Tscharntke et al. 2007). When function on larger scales is considered (Bengtsson et al. 2002), species differences are more likely to be considered as insurance instead of complementarity effects: temporal niche partitioning within a day is seen as complementarity (Hoehn et al. 2008), while changing importance of species among years is more likely seen as insurance or stability (Haddad et al. 2011).

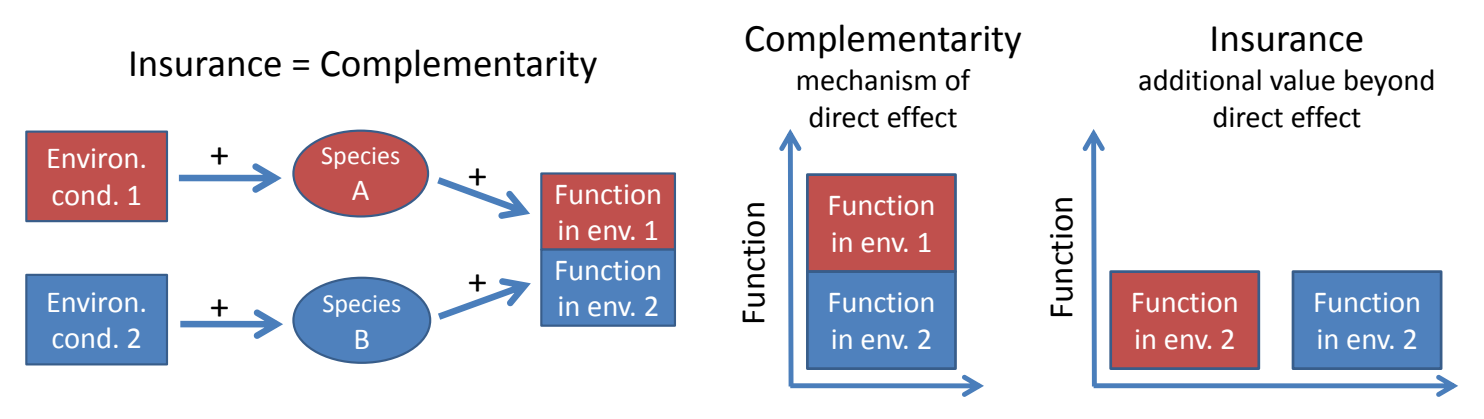

Figure B3: insurance and complementarity effects are two sides of the same coin in the 'multiple scales view'. Abbreviations: Environ. cond. 1 = environmental condition 1; Function in env. 1 = function under environmental condition 1.

\section{Conclusion}

Both concepts, complementarity and insurance, focus on interspecific trait differences leading to the functional value of species-rich communities. Both effects require that species provide different parts of a relevant combined function. The separation of the two effects will often be semantic unless the focal function and the scale of interest are clearly defined. The focus of the insurance hypothesis on future benefit makes it difficult to test, but further studies on the prevalence of response diversity and functional niche complementarity on multiple scales can further strengthen this important argument for the conservation of biodiversity. 


\section{Research objectives}

In this thesis, I tried to tackle the multiple aspects of pollinator biodiversity effects. The main underlying questions being addressed in one or more chapters were:

a) Does pollinator diversity have a positive effect on pollination of wild plants?

b) Are different pollinator species functionally complementary, i.e. do they have different functional niches in which they provide pollination?

c) How strong are daily temporal dynamics in plant-pollinator interactions and how are they related to daily patterns of flower opening and closure?

d) Do tropical and temperate mutualistic interaction networks differ in the degree of functional complementarity, i.e. specialization of pollinators and seed dispersers?

e) Can pollinator diversity provide an insurance against environmental change, including climate change and habitat destruction?

\section{Chapter outline}

Chapter 2 addresses questions (a) and (b), using a large pollinator biodiversity experiment that quantifies seed set of a diverse plant community in response to diversity and functional complementarity of up to five wild bee species. Functional complementarity is quantified by observing flower visitation in relation to plant species and temperature. The unique approach with each bee species being present in cages with and without other bee species allows to study the effects of bee diversity independent of bee abundance and to identify how plant-pollinator linkages are influenced by interspecific interactions among pollinators.

Chapter 3 focuses on question (c), combining different scales of investigation. Scrutinizing the reasons for the daily pattern of flower opening and closure known as "Linné's floral clock", it tests the effect of pollination on the time of flower closure by hand pollination experiments and comparison of the cages of the bee diversity experiment described in chapter 2. In a second step, it explores how this daily pattern influences plantpollinator interactions in a network context, using flower-visitor interaction data compiled 
on a set of different meadows, and discusses the consequences for the interpretation and design of field studies.

Chapter 4 focuses on question (d) and presents a global study on plant - pollinator and plant - seed disperser interaction networks. The study investigates global gradients in complementary specialization, which is relevant for objectives (b) and (e). The effects of latitude are compared to other factors providing possible mechanistic explanations, including current climate and past climatic stability as well as local and regional plant diversity.

Chapter 5, with an emphasis on question (e), addresses the possible interactions among environmental change drivers with a full-factorial field experiment. It is investigated how flower visitation and seed set of a generalized plant species are influenced by the presence of calcareous grasslands as a source habitat for pollinators, phenological shift as possible consequence of climate change and changes in plant height as a possible consequence of increasing nutrient levels.

Chapter 6 addresses another important aspect of question (e), the response of wild bees to changing winter temperatures. Nest cells of nine species of solitary bees are overwintered in climate chambers featuring a finely resolved temperature gradient to test whether bee diversity provides response diversity in metabolic and phenological sensitivity to climate change. 


\section{Study organisms and systems}

In this thesis, I studied plant-pollinator interactions in multiple different systems, focusing on the relationship between pollinator diversity and the pollination of wild plants. Plant-pollinator interaction networks typically involve many different species, and the relative importance may differ between sites, regions and on a global scale (Plates 13).Bees (Apiformes, Apoidea or Apidae, depending on taxonomic nomenclature) are generally the most important group of pollinators and the only major insect group whose larva depend entirely on floral resources (this life history is only shared with Masarinae, a small group of wasps, and some Coleoptera), and thus many parts of this thesis focuses on bees.

For the bee biodiversity cage experiment presented mainly in chapter 2, mesocosm communities were established consisting of up to five bee species (Plate 4) and 14 plant species (Plate 5). To enable near-natural behaviour of bees in the cages, nesting resources including species-specific requirements were provided in the cages (Plate 6). Cavitynesting solitary bees that colonize trap nests are a good model system that has been used successfully in previous studies (e. g. Tylianakis et al. 2007; Holzschuh et al. 2011), as live nests and brood cells can be accessed and handled more easily than for groundnesting bees. These bees were also used for chapter 6. Bumblebees, which are primitively (eu)social, can also be maintained in small colonies with queen and brood (Plate 6). Plant communities in the cages developed well and produced high numbers of flowers (Plate 7). Similar cages were used to isolate pollinators in the experiments on hand pollination effects on flower closure (chapter 3). Quantifying pollination success in relation to pollinator treatments, strong differences in fruit and seed set could be observed among different cages, most plant species producing no or few seeds in control cages (Plate 8 and 9). 

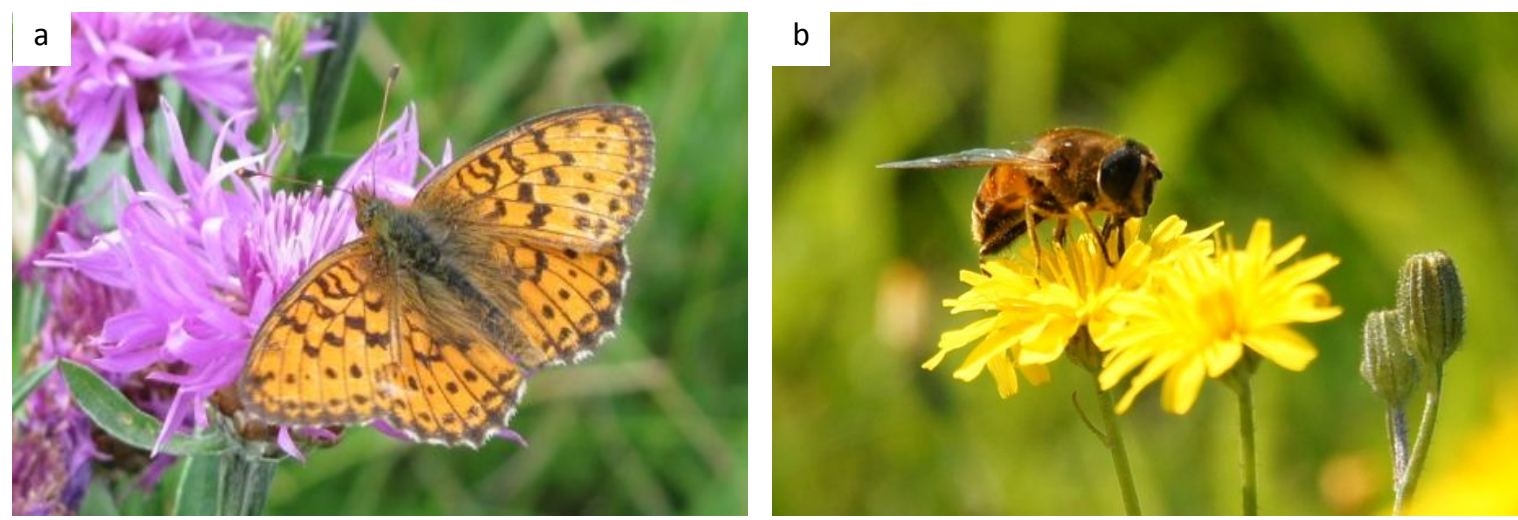

Plate 1: Among other insect pollinators, the orders Lepidoptera (a: Brenthis ino on Centaurea jacea) and Diptera (b: Eristalis sp. on Crepis capillaris, photo by Henning Schnellen) are most important.
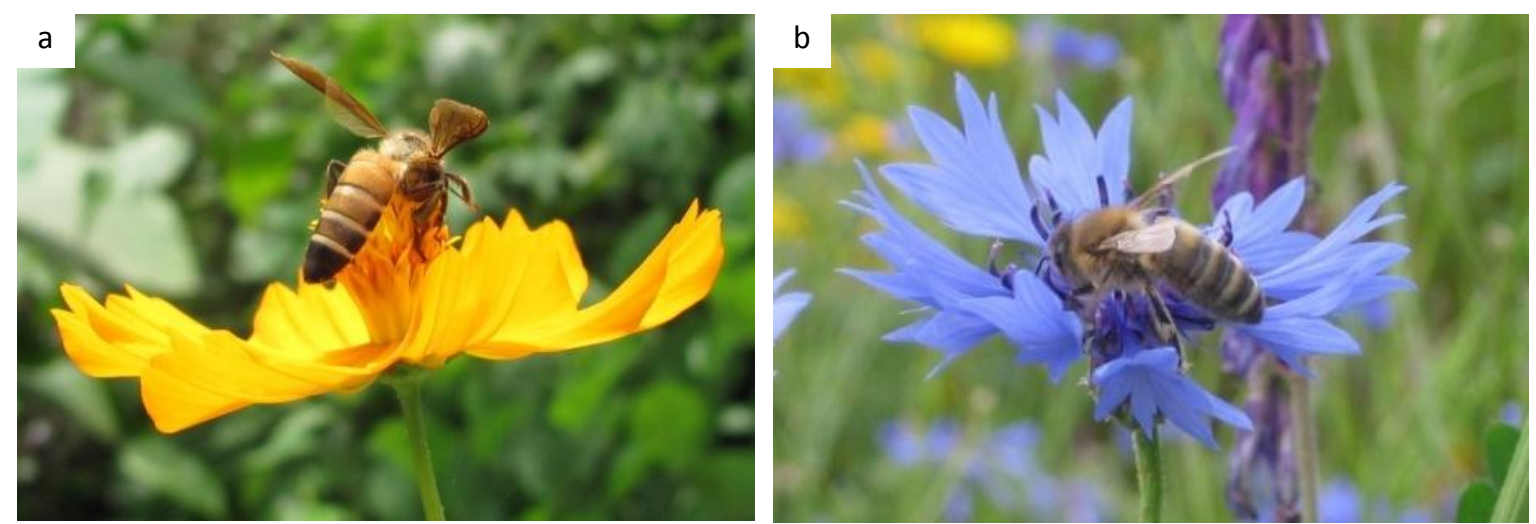

Plate 2: Different role of honeybees in different regions of the world: a) In the tropics, different species of highly social bees are often the main pollinators (giant honeybee, Apis dorsata, India). b) In Central Europe, the only highly social pollinator is a managed animal kept in beehives (European honeybee, Apis mellifera on Centaurea cyanea, Germany).
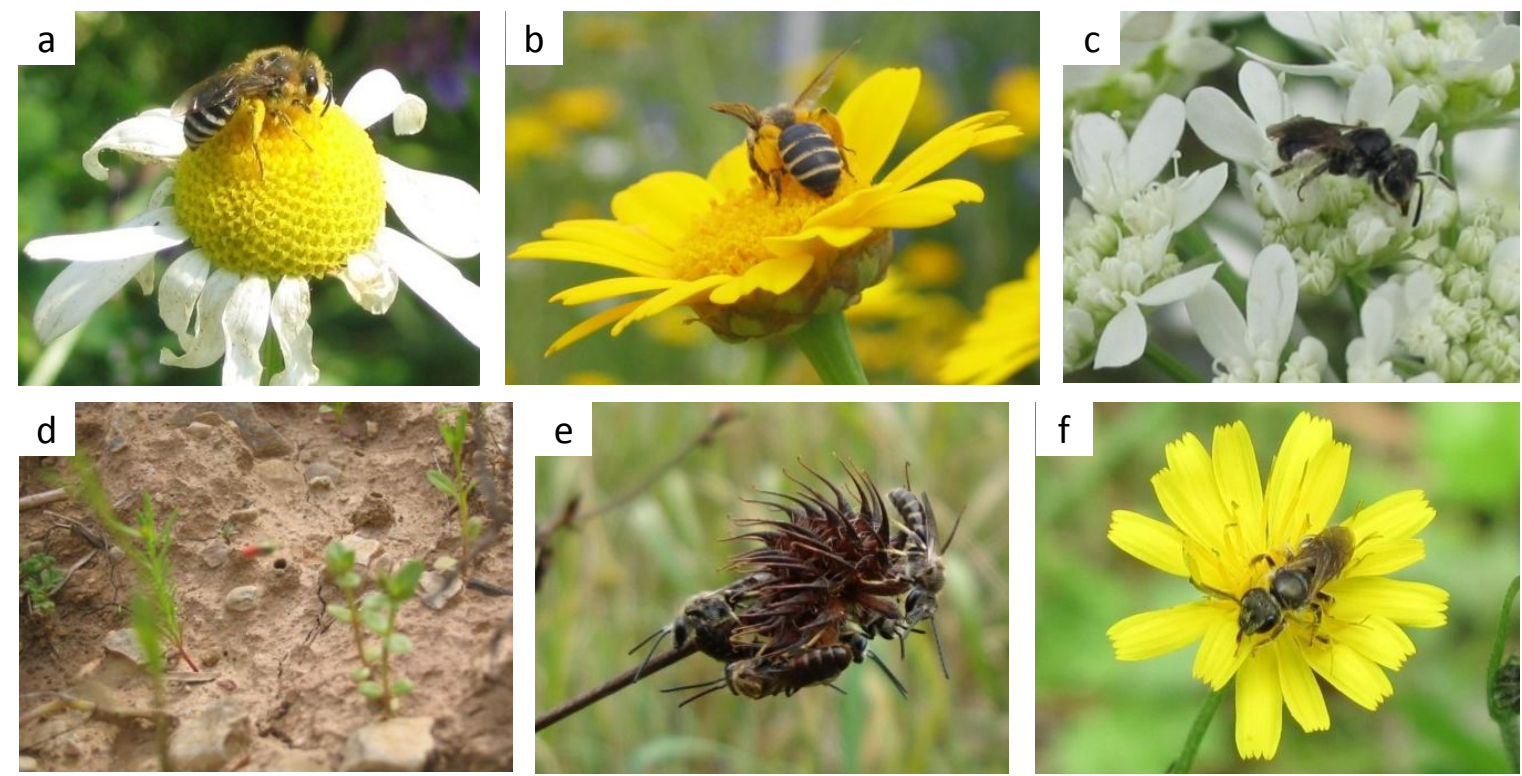

Plate 3: Wild bees in temperate regions are either solitary (a-c: Colletes cf. daviesanus on Tripleurospermum perforatum, Andrena cf. flavipes on Chrysanthemum segetum, Andrena cf. minutula on Orlaya grandiflora), or primitively social (d-f: Lasioglossum nest entrance, Lasioglossum sp. - males, Halictus cf. tumulorum on Crepis capillaris). 


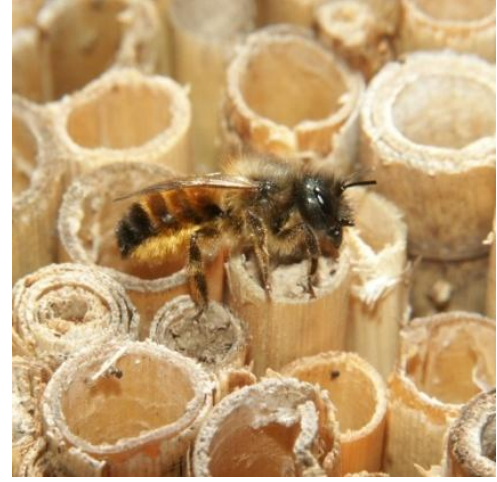

Osmia bicornis

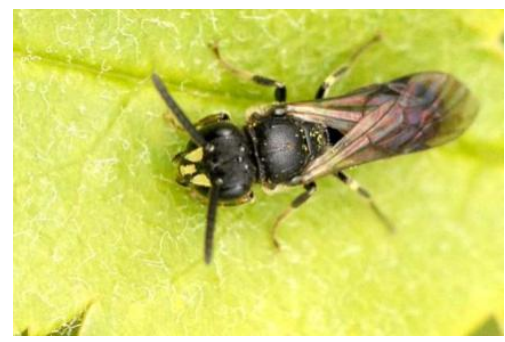

Hylaeus communis

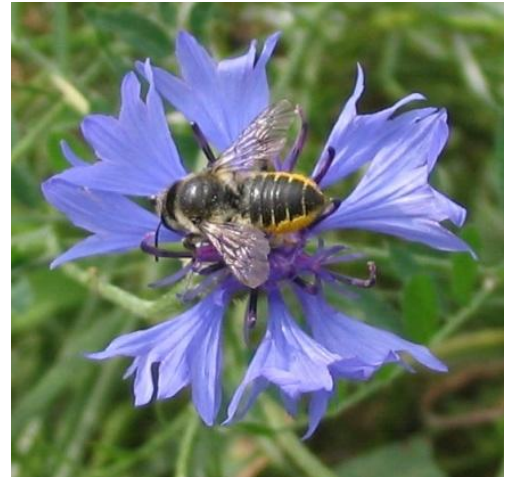

Megachile centuncularis

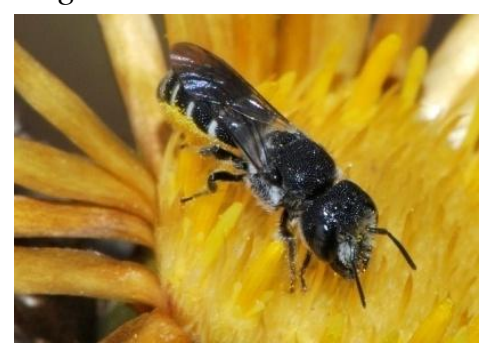

Heriades truncorum

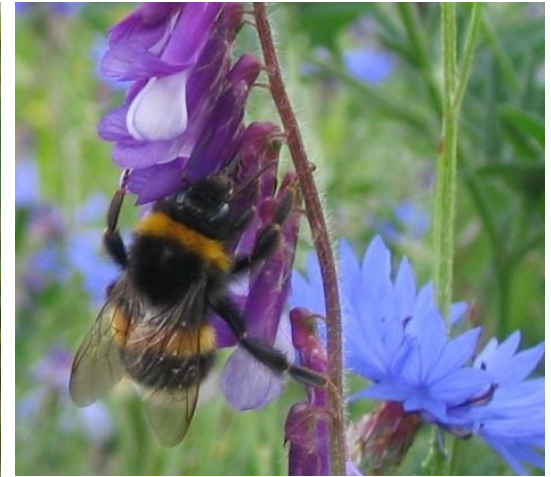

Bombus terrestris

Plate 4: The five bee species used in the bee biodiversity cage experiment. Photos by Jochen Fründ (Megachile, Bombus), Susanne Schiele (Osmia), James K. Lindsey (Hylaeus; licensed under Creative Commons) and Gideon Pisanty (Heriades; licensed under Creative Commons).

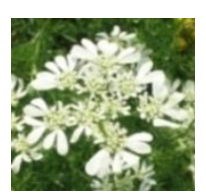

Orlaya grandiflora (Apiaceae)
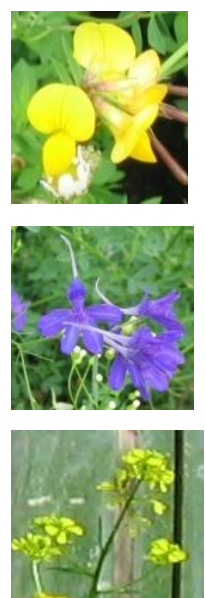

\section{Consolida} regalis
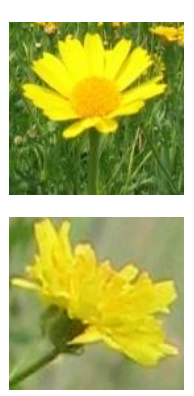
(Ranunculaceae)

Sinapis arvensis (Brassicaceae)

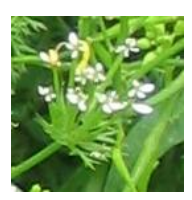

Chrysanthemum segetum (Asteraceae)

Crepis capillaris (Asteraceae)

Scandix pecten veneris

(Apiaceae)

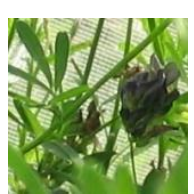
(Fabaceae)

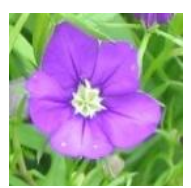

Legousia speculum-veneris (Campanulaceae)

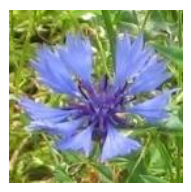

\section{Centaurea cyanus}

(Asteraceae)

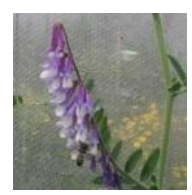

Vicia villosa

(Fabaceae)

Medicago x-varia other sown plants: Lamium purpureum (Lamiaceae), Anchusa arvensis (Boraginaceae), Calendula arvensis (Asteraceae)

Plate 5: flowers of the eleven sown plant species with peak flowering during the main phase of the bee biodiversity cage experiment. 

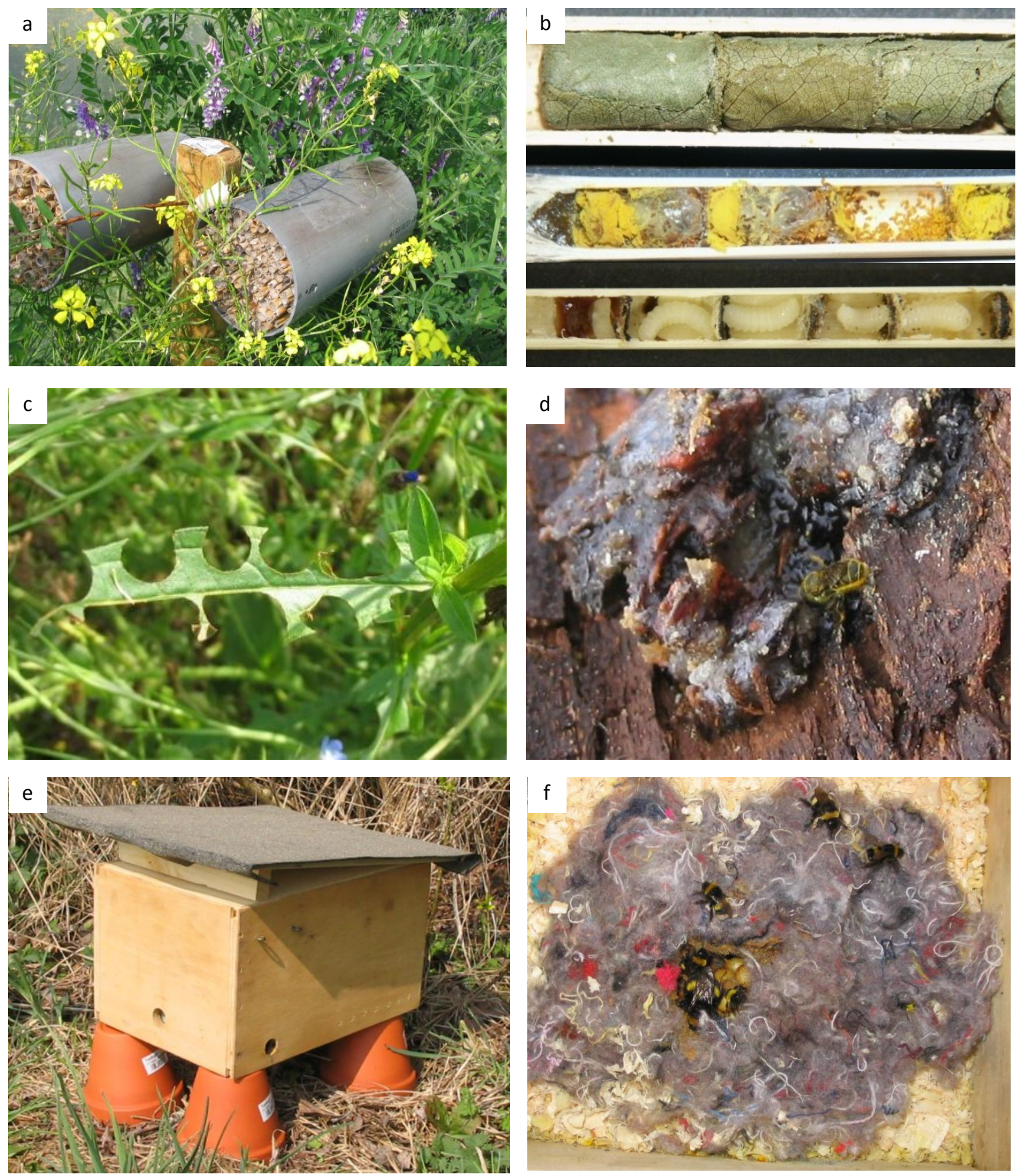

Plate 6: Bee nesting resources provided in the cages: a) trap nest for solitary species. b) Solitary bee nests in reed internodes (Megachile, Heriades, Hylaeus, photos by Susanne Schiele). Trap nests containing reed internodes were used both for acquiring the bees from the field and as nesting sites in the cages. c) Megachile cuts pieces of leaves and d) Heriades collects resin for nest construction (offered on bark pieces in the cages). e) Nest box for Bombus. f) Small Bombus colony in nest box, providing a substitute for an empty rodent nest. 

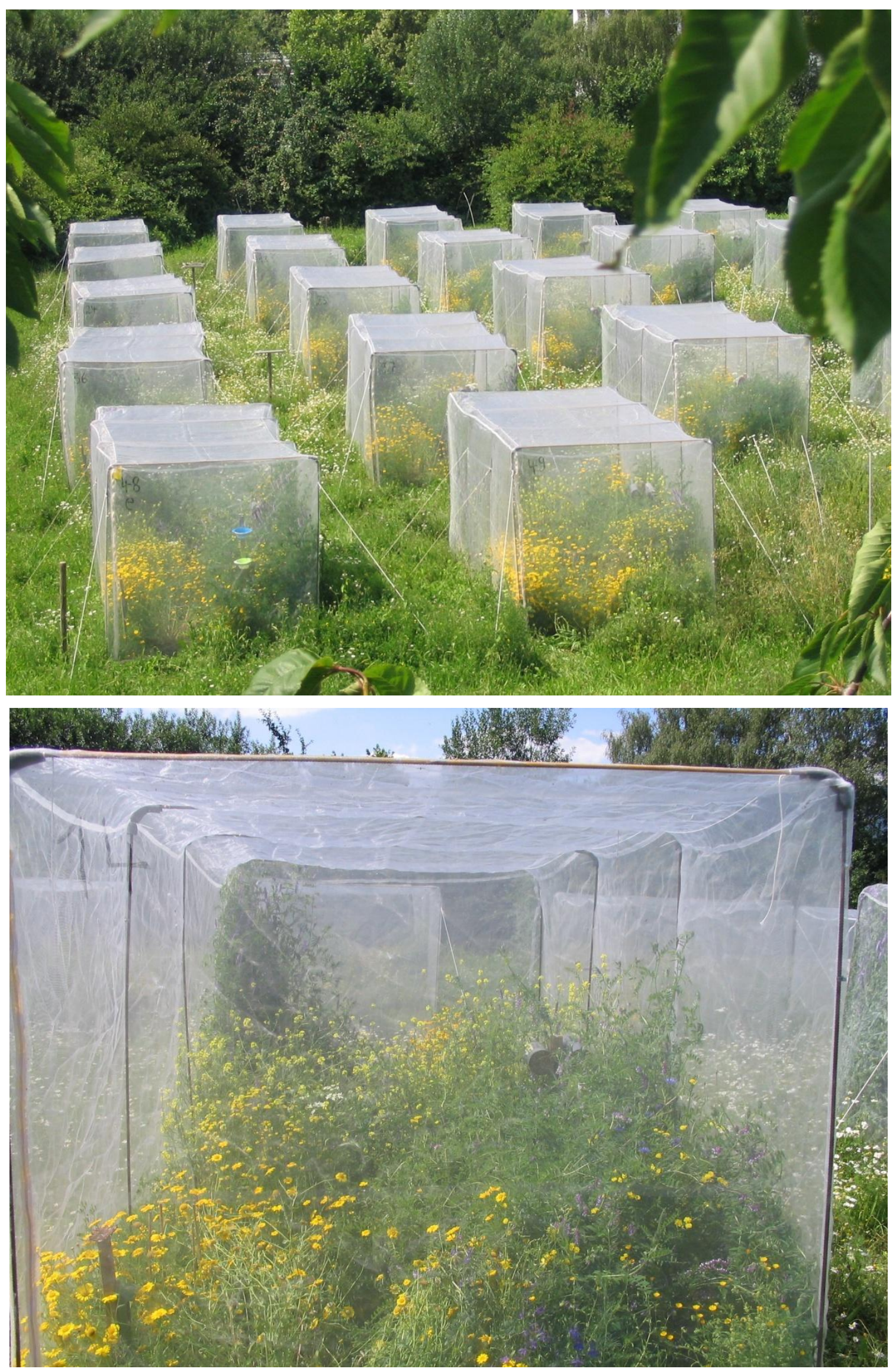

Plate 7: Close-up view of some of the cages in the bee biodiversity experiment. 


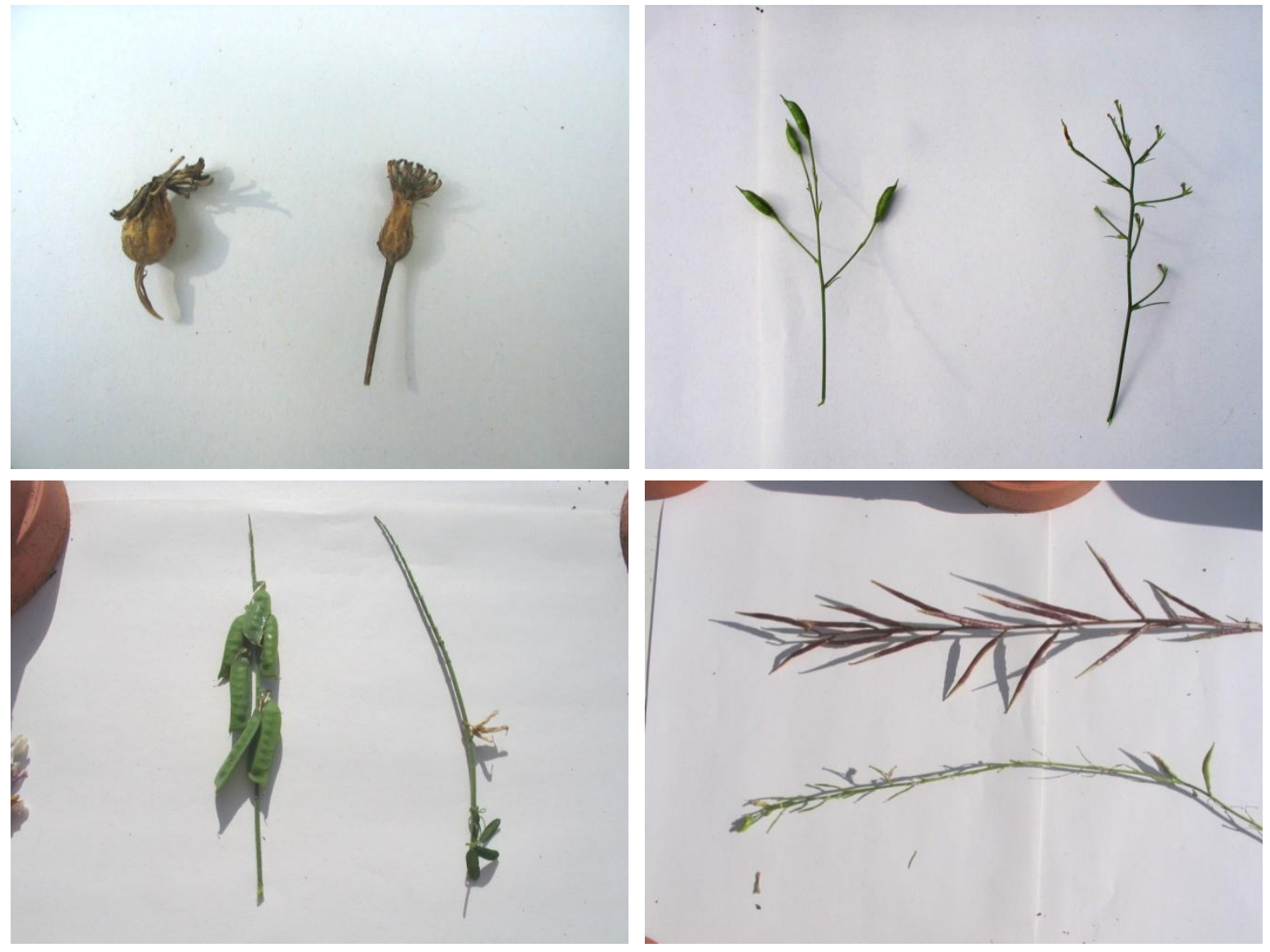

Plate 8: Fruit set of selected plant species in cages with bees (left in a-c, top in d) vs. cages without pollinators (right in a-c, bottom in d). a) Centaurea cyanus, b) Consolida regalis, c) Vicia villosa and d) Sinapis arvensis.
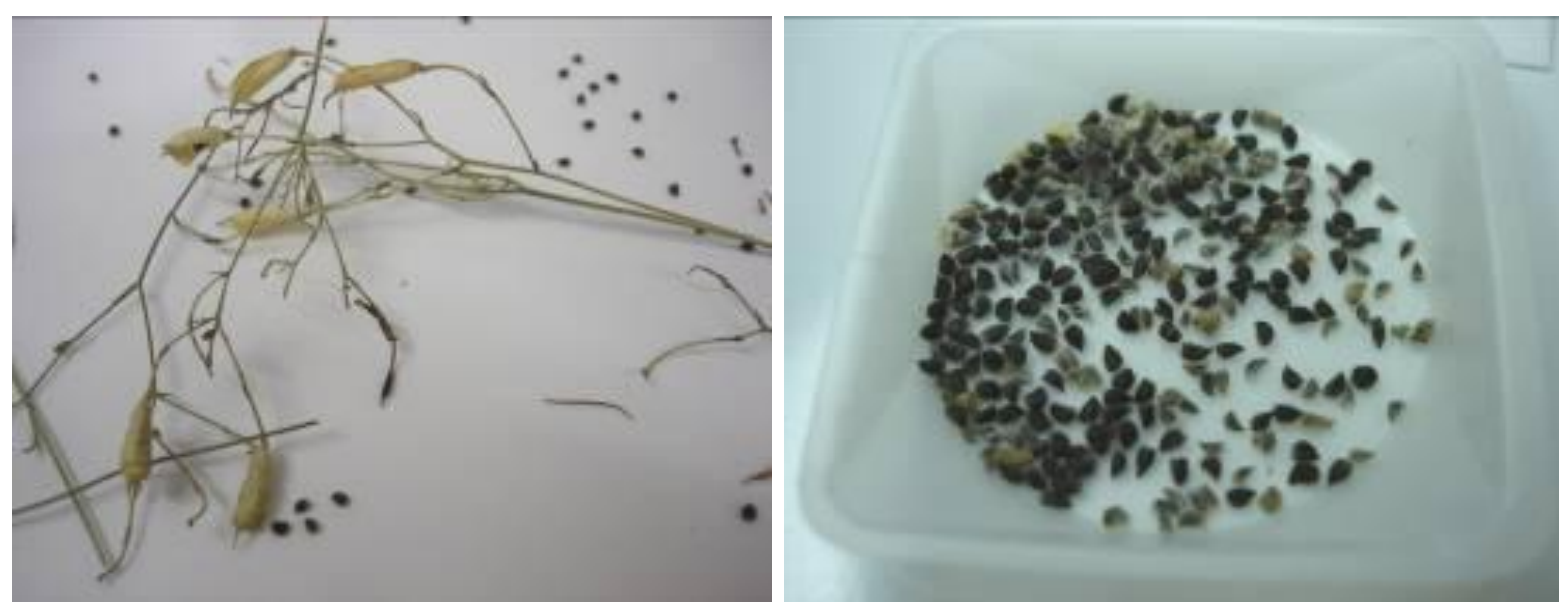

Plate 9: Processing of harvested fruits in the cage experiment: Consolida regalis as an example, (a) several infructescences ('fruiting units') and seeds, (b) seed sample of eight fruiting units from one patch. 


\section{References}

Alarcón, R., Waser, N.M. \& Ollerton, J. (2008). Year-to-year variation in the topology of a plant-pollinator interaction network. Oikos, 117, 1796-1807.

Allen-Wardell, G., Bernhardt, P., Ron Bitner, Burquez, A., Buchmann, S., Cane, J., Cox, P.A., Dalton, V., Feinsinger, P., Ingram, M., Inouye, D., Jones, C.E., Kennedy, K., Kevan, P., Koopowitz, H., Medellin, R., Medellin-Morales, S., Nabhan, G.P., Pavlik, B., Tepedino, V., Torchio, P. \& Walker, S. (1998). The potential consequences of pollinator declines on the conservation of biodiversity and stability of food crop yields. Conservation Biology, 12, 8-17.

Ashman, T.L., Knight, T.M., Steets, J.A., Amarasekare, P., Burd, M., Campbell, D.R., Dudash, M.R., Johnston, M.O., Mazer, S.J., Mitchell, R.J., Morgan, M.T. \& Wilson, W.G. (2004). Pollen limitation of plant reproduction: ecological and evolutionary causes and consequences. Ecology, 85, 2408-2421.

Baldock, K.C.R., Memmott, J., Ruiz-Guajardo, J.C., Roze, D. \& Stone, G.N. (2011). Daily temporal structure in African savanna flower visitation networks and consequences for network sampling. Ecology, 92, 687-698.

Balvanera, P., Pfisterer, A.B., Buchmann, N., He, J.S., Nakashizuka, T., Raffaelli, D. \& Schmid, B. (2006). Quantifying the evidence for biodiversity effects on ecosystem functioning and services. Ecology Letters, 9, 1146-1156.

Bascompte, J. \& Jordano, P. (2007). Plant-animal mutualistic networks: the architecture of biodiversity. Annual Review of Ecology, Evolution, and Systematics, 38, 567-593.

Bascompte, J., Jordano, P., Melian, C.J. \& Olesen, J.M. (2003). The nested assembly of plant-animal mutualistic networks. Proceedings of the National Academy of Science of the United States of America, 100, 9383-9387.

Bawa, K.S. (1990). Plant-pollinator interactions in tropical rain forests. Annual Review of Ecology and Systematics, 21, 399-422.

Bengtsson, J., Angelstam, P., Elmqvist, T., Emanuelsson, U., Folke, C., Ihse, M., Moberg, F. \& Nyström, M. (2003). Reserves, resilience and dynamic landscapes. Ambio, 389396.

Bengtsson, J., Engelhardt, K., Giller, P., Hobbie, S., Lawrence, D., Levine, J., Vilà, M. \& Wolters, V. (2002). Slippin' and slidin' between the scales: the scaling components of biodiversity-ecosystem functioning relations. In: Biodiversity and ecosystem functioning: synthesis and perspectives. Oxford University Press, Oxford, New York, pp. $209-220$. 
Biesmeijer, J.C., Roberts, S.P.M., Reemer, M., Ohlemüller, R., Edwards, M., Peeters, T., Schaffers, A.P., Potts, S.G., Kleukers, R., Thomas, C.D., Settele, J. \& Kunin, W.E. (2006). Parallel declines in pollinators and insect-pollinated plants in Britain and the Netherlands. Science, 313, 351-354.

Blüthgen, N. (2010). Why network analysis is often disconnected from community ecology: a critique and an ecologist's guide. Basic and Applied Ecology, 11, 185-195.

Blüthgen, N. \& Klein, A.-M. (2011). Functional complementarity and specialisation: The role of biodiversity in plant-pollinator interactions. Basic and Applied Ecology, 12, 282-291.

Blüthgen, N., Fründ, J., Vázquez, D.P. \& Menzel, F. (2008). What do interaction network metrics tell us about specialization and biological traits? Ecology, 89, 3387-3399.

Brook, B., Sodhi, N. \& Bradshaw, C. (2008). Synergies among extinction drivers under global change. Trends in Ecology \& Evolution, 23, 453-460.

Brown, M.J.F. \& Paxton, R.J. (2009). The conservation of bees: a global perspective. Apidologie, 40, 410-416.

Burkle, L.A. \& Alarcón, R. (2011). The future of plant-pollinator diversity: Understanding interaction networks across time, space, and global change. American Journal of Botany, 98, 528.

Cameron, S.A., Lozier, J.D., Strange, J.P., Koch, J.B., Cordes, N., Solter, L.F. \& Griswold, T.L. (2011). Patterns of widespread decline in North American bumble bees. Proceedings of the National Academy of Sciences, 108, 662.

Cardinale, B.J. (2011). Biodiversity improves water quality through niche partitioning. Nature, 472, 86-89.

Cardinale, B.J., Palmer, M.A. \& Collins, S.L. (2002). Species diversity enhances ecosystem functioning through interspecific facilitation. Nature, 415, 426-429.

Cardinale, B.J., Srivastava, D.S., Emmett Duffy, J., Wright, J.P., Downing, A.L., Sankaran, M. \& Jouseau, C. (2006). Effects of biodiversity on the functioning of trophic groups and ecosystems. Nature, 443, 989-992.

Dafni, A. (1993). Pollination Ecology: A Practical Approach. Oxford University Press, New York.

Doak, D.F., Bigger, D., Harding, E.K., Marvier, M.A., O’Malley, R.E. \& Thomson, D. (1998). The statistical inevitability of stability-diversity relationships in community ecology. The American Naturalist, 151, 264-276.

van Doorn, W.G. \& van Meeteren, U. (2003). Flower opening and closure: a review. 
Journal of Experimental Botany, 54, 1801-1812.

Duffy, J.E., Cardinale, B.J., France, K.E., McIntyre, P.B., Thébault, E. \& Loreau, M. (2007). The functional role of biodiversity in ecosystems: incorporating trophic complexity. Ecology Letters, 10, 522-538.

Dupont, Y.L., Padrón, B., Olesen, J.M. \& Petanidou, T. (2009). Spatio-temporal variation in the structure of pollination networks. Oikos, 118, 1261-1269.

Ebeling, A., Klein, A.M., Schumacher, J., Weisser, W.W. \& Tscharntke, T. (2008). How does plant richness affect pollinator richness and temporal stability of flower visits? Oikos, 117, 1808-1815.

Elmqvist, T., Folke, C., Nyström, M., Peterson, G., Bengtsson, J., Walker, B. \& Norberg, J. (2003). Response diversity, ecosystem change, and resilience. Frontiers in Ecology and the Environment, 1, 488-494.

Emmerson, M., Solan, M., Emes, C., Paterson, D. \& Raffaelli, D. (2001). Consistent patterns and the idiosyncratic effects of biodiversity in marine ecosystems. Nature, 411, 73-77.

Finke, D.L. \& Snyder, W.E. (2008). Niche partitioning increases resource exploitation by diverse communities. Science, 321, 1488-1490.

Fontaine, C., Dajoz, I., Meriguet, J. \& Loreau, M. (2006). Functional diversity of plantpollinator interaction webs enhances the persistence of plant communities. Plos Biol, 4, e1.

Fründ, J., Dormann, C.F. \& Tscharntke, T. (2011). Linné's floral clock is slow without pollinators - flower closure and plant-pollinator interaction webs. Ecology Letters, 14, 896-904.

Fründ, J., Linsenmair, K.-E. \& Blüthgen, N. (2010). Pollinator diversity and specialization in relation to flower diversity. Oikos, 119, 1581-1590.

Ghazoul, J. (2005). Buzziness as usual? Questioning the global pollination crisis. Trends in Ecology \& Evolution, 20, 367-373.

Gómez, J.M., Bosch, J., Perfectti, F., Fernández, J. \& Abdelaziz, M. (2007). Pollinator diversity affects plant reproduction and recruitment: the tradeoffs of generalization. Oecologia, 153, 597-605.

Greenleaf, S.S. \& Kremen, C. (2006). Wild bees enhance honey bees' pollination of hybrid sunflower. Proceedings of the National Academy of Science of the United States of America, 103, 13890-13895.

Guimarães Jr, P.R., Jordano, P. \& Thompson, J.N. (2011). Evolution and coevolution in 
mutualistic networks. Ecology Letters, 14, 877-885.

Haddad, N.M., Crutsinger, G.M., Gross, K., Haarstad, J. \& Tilman, D. (2011). Plant diversity and the stability of foodwebs. Ecology letters, 14, 42-46.

Hector, A., Schmid, B., Beierkuhnlein, C., Caldeira, M.C., Diemer, M., Dimitrakopoulos, P.G., Finn, J.A., Freitas, H., Giller, P.S., Good, J., Harris, R., Högberg, P., HussDanell, K., Joshi, J., Jumpponen, A., Körner, C., Leadley, P.W., Loreau, M., Minns, A., Mulder, C.P.H., O’Donovan, G., Otway, S.J., Pereira, J.S., Prinz, A., Read, D.J., Scherer-Lorenzen, M., Schulze, E.-D., Siamantziouras, A.-S.D., Spehn, E.M., Terry, A.C., Troumbis, A.Y., Woodward, F.I., Yachi, S. \& Lawton, J.H. (1999). Plant Diversity and Productivity Experiments in European Grasslands. Science, 286, 1123 1127.

Herrera, C.M. (1987). Components of pollinator "quality": comparative analysis of a diverse insect assemblage. Oikos, 79-90.

Hoehn, P., Tscharntke, T., Tylianakis, J.M. \& Steffan-Dewenter, I. (2008). Functional group diversity of bee pollinators increases crop yield. Proceedings of the Royal Society B: Biological Sciences, 275, 2283-2291.

Hoffmann, M., Hilton-Taylor, C., Angulo, A., Bohm, M., Brooks, T.M., Butchart, S.H.M., Carpenter, K.E., Chanson, J., Collen, B., Cox, N.A., Darwall, W.R.T., Dulvy, N.K., Harrison, L.R., Katariya, V., Pollock, C.M., Quader, S., Richman, N.I., Rodrigues, A.S.L., Tognelli, M.F., Vie, J.-C., Aguiar, J.M., Allen, D.J., Allen, G.R., Amori, G., Ananjeva, N.B., Andreone, F., Andrew, P., Ortiz, A.L.A., Baillie, J.E.M., Baldi, R., Bell, B.D., Biju, S.D., Bird, J.P., Black-Decima, P., Blanc, J.J., Bolanos, F., Bolivar-G., W., Burfield, I.J., Burton, J.A., Capper, D.R., Castro, F., Catullo, G., Cavanagh, R.D., Channing, A., Chao, N.L., Chenery, A.M., Chiozza, F., Clausnitzer, V., Collar, N.J., Collett, L.C., et al. (2010). The impact of conservation on the status of the world's vertebrates. Science, 330, 1503-1509.

Holzschuh, A., Dormann, C.F., Tscharntke, T. \& Steffan-Dewenter, I. (2011). Expansion of massflowering crops leads to transient pollinator dilution and reduced wild plant pollination. Proceedings of the Royal Society B: Biological Sciences, published online before print: doi: 10.1098/rspb.2011.0268

Hooper, D., Chapin Iii, F., Ewel, J., Hector, A., Inchausti, P., Lavorel, S., Lawton, J., Lodge, D., Loreau, M., Naeem, S. \& others. (2005). Effects of biodiversity on ecosystem functioning: a consensus of current knowledge. Ecological monographs, 75, $3-35$. 
Ives, A.R. \& Carpenter, S.R. (2007). Stability and diversity of ecosystems. Science, 317, $58-62$.

Jauker, F., Diekötter, T., Schwarzbach, F. \& Wolters, V. (2009). Pollinator dispersal in an agricultural matrix: opposing responses of wild bees and hoverflies to landscape structure and distance from main habitat. Landscape Ecol, 24, 547-555.

Kaiser-Bunbury, C.N., Muff, S., Memmott, J., Müller, C.B. \& Caflisch, A. (2010). The robustness of pollination networks to the loss of species and interactions: a quantitative approach incorporating pollinator behaviour. Ecology letters, 13, 442-452.

Kearns, C.A., Inouye, D.W. \& Waser, N.M. (1998). Endangered mutualisms: The conservation of plant-pollinator interactions. Annual Review of Ecology and Systematics, 29, 83-112.

Klein, A.M., Cunningham, S.A., Bos, M. \& Steffan-Dewenter, I. (2008). Advances in pollination ecology from tropical plantation crops. Ecology, 89, 935-943.

Klein, A.M., Steffan-Dewenter, I. \& Tscharntke, T. (2003). Fruit set of highland coffee increases with the diversity of pollinating bees. Proceedings of the Royal Society of London Series B-Biological Sciences, 270, 955-961.

Klein, A.M., Vaissiere, B.E., Cane, J.H., Steffan-Dewenter, I., Cunningham, S.A., Kremen, C. \& Tscharntke, T. (2007). Importance of pollinators in changing landscapes for world crops. Proceedings of the Royal Society of London B-Biological Sciences, 274, 303-313.

Knight, T.M., Steets, J.A., Vamosi, J.C., Mazer, S.J., Burd, M., Campbell, D.R., Dudash, M.R., Johnston, M.O., Mitchell, R.J. \& Ashman, T.-L. (2005). Pollen limitation of plant reproduction: pattern and process. Annu. Rev. Ecol. Evol. Syst., 36, 467-497.

Kremen, C. (2005). Managing ecosystem services: what do we need to know about their ecology? Ecology Letters, 8, 468-479.

Kremen, C., Williams, N.M. \& Thorp, R.W. (2002). Crop pollination from native bees at risk from agricultural intensification. Proceedings of the National Academy of Sciences of the United States of America, 99, 16812-16816.

Laliberté, E. \& Legendre, P. (2010). A distance-based framework for measuring functional diversity from multiple traits. Ecology, 91, 299-305.

Laliberte, E., Wells, J.A., DeClerck, F., Metcalfe, D.J., Catterall, C.P., Queiroz, C., Aubin, I., Bonser, S.P., Ding, Y., Fraterrigo, J.M. \& others. (2010). Land-use intensification reduces functional redundancy and response diversity in plant communities. Ecology letters, 13, 76-86. 
Larsen, T.H., Williams, N.M. \& Kremen, C. (2005). Extinction order and altered community structure rapidly disrupt ecosystem functioning. Ecology Letters, 8, 538547.

Loreau, M. \& Hector, A. (2001). Partitioning selection and complementarity in biodiversity experiments. Nature, 412, 72-76.

Loreau, M., Mouquet, N. \& Gonzalez, A. (2003). Biodiversity as spatial insurance in heterogeneous landscapes. Proceedings of the National Academy of Sciences, 100, 12765.

Loreau, M., Naeem, S., Inchausti, P., Bengtsson, J., Grime, J.P., Hector, A., Hooper, D.U., Huston, M.A., Raffaelli, D., Schmid, B., Tilman, D. \& Wardle, D.A. (2001). Biodiversity and ecosystem functioning: Current knowledge and future challenges. Science, 294, 804-808.

MacArthur, R. (1955). Fluctuations of animal populations, and a measure of community stability. Ecology, 36, 533-536.

Memmott, J., Waser, N.M. \& Price, M.V. (2004). Tolerance of pollination networks to species extinctions. Proceedings of the Royal Society of London B-Biological Sciences, 271, 2605-2611.

Naeem, S. \& Li, S. (1997). Biodiversity enhances ecosystem reliability. Nature, 390, 507509.

Naeem, S. \& Wright, J.P. (2003). Disentangling biodiversity effects on ecosystem functioning: deriving solutions to a seemingly insurmountable problem. Ecology Letters, 6, 567-579.

Olesen, J.M., Bascompte, J., Elberling, H. \& Jordano, P. (2008). Temporal dynamics in a pollination network. Ecology, 89, 1573-1582.

Ollerton, J. \& Cranmer, L. (2002). Latitudinal trends in plant-pollinator interactions: are tropical plants more specialised? Oikos, 98, 340-350.

Ollerton, J., Alarcón, R., Waser, N.M., Price, M.V., Watts, S., Cranmer, L., Hingston, A., Peter, C.I. \& Rotenberry, J. (2009). A global test of the pollination syndrome hypothesis. Annals of Botany, 103, 1471 -1480.

Ollerton, J., Winfree, R. \& Tarrant, S. (2011). How many flowering plants are pollinated by animals? Oikos, 120, 321-326.

Palmer, T.M., Stanton, M.L. \& Young, T.P. (2003). Competition and coexistence: Exploring mechanisms that restrict and maintain diversity within mutualist guilds. American Naturalist, 162, S63-S79. 
Pellmyr, O. (2002). Pollination by animals. In: Plant-Animal Interactions: An Evolutionary Approach (eds. Herrera, C.M. \& Pellmyr, O.). Blackwell, pp. 157-184.

Perfectti, F., Gómez, J.M. \& Bosch, J. (2009). The functional consequences of diversity in plant-pollinator interactions. Oikos, 118, 1430-1440.

Petanidou, T., Kallimanis, A.S., Tzanopoulos, J., Sgardelis, S.P. \& Pantis, J.D. (2008). Long-term observation of a pollination network: fluctuation in species and interactions, relative invariance of network structure and implications for estimates of specialization. Ecology Letters, 11, 564-575.

Petchey, O.L. \& Gaston, K.J. (2006). Functional diversity: back to basics and looking forward. Ecology Letters, 9, 741-758.

Potts, S.G., Biesmeijer, J.C., Kremen, C., Neumann, P., Schweiger, O. \& Kunin, W.E. (2010). Global pollinator declines: trends, impacts and drivers. Trends in Ecology \& Evolution, 25, 345-353.

Potts, S.G., Petanidou, T., Roberts, S., O’Toole, C., Hulbert, A. \& Willmer, P. (2006). Plant-pollinator biodiversity and pollination services in a complex Mediterranean landscape. Biological Conservation, 129, 519-529.

Potts, S.G., Vulliamy, B., Dafni, A., Ne'eman, G. \& Willmer, P. (2003). Linking bees and flowers: How do floral communities structure pollinator communities? Ecology, 84, $2628-2642$.

De la Rúa, P., Jaffé, R., Dall’Olio, R., Muñoz, I. \& Serrano, J. (2009). Biodiversity, conservation and current threats to European honeybees. Apidologie, 40, 263-284.

Sala, O.E., Chapin, F.S., Armesto, J.J., Berlow, E., Bloomfield, J., Dirzo, R., HuberSanwald, E., Huenneke, L.F., Jackson, R.B., Kinzig, A., Leemans, R., Lodge, D.M., Mooney, H.A., Oesterheld, M., Poff, N.L., Sykes, M.T., Walker, B.H., Walker, M. \& Wall, D.H. (2000). Global biodiversity scenarios for the year 2100. Science, 287, 1770 -1774 .

Santamaria, L. \& Rodriguez-Girones, M.A. (2007). Linkage rules for plant-pollinator networks: trait complementarity or exploitation barriers? PLOS Biology, 5 (2), e31.

Scherber, C., Eisenhauer, N., Weisser, W.W., Schmid, B., Voigt, W., Fischer, M., Schulze, E.D., Roscher, C., Weigelt, A., Allan, E., Beßler, H., Bonkowski, M., Buchmann, N., Buscot, F., Clement, L.W., Ebeling, A., Engels, C., Halle, S., Kertscher, I., Klein, A.-M., Koller, R., König, S., Kowalski, E., Kummer, V., Kuu, A., Lange, M., Lauterbach, D., Middelhoff, C., Migunova, V.D., Milcu, A., Müller, R., Partsch, S., Petermann, J.S., Renker, C., Rottstock, T., Sabais, A., Scheu, S., Schumacher, J., 
Temperton, V.M. \& Tscharntke, T. (2010). Bottom-up effects of plant diversity on multitrophic interactions in a biodiversity experiment. Nature, 440, 553-556.

Stang, M., Klinkhamer, P.G.L., Waser, N.M., Stang, I. \& van der Meijden, E. (2009). Size-specific interaction patterns and size matching in a plant-pollinator interaction web. Annals of Botany, 103, 1459-1469.

Steffan-Dewenter, I. \& Tscharntke, T. (1999). Effects of habitat isolation on pollinator communities and seed set. Oecologia, 121, 432-440.

Steffan-Dewenter, I. \& Tscharntke, T. (2001). Succession of bee communities on fallows. Ecography, 24, 83-93.

Steffan-Dewenter, I., Münzenberg, U., Burger, C., Thies, C. \& Tscharntke, T. (2002). Scale-dependent effects of landscape context on three pollinator guilds. Ecology, 83, $1421-1432$.

Stone, G.N., Gilbert, F., Willmer, P., Potts, S., Semida, F. \& Zalat, S. (1999). Windows of opportunity and the temporal structuring of foraging activity in a desert solitary bee. Ecological Entomology, 24, 208-221.

Tilman, D. \& Downing, J.A. (1994). Biodiversity and stability in grasslands. Nature, 367, 363-365.

Tscharntke, T., Bommarco, R., Clough, Y., Crist, T.O., Kleijn, D., Rand, T.A., Tylianakis, J.M., Nouhuys, S. \& Vidal, S. (2007). Conservation biological control and enemy diversity on a landscape scale. Biological Control, 43, 294-309.

Tscharntke, T., Klein, A.M., Kruess, A., Steffan-Dewenter, I. \& Thies, C. (2005). Landscape perspectives on agricultural intensification and biodiversity-ecosystem service management. Ecology Letters, 8, 857-874.

Tylianakis, J.M., Didham, R.K., Bascompte, J. \& Wardle, D.A. (2008a). Global change and species interactions in terrestrial ecosystems. Ecology Letters, 11, 1351-1363.

Tylianakis, J.M., Rand, T.A., Kahmen, A., Klein, A.-M., Buchmann, N., Perner, J. \& Tscharntke, T. (2008b). Resource heterogeneity moderates the biodiversity-function relationship in real world ecosystems. Plos Biol, 6, e122.

Tylianakis, J.M., Tscharntke, T. \& Lewis, O.T. (2007). Habitat modification alters the structure of tropical host-parasitoid food webs. Nature, 445, 202-205.

Tylianakis, J.M., Tscharntke, T. \& Klein, A.M. (2006). Diversity, ecosystem function, and stability of parasitoid-host interactions across a tropical habitat gradient. Ecology, 87, 3047-3057.

United Nations. (1992). Convention on Biological Diversity. Accessed from: 
http://www.cbd.int/convention/

Vazquez, D.P., Blüthgen, N., Cagnolo, L. \& Chacoff, N.P. (2009). Uniting pattern and process in plant-animal mutualistic networks: a review. Annals of Botany, 103, 14451457.

Vazquez, D.P., Morris, W.F. \& Jordano, P. (2005). Interaction frequency as a surrogate for the total effect of animal mutualists on plants. Ecology Letters, 8(10), 1088-1094.

Villéger, S., Mason, N.W.H. \& Mouillot, D. (2008). New multidimensional functional diversity indices for a multifaceted framework in functional ecology. Ecology, 89, $2290-2301$.

WallisDeVries, M.F., Poschlod, P. \& Willems, J.H. (2002). Challenges for the conservation of calcareous grasslands in northwestern Europe: integrating the requirements of flora and fauna. Biological Conservation, 104, 265-273.

Waser, N.M., Chittka, L., Price, M.V., Williams, N.M. \& Ollerton, J. (1996). Generalization in pollination systems, and why it matters. Ecology, 77, 1043-1060.

Westrich, P. (1996). Habitat requirements of central European bees and the problems of partial habitats. In: The conservation of bees (eds. Matheson, P., Buchmann, S.L., O’Toole, C., Westrich, P. \& Williams, I.H.). Linnean Society Symposium Series, London, pp. 1-16.

Westrich, P., Ulrich Frommer, Klaus Mandery, Helmut Riemann, Haike Ruhnke, Christoph Saure \& Johannes Voith. (2008). Rote Liste der Bienen Deutschlands (Hymenoptera, Apidae) (4. Fassung, Dezember 2007). Eucera, 1.

Winfree, R. \& Kremen, C. (2009). Are ecosystem services stabilized by differences among species? A test using crop pollination. Proceedings of the Royal Society B: Biological Sciences, 276, 229.

Winfree, R., Williams, N.M., Dushoff, J. \& Kremen, C. (2007). Native bees provide insurance against ongoing honey bee losses. Ecol Letters, 10, 1105-1113.

WRI, IUCN \& UNEP. (1992). Global Biodiversity Strategy. Accessed from: http://www.wri.org/publication/global-biodiversity-strategy

Yachi, S. \& Loreau, M. (1999). Biodiversity and ecosystem productivity in a fluctuating environment: the insurance hypothesis. Proceedings of the National Academy of Sciences of the United States of America, 96, 1463-1468. 


\section{Chapter 2}

\section{Bee diversity effect on pollination depends on functional complementarity and niche shifts}

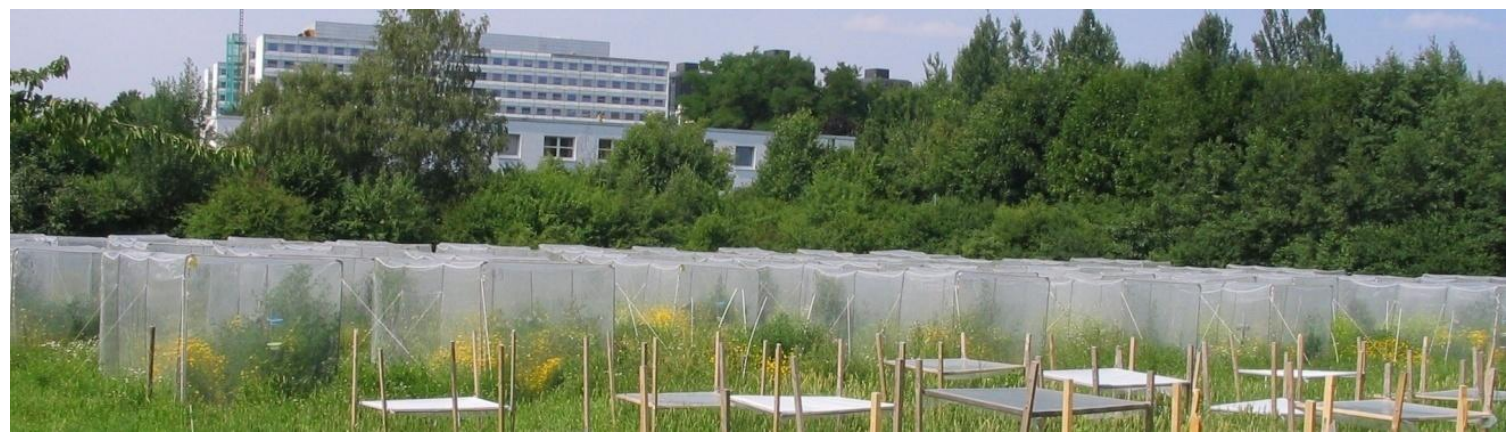

Authors: Jochen Fründ, Carsten F. Dormann, Andrea Holzschuh \& Teja Tscharntke

This chapter is has been submitted for publication to Ecology. 


\section{Abstract}

Biodiversity is important for many ecosystem processes. Global declines in pollinator diversity and abundance have been recognized, raising concerns about a pollination crisis of crops and wild plants. However, experimental evidence for effects of pollinator species diversity on plant reproduction is extremely scarce. By establishing communities with one to five bee species, we showed that seed production of a plant community increased with bee diversity. We identified functional complementarity as the most likely driving mechanism, as it explained seed production far better than bee diversity did. Plants produced more seeds when the available bee species differed in their flower and temperature preferences. Functional complementarity was mediated by interspecific interactions among bee species, as bees reduced interspecific overlap by shifting to alternative flowers in the presence of other species. Both fundamental and interactive complementarity determined how many plant species were visited by a bee community, which demonstrates a new mechanism for a biodiversity-function relationship. In conclusion, our results highlight both the importance of bee diversity for the reproduction of plant communities and the need to identify complementarity traits for accurately predicting pollination services by different bee communities. 


\section{Introduction}

Positive effects of biodiversity on functioning of terrestrial ecosystems have mainly been shown by experimental manipulations of plant diversity (Loreau et al. 2001, Cardinale et al. 2006, Scherber et al. 2010, Isbell et al. 2011), whereas experiments manipulating diversity of higher trophic levels are more sparse (Duffy et al. 2007, Finke and Snyder 2008). Biotic pollination is important for wild plant reproduction (Ollerton et al. 2011) and crop pollination as an ecosystem service (Klein et al. 2003). Recent largescale declines in pollinator diversity (Biesmeijer et al. 2006, Potts et al. 2010) raise concerns about the maintenance of pollination services, but biodiversity experiments focusing on pollinators are surprisingly limited. Previous studies on pollinator diversity effects have employed natural gradients of diversity, leaving species richness confounded with other variables such as environment, abundance or community composition (Kremen et al. 2002, Klein et al. 2003, Potts et al. 2006, Gómez et al. 2007, Hoehn et al. 2008). Most of these studies suggest a positive effect of bee species diversity on pollination, but this has still not been confirmed experimentally. There is only a single published experiment on diversity effects on pollination (Fontaine et al. 2006), which did not separate effects of diversity from number of pollinator individuals, considered only two levels of functional group diversity without controlling species richness and did not include nesting sites for bees. To understand consequences of pollinator declines and bridge the gap between the previous studies, experiments assessing the effects of pollinator diversity on plant reproduction independently of important confounding factors and in more realistic settings are highly needed.

Mechanistic explanations of biodiversity effects commonly involve functional niche complementarity (Loreau and Hector 2001), which has also been suggested for pollinator diversity (Fontaine et al. 2006, Hoehn et al. 2008, Tylianakis et al. 2008). Bee species could have complementary pollination niches because they differ in the plant species they visit and in the place and time of visitation (Hoehn et al. 2008, Blüthgen and Klein 2011), but this is not trivial because most bee species are considered to be trophic generalists (Williams et al. 2010). An 'interactive complementarity effect' can arise when interspecific interactions such as facilitation, interference, intraguild predation or competition change the outcome expected from fundamental niches or a species' behavior in isolation (Cardinale et al. 2002, Casula et al. 2006, Ashton et al. 2010). For example, interactions with wild bees have been shown to increase honeybees' pollination effectiveness on hybrid sunflowers (Greenleaf and Kremen 2006). Interspecific 
competition should force species to reduce niche overlap with coexisting species (interspecific repulsion), which may be realized by niche contraction or niche shifts (Morse 1974). Thus pollinators may respond to interspecific competition by increasing specialization (Inouye 1978) and shifting to less preferred plant species (Walther-Hellwig et al. 2006). Both responses might have positive effects on pollination function: pollinator specialization may increase conspecific pollen deposition (Wissel 1977), while niche shifts to alternative plants may cause more complete coverage of the whole plant community.

In this study, we performed a biodiversity experiment manipulating species richness of bees as the most important group of pollinators (Potts et al. 2010) and tested the effects of bee diversity and functional complementarity on seed production of a sown plant community including nine pollinator-dependent plant species. We established caged bee communities of one to five species in different combinations, standardizing the total number of bees per cage to identify bee diversity effects independent of total bee abundance and to vary the degree of intraspecific and interspecific competition. Niche complementarity in flower visitation was quantified for two niche dimensions: temporal niche partitioning driven by differences in temperature-dependence of activity (Willmer and Corbet 1981, Willmer 1983), and niche partitioning regarding the plant species visited (Fründ et al. 2010, Blüthgen and Klein 2011). We test whether the presence of other species leads to larger realized differences in flower visitation, and whether functional niche coverage as the outcome of fundamental and interactive complementarity explains the effect of bee diversity on the pollination of plant communities.

\section{Methods}

\section{Experimental Design}

We established 55 caged 'mesocosms' (each $4 \times 2 \times 2 \mathrm{~m}=16 \mathrm{~m}^{3}$ ) with one to five wild bee species (Fig. 1a-b) in different combinations, following a substitutive design aimed at analyzing bee diversity effects independent of total bee abundance (39 cages with bees, 8 control cages without bees, but hoverflies allowed to colonize plants before cages were closed, 4 control cages where all insects were regularly removed, and 4 open cages; Table 1; see Appendix S1). The total number of bees per cage was $20.5 \pm 2.7$ (mean $\pm \mathrm{sd}$ ). Treatments were randomly assigned to cages (see Fig. S1 in Supporting 
Information). The experiment was performed on the experimental field of the Agroecology group in Göttingen, Germany, in 2008. Seeds of the same plant community in each cage were sown in April 2008. Some plants started flowering in early June. On 12 - 16 June, early blooming flowers were cut and flying insects removed from the cages. By end of June most species were in flower. The main experimental period started with the introduction of target bee species on 3 - 5 July and lasted five weeks until 8 August 2008. Fruits were harvested from 30 July to 27 August 2008.

In this study, we used a substitutive design (see Appendix S1 for further details), focusing on the effect of diversity independent of total abundance. Each bee species was present in cages across the diversity gradient. As often in biodiversity experiments, it was impossible to realize all possible species combinations (Bell et al. 2009); in our case this was due to limited availability of some bee species.

Table 1: Overview of the design (treatments) of the bee diversity experiment

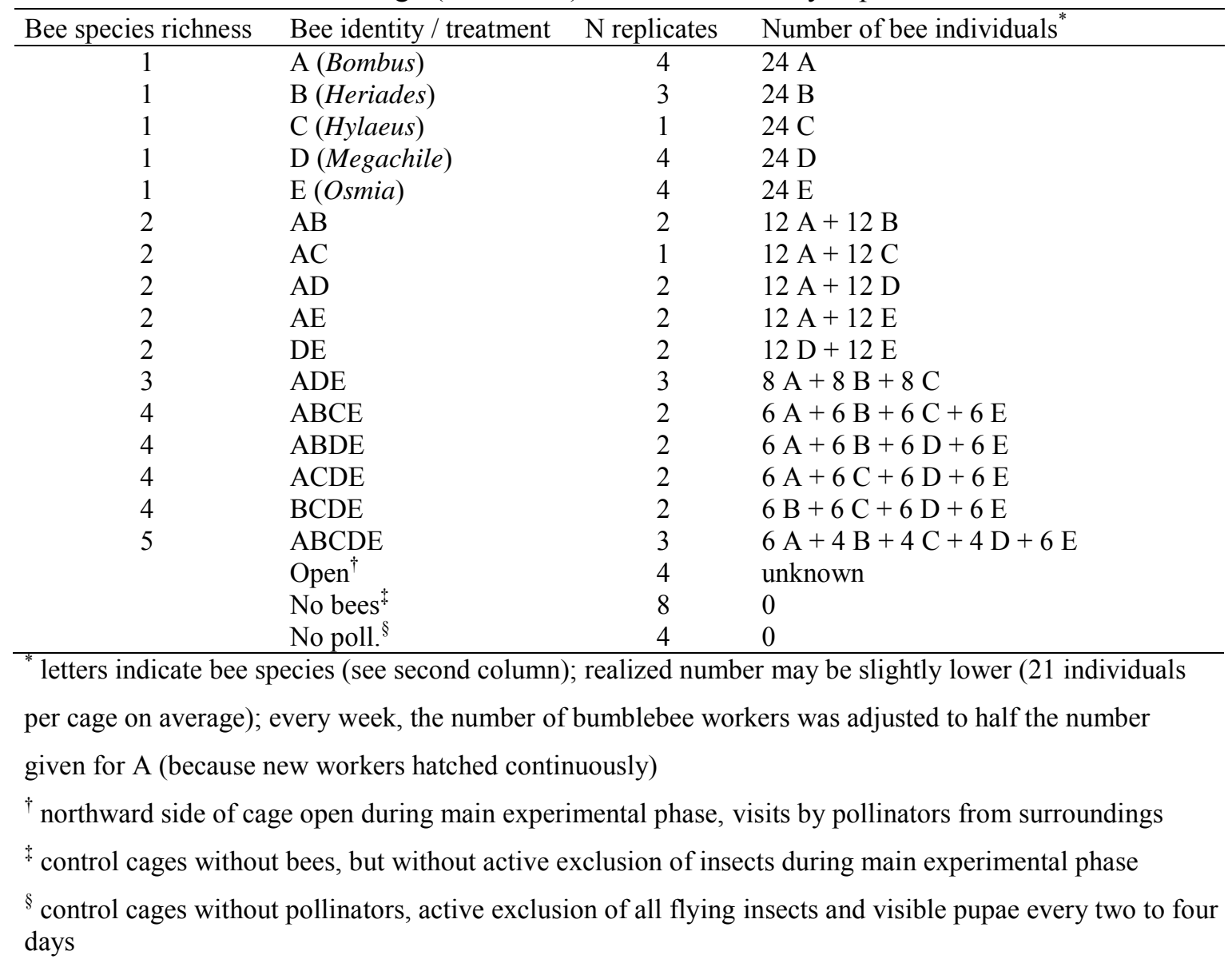




\section{Plant community and reproductive success}

Seeds were purchased from commercial suppliers of wild plants (Appendix S1). In each cage, a community of 16 plant species was sown in a regular pattern with two patches per plant species (Fig. S2), with intraspecific aggregation reducing interspecific competition among plants. Aiming for a standardized target plant density, the number of seeds sown per species was based on prior germination tests. Seeds were sown into standardized commercial soil substrate (Fruhstorfer Erde T25, Hawita, Lauterbach, Germany; 6001 per cage) that was evenly spread on the tilled soil. After sowing, plants were first allowed to grow without isolation netting and watered as needed. Unsown plants were controlled by weeding and grass-specific herbicide (Fusilade, Syngenta) before the cages were closed on 2 June 2008 with netting of $0.8 \mathrm{~mm}$ mesh size (Rantai Typ S48, Schachtrupp, Hamburg, Germany).

The number of flowering units per plant species and cage was counted twice during the main phase (counting dates 9-11 July and 28-30 July; see Table S1 for plant species details). Eleven of the sown plant species were in full bloom during the main experimental phase (Centaurea cyanus, Chrysanthemum segetum, Consolida regalis, Crepis capillaris, Legousia speculum-veneris, Lotus corniculatus, Medicago x varia, Orlaya grandiflora, Scandix pecten-veneris, Sinapis arvensis and Vicia villosa).

For these eleven plant species (others were considered for flower visitation, but not for seed production), fruiting units were harvested when a species had mostly ripened, three to four weeks after its peak flowering time. For a given plant species, all cages were harvested on the same day. The number of seeds per cage and plant species was assessed by counting the number of fruiting units in the cage and then counting the number of seeds in a harvested subset (eight fruiting units per patch). A 'fruiting unit' was defined as a flower head in Asteraceae, Lotus and Medicago, as an umbel in Apiaceae, as a pedicle for Consolida, Sinapis and Vicia, and as a single fruit in Legousia. Harvested fruiting units were dried and dissected in the laboratory. In general, all clearly developed seeds in these samples were considered viable and counted.

It was not possible to reliably distinguish fruits containing a seed from empty fruits in Asteraceae, whose fruits form an inseparable unit with the single seed. Therefore, viability of seeds was assessed by germination tests for Centaurea, Chrysanthemum and Crepis: the number of viable seeds was calculated multiplying the number of fruits by $\%$ germination (20 fruits of each patch, i.e. 40 per cage, from separately harvested fully ripe fruiting units were placed in Petri dishes with wet filter paper for four weeks in dark 
climate chambers with $14{ }^{\circ} \mathrm{C}$ and $96 \%$ relative humidity; visibly empty fruits were excluded). To estimate the number of seeds (Nseed $\left.s_{i, j}\right)$ per cage $i$ for each plant species $j$, the number of fruiting units in the cage was multiplied by the number of seeds per fruiting unit in the harvested subset. In Crepis, seeds in unripe flower heads could not be counted and were therefore excluded from the calculation.

Nine plant species (all except Orlaya and Scandix) produced significantly lower numbers of viable seeds in control cages than in cages with bees. These species were considered as pollinator-dependent plants, hereafter 'the plant community'. Seed production of the plant community $\left(S P_{i}\right.$, the main response variable) was calculated per cage $i$ as the mean of standardized seed numbers (i.e. observed number of seeds divided by the maximum of the respective plant species) across plant species:

$$
S P_{i}=\frac{\sum_{j=1}^{9} \frac{N \text { Need } s_{i, j}}{\max N \text { seed } s_{1-59, j}}}{9}
$$

\section{Pollinator communities}

We used five bee species in the experiment: bumblebees (Bombus terrestris) inhabiting nest boxes, and four solitary bee species inhabiting reed internodes (Heriades truncorum, Hylaeus communis, Megachile centuncularis group, Osmia bicornis). These five bee species were selected to represent a relatively realistic distribution of traits within the constraint of sufficient availability. Typical for bee communities in Central Europe (Westrich 1989), one in five species was primitively eusocial (Bombus), one in five species was oligolectic (specialized on one plant family, Asteraceae: Heriades), body length ranged from $5 \mathrm{~mm}$ (Hylaeus) to larger than $15 \mathrm{~mm}$ (Bombus), and the different species collect pollen on different parts of their body.

Small bumblebee colonies were purchased (STB Control, Aarbergen, Germany) and set to the target number of workers. Colonies also included a queen and brood, favoring natural behavior. To keep abundance constant despite newly hatching bees, colonies were reduced to the target number of workers every week (removing excess workers and brood cells).

Overwintering solitary bees were collected from trap nests that had been exposed in the field in 2007 around Göttingen, Germany (reed internodes in plastic tubes), and close to Leipzig, Germany (bundles of bamboo internodes). Trap nests were brought into the lab in autumn 2007 and stored at $4{ }^{\circ} \mathrm{C}$ until spring 2008, while opening stems throughout 
the winter to inspect the type and number of bee brood cells. Due to shortage of material, we used two closely related and functionally similar species of Megachile in a constant ratio (2:1 M. centuncularis [L.] and $M$. versicolor Smith) and treated them as a functional unit comparable to a species ( $M$. centuncularis group) for the experiment. After hibernation, bee nests were incubated at room temperature (incubation time per bee species based on prior experience). Bee species combinations (using a 1:1 sex ratio) were prepared in cardboard boxes with paper tube exits. Bees hatching before the start of the experiment were stored in dark climate chambers $\left(12^{\circ} \mathrm{C}\right)$. Once all boxes were prepared, they were placed in the cages to allow for near-natural emergence behavior. At this time, bumblebee nest boxes and reed internodes as nesting substrate for solitary bees had already been placed in the cages. See Appendix S1 for further pollinator details.

Throughout the main phase, flower visitation was observed for all cages. In each of six rounds, all cages were observed in randomized order. In each observation session, one observer slowly walked around the cage and noted the number of flower visitors of each pollinator species per plant patch (average observation time of 7 minutes per session). All observations were performed between 8 am and $7 \mathrm{pm}$ during different weather conditions but not during heavy rain.

\section{Statistical analysis}

All analyses were performed with the software R 2.11.1 (R Development Core Team 2010). If not stated otherwise, a replicate is considered to be a cage.

Different functions have been proposed to describe the form of the biodiversityfunctioning relationship (Cardinale et al. 2006). These were fitted to the relationship between seed production and bee diversity by non-linear least squares regression and compared with AICc (Akaike's information criterion with sample size correction). Models with smallest AICc-values are best supported by the data, with a difference in AICc $>2$ indicating that the alternative model is clearly worse (Burnham and Anderson 2001). Seed production was related to mechanistic variables (functional niche coverage or bee specialization) by multiple regression, in which explanatory variables were only weakly correlated $(\mathrm{r} \leq 0.34)$. Partial residual plots (= component plus residuals plots) were used to show the influence of one variable while holding the values of other variables in the model constant (on their mean value). Diversity effects on seed production or functional coverage could not be explained by variation in species composition among diversity levels (Appendix S1, Fig. S3). 
Temperature coverage was defined as the integral of bee community activity in relation to temperature. To calculate this, the relationship between temperature and bee foraging activity was estimated for each species by fitting a Gaussian response curve, using function 'nls' in R with a formula adapted from Jongman et al. (1987):

$$
\sqrt{\text { activity }_{i}}=c \cdot \exp \left(\frac{-0.5(\text { temp }-u)^{2}}{t^{2}}\right)
$$

where activity $_{\mathrm{i}}$ is the number of visits by bee species $i$ observed during an observation session (see above for sampling approach for flower visitation), temp is temperature measured during the observation session (i.e. reflecting variation within and between days), and the fitted parameters are $c$ (square root of maximum activity), $u$ (optimum temperature) and $t$ (tolerance or niche width).

From these species-specific response curves, temperature coverage was calculated in three steps. First, activity $_{\mathrm{i}}$ was rescaled to a maximum of 1 for each species. Rescaling was used to have temperature-related effects independent of total activity, but temperature coverage without rescaling yielded similar results (Appendix S1). Second, rescaled response curves were averaged across all bee species present in a community, yielding bee community activity (activity ${ }_{\mathrm{com}}$ ). Third, the integral of this composite function was calculated numerically:

$$
\text { temperature coverage }=\int_{15^{\circ} \mathrm{C}}^{44^{\circ} \mathrm{C}} \operatorname{activity}_{\mathrm{com}}(\text { temp }) \text { dtemp }
$$

Plant species coverage was defined as the number of visited plant species, which may be influenced by low numbers of observations and variation in flower abundance. To correct for these types of possible sampling artifacts, the number of plant species was divided by the mean of a null model that closely resembled null model 'IR' of Ulrich \& Gotelli (2010), but also incorporated independently measured data about all available flower resources. The null model simulated completely non-selective flower choice by randomly redistributing interactions among plants within bee species and cage, i.e. it generated data with the same number of visits per bee species and cage. The probability of each plant species to be visited was proportional to its flower abundance in the cage. Results were similar when plant species coverage was not corrected by the null model (Appendix S1).

Aiming to separate effects of fundamental and realized preferences on plant species coverage, we simulated visitation network data using the following approach: the number of visits per bee species and cage was randomly redistributed among plant 
species, using interaction probabilities based on flower availability and flower preferences. Flower preferences (forage ratio sensu Krebs 1998, termed 'fundamental preferences' here) for each bee species were calculated comparing visits pooled across all cages with one bee species to overall flower availability. These simulations were similar to the null model used to correct plant species coverage, but the probability for a plant species to be visited by a bee species also depended on the estimated flower preferences of this bee species. Plant species coverage calculated from these simulated visitation data is referred to as "prediction without shifts". An extended presentation of this simulation can be found in Appendix S1. Quantitative niche overlap $(O)$ between a bee species pair was calculated as

$$
O=1-\frac{\sum_{j}\left|p_{1, j}-p_{2, j}\right|}{\sum_{j} p_{1, j}+p_{2, j}}
$$

where $p_{1, j}$ and $p_{2, j}$ are proportional visitation to plant species $j$ by bee species 1 and 2 , respectively.

Bee specialization was calculated as the index $d^{\prime}$ (Blüthgen et al. 2006), which describes how strongly resource use (visitation) differs from resource availability. Flower availability per cage was calculated from the counted number of flower units, weighted for each plant species by the total visits received per flower unit across all cages. Bee specialization was compared between 'mono' and 'poly' cages with a linear mixed effects model including random effects of cage identity and fixed effects of bee species. Bee community-wide specialization per cage was quantified by the weighted mean of $d^{\prime}$ (weights $=$ number of visits of a bee species in that cage). Results for specialization were robust to the choice of alternative specialization (Appendix S1). The related index $H_{2}{ }^{\prime}$ (Blüthgen et al. 2006) was used for testing for complementarity in networks pooled across cages, but could not be used for individual cages because it is not defined for mono-specific communities. Significance of preference differences among bee species in the pooled network was assessed by comparing $H_{2}{ }^{\prime}$ to a null model (Blüthgen et al. 2006). Specialization indices were calculated with the R-package 'bipartite'1.15 (Dormann et al. 2009).

\section{Results}

First, we looked at the effect of bee species richness on pollination. Overall, a positive non-linear effect of bee diversity on seed production by the plant community was 
observed (Fig. 1c). The relationship between bee diversity and seed production was best described by a saturating function (Michaelis-Menten), followed by log and power functions, while a linear model and the null model performed clearly worse (Table 2). Plants in cages with two to five bee species produced significantly more seeds than plants in cages with a single bee species (Fig. 1d). More seeds were produced in cages with two bee species than expected for additive effects (Fig. S4). Plants in control cages without bees but with hoverflies produced significantly fewer seeds than plants in bee cages of all diversity levels (Welch t-test, $\mathrm{p}<0.001$, Fig. 1c), but slightly more seeds than in cages where all insects were regularly removed ('no pollinators', $\mathrm{p}=0.002$ ). Plants in open cages, which were visited by diverse pollinators from the surrounding area, produced more seeds than plants in any other cage type ( $p=0.004$, Fig. 1c).

Second, we considered complementarity as the potential underlying driver of bee diversity effects. To quantify temperature niche coverage (Fig. 2a), a Gaussian curve was fitted to the relationship between foraging activity and ambient temperature for each bee species, which showed interspecific differences (Fig. 2b). This was used to estimate flower visitation across different temperatures, i.e. the completeness of flower visitation across variable weather conditions. Temperature niche coverage did not increase monotonously with bee diversity (Fig. 2c). It tended to be higher when different bee species were combined (Fig. 2d), but it did not increase beyond two bee species (Fig. 2c), as all bees except Bombus had the highest activity during warm and sunny days (Fig. 2b).

Functional complementarity among bee species was also related to the plant species visited (Fig. 3). Different bee species visited different plant species, and this difference was larger when several bee species were present in a cage, as interspecific overlap was reduced (Fig. 3a, Fig. S5). The difference in floral preferences among bee species was significant both in networks pooled across cages without co-occurring bee species and across cages with more than one bee species (Fig. 3b-c, $H_{2}{ }^{\prime}=0.19$ and 0.22 , respectively; excluding the known specialist Heriades, $H_{2}{ }^{\prime}=0.15$ and 0.20 ; all $\mathrm{p}<$ 0.001 ). Half of all plant species were observed to be visited only in cages with more than one bee species (Fig. 3c, Fig. S6).

Plant species niche coverage was quantified as the number of plant species visited by all bees in a cage, corrected for possible sampling effects. Plant species coverage tended to slightly increase with bee diversity $(p=0.11$ in linear regression and $p=0.04$ in loglinear regression), but the highest values were not observed in cages with the highest number of bee species (Fig. 4a). More plant species were visited by the bee community 
(a)
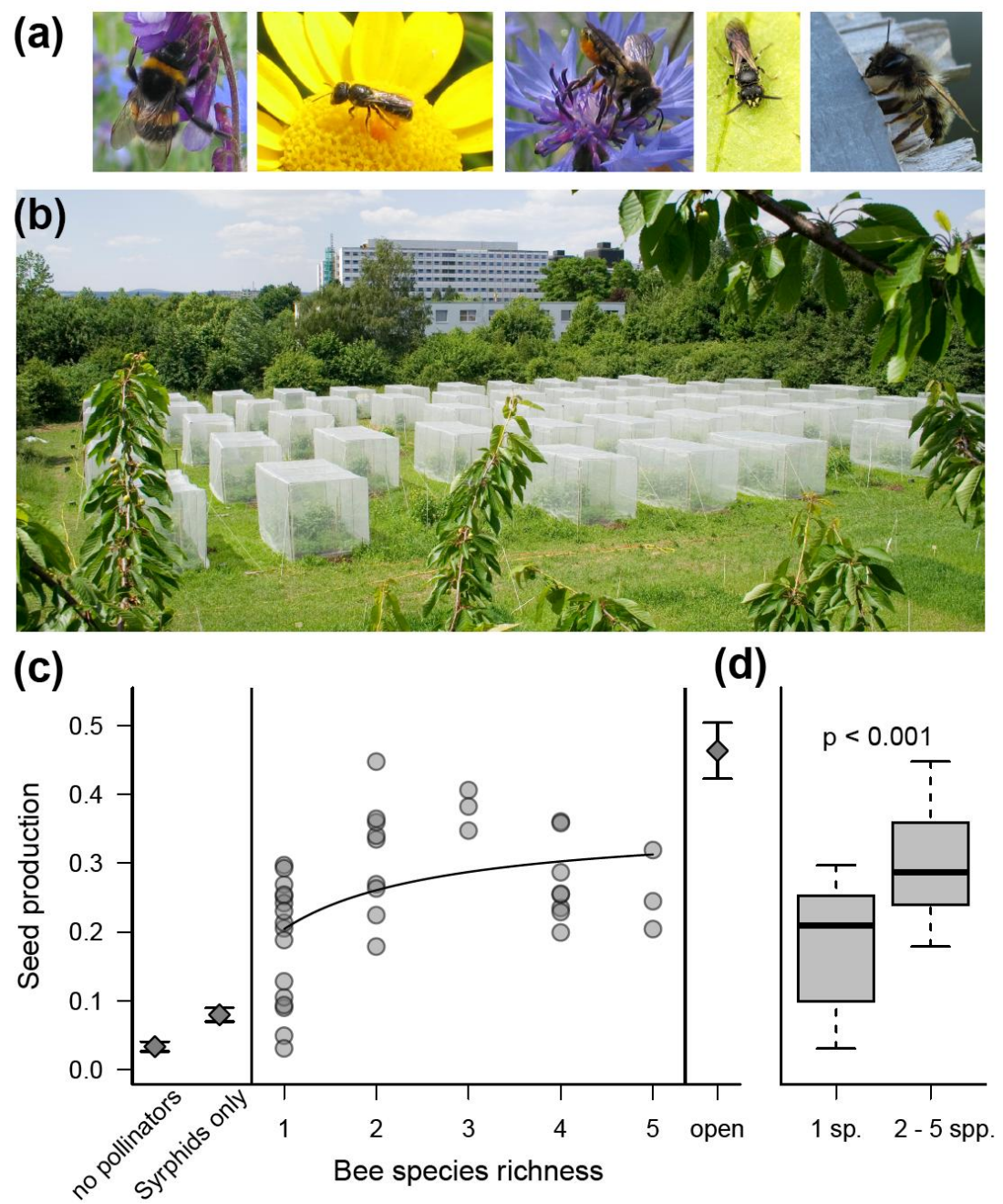

Fig. 1: Experimental test of bee diversity effects on pollination of plant communities. (a) The five bee species inhabiting the cages in different combinations, from left to right: Bombus terrestris, Heriades truncorum, Megachile centuncularis group, Hylaeus communis, Osmia bicornis (photos by JF, except $H$. communis by J.K. Lindsey). (b) View of the bee diversity experiment (photo by M. v. Fragstein). (c, d) Seed production of the plant community (number of seeds per cage, standardized relative to maximum and averaged across nine plant species) in relation to the number of bee species present in a cage (circles $=$ one data point per cage, $\mathrm{N}=39$ ). Diamonds show mean \pm s.e.m. for the three types of controls $(\mathrm{N}=4,8$ and 4 cages). The solid line shows the best fitting curve (Michaelis-Menten saturation). P-value in (d) based on Welch ttest.

Table 2: Comparison of different models explaining plant community seed production

\begin{tabular}{llll}
\hline Model and explanatory variables & AICc & $\Delta$ AICc & $\mathrm{R}^{2}$ \\
\hline Null model & -67.9 & 24.0 & N.A. \\
Bee species richness: linear & -70.8 & 26.9 & 0.13 \\
Bee species richness: power & -73.5 & 21.3 & N.A. \\
Bee species richness: log-linear & -74.5 & 20.3 & 0.21 \\
Bee species richness: saturating (Michaelis-Menten) & -76.2 & 18.6 & N.A. \\
Bee species richness: 1 sp. vs. 2 - 5 spp. (two-level factor in & -82.1 & 12.7 & 0.35 \\
linear model) & -94.8 & 0 & 0.56 \\
Plant spp. coverage + temperature coverage: linear & & & \\
\hline
\end{tabular}


in cages with two or more bee species than in cages with only one bee species (Fig. 4b). Importantly, this could not be predicted by fundamental flower preferences (floral niches of bees in cages without other species): plant species coverage for cages with more than one bee species was lower in simulated bee visitation data based on plant species preferences calculated from monospecific cages (Fig. 4b, Fig. S5). The niche shift in the presence of other bee species also involved a significant increase in bee specialization $d$ ' $(\mathrm{p}<0.001, \mathrm{df}=37$, linear mixed effects model with bee species nested within cage, Fig. $4 \mathrm{c})$, but plant species coverage by the bee community was still higher.

Plant community seed production was explained far better by a multiple regression model combining both variables of functional niche coverage (temperature coverage and plant species coverage) than it was explained by bee species richness (Table 2, Fig. 5a-c). In contrast, pollinator specialization ( $d$ ', weighted mean per cage) did not explain plant community seed production ( $\mathrm{p}=0.76$, when added to the multiple regression model).

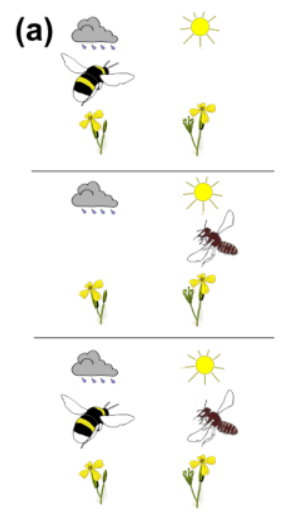

(b)

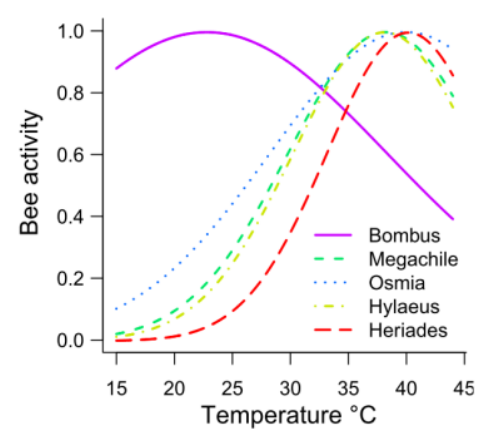

(c)

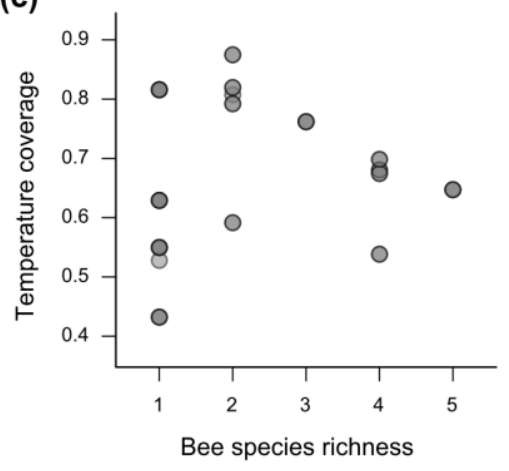

(d)

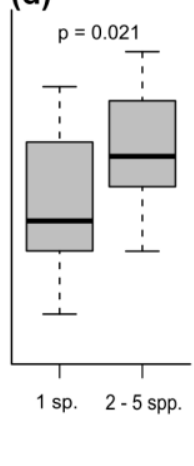

Fig. 2: Functional complementarity among bee species related to weather conditions. (a) Bee species active under different weather conditions provide more complete pollination (visitation) when they occur together. (b) Relationship between temperature (of partly shaded thermometers, integrating air temperature and solar radiation) and flower visitation activity of the five bee species used in the experiment (fitted Gaussian niche curves). (c, d) Functional temperature niche coverage (how evenly a bee community covers the whole temperature range, a measure of complementarity) in relation to the number of bee species present in a cage. P-value in (d) based on Welch t-test. 
(a)

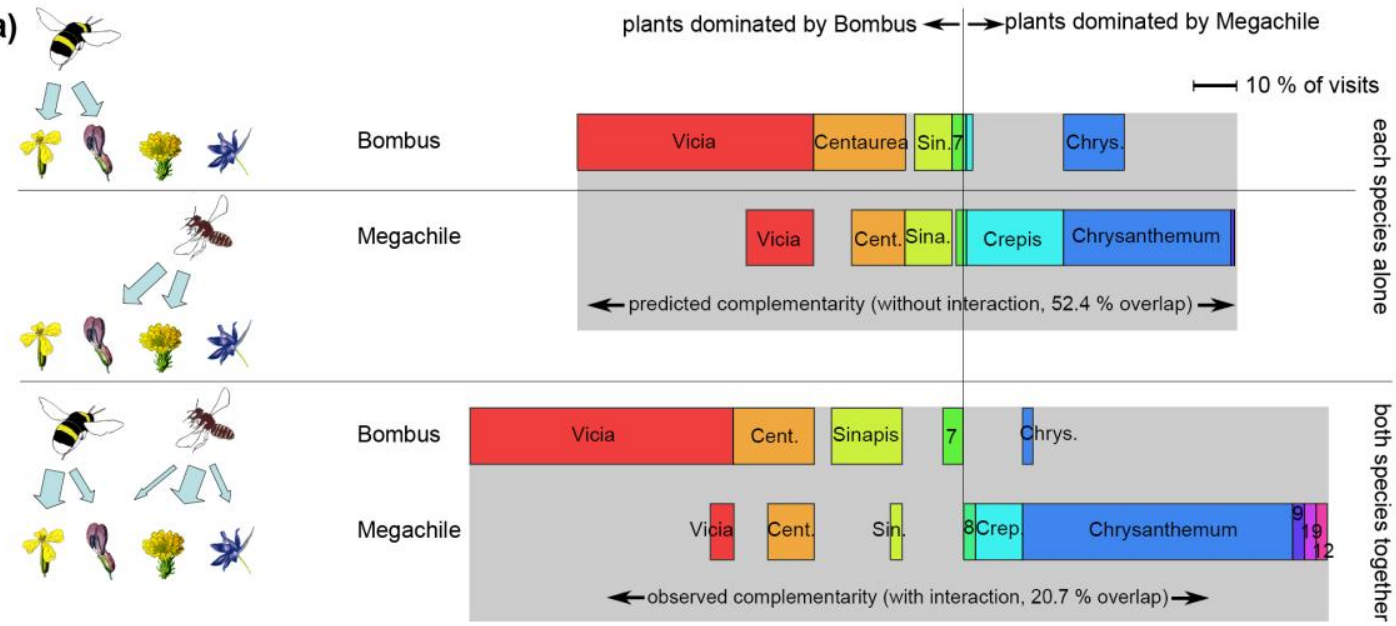

(b) cages with 1 bee species (fundamental complementarity)

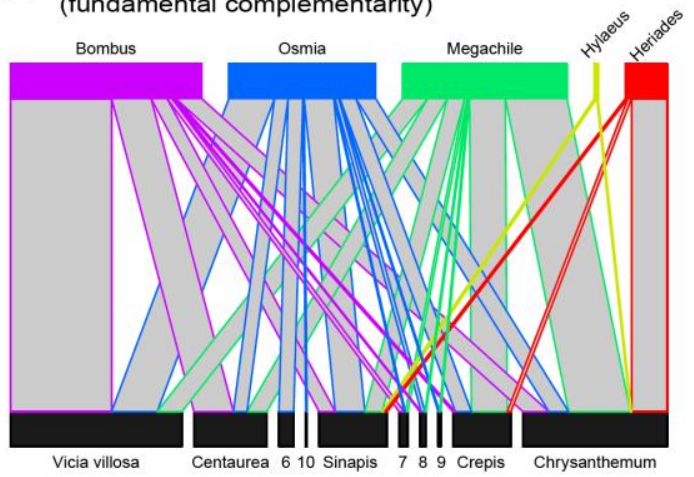

(c) cages with $2-5$ bee species
(realized complementarity)

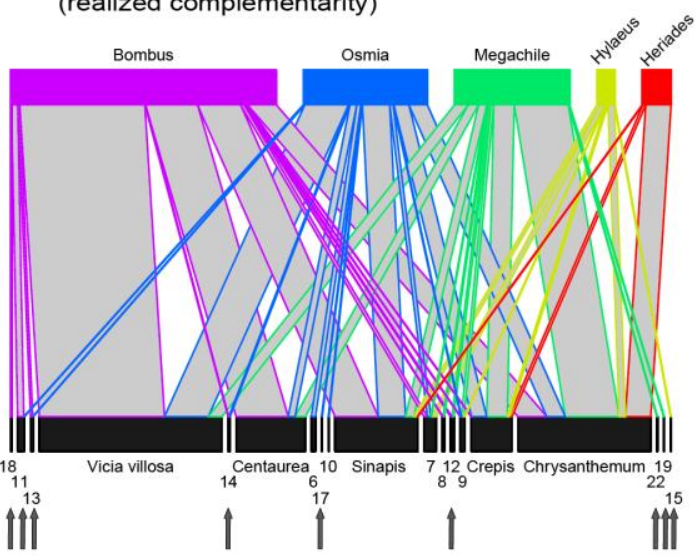

Fig. 3: Functional complementarity among bees in plant species visited. Bee species combinations visit more plant species both due to fundamental differences in flower preferences and due to interspecific interactions. (a) On the left a conceptual illustration of the complementarity mechanism, on the right a corresponding example from our experiment, showing flower visitation patterns of two bee species in communities with one species (top) and with both species (bottom). The proportion of different plant species (color-coded, see Table S1 for species names) in all visits is shown for each bee species and community context. Cooccurring bee species reduce niche overlap, which amplifies complementarity. See Fig. S5 for a null model showing that the decrease in overlap is significant. (b, c) Pooled quantitative interaction networks; arrows indicate plant species only visited in cages with 2-5 spp., see also Fig. S6. 

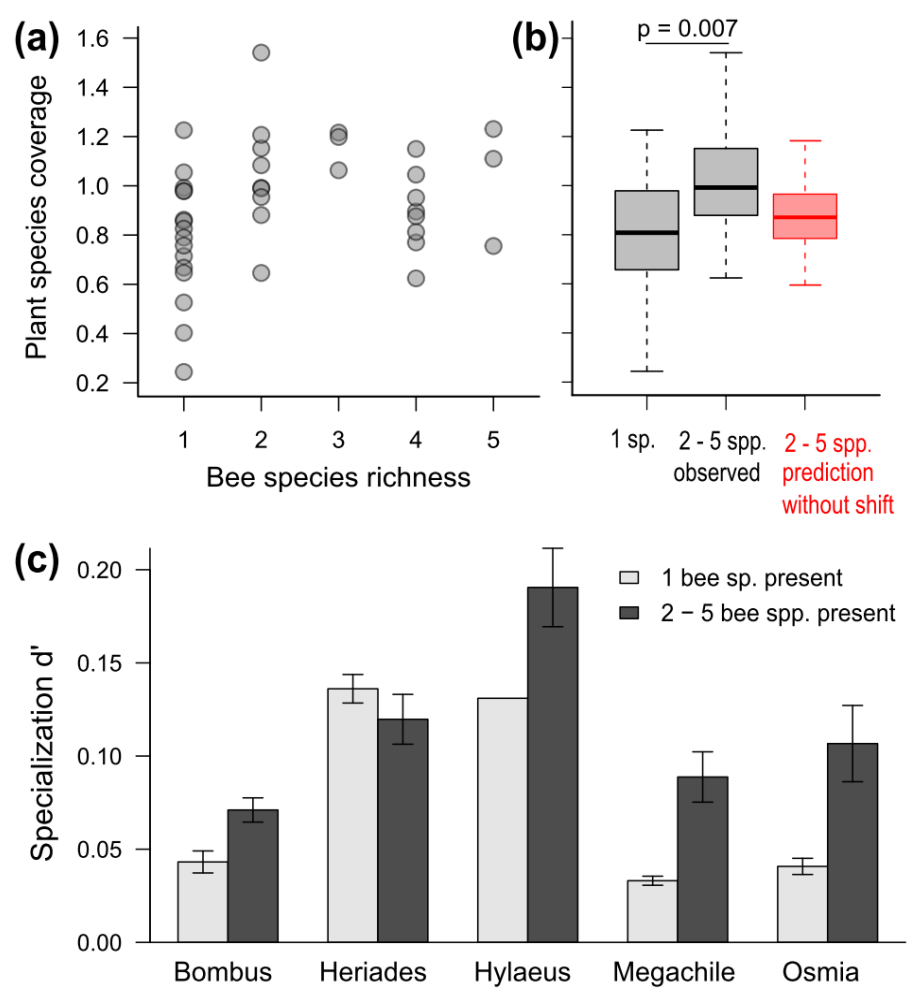

Fig. 4: Bees' floral niche shifts in response to community context. (a) Plant species coverage (i.e. the number of plant species visited per cage, corrected for sampling effects) in relation the number of bee species present. (b) Plant species coverage per cage in cages with one vs. more than one bee species ( $p$-value based on Welch t-test). The red box on the right shows the expectation if there were no changes in flower preferences (simulation based on visitation in cages with one bee species, see Fig. S5 for an extended version including an appropriate test showing that observed coverage is significantly higher than expected). (c) Specialization per bee species and cage, mean \pm sem. Specialization increased under interspecific competition, but less so for Bombus (strong competitor) and not for Heriades (specialist).
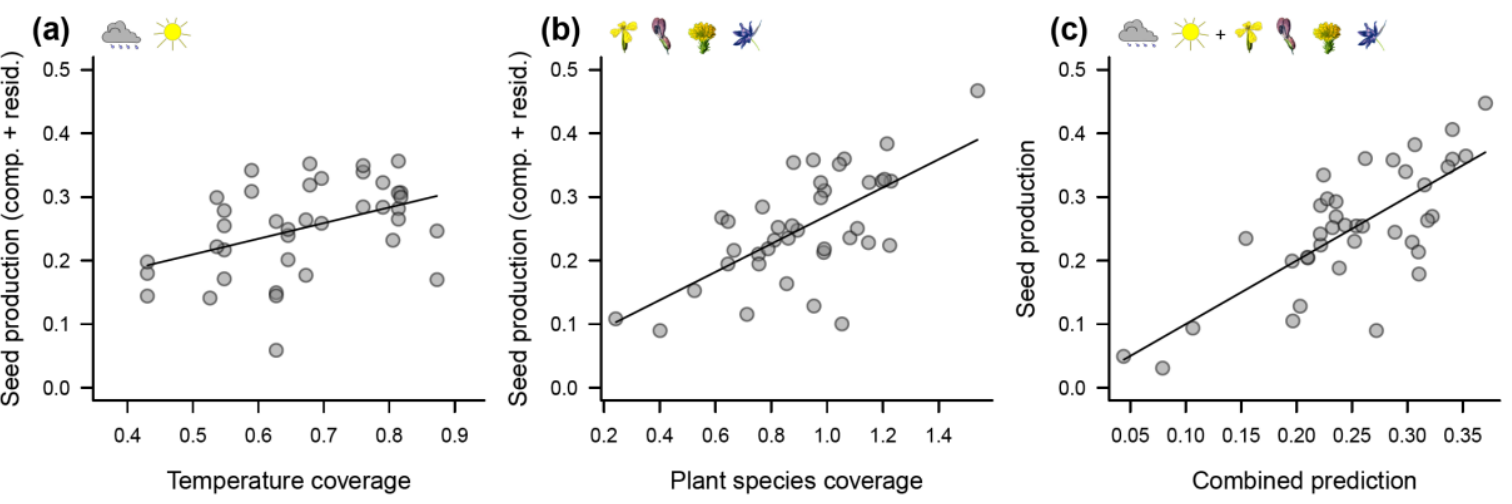

Fig. 5: Relationship between seed production of the plant community and two variables of functional niche complementarity. $(a, b)$ Partial residual plots of a multiple regression including both variables (temperature coverage, $\mathrm{p}=0.01$, and plant species coverage, $\mathrm{p}<0.001$, respectively). (c) Seed production in relation to the model prediction of that multiple regression. See Fig. 2 for explanation of variables. $\mathrm{N}=39$ cages in all three panels. 


\section{Discussion}

Our experiment showed that higher bee diversity leads to higher seed production, but this required that an increase in richness caused higher coverage of functional niches. Functional coverage, which reflects the mechanism of complementarity effects, predicted seed production far better than species richness per se did. The relationship between seed production and bee diversity was relatively weak and tended to saturate, because not all combinations of bee species showed high complementarity. Functional complementarity was related to interspecific differences in temperature dependence and in flower preferences. Flower preferences appeared to be flexible and depended on community context: interspecific overlap was reduced in multi-species cages, resulting in both higher specialization and higher functional coverage (i.e. more plant species being visited) than expected from preferences in single-species cages.

\section{Bee diversity per se}

We found that pollination of a diverse plant community tended to be higher when more bee species were present. This confirms that bee diversity is important for pollination as suggested by field studies (Kremen et al. 2002, Klein et al. 2003, Potts et al. 2006, Hoehn et al. 2008), and shows that this diversity effect is independent of bee abundance or environmental effects. In contrast to the results of Fontaine et al. (2006), we show that pollinator diversity matters also within a functional group. Moreover, by using all species in different combinations across the diversity gradient, we showed that the relationship is not merely driven by effective bee species being present mostly in more diverse communities, which has been considered as an explanation for field data (Klein et al. 2003, Larsen et al. 2005). The bee diversity effect reflects a complementarity effect rather than a sampling or selection effect (Loreau and Hector 2001), as the most effective species had the highest abundance in single-species cages, but maximum seed production was not observed in these cages. That our results were not simply driven by differences in pollination effectiveness was further supported by seed production in cages with two bee species being higher than expected for additive single-species effects ('overyielding'). However, bee species diversity per se was not a very good predictor of reproductive output of the plant community. The strongest difference was found comparing communities with one bee species to communities with several bee species. 
The diversity effect tended to saturate with higher bee diversity and this cannot be explained by complete pollination across cages with multiple bee species, because seed production was highest in open cages. The saturating model for the bee diversitypollination relationship must still be treated with care and does not mean that two bee species are sufficient for pollination of plant communities. Firstly, a model with diminishing but not saturating increase was not much worse. Secondly, the exact form of the relationship depends on the spatiotemporal scale (Bengtsson et al. 2002), the selected plant and bee species combinations, and environmental conditions. Thirdly, as species abundances in real communities are often highly skewed, effective diversity levels used in our experiment are more realistic than might appear from species richness. Fourthly, in many real-world scenarios of bee diversity declines, total bee abundance declines in parallel because density compensation by the remaining species is incomplete or lacking (Winfree and Kremen 2009), resulting in steeper declines of function (Larsen et al. 2005).

Biodiversity-function relationships in the real world may also be determined by extinction order (Larsen et al. 2005, Srivastava and Vellend 2005). For example, hoverflies are likely to be still present in real landscapes after declines in bee diversity (Jauker et al. 2009). In our experiment, hoverflies contributed only little to pollination despite similar number of flower visits and higher number of individuals compared to bees. Low pollination effectiveness of hoverflies compared to bees is consistent with previous studies (e.g. Jauker et al. 2012), questioning how far they can offset loss of pollination by bees.

\section{Functional complementarity and bee diversity}

Bee species differed in their response to temperature or weather conditions. While bumblebees showed highest flower visiting activity during colder periods, other bees were mostly active under warm and sunny conditions. This means that they perform complementary functions and in combination they cover different environmental conditions particularly well.

In our study, more plant species were visited in cages with two or more bee species than in cages with one bee species. Bee species differed in their floral preferences and thus performed complementary functions for the plant community. This confirms that there is complementary specialization among polylectic ('generalist') bee species (Fründ et al. 2010). This is an important contribution to overall specialization of bee 
communities, since highly specialized oligolectic bees are only a minority in most bee communities (Fründ et al. 2010). For the optimal pollination of a plant community, it is essential that all plant species are visited, which will be determined by the interplay between generalization and complementarity.

Functional coverage did not increase linearly with bee diversity and was not highest in cages with the highest number of bee species. This can be explained by a variable degree of functional redundancy among species pairs, and consequentially higher overlaps in some combinations than in others. Functional complementarity of a bee community will be determined by differences among species' realized niches and the evenness of niche coverage. Thus, a bee community providing high coverage of all relevant niche dimensions can have better pollination function than a randomly composed community with more species.

In addition to the functional niche dimensions important in our study (weather and plant species), bee species can also be complementary in their behavior in individual flowers (Blüthgen and Klein 2011), in preferred resource density (Tylianakis et al. 2008), in preferred flower height (Hoehn et al. 2008) and in time of pollinating activity (Hoehn et al. 2008). Temporal niche partitioning may also be related to daily temperature dynamics (Willmer and Corbet 1981), but temperature complementarity is also related to differences among days. Future studies should try to design diversity gradients of bee communities with realistic trait distributions that help to disentangle the relative importance of the different dimensions of functional complementarity.

\section{Niche shifts}

Most importantly, the floral niche partitioning among polylectic bee species was not simply due to fundamental preferences, as we observed shifts in bees' floral niches when other bee species were present. These shifts were probably a result of interspecific competition. In cages with multiple bee species, bees visited plant species that were not visited in any of the cages with one bee species. Fundamental flower preferences (i.e. without competing species) were not sufficient to explain the high plant species coverage in cages with multiple bee species. Note that our quantitative concept of fundamental niche puts more emphasis on the relative use of different resources than a possible alternative concept that views the fundamental niche as a list of all resources a species can potentially use. These findings highlight that competition for floral resources 
influences the structure of interaction networks and may explain why flower preferences in the field are variable (Fründ et al. 2010).

As predicted by competition theory (Inouye 1978), niche shifts not only involved use of novel resources, but also increased specialization on previously preferred plant species (niche contraction). Both effects reduce interspecific overlap and are not mutually exclusive: community niche coverage can increase at the same time as niche breadth of individual bee species decreases. These shifts in floral niches enhanced functional complementarity among bee species.

We showed that fundamental flower preferences and competition among bee species both shape the realized pattern of plant pollinator interactions. This finding of dynamic plant-pollinator linkages adds to recently shown temporal dynamics of plant-pollinator networks (Alarcón et al. 2008, Olesen et al. 2008, Fründ et al. 2011), which both cautions against assumptions of homogeneity in plant-pollinator associations (e.g. Memmott et al. 2004). Pollinator generalization increases with intraspecific competition (Fontaine et al. 2008) and thus should occur in scenarios of pollinator species loss with density compensation. This effect occurred also in our study: bees were more generalized in single-species cages where intraspecific competition was highest. However, more plant species were visited in multi-species cages, which highlights that responses to intraspecific competition cannot compensate for the decrease in total niche coverage resulting from reduced interspecific competition and loss of complementary species. Thus, predictions based on single-species studies can underestimate functional niche coverage in multi-species communities.

\section{Determinants of seed production}

Seed production was highest when bee communities displayed a broad range of temperature dependence and floral preferences. In contrast, plant community seed production was not related to pollinator specialization, so we could not confirm the longstanding hypothesis in pollination ecology that plants benefit from pollinator specialization due to increased conspecific pollen delivery (Wissel 1977). This might be because our specialization index focuses on the consumer's overall resource specialization (i.e., selectiveness, or the diversity of plant species used by a bee species), while the benefit of pollinator specialization for pollination effectiveness might be better estimated by considering the sequence of visits, which drives the purity of deposited pollen. The frequency of consecutive visits to the same plant species can also be high in 
generalist pollinator species that show floral constancy (Wilson and Stine 1996). A positive effect of specialization on function was found for aphid parasitoids when functional niche coverage was standardized by the experimental design (Finke and Snyder 2008). In our case, functional niche coverage was the best predictor of reproductive success of the plant community. The likely underlying mechanism is that a more even distribution of flower visitation ensures pollination where it is most limiting: additional visits bring the highest benefit when they avoid failure of pollination and relatively low benefit when a plant is already well pollinated.

\section{Conclusion}

We demonstrated that bee diversity determines pollination success in plant communities, but this relationship depends on the species-specific traits that drive functional complementarity. This corroborates recent studies reporting functional complementarity due to niche partitioning as the main driver of biodiversity effects (Loreau and Hector 2001, Finke and Snyder 2008, Cardinale 2011). Furthermore, interspecific interactions are important in determining the functional value of bee communities, highlighting that compilation of traits from single species studies can be misleading. Our study supports that 'interactive complementarity effects' are important for biodiversity-functioning relationships. Our results provide experimental evidence that functionally diverse bee communities are needed to maintain plant communities that rely on pollination for high reproductive success.

\section{Acknowledgments}

We thank the people who helped with the experiment: E Eilers, C Fessel, B Gruber, B Jünemann, S Jahn, V Karwath, S Parsche, S Schiele, B Tappe, C Thies and many others. Helpful comments, suggestions or advice were provided by R Capell, HC Fründ, A Hector, AM Klein, O Lewis, I Steffan-Dewenter, C Scherber, JM Tylianakis, C Westphal, NM Williams and two anonymous reviewers. JF received a scholarship of the DBU (German Federal Environmental Foundation). The Helmholtz Association (grant VH-NG 247 to CFD, TT and AH) and the DFG (German Science Foundation) are acknowledged for funding. 


\section{Literature cited}

Alarcón, R., N. M. Waser, and J. Ollerton. 2008. Year-to-year variation in the topology of a plant-pollinator interaction network. Oikos 117:1796-1807.

Ashton, I. W., A. E. Miller, W. D. Bowman, and K. N. Suding. 2010. Niche complementarity due to plasticity in resource use: plant partitioning of chemical $\mathrm{N}$ forms. Ecology 91:3252-3260.

Bell, T., A. K. Lilley, A. Hector, B. Schmid, L. King, and J. A. Newman. 2009. A linear model method for biodiversity-ecosystem functioning experiments. The American Naturalist 174:836-849.

Bengtsson, J., K. Engelhardt, P. Giller, S. Hobbie, D. Lawrence, J. Levine, M. Vilà, and V. Wolters. 2002. Slippin' and slidin' between the scales: the scaling components of biodiversity-ecosystem functioning relations. Pages $209-220$ Biodiversity and ecosystem functioning: synthesis and perspectives. . Oxford University Press, Oxford, New York.

Biesmeijer, J. C., S. P. M. Roberts, M. Reemer, R. Ohlemüller, M. Edwards, T. Peeters, A. P. Schaffers, S. G. Potts, R. Kleukers, C. D. Thomas, J. Settele, and W. E. Kunin. 2006. Parallel declines in pollinators and insect-pollinated plants in Britain and the Netherlands. Science 313:351-354.

Blüthgen, N., and A.-M. Klein. 2011. Functional complementarity and specialisation: the role of biodiversity in plant-pollinator interactions. Basic and Applied Ecology $12: 282-291$.

Blüthgen, N., F. Menzel, and N. Blüthgen. 2006. Measuring specialization in species interaction networks. BMC Ecology 6:9.

Burnham, K. P., and D. R. Anderson. 2001. Kullback-Leibler information as a basis for strong inference in ecological studies. Wildlife Research 28:111-119.

Cardinale, B. J. 2011. Biodiversity improves water quality through niche partitioning. Nature 472:86-89.

Cardinale, B. J., M. A. Palmer, and S. L. Collins. 2002. Species diversity enhances ecosystem functioning through interspecific facilitation. Nature 415:426-429.

Cardinale, B. J., D. S. Srivastava, J. Emmett Duffy, J. P. Wright, A. L. Downing, M. Sankaran, and C. Jouseau. 2006. Effects of biodiversity on the functioning of trophic groups and ecosystems. Nature 443:989-992.

Casula, P., A. Wilby, and M. B. Thomas. 2006. Understanding biodiversity effects on prey in multi-enemy systems. Ecology Letters 9:995-1004. 
Dormann, C. F., J. Fründ, N. Blüthgen, and B. Gruber. 2009. Indices, graphs and null models: analyzing bipartite ecological networks. The Open Ecology Journal 2:7-24.

Duffy, J. E., B. J. Cardinale, K. E. France, P. B. McIntyre, E. Thébault, and M. Loreau. 2007. The functional role of biodiversity in ecosystems: incorporating trophic complexity. Ecology Letters 10:522-538.

Finke, D. L., and W. E. Snyder. 2008. Niche partitioning increases resource exploitation by diverse communities. Science 321:1488-1490.

Fontaine, C., C. L. Collin, and I. Dajoz. 2008. Generalist foraging of pollinators: diet expansion at high density. Journal of Ecology 96:1002-1010.

Fontaine, C., I. Dajoz, J. Meriguet, and M. Loreau. 2006. Functional diversity of plantpollinator interaction webs enhances the persistence of plant communities. PLoS Biology 4:e1.

Fründ, J., C. F. Dormann, and T. Tscharntke. 2011. Linné's floral clock is slow without pollinators - flower closure and plant-pollinator interaction webs. Ecology Letters 14:896-904.

Fründ, J., K.-E. Linsenmair, and N. Blüthgen. 2010. Pollinator diversity and specialization in relation to flower diversity. Oikos 119:1581-1590.

Gómez, J. M., J. Bosch, F. Perfectti, J. Fernández, and M. Abdelaziz. 2007. Pollinator diversity affects plant reproduction and recruitment: the tradeoffs of generalization. Oecologia 153:597-605.

Greenleaf, S. S., and C. Kremen. 2006. Wild bees enhance honey bees' pollination of hybrid sunflower. Proceedings of the National Academy of Sciences of the United States of America 103:13890-13895.

Hoehn, P., T. Tscharntke, J. M. Tylianakis, and I. Steffan-Dewenter. 2008. Functional group diversity of bee pollinators increases crop yield. Proceedings of the Royal Society of London Series B-Biological Sciences 275:2283-2291.

Inouye, D. W. 1978. Resource partitioning in bumblebees: experimental studies of foraging behavior. Ecology 59:672-678.

Isbell, F., V. Calcagno, A. Hector, J. Connolly, W. S. Harpole, P. B. Reich, M. SchererLorenzen, B. Schmid, D. Tilman, J. van Ruijven, A. Weigelt, B. J. Wilsey, E. S. Zavaleta, and M. Loreau. 2011. High plant diversity is needed to maintain ecosystem services. Nature 477:199-202.

Jauker, F., B. Bondarenko, H. C. Becker, and I. Steffan-Dewenter. 2012. Pollination efficiency of wild bees and hoverflies provided to oilseed rape. Agricultural and 
Forest Entomology 14:81-87.

Jauker, F., T. Diekötter, F. Schwarzbach, and V. Wolters. 2009. Pollinator dispersal in an agricultural matrix: opposing responses of wild bees and hoverflies to landscape structure and distance from main habitat. Landscape Ecology 24:547-555.

Jongman, R. H. G., C. J. F. T. Braak, and O. F. R. van Tongeren. 1987. Data analysis in community and landscape ecology. . Pudoc, Wageningen.

Klein, A. M., I. Steffan-Dewenter, and T. Tscharntke. 2003. Fruit set of highland coffee increases with the diversity of pollinating bees. Proceedings of the Royal Society of London Series B-Biological Sciences 270:955-961.

Krebs, C. J. 1998. Ecological Methodology (2nd Edition). . Benjamin Cummings.

Kremen, C., N. M. Williams, and R. W. Thorp. 2002. Crop pollination from native bees at risk from agricultural intensification. Proceedings of the National Academy of Sciences of the United States of America 99:16812-16816.

Larsen, T. H., N. M. Williams, and C. Kremen. 2005. Extinction order and altered community structure rapidly disrupt ecosystem functioning. Ecology Letters 8:538547.

Loreau, M., and A. Hector. 2001. Partitioning selection and complementarity in biodiversity experiments. Nature 412:72-76.

Loreau, M., S. Naeem, P. Inchausti, J. Bengtsson, J. P. Grime, A. Hector, D. U. Hooper, M. A. Huston, D. Raffaelli, B. Schmid, D. Tilman, and D. A. Wardle. 2001. Biodiversity and ecosystem functioning: current knowledge and future challenges. Science 294:804-808.

Memmott, J., N. M. Waser, and M. V. Price. 2004. Tolerance of pollination networks to species extinctions. Proceedings of the Royal Society of London Series B-Biological Sciences 271:2605-2611.

Morse, D. H. 1974. Niche breadth as a function of social dominance. The American Naturalist 108:818-830.

Olesen, J. M., J. Bascompte, H. Elberling, and P. Jordano. 2008. Temporal dynamics in a pollination network. Ecology 89:1573-1582.

Ollerton, J., R. Winfree, and S. Tarrant. 2011. How many flowering plants are pollinated by animals? Oikos 120:321-326.

Potts, S. G., J. C. Biesmeijer, C. Kremen, P. Neumann, O. Schweiger, and W. E. Kunin. 2010. Global pollinator declines: trends, impacts and drivers. Trends in Ecology \& Evolution 25:345-353. 
Potts, S. G., T. Petanidou, S. Roberts, C. O’Toole, A. Hulbert, and P. Willmer. 2006. Plant-pollinator biodiversity and pollination services in a complex Mediterranean landscape. Biological Conservation 129:519-529.

R Development Core Team. 2010. R: A language and environment for statistical computing. . R Foundation for Statistical Computing, Vienna, Austria.

Scherber, C., N. Eisenhauer, W. W. Weisser, B. Schmid, W. Voigt, M. Fischer, E. D. Schulze, C. Roscher, A. Weigelt, E. Allan, H. Beßler, M. Bonkowski, N. Buchmann, F. Buscot, L. W. Clement, A. Ebeling, C. Engels, S. Halle, I. Kertscher, A.-M. Klein, R. Koller, S. König, E. Kowalski, V. Kummer, A. Kuu, M. Lange, D. Lauterbach, C. Middelhoff, V. D. Migunova, A. Milcu, R. Müller, S. Partsch, J. S. Petermann, C. Renker, T. Rottstock, A. Sabais, S. Scheu, J. Schumacher, V. M. Temperton, and T. Tscharntke. 2010. Bottom-up effects of plant diversity on multitrophic interactions in a biodiversity experiment. Nature 440:553-556.

Srivastava, D. S., and M. Vellend. 2005. Biodiversity-ecosystem function research: is it relevant to conservation? Annual Review of Ecology, Evolution, and Systematics $36: 267-294$.

Tylianakis, J. M., T. A. Rand, A. Kahmen, A.-M. Klein, N. Buchmann, J. Perner, and T. Tscharntke. 2008. Resource heterogeneity moderates the biodiversity-function relationship in real world ecosystems. PLoS Biology 6:e122.

Ulrich, W., and N. J. Gotelli. 2010. Null model analysis of species associations using abundance data. Ecology 91:3384-3397.

Walther-Hellwig, K., G. Fokul, R. Frankl, R. Büchler, K. Ekschmitt, and V. Wolters. 2006. Increased density of honeybee colonies affects foraging bumblebees. Apidologie 37:517-532.

Westrich, P. 1989. Die Wildbienen Baden-Württembergs. Teil 1: Lebensräume, Verhalten, Ökologie und Schutz. Teil 2: Die Gattungen und Arten. . Ulmer, Stuttgart.

Williams, N. M., E. E. Crone, T. H. Roulston, R. L. Minckley, L. Packer, and S. G. Potts. 2010. Ecological and life-history traits predict bee species responses to environmental disturbances. Biological Conservation 143:2280-2291.

Willmer, P. G. 1983. Thermal constraints on activity patterns in nectar-feeding insects. Ecological Entomology 8:455-469.

Willmer, P. G., and S. A. Corbet. 1981. Temporal and microclimatic partitioning of the floral resources of Justicia aurea amongst a concourse of pollen vectors and nectar robbers. Oecologia 51:67-78. 
Wilson, P., and M. Stine. 1996. Floral constancy in bumble bees: handling efficiency or perceptual conditioning? Oecologia 106:493-499.

Winfree, R., and C. Kremen. 2009. Are ecosystem services stabilized by differences among species? A test using crop pollination. Proceedings of the Royal Society of London Series B-Biological Sciences 276:229-237.

Wissel, C. 1977. On the advantage of the specialization of flowers on particular pollinator species. Journal of Theoretical Biology 69:11-22. 


\section{Supporting Information for Chapter 2}

\section{Contents:}

Appendix S1: Supporting Methods, including

Experimental Design

Plant community

Pollinator community

Alternative predictors of seed production

Influence of imbalance in species composition

Simulation of visitation data based on fundamental vs. realized preferences

References in Appendix S1

Figures $\mathrm{S} 1$ to $\mathrm{S} 6$

Table S1

\section{Appendix S1: Supporting Methods}

\section{Experimental Methods}

\section{Experimental Design}

The substitutive design focusing on the effect of diversity independent of abundance was chosen because it helps to identify mechanisms of diversity effects and because it is most appropriate for a cage experiment. On long time-scales, pollinator diversity might also have a positive effect by allowing higher total pollinator populations when density compensation is limited (Larsen et al. 2005, Winfree and Kremen 2009). This means that mechanisms of coexistence would be part of the diversity effect (Loreau et al. 2003). We chose to exclude this intractable type of 'diversity effect' and focus on 'pure' diversity effects for a given number of bees. This roughly corresponds to design 2 (controlling standing stocks) in the framework of Petchey (2003).

We tried to optimize the design considering recommendations from the literature (Schmid et al. 2002, Petchey 2003, Bell et al. 2009) and the availability of the different bee species (Table S1). As a great advantage for mechanistic interpretations, and as recommended by Schmid et al. (Schmid et al. 2002), we included all monocultures, and replicated all realized compositions (except for two compositions that were affected by 
shortage of material caused by uneven sex ratio in one of the reared bee species). In contrast to some other experiments (Schmid et al. 2002, Fontaine et al. 2006), the species composition was exactly known for all cages. We held bee abundance constant among cages, thereby preventing sampling or selection effects to affect our results in the way described for grassland plant diversity experiments (Bell et al. 2009). We measured functional traits and relevant ecological processes for all species during the experiment, which allows for a clearer mechanistic and functional interpretation than many other biodiversity experiments where these are unknown (Schmid et al. 2002).

As often in biodiversity experiments, it was impossible to realize all possible species combinations (Bell et al. 2009). For example, we used only one species combination for cages with 3 bee species as this level was expected to be less important for finding an overall trend. In consequence, the 3-species-level in our experiment does not give much information on the form of the diversity-function relationship.

\section{Plant community}

Seeds were purchased from the following suppliers:

- Vicia villosa: Appels Wilde Samen, Darmstadt, Germany

- Sinapis arvensis: harvested from plants reared from seeds supplied by IPK Gatersleben, Germany

- all other species: Rieger-Hofmann, Blaufelden, Germany.

\section{Pollinator community}

As intended, the total number of bees (solitary bees plus temporal mean of bumblebee worker numbers) was almost constant among all cages (mean \pm sd: $20.5 \pm 2.7$ ) and independent of bee species richness $(r=0.05, p=0.76)$. Bees behaved fairly natural in the cages. Behavior only shown by captive bees such as flying against the net walls was negligible after the first day in the cage. We observed mating behavior, collection of species-specific nesting material, and pollen and nectar collection similar to bees foraging outside the cages. On average, each female solitary bee created several nests. Bumblebee queens did not leave the nest after the first day of presence in the cage, new brood cells were produced in bumblebee nests and pollen and honey storage was build.

Hoverflies were allowed to colonize the plants before the cages were closed. No pollinators could pass the mesh after cages were closed, but larvae present on the plants 
could develop to adults. Hoverflies were present throughout the experiment and visited flowers in similar numbers as bees $(23.5 \pm 10.0$ visits by hoverflies vs. $32.1 \pm 12.3$ visits by bees per cage). Hoverfly abundance was even higher than bee abundance (214 \pm 40 hoverfly individuals captured in the exclusion bouts per 'no pollinators' control cage, which held abundance at a near-zero level). Hoverfly species composition was similar among cages, $98 \%$ of individuals belonging to the aphidophagous genera Sphaerophoria, Episyrphus, Melanostoma and Platycheirus, which are common also in intensively used agricultural land (Jauker et al. 2009) and often ineffective pollinators (Herrera 1987, Jauker et al. 2012). In many landscapes, hoverflies do not decline in parallel with bee diversity (Biesmeijer et al. 2006), which makes our design with background flower visitation by flies a particularly realistic scenario of real-world changes in bee diversity. We did not consider hoverflies for flower visitation analyses because they were much less efficient pollinators than bees. The conclusions about niche shifts in response to interspecific competition among bees are also not qualitatively affected by the presence of hoverflies, because they were present in similar numbers in all cages and therefore do not change that the ratio between interspecific to intraspecific competition increased with the bee diversity treatment.

\section{Statistical Analyses}

\section{Alternative predictors of seed production}

We explored alternative explanations for the effects of bee diversity and functional niche coverage on seed production:

The variation in the number of observed hoverfly visits among bee cages did not explain seed production (linear regression, $\mathrm{p}=0.81, \mathrm{R}^{2}=0.002, \mathrm{df}=37$ ). The number of bumblebees in a cage was not the main determinant of seed production $\left(\mathrm{p}=0.06, \mathrm{R}^{2}=\right.$ 0.09). Total biomass of a bee community (dry weight of 80, 4, 2, 20 and $30 \mathrm{mg}$ for Bombus, Heriades, Hylaeus, Megachile and Osmia, respectively) was significantly related to seed production, but explained far less than the mechanistic variables of functional niche coverage $\left(\mathrm{p}=0.007, \mathrm{R}^{2}=0.18 \mathrm{vs}\right.$. $\mathrm{R}^{2}=0.56$ for multiple regression with functional coverage). The number of flowering units was similar across cages and bee diversity levels, and it was not a significant predictor for seed production (linear regression, $\mathrm{p}=0.81, \mathrm{R}^{2}=0.002, \mathrm{df}=37$; sum of flowering units across bee-dependent plant species). 
We also explored the robustness of our results regarding functional coverage and bee specialization to the definition of the variables:

Temperature coverage without standardization of bee species specific temperature dependence to a maximum of one was slightly more positively related to bee diversity ( $p$ $=0.043, \mathrm{R}^{2}=0.11$ in linear regression; $\mathrm{t}=4.0, \mathrm{p}=0.001$ in Welch $\mathrm{t}$-test comparing single-species to multi-species cages) and it was also a significant predictor of seed production $(\mathrm{p}=0.011$ in multiple regression with plant species coverage). Plant species coverage without the null model correction for sampling effects (i.e., plain number of visited plant species per cage) increased significantly with bee diversity $\left(p=0.042, R^{2}=\right.$ 0.11 in linear regression; $t=3.3, p=0.003$ in Welch $t$-test comparing single-species to multi-species cages) and was a significant predictor of seed production $(p<0.001$ in multiple regression with temperature coverage).

Bee specialization $\left(d^{\prime}\right)$ with a correction for potential sampling effects (subtracting the mean of the null model described for plant species coverage; subtraction was chosen because $d$ ' has a theoretical minimum of zero) also showed significantly higher specialization in cages with more than one bee species (linear mixed effects model, $\mathrm{p}=$ 0.005 , $\mathrm{df}=37)$ and no relationship with seed production $(\mathrm{p}=0.48$ added to multiple regression including the two functional coverage variables, also n.s. in simple linear regression). An alternative measure of specialization ( $P S I_{w e b}$, similar to PSI proposed by Dormann and Blüthgen (Dormann et al. 2009)) trying to estimate the proportion of conspecific pollen delivery from the visitation network data was also no significant predictor of seed production ( $\mathrm{p}=0.603$ added to the multiple regression). This measure was calculated as:

$$
P S I_{w e b}=\sum_{i} \sum_{j}\left(\mathrm{Nvis}_{\mathrm{i}, \mathrm{j}} / N v i s_{., j}\right)\left(N v i s_{i, j}\right) / N v i s_{., .} \text {, i.e. the network-wide sum of the }
$$

proportion of plant species $i$ in visits of bee species $j$ multiplied by the number of visits by bee species $j$ on plant species $i$, divided by the total number of visits in the network.

\section{Influence of imbalance in species composition}

As we could not realize all possible combinations of the five bee species used in our experiment, relative species composition (the prevalence of the different bee species) varied slightly among levels of diversity. Therefore, we explored how far bee species identity effects could influence the bee diversity - functioning relationships observed in 
our experiment (Fig. S3). This was achieved by re-calculating the relationships for a theoretical design with completely equal contribution of each bee species to each diversity level. Different strategies were used for each response (see below). Note that these extrapolations had to assume no effect of bee communities on bee species-specific parameters, and thus ignore interactive complementarity.

The bee diversity - seed production relationship was re-examined applying an adjustment to observed seed data aiming at an unbiased estimate (Fig. S3a-b). This correction accounted for variation in the relative species composition among diversity levels, i.e. efficient bee species being overrepresented in some diversity levels. Similar to methods proposed by Hector (1998) and Petchey (2003) to detect complementarity effects, we estimated the expected value of an ecosystem process based on 'monoculture' performance. Adjusted seed production values were calculated in three steps: First, the 'fundamental pollination efficiency' $\left(S_{\text {mono, } i}\right)$ of each bee species $i$ was estimated as the mean seed production in the cages inhabited by only this species without other species. Second, expected average seed production $\left(S_{j}\right)$ per diversity level $j$ was calculated from pooled bee species composition per diversity level (proportions $p_{i, j}$ of species $i$ in level $j$ ) and 'efficiencies' $S_{\text {mono,i. }}$ Value $S_{j}$ reflected the bias due to missing combinations compared to a full-factorial design (in which a seed production of $S_{\text {null }}=$ mean of $S_{\text {mono, }}$ would be expected for all diversity levels in the absence of diversity effects). Third, observed seed production values $\left(S_{o b s, k}\right)$ for each cage $k$ were adjusted for the deviation from a full-factorial design (i.e., calculating corrected seed production $S_{c o r r, k}$ by subtracting the estimated bias).

$$
\begin{aligned}
& p_{i, j}=\frac{\operatorname{Ncages}_{j}\left(N_{i}>0\right)}{\operatorname{Ncages}_{j} \cdot j} \\
& S_{j}=\sum_{i=1}^{5} S_{\text {mono }, i} \cdot p_{i, j} \\
& S_{\text {corr }, k}=S_{\text {obs }, k}-\left(S_{j}-S_{\text {null }}\right)
\end{aligned}
$$

where $\operatorname{Ncages}_{j}\left(N_{i}>0\right)$ refers to the number of cages with diversity $j$ in which species $i$ was present. See also Fig. S4 as additional evidence that the diversity effect cannot be explained by pollinator identities.

Temperature niche coverage (Fig. S3c-d) was calculated for all 31 theoretically possible combinations of the 5 bee species, using the same approach and parameters as in 
the main text. Plant species coverage (Fig. S3 e-f) was simulated for all possible bee species combinations using plant species preferences for each bee species estimated from single-species cages ('fundamental preferences', see Methods and next subheading "Simulation of visitation data ..."). The number of visits per bee species and cage was set equal to the mean total number of bee visits per cage in our experiment (32), divided by the number of bee species in the community and rounded if necessary. As in the other simulation of fundamental preferences, probability of a plant species to be visited was proportional to the product of preference and flower abundance (which was set to the mean of visitation-weighted flower abundance across experimental cages).

\section{Simulation of visitation data based on fundamental vs. realized preferences}

We evaluated the effect of community context on floral niches and plant species coverage with a simulation approach (Fig. 3a, Fig. S5), showing that the observed shifts in bees' functional niches cannot be explained by chance or sampling effects. Aiming to separate effects of fundamental (i.e., without competing bee species) and realized preferences on plant species coverage (Fig. S5), we simulated networks based only on floral preferences in (i) cages with a single bee species and (ii) cages with multiple bee species. Source code (R language) of this simulation can be found as a separate file in Ecological Archives.

Visitation network data were simulated using the following approach: the number of visits per bee species and cage was randomly redistributed among plant species (1000 replicate simulations), using interaction probabilities based on flower availability and flower preferences. Flower preferences (forage ratio sensu Krebs (1998), i.e. proportion of plant species in diet divided by proportional availability of plant species) were calculated for each bee species comparing visits pooled across all cages with one bee species ('fundamental preferences') or all cages with more than one bee species ('realized preferences') to overall flower availability.

These simulations were similar to the null model used to correct plant species coverage, but the probability for a plant species to be visited by a bee species also depended on the estimated flower preferences of this bee species. For each plant species $i$, the probability of a visit by bee species $j$ in cage $k$ under 'fundamental preferences' was proportional to:

$$
\mathrm{NFU}_{\mathrm{i}, \mathrm{k}} \times\left(\mathrm{Nvis}_{\mathrm{i}, \mathrm{j}} \text {, cages mono with } \mathrm{j} / \mathrm{NFU} \mathrm{i}_{\mathrm{i}} \text { cages mono with } \mathrm{j}\right)
$$


where $N F U$ is the number of flower units, $N v i$ is is the number of bee visits and 'cages mono' refers to cages with a single bee species (in difference to 'cages poly' with two to five bee species). Hence, 'cages mono with j' are all single-species cages in which bee species $j$ was present. Probability of visit under 'realized preferences' was likewise:

$\mathrm{NFU}_{\mathrm{i}, \mathrm{k}} \times\left(\mathrm{Nvis}_{\mathrm{i}, \mathrm{j}}\right.$, cages poly with $\left.\mathrm{j} / \mathrm{NFU}_{\mathrm{i} \text {, cages poly with } \mathrm{j}}\right)$

To avoid sampling effects due to more observations per bee species available for the calculation of 'realized preferences', we rarefied the number of observations per bee species to the same numbers as used to calculate 'fundamental preferences' (function 'rrarefy' in R-package 'vegan', one sample per simulation run). Note that for simplicity and in order to retain enough observations per species, we calculated only one set of realized preferences for each bee species and did not account for potential differences among different multi-species community contexts.

The simulated visitation network data were used to validate the findings in the main paper. Niche overlap between Bombus and Megachile (cf. Fig. 3 in the main paper) was calculated for 'fundamental preferences' to show that the decreased overlap under cooccurrence cannot be explained by a sampling effect (Fig. S5a). Plant species coverage was calculated for 'fundamental' and 'realized preferences'. In the main paper (Fig. 4a), we show the average distribution across cages of plant species coverage for 'fundamental preferences', for best comparison with observed values. In the supplement, we focus on mean plant species coverage across cages and the corresponding simulated confidence intervals (Fig. S5b).

\section{References in SI}

Bell, T., A. K. Lilley, A. Hector, B. Schmid, L. King, and J. A. Newman. 2009. A linear model method for biodiversity-ecosystem functioning experiments. The American Naturalist 174:836-849.

Biesmeijer, J. C., S. P. M. Roberts, M. Reemer, R. Ohlemüller, M. Edwards, T. Peeters, A. P. Schaffers, S. G. Potts, R. Kleukers, C. D. Thomas, J. Settele, and W. E. Kunin. 2006. Parallel declines in pollinators and insect-pollinated plants in Britain and the Netherlands. Science 313:351-354.

Dormann, C. F., J. Fründ, N. Blüthgen, and B. Gruber. 2009. Indices, graphs and null models: analyzing bipartite ecological networks. The Open Ecology Journal 2:7-24.

Fontaine, C., I. Dajoz, J. Meriguet, and M. Loreau. 2006. Functional diversity of plantpollinator interaction webs enhances the persistence of plant communities. PLoS 
Biology 4:e1.

Hector, A. 1998. The effect of diversity on productivity: detecting the role of species complementarity. Oikos 82:597-599.

Herrera, C. M. 1987. Components of pollinator "quality": comparative analysis of a diverse insect assemblage. Oikos:79-90.

Jauker, F., B. Bondarenko, H. C. Becker, and I. Steffan-Dewenter. 2012. Pollination efficiency of wild bees and hoverflies provided to oilseed rape. Agricultural and Forest Entomology 14:81-87.

Jauker, F., T. Diekötter, F. Schwarzbach, and V. Wolters. 2009. Pollinator dispersal in an agricultural matrix: opposing responses of wild bees and hoverflies to landscape structure and distance from main habitat. Landscape Ecology 24:547-555.

Krebs, C. J. 1998. Ecological Methodology (2nd Edition). . Benjamin Cummings.

Larsen, T. H., N. M. Williams, and C. Kremen. 2005. Extinction order and altered community structure rapidly disrupt ecosystem functioning. Ecology Letters 8:538547.

Loreau, M., N. Mouquet, and A. Gonzalez. 2003. Biodiversity as spatial insurance in heterogeneous landscapes. Proceedings of the National Academy of Sciences of the United States of America 100:12765.

Petchey, O. L. 2003. Integrating methods that investigate how complementarity influences ecosystem functioning. Oikos 101:323-330.

Schmid, B., A. Hector, M. A. Huston, P. Inchausti, I. Nijs, P. W. Leadley, and D. Tilman. 2002. The design and analysis of biodiversity experiments. Pages $61-75$ in M. Loreau, S. Naeem, and P. Inchausti, editors. Biodiversity and ecosystem functioning: synthesis and perspectives. . Oxford University Press, Oxford, New York.

Winfree, R., and C. Kremen. 2009. Are ecosystem services stabilized by differences among species? A test using crop pollination. Proceedings of the Royal Society of London Series B-Biological Sciences 276:229-237. 


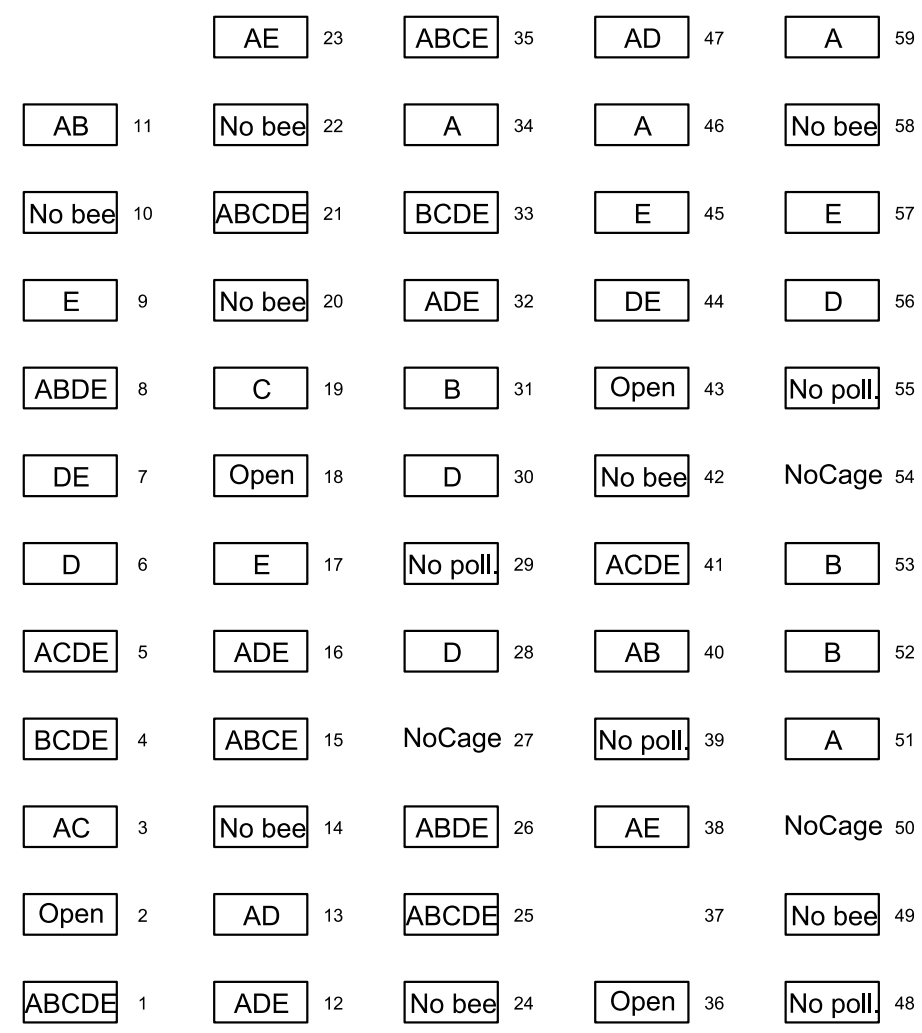

Fig. S1. Experimental design - spatial arrangement of treatments among cages. Positions were assigned by a randomization algorithm, assuring that each treatment is realized in cages of both edge and center of the field. Capital letters A - E indicate bee species; other treatments are different types of controls (see Table 1 for details of treatments and species names).

\begin{tabular}{|c|c|c|c|c|c|c|c|c|}
\hline 2 & 20 & 7 & 12 & $\frac{20}{\infty}$ & 21 & 3 & 5 & 9 \\
\hline 13 & 14 & 23 & 4 & $(z)$ & 8 & 1 & 22 & 11 \\
\hline 3 & 12 & 21 & 9 & 7 & 5 & 20 & 2 & \\
\hline 1 & 13 & 14 & 4 & 23 & 11 & 8 & 22 & \\
\hline
\end{tabular}

Fig. S2. Sowing pattern for the 16 plant species within a cage, numbers identify the species sown in the patch (see Table S2 for species names). Grey area indicates bare soil, which was used for accessing the cage (zip for entry in lower right corner). Positions of species were assigned by a randomization algorithm, assuring that each species was present on either side. 


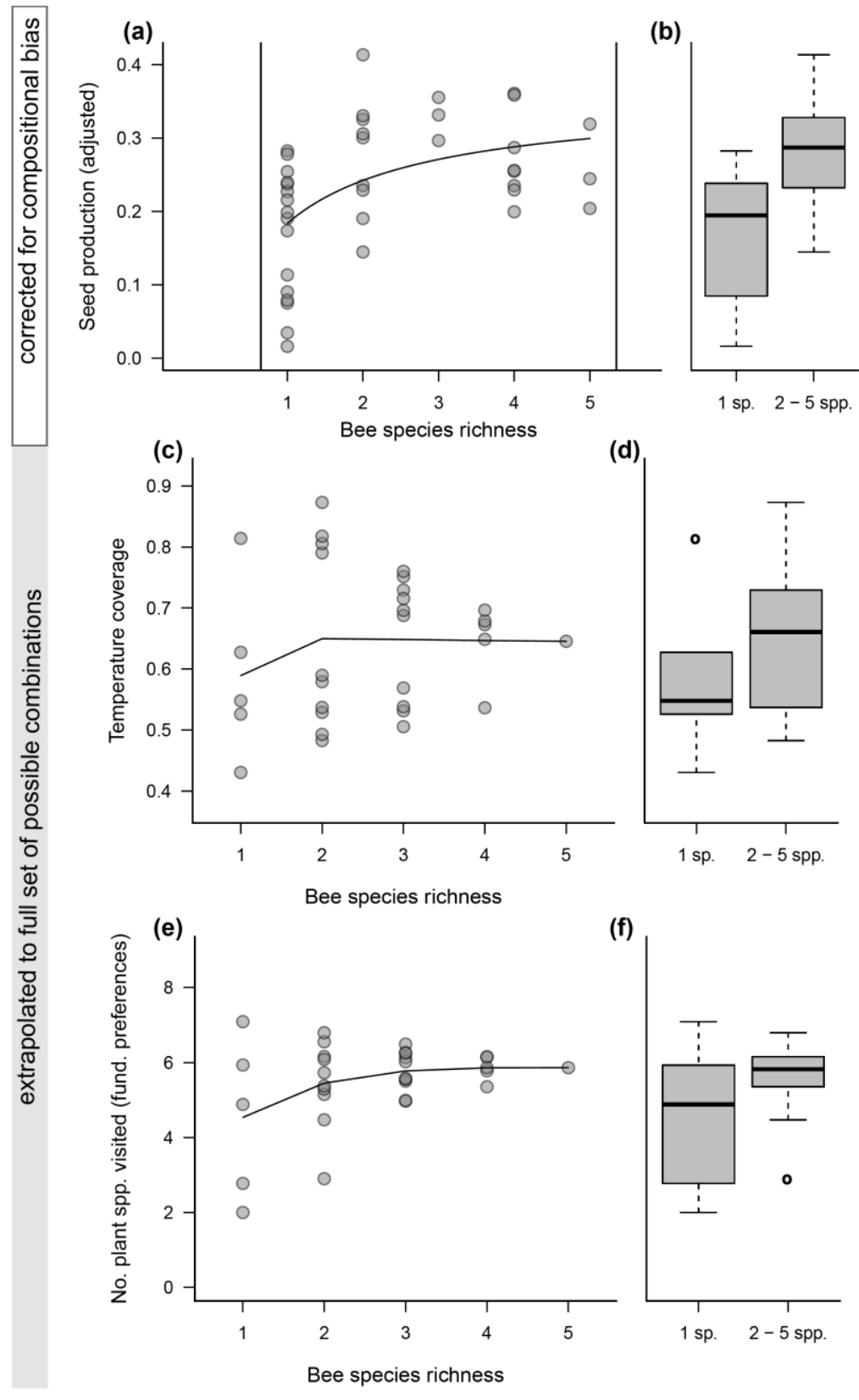

Fig. S3. Little influence of missing species combinations on our estimates of the bee diversity function relationships: corrections for variation in pooled species composition among diversity levels. (a, b) Adjusted seed production values in relation to bee diversity (potential species identity bias removed). Compare with Fig. 2. Adjusted seed production values suggested the same form of the bee diversity - seed production relationship: $\triangle \mathrm{AICc}=0$ (saturating), $1.2(\log )$, 2.3 (power), 4.8 (linear) and 10.6 (null), respectively. Note that only models with bee richness as predictor are included here, so that $\triangle \mathrm{AICc}$ values are not comparable with those from the main text. The line shows the fitted relationship for the saturating model. (c, d) Temperature niche coverage in relation to bee diversity for a theoretical design with all possible combinations of the 5 bee species used in our experiment. The line connects the mean values of each diversity level. (e, f) Plant species coverage due to 'fundamental' flower preferences, in relation to bee diversity for a theoretical design with all possible combinations of the 5 bee species used in our experiment. The line connects the mean values of each diversity level. The correction for possible sampling artifacts was not employed here because the same number of visits was simulated for each bee community. 

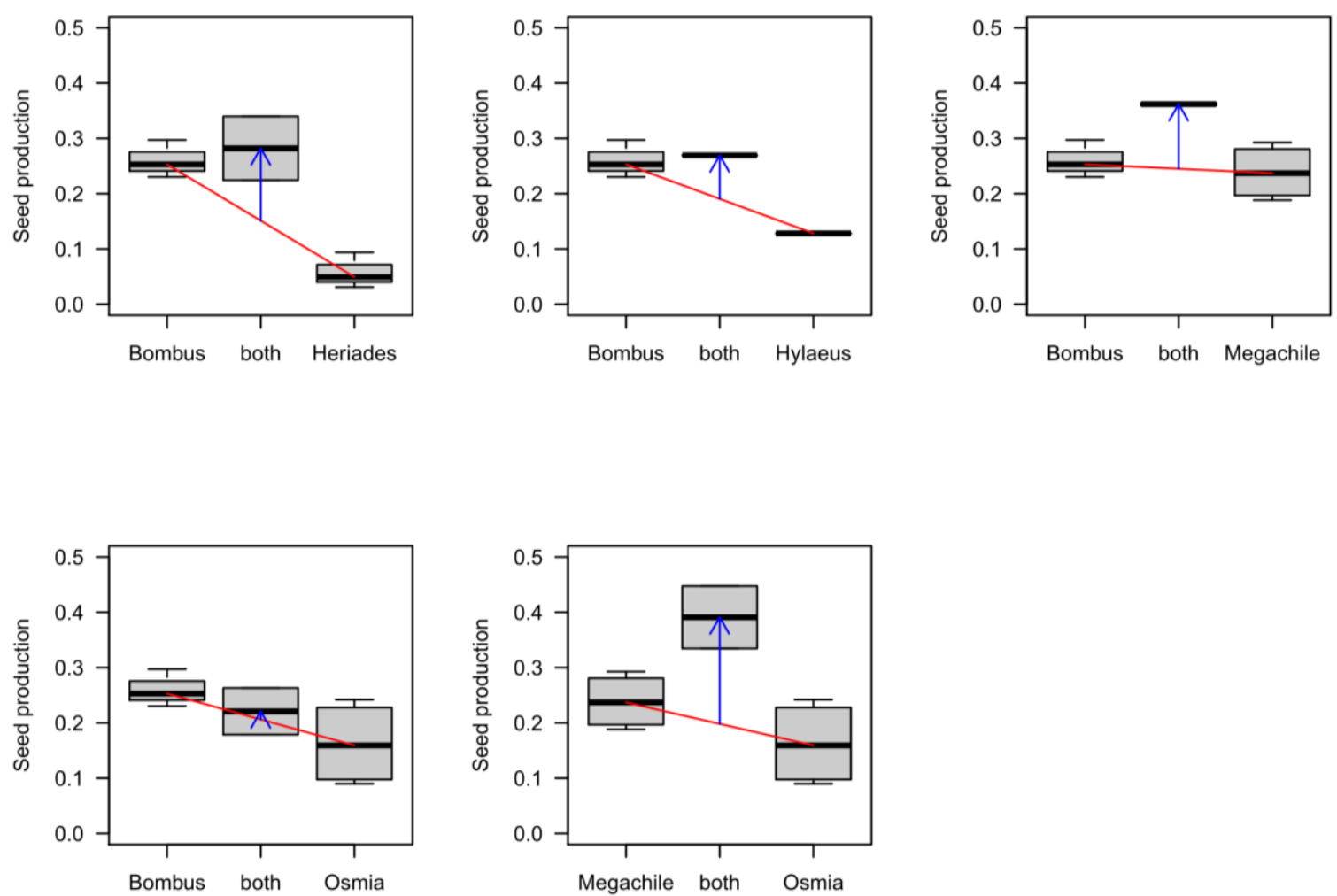

Fig. S4. 'Overyielding' in combinations of two bee species. Box plots show seed production (median, interquartile range and total data range) in cages with only one bee species and in cages with their mixture ('both'), holding total abundance constant across treatments. The red line shows the expectation for additive effects of the two species in relation to their relative abundance, and the blue arrow shows the deviations from additivity (interactive effects), which indicate various degrees of overyielding (positive deviations). This illustrates that species identity or sampling effects are not responsible for the observed positive diversity effect. 
(a)

cages with one species

cages with both species

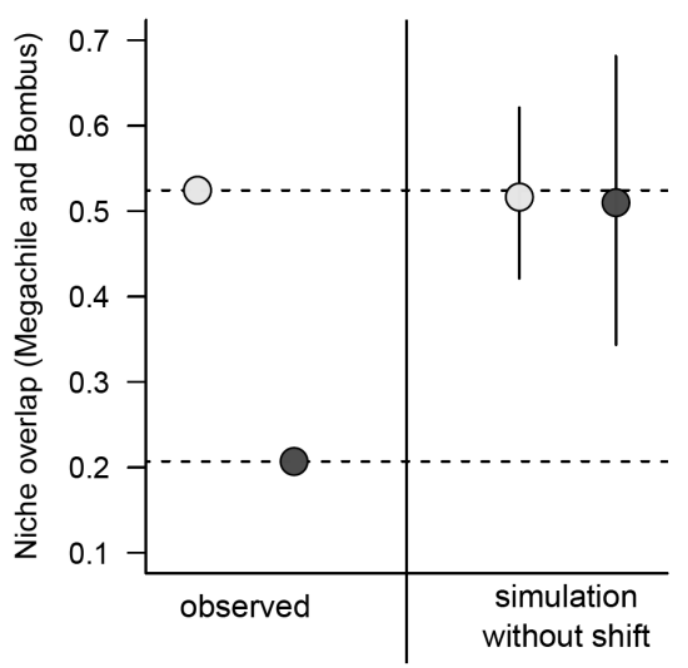

(b) cages with one species

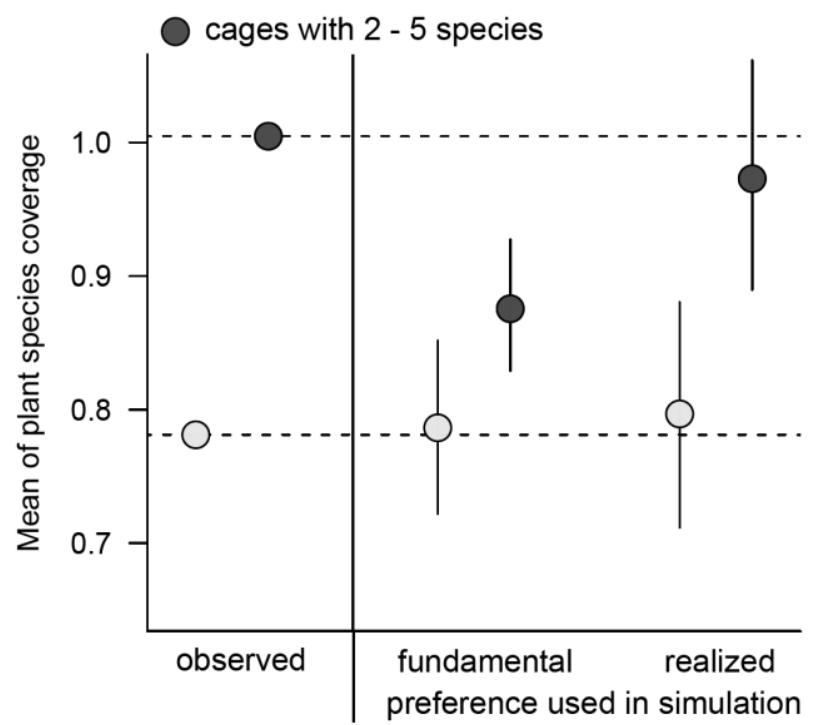

Fig. S5. (a) Niche overlap between two bee species in cages with one species vs. cages with both species, and mean and 95\% confidence intervals assuming no shift in preferences (simulation based on 'fundamental preferences'). (b) Mean number of plant species visited per cage with one vs. more than bee species, comparing the observed difference to simulated visitation data. Simulations were based on fixed preferences calculated from visits observed in cages without (fundamental preference, only intraspecific competition) and with (realized preference, intra- and interspecific competition) other bee species, respectively. Error bars show 95\% confidence intervals of 1000 simulation runs. Fundamental flower preferences did not predict the observed increase from cages with one to cages with multiple bee species.

Plant species coverage in cages with multiple bee species was significantly underestimated when simulations were based on fixed flower preferences calculated from visits observed in cages with one bee species. This means that fundamental preferences were not sufficient to predict realized plant species coverage. However, simulations based on 'realized preferences' were not significantly different from observed values of mean plant species coverage for singleor multi-species cages, respectively. This illustrates that the niche shift increasing plant species coverage was not driven by an increase in generalization, but only a decrease in niche overlap. 

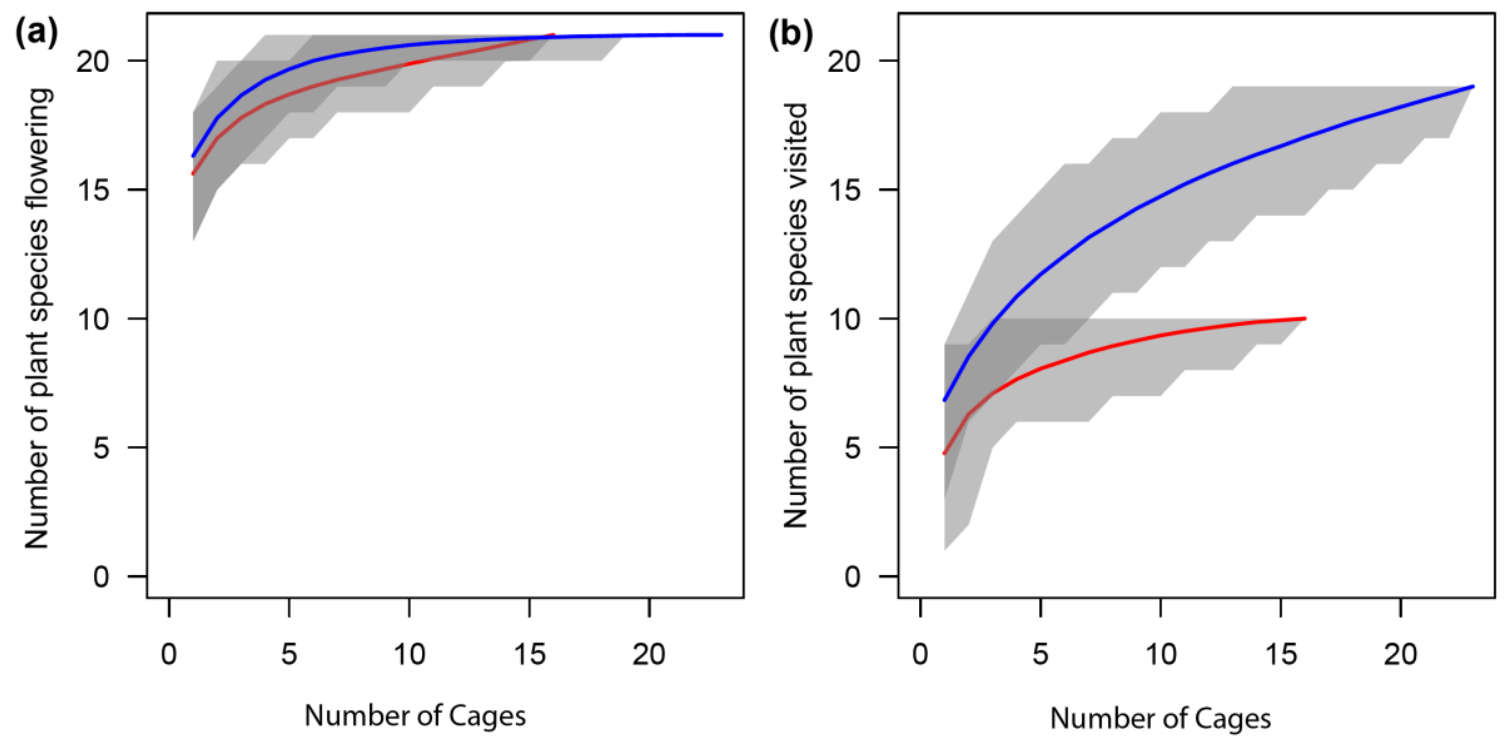

Fig. S6. Plant species accumulation curves (cumulative number of plant species visited in cages with one vs. multiple bee species). (a) Flower counting data (no difference between lines), (b) flower visitation data (clear difference between lines); lines indicate the mean cumulative number of plant species, red $=$ cages with a single bee species, blue $=$ cages with $2-5$ bee species; shaded area $=95 \%$-confidence intervals. As shown in Fig. 3b-c, more plant species were visited in cages with multiple bee species than in cages with a single bee species. This can be explained neither by bee species identity (all five bee species are also present in some of the cages with a single bee species), nor by sampling effects or differences in plant species present. This figure shows that the number of plant species present did not differ between these two types of treatments and saturated after a few cages had been accumulated. On the contrary, the higher (cumulative) number of plant species visited in cages with multiple bee species was consistent when identical numbers of cages were compared. 
Table S1: Plant species in the experiment with ID-codes used in Figs. 3 and S2.

\begin{tabular}{|c|c|c|c|c|c|}
\hline ID & Plant species $^{1}$ & sown $^{2}$ & Flowering $^{3}$ & Harvest & Notes \\
\hline 1 & Vicia villosa $\mathrm{ROTH}$ & Yes & main-late & $27 \mathrm{Aug}^{4}$ & \\
\hline 2 & $\begin{array}{l}\text { Chrysanthemum segetum (L.) } \\
\text { FOURN. }\end{array}$ & Yes & main & $30 \mathrm{Jul}$ & \\
\hline 3 & Centaurea cyanus L. & Yes & main & 05 Aug & \\
\hline 4 & Sinapis arvensis $\mathrm{L}$. & Yes & early-main & 13 Aug & \\
\hline 5 & Crepis capillaris (L.) WALLR. & Yes & main & $30 \mathrm{Jul}$ & $\begin{array}{l}N f r u i t U_{\text {sample }} \text { refers to ripe fruiting units } \\
\text { only, averaging to } 74 \% \text { of harvested } \\
\text { sample }\end{array}$ \\
\hline 6 & Plantago lanceolata $\mathrm{L}$. & No & & & \\
\hline 7 & Orlaya grandiflora (L.) HoFFM. & Yes & main-late & $27 \mathrm{Aug}^{4}$ & selfing occurs according to BiolFlor ${ }^{5}$ \\
\hline 8 & Medicago X varia MARTYN & Yes & main-late & $27 \mathrm{Aug}^{4}$ & \\
\hline 9 & Calendula arvensis $\mathrm{L}$. & Yes & early & & \\
\hline 10 & Sonchus L. sp. & No & & & \\
\hline 11 & Consolida regalis GRAY & Yes & main & $21 \mathrm{Aug}$ & \\
\hline 12 & Lotus corniculatus L. & Yes & main-late & $27 \mathrm{Aug}^{4}$ & \\
\hline 13 & Lamium purpureum $\mathrm{L}$. & Yes & early & & \\
\hline 14 & Anchusa arvensis (L.) M. BIEB. & Yes & early & & \\
\hline 15 & Cirsium arvense (L.) SCOP. & No & & & \\
\hline 16 & Lathyrus pratensis L. & No & & & \\
\hline 17 & Sisymbrium officinale L. & No & & & \\
\hline 18 & Trifolium pratense L. & No & & & \\
\hline 19 & $\begin{array}{l}\text { Tripleurospermum perforatum } \\
\text { (MÉR.) WAG. }\end{array}$ & No & & & \\
\hline 20 & $\begin{array}{l}\text { Legousia speculum-veneris (L.) } \\
\text { CHAIX }\end{array}$ & Yes & main & 05 Aug & \\
\hline 21 & Scandix pecten-veneris L. & Yes & main & 05 Aug & selfing is common according to BiolFlor \\
\hline 22 & Lathyrus tuberosus L. & Yes & late & & flowering only in a minority of cages \\
\hline 23 & Campanula rapunculoides $\mathrm{L}$. & Yes & no & & \\
\hline
\end{tabular}

sorting related to visitation frequency, see Fig. $3 \mathrm{~b}$

2 'no' indicates unsown weed species, which occurred only in a subset of cages in limited abundance

${ }^{3}$ flowering time in the experiment in relation to main experimental phase; only plants in full bloom during

'main' could be considered for seed production analyses

${ }^{4}$ all remaining plant species were harvested even if not fully ripe to avoid mould

${ }^{5}$ Klotz, S., Kühn, I. \& Durka, W. [editors] (2002): BIOLFLOR - Eine Datenbank zu biologischökologischen Merkmalen der Gefäßpflanzen in Deutschland. - Schriftenreihe für Vegetationskunde 38.

Bonn: Bundesamt für Naturschutz. 


\section{Chapter 3}

\section{Linné's floral clock is slow without pollinators - flower closure and plant-pollinator interaction webs}

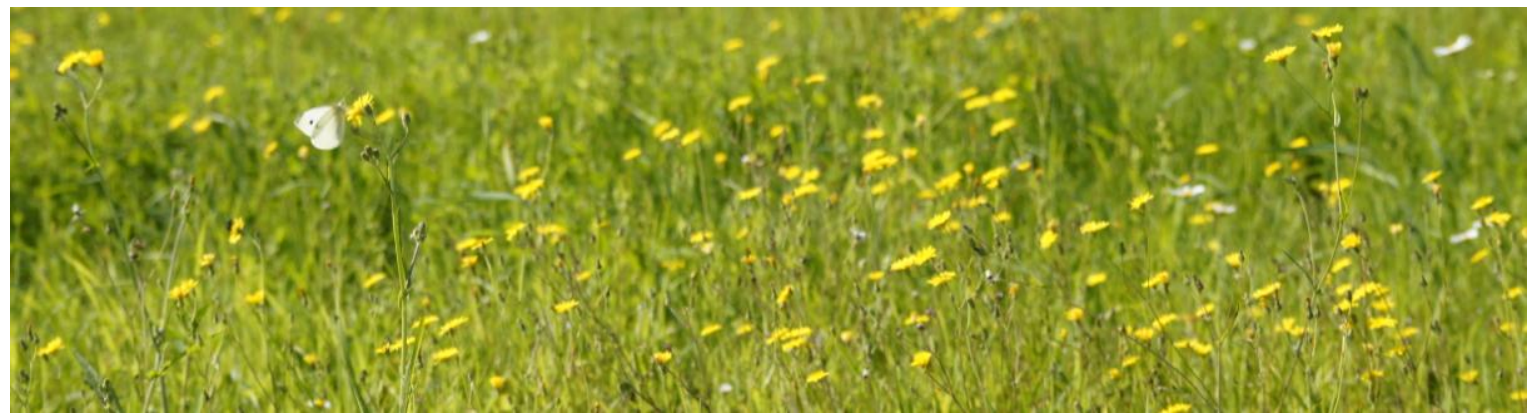

Photo by Henning Schnellen

Authors: Jochen Fründ*, Carsten F. Dormann \& Teja Tscharntke

* Corresponding Author

This chapter is published in:

Ecology Letters (2011), vol. 14, pages 896-904

Please access by doi: 10.1111/j.1461-0248.2011.01654.x

(C) Wiley-Blackwell 2011 


\section{Abstract}

Temporal patterns of flower opening and closure within a day are known as Linné's floral clock. Time of flower closure has been explained mainly by light in the traditional botanical literature. We show with a set of experiments that Asteraceae flower heads can close within three hours after pollination, whereas unpollinated flower heads stay open until the late afternoon. This suggests that closing time strongly depends on pollinators. Using plant-pollinator interaction webs we further demonstrate that the daily pattern of flower opening and the rapid response to pollination can impose strong temporal dynamics on interspecific interactions within a single day. We observed pollinator species turnover and changes in facilitation vs. competition among plants. Our results show for the first time that pollination induces rapid flower closure on the community level. This causes imprecision in Linné's floral clock with far-reaching consequences for plant-pollinator interactions. 


\section{LETTER}

\section{Linné's floral clock is slow without pollinators - flower closure and plant-pollinator interaction webs}

Jochen Fründ, ${ }^{1 *}$ Carsten

F. Dormann ${ }^{2}$ and Teja Tscharntke

${ }^{1}$ Agroecology, Department of Crop Sciences, Georg-August-University Göttingen, Grisebachstr. 6, 37077 Göttingen, Germany ${ }^{2}$ Department of Computational Landscape Ecology, HelmholtzCenter for Environmental Research (UFZ), Leipzig, Germany *Correspondence: E-mail: jfruend@uni-goettingen.de

\section{Abstract}

Temporal patterns of flower opening and closure within a day are known as Linné's floral clock. Time of flower closure has been explained mainly by light in the traditional botanical literature. We show with a set of experiments that Asteraceae flower heads can close within three hours after pollination, whereas un-pollinated flower heads stay open until the late afternoon. This suggests that closing time strongly depends on pollinators. Using plant-pollinator interaction webs we further demonstrate that the daily pattern of flower opening and the rapid response to pollination can impose strong temporal dynamics on interspecific interactions within a single day. We observed pollinator species turnover and changes in facilitation vs. competition among plants. Our results show for the first time that pollination induces rapid flower closure on the community level. This causes imprecision in Linné's floral clock with far-reaching consequences for plant-pollinator interactions.

\section{Keywords}

Capitulum closure, Cichorioideae, circadian, Crepis capillaris, flower opening, interaction networks, mutualism, pollination response, temporal specialisation, temporal turnover.

Ecology Letters (2011) 14: 896-904

\section{INTRODUCTION}

It has long been recognised that many flowers are open for a restricted time of the day and this inspired Linné (1783) to propose the concept of a flower clock based on observed flower opening and closing times of different plant species (Fig. 1). Later, detailed observations and experiments showed that flower opening and closure depend on light and temperature, with some evidence for influence of endogenous rhythms and humidity (Oltmanns 1895; Burgerstein 1901; Todt 1962; Ewusie \& Quaye 1977; Tanaka et al. 1988; van Doorn \& van Meeteren 2003; von Hase et al. 2006) including some knowledge about the underlying modes of inheritance (Nitta et al. 2010).

However, the daily (circadian) pattern of flower opening and closure has not been connected to pollination. It is known for some plants, e.g. many orchids, that unpollinated flowers remain attractive longer than pollinated flowers (Fitting 1909; van Doorn 1997; AbdalaRoberts et al. 2007; Clark \& Husband 2007). Most floral responses to pollination are too slow to affect the daily pattern of flower opening and closure: in Epilobium angustifolium flowers began to close about $10 \mathrm{~h}$ after pollination (Clark \& Husband 2007), and in Gentiana straminea pollination-induced closure occurred after 2 days ( $\mathrm{He}$ et al. 2005). The few plants known to react within a few hours (e.g. petal abscission in Geraniaceae: Fitting 1911) do not close in a daily pattern. Here, we focus on liguliflorous Asteraceae (subfamily Cichorioideae), which are textbook examples of floral movements (e.g. Sitte et al. 2002, p. 476). This group includes 27 of the 44 species in Linné's floral clock, it is an important part of European vegetation (Memmott 1999; Lázaro et al. 2009) and invasive elsewhere (Alexander et al. 2009; Hao et al. 2010).

We provide evidence that flower heads (capitula) of a number of species in this group close rapidly after pollination, but stay open much longer without pollination. The questions we address in the first part of the article are:
(1) Do pollinated flower heads close earlier than non-pollinated flower heads (i.e. does pollination induce advanced capitulum closure)?

(2) Is this effect consistent for a number of common species and for closure time on the level of single flower heads as well as populations?

Despite the importance of plant-pollinator interactions and the high interest in them, within-day patterns have received only limited attention in the last few years. While it is known that for example nectar production varies throughout the day (Willmer \& Corbet 1981; Pleasants \& Chaplin 1983), time of day is rarely considered in community approaches (but see Stone et al. 1996, 1998; Hoehn et al. 2008). The network approach for plant-pollinator interactions has gained popularity (Bascompte \& Jordano 2007; Vázquez et al. 2009), but within-day patterns are not considered in such studies, while temporal dynamics on larger time scales have recently been highlighted (Alarcón et al. 2008; Olesen et al. 2008; Petanidou et al. 2008). However, changes in flower opening of dominant plant species within a single day may affect the whole network e.g. by dynamics of competition for pollinators and temporal specialisation, which may be further complicated by pollination-dependence of flower closure.

In the second part of this article, we analyse whether or not an influence of early flower closure of Cichorioideae can be found in plant-pollinator interaction webs, addressing the following questions:

(1) Do interactions differ between morning and afternoon? Are the pollinators of early-closing Cichorioideae only foraging during the morning or do they switch to other plants in the afternoon?

(2) Do co-flowering plants experience increased competition for pollinators during the morning when Cichorioideae are open?

(3) Are field data consistent with the experimental evidence for pollination as a determinant of flower closure time (i.e. are Cichorioideae flower heads open for longer in webs with low visitation rate)? 


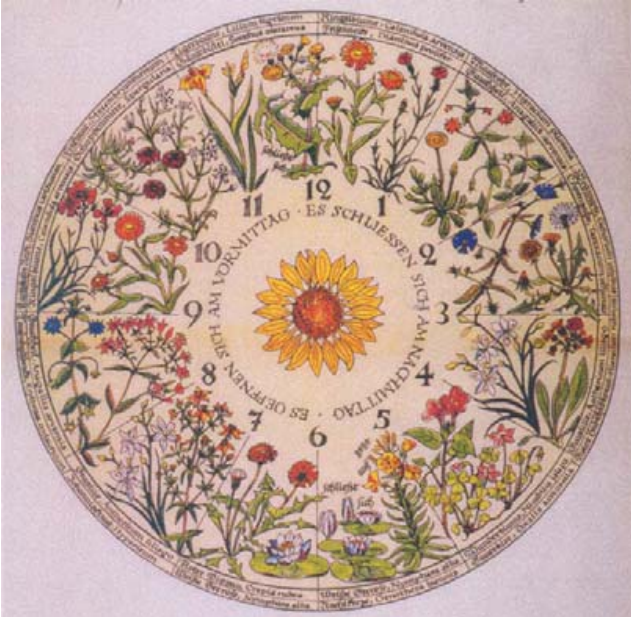

Figure 1 A floral clock drawn after the Horologium florae by Carl von Linné, where he listed opening and closing times for a number of plant species and proposed that these could be used to accurately predict the time of the day. Drawing by Ursula Schleicher-Benz. From: Lindauer Bilderbogen (Series 1, No. 5) ed by Friedrich Böer

( Jan Thorbecke Verlag, Lindau/Reutlingen, 1948.

We show that pollination can induce rapid flower closure and this in turn can effect the community-level pattern of interactions, causing temporal shifts of plant-pollinator interactions within a single day.

\section{MATERIAL AND METHODS}

\section{Experimental set-up}

In 2008 a large field experiment was set up in Göttingen, Germany, to study the relationship between wild bee diversity and pollination of a plant community (Fründ et al., unpublished). In April 59 beds of $4 \mathrm{~m} \times 2 \mathrm{~m}$ were seeded in a fixed pattern (separate patches) with 16 species of wild herbs and covered by gauze cages to exclude insects. At the beginning of July wild bees were released in 40 of the cages until mid-August. Different combinations of five wild bee species (Bombus terrestris, Osmia bicornis, Megacbile centuncularis/versicolor, Heriades truncorum, Hylaeus communis) were used with the same total abundance per cage (Mean $=20.5$ bee individuals). For this article, they will be referred to as 'bee cages' regardless of the species. Twelve cages served as controls (without bees), and seven beds were left un-caged or with open cages allowing access to pollinators from the surrounding area ('open'). Among the 14 herb species that flowered during the experiment one was a member of the subfamily Cichorioideae within the Asteraceae: Crepis capillaris (L.) Wallr. which flowered primarily in July and August in each of two patches per cage.

\section{Circadian pattern of flower opening in different pollinator} treatments

On 2 August 2008, all cages were monitored for openness of C. capillaris flower heads. Starting at 10:50 h, when almost all flower heads had opened in all cages, the number of open flower heads (opening angle $>\sim 90^{\circ}$ ) were counted (to the nearest 10) from the same relative position for each cage. Counting was repeated three times, at 13:30 h, 17:00 $\mathrm{h}$ and 19:00 h. From these estimated numbers of open flowers, the proportion of open flowers at a time relative to the first count was calculated.

\section{Hand pollination of flower heads}

In a cage identical to the control cages, the relationship between pollination and capitulum closure was tested by hand pollinating single flower heads on 14 August 2008. All flying insects were removed from the cage. Twenty-four flower heads of C. capillaris on several individuals were marked with thread and numbered. Twelve flower heads were assigned to the pollination treatment and 12 neighbouring flower heads were left as controls (controls were always near to a treatment flower head and on the same plant, Fig. 2a). At 11:00 h, when all flower heads had opened, treatment flowers were handpollinated with three flower heads from other C. capillaris individuals. After hand pollination, the opening angle (Fig. 2b) of each flower head was noted every 30-60 min until 19:10 h, when all flower heads were closed. Flower heads were also assessed three times the next day.

Similar experiments were conducted for other sets of plants and different species in 2008 and 2009: Crepis biennis L. (five naturally growing plants), C. capillaris (a second set of 12 plants, sown into pots in spring 2009), Leontodon autumnalis L. (six plants from a ruderal area in Göttingen, planted into two $5 \mathrm{~L}$ pots) and Taraxacum officinale $[(\mathrm{L})$. Weber] (naturally growing plants). Experiments in 2009 were performed in a cage of the same type as in 2008. Further details on all hand pollination experiments can be found in Table S1 of
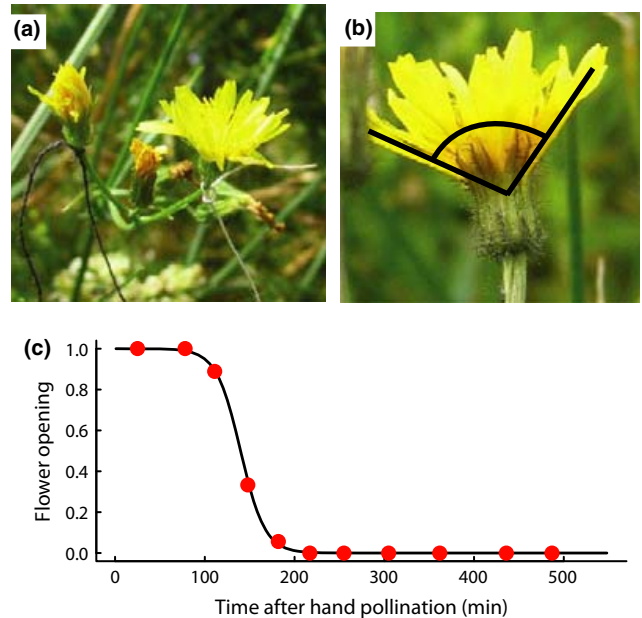

Figure 2 Closure of flower heads in hand pollination experiments. (a) A pair of flower heads of $C$ capillaris, outer left $=$ cross pollinated, outer right $=$ control. (b) Opening angle was used to quantify opening and closure of flower heads, the photo shows a flower head with $98^{\circ}$ opening. Photo credit Kristian Peters, GNU licence. (c) Logistic curve fitted to temporal flower opening data of one example flower head of $C$. capillaris. This curve has the parameters $b=0.0736$ and $t_{0}=138.9$ (see Material and methods for explanations, see Table S2 for fitted parameters for all flower heads). Note that the $y$-axis indicates proportional opening in relation to maximum opening degree. 
Supporting Information. To check whether the measured response to pollination was just a response to mechanical stimulation, additional controls were used in two of the experiments: for $C$. biennis, three flower heads were touched with flower heads of another species (Picris bieracioides $\mathrm{L}$.) in the same manner as in the pollination treatments, and for C. capillaris in 2009, six flower heads were self-pollinated with flower heads from the same plant individual.

\section{Data analysis Part 1 - flower closure}

All analyses were performed using R 2.11.1 (R Development Core Team 2010). To analyse the effects of hand pollination on capitulum closure, we first fitted a logistic function (Fig. 2c) with non-linear least squares regression:

$$
y=1-\frac{1}{1+e^{-b \cdot\left(t-t_{0}\right)}}
$$

where $y$ is standardised opening degree (opening angle divided by the initial estimate of opening angle, which sometimes slightly deviated from $\left.180^{\circ}\right), t$ is time after pollination treatment and $b$ and $t_{0}$ are the fitted parameters. Parameter $b$ measures the 'slope' (i.e. speed of closure after initiation), while parameter $t_{0}$ represents the inflection point of the curve (i.e. the time until the flower is half closed). This function described the temporal process of flower closure generally very well (Fig. 2c). In a few cases in which flower heads were still fully open at the end of the observations (opening angle $>150^{\circ}$, five controls in C. biennis), curves could not be fitted and we used a conservative estimate of $600 \mathrm{~min}$ for $t_{0}$ (which would represent immediate closure after the last measurement). The effect of hand pollination was tested by comparing the parameter $t_{0}$ (relative time of closure) between flower heads of the different treatment groups. All hand pollination experiments were analysed using ANOVA with treatment, experimental set and their interaction as explanatory variables.

Part 2: Effects of early flower closure in interaction network data data and analysis

We explored the evidence for effects of Cichorioideae flower closure on community-wide plant-pollinator interactions with a dataset of quantitative plant flower-visitor networks from 27 meadow sites in southern Germany. Details of the study can be found in Fründ $e t$ al. (2010). Flower visitation data were collected in transects and observation plots on single day, between 8:30 h and 19:00 h (all webs have data before 12:00 $\mathrm{h}$ and after 13:00 h). The number of flowers or flower heads was counted for each of ten $2 \mathrm{~m}^{2}$ observation plots per network. All flower visitors on all plants were noted to family and morphotype, and bees and hoverflies were captured and determined to species level. In contrast to the original article, here we used both captured and non-captured flower visitors and we included two different single-day networks for five of the sites (resulting in a total of 32 webs). For these five sites, resamples were at least three weeks apart, when floral composition had already changed. On average, these networks comprised 219 observed flower visitors, of which 61 bees and hoverflies were determined to species level. We used these data to characterise circadian patterns of flower visitation.

Time of the day was noted for each observation plot $(15 \mathrm{~min})$ and sub-transect (c. $30 \mathrm{~min})$. For the analyses, we assigned the mean time of each observational unit (i.e. observation plot or sub-transect) to all interactions observed in the respective unit. Because we did not collect temporally resolved data for actual flower opening in the field study, we focussed on patterns of flower visitation in this part of the article as an indirect measure of flower closure.

To analyse the temporal dynamics of plant - pollinator interactions within a single day, we separated the networks into morning(AM) and afternoon- (PM) subwebs. For this purpose, 'noon' was defined as the time of solar zenith $(13: 00 \mathrm{~h})$. Thus, AM-subwebs include times until $12: 59 \mathrm{~h}$. Web plots were created with the Rpackage bipartite 1.12 (Dormann et al. 2009). We compared the identity of pollinators and the identity of links between the two subwebs for each network using Bray - Curtis dissimilarity of relative frequencies including only specimens determined to species level. To account for the fact that dissimilarity values are sensitive to sample size (see Appendix S1), we focussed on the difference to a null model. This null model re-assigned observations among the two subwebs (times of day), while fixing the total frequency per species (or link) and subweb (function r2dtable in $\mathrm{R}$, mean of $N=1000$ replicates; see Appendix S1 for further details). Consequently, species richness (or connectance) was constant for each web, but variable for each subweb. The proportion of visits to Cichorioideae among all visits was calculated to quantify the dominance of these flowers in the network and their importance for the temporal turnover of pollinators and interactions.

To check for the influence of Cichorioideae flower closure on visitation to other plants, we calculated separately for morning and afternoon (i.e. before and after 13:00 h) visitation rate to the two plant species without closing mechanism observed in plots of more than 10 networks: Acbillea millefolium L. (Asteraceae), a species with a visitor spectrum overlapping with Cichorioideae, and Trifolium pratense L. (Fabaceae), which attracts a very different pollinator spectrum. Visitation rate was calculated as the number of observed flower visitors in observation plots divided by the number of inflorescences in observation plots for each of the two time periods. To quantify the importance of afternoon visitation, the proportion of visits received during the afternoon was calculated as the visitation rate during the afternoon divided by the sum of morning and afternoon visitation rates.

To check for evidence of pollinator-dependent flower closure in the field, we compared the morning visitation rate by bees and the temporal pattern of visitation to Cichorioideae, i.e. estimated time of flower closure. The latter was expressed as the time from sunrise until at least $90 \%$ of visits were observed, thereby adjusting for differences in day length. In this case, the only web where Cichorium intybus $\mathrm{L}$. was the dominant Cichorioideae was excluded because this species was an unusual Cichorioideae in the dataset (however, its inclusion would only strengthen the observed pattern). Webs with $<2$ observed visits to Cichorioideae were also excluded. Using visitation rate by all flower visitors instead of bees showed a similar pattern but with less explanatory power $\left(\Delta_{\mathrm{AICc}}>10\right.$, comparison of the two models, see Burnham \& Anderson 2001).

\section{RESULTS}

Circadian pattern of flower opening in different pollinator treatments

On average, flower heads of Crepis capillaris closed first in the open cages, second in the bee cages and last in the control cages. All flower 


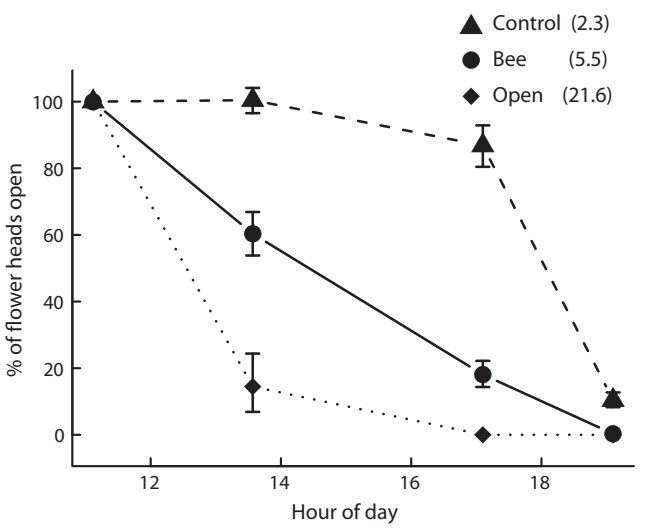

Figure 3 Pattern of flower opening in relation to time of the day for C. capillaris under three different pollinator treatments (cage types). Number of open flower heads is shown in relation to the first estimate. Mean \pm SEM [calculated from arcsine (square-root) -transformed datal are shown, and the mean number of visits to C. capillaris per cage is indicated for each treatment in the legend.

heads were closed at night. Even in the control cages most had closed by 19:00 h. In open cages and some of the bee cages, however, most flower heads closed already $5 \mathrm{~h}$ earlier (Fig. 3). The proportion of closed flower heads differed significantly among cage types (Kruskal Wallis tests: $P<0.001$ for all three times after the reference count). Differences in the number of observed bee visits to $C$. capillaris flowers due to different bee community composition corresponded well to the proportion of flower heads closed before $13: 30 \mathrm{~h}$ (correlation across 39 'bee cages': $P=0.009$, Pearson's $r=0.41$ ). Among the control cages there were two different sub-treatments: in eight of the cages, hoverflies were present and regularly visited C. capillaris, while in four of the control cages, all flying insects were regularly excluded. This difference in the presence of hoverflies corresponded only to a minor difference in early closing flower heads (significant difference only at 19:00 h, $t=2.9, \quad P=0.021$, Mean $\pm 1 \mathrm{SD}=9.0 \pm 5.0 \%$ and $16.9 \pm 4.1 \%$ with and without hoverflies, respectively).

\section{Hand pollination of flower heads}

Cross pollination by hand strongly effected closing time in all species except Taraxacum officinale (Fig. 4; interaction of treatment by experimental set, $F_{4,62}=3.2, P=0.019$; excluding $T$. officinale: interaction $F_{3,48}=1.1, \quad P=0.33$, treatment effect $F_{1,48}=50.9$, $P<0.001$ ). Capitulum closure was advanced by $3 \mathrm{~h}$ in Crepis capillaris in 2008. In this case, the reaction started $\sim 137$ min after pollination (mean time to $90 \%$ openness according to fitted curves) and flowers were closed after $\sim 209 \mathrm{~min}$ (10\% openness).

Neither heterospecific pollination in C. biennis nor self pollination in C. capillaris reproduced the closing reaction to intraspecific crosspollination: in both cases, the additional control closed significantly later than cross pollinated flower heads, but did not differ from un-pollinated flower heads (see Table S3). For flower heads, closure was not necessarily permanent: younger flower heads opened again the next day exposing fresh, previously immature florets. In C. biennis

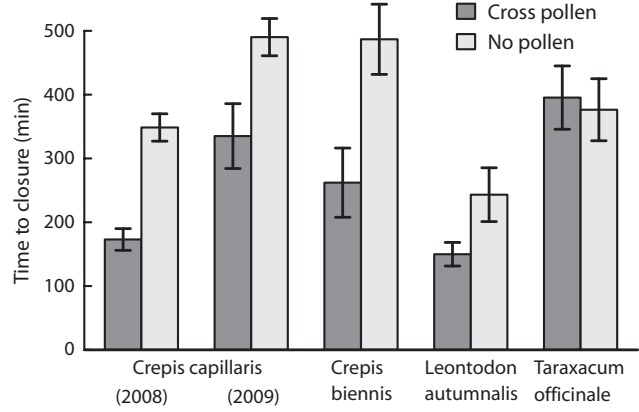

Figure 4 Effect of hand pollination on closure of flower heads in Asteraceae: Cichorioideae. Time to closure (Mean \pm SEM) refers to the time from treatment until half closure estimated from a logistic curve fitted to flower closure dynamics per flower head (see Fig. 2c).

we counted the number of seeds, which corresponded well with pollination treatments and time of closure (see Table S4).

\section{Effects of early flower closure in interaction network data}

Plants of the subfamily Cichorioideae were important in the networks dataset, comprised $17 \%$ of all observed interactions and $>10 \%$ of interactions in 18 of 32 networks. Interactions with these plants happened early within the day, mostly between 10 to $11: 00 \mathrm{~h}$, and $>91 \%$ of visits were observed before 13:00 h (see Figure S1). This predominance of interactions in the morning was not apparent for all other plant species combined and could not be explained by sampling effort which was relatively homogeneously distributed across the main period of bee activity (9:00 h to 17:00 h). Cichorioideae in this dataset were Picris hieracioides, Leontodon autumnalis, Hypochaeris radicata L., Crepis biennis (all $>100$ observed visits) and seven less frequently observed species.

Strong differences between morning and afternoon subsets of plant-pollinator interaction webs were found (Figs 5 and 6). These differences were particularly dramatic for networks with a high proportion of Cichorioideae. The dissimilarity between interactions of the two subwebs increased with the proportion of Cichorioideae in the network $\left(F_{1,28}=11.7 P=0.002\right.$, response $=$ difference to null model, Fig. 6a; see Figure S3 for raw dissimilarity values). Likewise, pollinator communities differed more strongly between morning and afternoon in networks with higher proportions of Cichorioideae $\left(F_{1,28}=14.4, P<0.001\right.$, Fig. 6b, Figure S3). The intercept was significant for interaction dissimilarity $(P=0.003)$, but not for the difference in pollinator communities $(P=0.19)$.

Flower visitation to Achillea millefolium was reduced during the morning in networks with a high proportion of Cichorioideae, and for this plant species the relative contribution of visitation during the afternoon increased with dominance of Cichorioideae (linear regression, $F_{1,10}=13.4, P=0.004$, Fig. 6c; see also Figure S3). This relationship was also significant when the dominance of Cichorioideae was defined by $\%$ of flower area rather than $\%$ of flower visits. The same relationship was not significant for Trifolium pratense $\mathrm{L}$.

Estimated time of Cichorioideae flower closure in the network study was earlier in networks with high bee visitation rate to Cichorioideae, and later in webs with low bee visitation rate: the time 
(a) Interactions before 1 p.m.

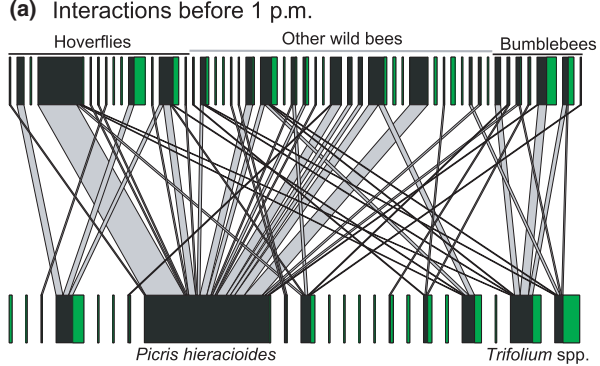

(c) Interactions after 1 p.m.

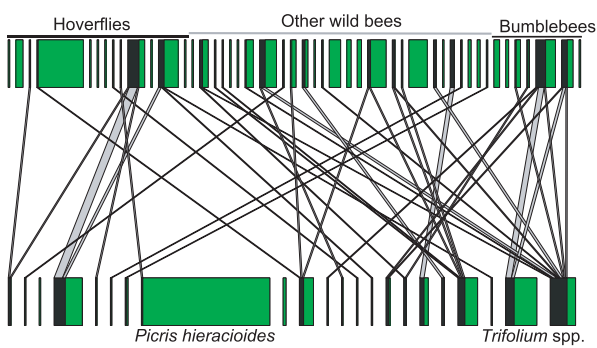

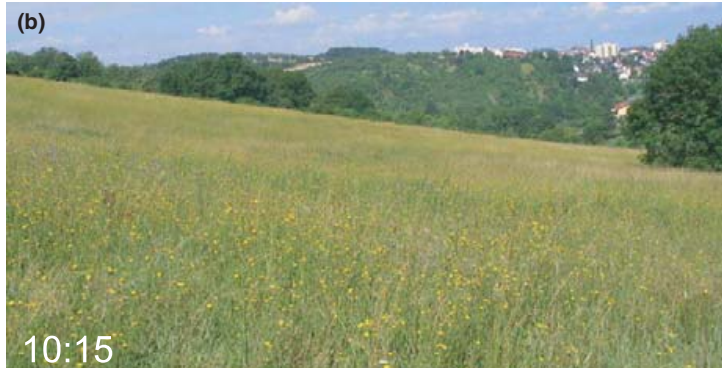

(d)

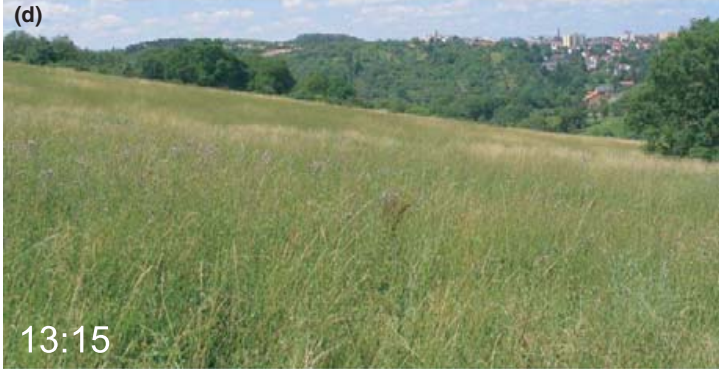

Figure 5 Flower-visitor interaction networks change between morning and afternoon. The graphs on the left show a quantitative plant-pollinator network (close to Gerbrunn, Southern Germany; pooled across five sampling days on four sites). (a) Morning subweb (i.e. all interactions observed before 13:00 h), (c) afternoon subweb (after 13:00 h.). (b and d) show part of the meadow complex where the web was compiled, both pictures were taken on the same day, but with a time-lag of $3 \mathrm{~h}$, during which almost all of the yellow flowers of Picris bieracioides had closed. In (a and c) width of the marginal rectangles is relative to a species' interaction frequency in the total network and interactions not occurring during the focal time period are marked in green. In the network graphs, plants are sorted by family, and flower visitors by functional group. Full species names are available in the Supporting Information (Figure S2, Tables S5, S6).

from sunrise until at least $90 \%$ of visits to Cichorioideae had been observed decreased significantly with visitation rate by bees, while weather had an additional influence with estimated flower closure on sunny days being about half an hour earlier than on partly clouded days (multiple regression; weather: $F_{1,16}=8.02, P=0.01 ; \log$ [bee visitation rate +0.05$]: F_{1,16}=51.8, P<0.001$, Fig. 6d; excluding webs from overcast days to avoid intercorrelated independent variables). This decrease was also significant when hour of day was used as the response variable (ranging between 11:00 $\mathrm{h}$ and 15:00 h; see Figure S3).

\section{DISCUSSION}

Our study clearly shows that plants within the subfamily Cichorioideae of the Asteraceae close their flower heads shortly after pollination and that this effect is fast enough to affect the circadian pattern of flower opening and closure, the so called 'floral clock'. We further show that this early flower closure can be an important component of plant-pollinator interaction webs influencing the dynamics of interaction patterns within the course of a day. Both parts of the article suggest that the 'floral clock' is delayed when only few pollinators are visiting.

\section{Experimental approaches}

Differences in flower closure among the cages reflect differences in pollination. In the open cages and some of the bee cages, C. capillaris was pollinated well and most flower heads had closed by noon, suggesting that flowers were pollinated during the first two hours after opening. Microclimatic conditions were identical at least in the closed cages, such that only pollinator visitation differed. Early flower closure in open cages can also be explained by pollination. The proportion of open flower heads at intermediate times could thus be used to estimate pollination success.

The hand pollination experiments strikingly confirmed that pollination caused advanced flower closure. Three of the four tested species showed this effect, suggesting that it is widespread among Cichorioideae. The only species that did not respond to pollination was Taraxacum officinale, which is often apomictic (Collier \& Rogstad 2004) meaning that pollen application does not lead to pollination (presumably also in the studied population, as seeds were produced also in the non-pollinated flower heads). Observed differences in the closure time of unpollinated flower heads may be explained by differences between species and experimental conditions (e.g. weather conditions or the time from the first measurement until sunset). The time from pollination to closure is likely also influenced by pollen quality and quantity. Correspondingly, visits by hoverflies had a much smaller effect on opening patterns in the cages than visits by bees, probably reflecting their lower rate of (conspecific) pollen deposition (Alarcón 2010).

Our findings suggest that the capitulum closure is controlled by a combination of pollination and other factors. The time of flower opening seems to be determined by light (Stoppel 1910), and light is probably the reason that pollinated and unpollinated flowers will eventually be closed at night. However, pollination is probably more 

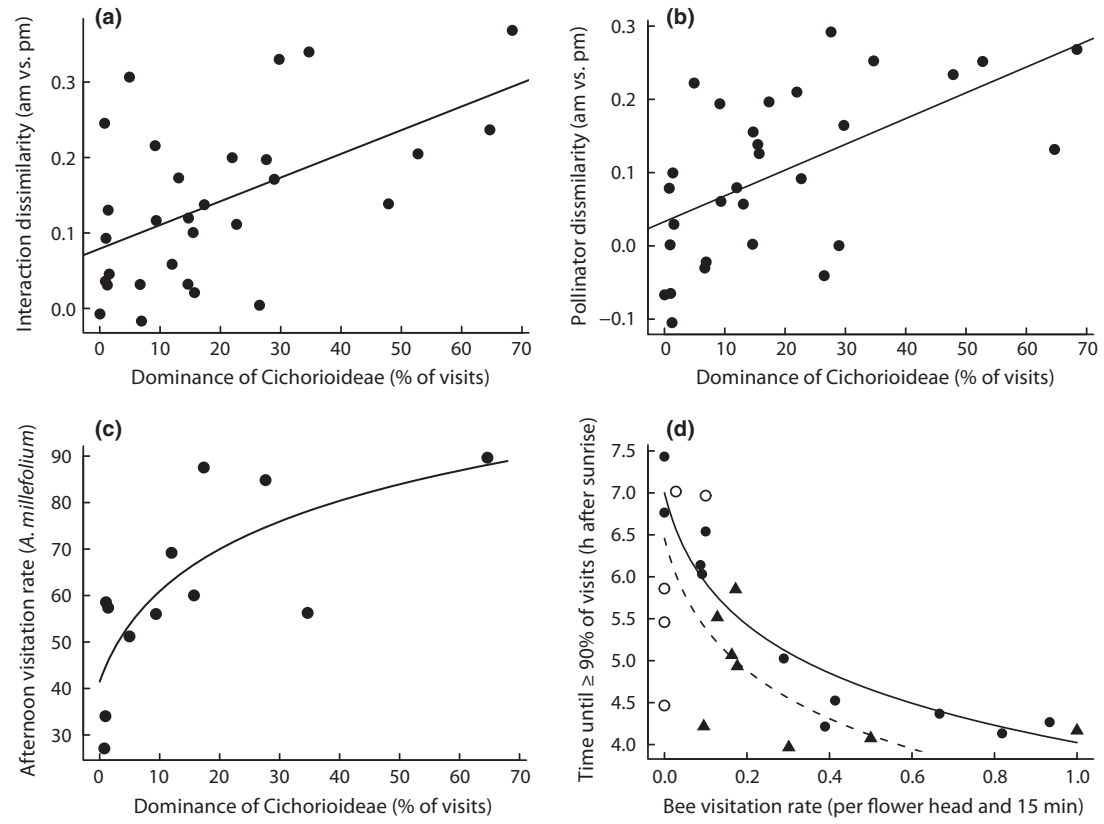

Figure 6 Patterns in a set of flower-visitor networks, highlighting the consequences of early flower closure in the field. (a - c) show the influence of the proportion of Cichorioideae (closing early during the day) in the web on community interactions, and (d) shows the influence of visitation rate on temporal patterns of Cichorioideae. (a,b) Difference between morning and afternoon subsets of plant-pollinator interaction webs. (a) Differences in interactions, (b) differences in pollinator communities. Dissimilarity is measured as Bray - Curtis distance subtracting the expected value for sampling from a homogeneous community (i.e. the null model mean). (c) 'Importance' of afternoon visitation to Acbillea millefolium (in \% of AM + PM visitation) increases with the proportion of Cichorioideae. (d) Negative feedback - relative time to flower closure of Cichorioideae (estimated by visitation) in relation to bee visitation rate. The $y$-axis reflects estimated closure time relative to sunrise, i.e. controlling for seasonal differences in day length. Dashed line and triangles = sunny days, solid line and filled circles $=$ partly clouded, open circles $=$ overcast days (not included in regression).

important in determining the time of closure in typical field situations. As many pollinator species are also influenced by light and weather conditions (Kevan \& Baker 1983; Fründ et al. 2010), it is difficult to tease apart the different factors influencing flower closure in field scenarios. Our controlled cage experiments showed that plants of the Cichorioideae have the potential to visibly respond to pollination within 1-2 h. This is by far the fastest known flower closure response to pollination (van Doorn 1997) and combined with high pollinator visitation it makes early flower closure on the population level possible.

Our data suggest that many species within the Cichorioideae might show such a response, given that capitula of probably all Cichorieae perform closure movements. However the effect of pollinatormediated flower closure will not be found in all Cichorioideae. Several species of Cichorioideae can produce seeds asexually or following selfpollination (Fryxell 1957; Ferrer \& Good-Avila 2007). The strength of the closure response may be related to a species' breeding system, with apomictic species not responding to deposition of cross pollen. Furthermore, the lack of response after self pollination in C. capillaris suggests that there is a very fast mechanism for detecting effective pollination and for transferring this signal from the stigma to the involucral bracts that perform the closure movement. The underlying physiological mechanisms should be identified by future laboratory experiments.
Compared to published examples of flower closure in response to pollination, the example shown here differs because it refers to flower heads that may re-open after closure (if immature flowers are still present), and thus represents a plant movement rather than a simple sign of senescence. It is particularly surprising because van Doorn $(1997,2002)$ proposed that Asteraceae do not cease floral attraction in response to pollination because they are not sensitive to ethylene. Ethylene is considered to be the main signal in floral pollination responses (O'Neill 1997; van Doorn 2002). Whether plants from other taxa that also show flower opening and closure movements in a roughly circadian pattern (e.g. Convolvulus, Legousia, Calendula, Cucurbita) also respond to pollination remains an important question for future studies.

\section{Early flower closure in the field and plant-pollinator interactions}

Interactions between Cichorioideae and their flower visitors almost exclusively happened during the morning, probably due to the circadian pattern of flower opening and closure. As these plants were also highly-visited and abundant components of plant communities, early flower closure had a strong impact on plant-pollinator interaction networks.

There was a strong difference between morning and afternoon subwebs. This adds a new dimension to temporal dynamics of plant- 
pollinator networks. The temporal turnover within single day was mainly driven by the presence of Cichorioideae closing their flowers around noon. In networks with a relevant proportion of Cichorioideae, morning subwebs included a number of pollinators specialised on this subfamily of Asteraceae, e.g. Lasioglossum villosulum and Panurgus calcaratus (Westrich 1989). These and other pollinators were absent from the afternoon subwebs. It is difficult to separate how much of the declining foraging activity of this subset of pollinators can be explained by a preference for Cichorioideae or by a circadian activity pattern (i.e. peak activity during the morning). Circadian patterns of pollinator activity due to abiotic or biotic reasons have already been recognised (Willmer \& Corbet 1981; Stone et al. 1999 Lienhard et al. 2010). The non-significant intercept of community difference suggests that in our system there was only a limited turnover of pollinator species within a day other than the decrease in 'Cichorioideae specialists'. However, as the intercept for interaction dissimilarity was significant, a certain amount of circadian dynamics independent of Cichorioideae flower closure also seem to be present.

Despite the absence of some pollinators from the afternoon networks, there was also evidence that some generalist pollinators switched from Cichorioideae to other plant species offering floral resources also in the afternoon. Correspondingly, Acbillea millefolium was mainly visited during the afternoon in networks with high proportion of Cichorioideae, while visitation rate was higher during the morning in networks with a low proportion of Cichorioideae. This result suggests that visitation rate to $A$. millefolium is reduced during the morning due to competition for pollinators from Cichorioideae, but it receives more visits in the afternoon by pollinators that remain active. It is unknown whether this adds up to a net facilitation or competition effect, as pollinator abundance might also vary between networks and the outcome for the plant (i.e. seed set) also depends on the receptivity of the flowers throughout the day. Similar dynamics of competition can be expected for other plant species if they share a sufficient part of their pollinator community (see also Lázaro et al. 2009; Mitchell et al. 2009), which was not the case for Trifolium pratense. These observations show temporal dynamics in mutualistic and competitive interactions similar to patterns suggested for larger temporal scales (phenology: Mosquin 1971): competition for pollinators (Mitchell et al. 2009) seems to be more important in the morning, while pollination facilitation (Ghazoul 2006) and competition between pollinators are probably more pronounced during the afternoon. While optimal flower opening times can be predicted by models (Miyake \& Yahara 1999), models on the consequences of pollination driven flower closure for community and network dynamics are lacking.

Current theory on mutualistic networks suggests that generalist core species make the network stable and tolerant to extinctions (Memmott et al. 2004; Bascompte \& Jordano 2007). Our findings show that different links are not equivalent, questioning the assumption of functional redundancy. For example, pollinators with a long activity period may need different plant species providing resources at different times of day. However, pollination-induced flower closure also suggests a flexible link structure, enabling plants to establish new links when pollinator communities change. Furthermore, our findings caution against homogeneous assump tions when considering the relationship between pollinator specialisation and pollination success. Intraday turnover of interaction should particularly be considered in the interpretation of networks without whole-day sampling: important interactions may be missed in studies with sampling restricted to either morning or afternoon, and interday turnover may be overestimated in studies with variable sampling times. This is of general importance as many plantpollinator communities include species of Cichorioideae (see Table S7: 22 of 37 studies), and similar circadian patterns of interactions may be expected also for systems without Cichorioideae: many plant species show intraday patterns of flower opening, nectar and pollen availability (Ewusie \& Quaye 1977; Pleasants \& Chaplin 1983; Stone et al. 1998; Hoehn et al. 2008). However, it is yet unknown whether those patterns are also driven by pollination responses.

The network data suggest that pollination advances flower closure in the field similar to the experimental results. The negative relationship between bee visitation rate and estimated time of flower closure suggests a delay in flower closing time by several hours on sites or days with low pollination, with limited additional influence of day length and weather conditions. However, this pattern must be interpreted with caution, because it is only indirect evidence of advanced closure and also plant species composition differed between networks. The correlation between closing time and visitation rate suggests that the observed closure response to pollination is not restricted to the species tested in our experiments, but rather widespread among Cichorioideae.

Temporal dynamics within plant-pollinator networks might enhance biodiversity maintenance through temporal niche partitioning (Mosquin 1971; Abdala-Roberts et al. 2007), which is also possible on a daily basis (Stone et al. 1996, 1998). Diverse plant communities in particular should benefit from this pattern due to reduced heterospecific pollen delivery. The finding that flowers are quickly closed in response to pollination introduces also a flexible component to circadian niche partitioning. This probably contributes to the selective advantages that might have led to this 'plant behaviour': on the one hand, it might lead to improved pollinator behaviour by guiding pollinators to flowers that still require pollination and on the other hand, rapid flower closure might help to reduce costs of open flowers such as increased water loss and susceptibility to antagonists (Ashman \& Schoen 1994). Plasticity in the timing of flower closure combines the benefits of short flower opening and temporal specialisation while avoiding the cost of pollination failure.

\section{CONCLUSIONS: CONSEQUENCES FOR FLOWER AND POLLINATOR SURVEYS}

The circadian dynamics of flower opening and plant-pollinator interactions that we demonstrated here need to be considered when designing field survevs on pollinators, flower availability and plantpollinator interactions. If sampling is only performed in the afternoon, it will systematically miss parts of the pollinator community and interactions, and this bias will increase with the dominance of plants with early flower closure. Flower availability and pollinator diversity will probably be most strongly underestimated on sites or dates with highest pollination service (to plants responding with rapid closure). Apart from helping to avoid bias in field studies, our findings are also promising for multiple applications: flower closure may be used as a fast and effective proxy for estimating pollination success in field and laboratory experiments and assessments. Literally speaking, we show that Linné's floral clock needs to be adjusted in times of pollinator declines - flowers 
originally closing at 15:00 $\mathrm{h}$. (such as Leontodon autumnalis) may remain open until 18:00 $\mathrm{h}$ without pollination.

\section{ACKNOWLEDGEMENTS}

We thank the people who helped with the bee diversity pollination cage experiment: B. Jünemann, S. Jahn, S. Schiele, B. Tappe, E. Eilers, C. Fessel, V. Karwath, S. Parsche, A. Holzschuh, C. Thies and many others. We further thank Nico Blüthgen and Karl-Eduard Linsenmair for help in designing the study underlying the network dataset and for kindly allowing us to use these data for this study. J. Husse, N. Williams, K. Ullmann, D. Vázquez, M. Vellend and one anonymous reviewer provided helpful comments on earlier drafts of the manuscript. Bernd Gruber helped with data analysis. JF acknowledges funding by a scholarship of the DBU (German Federal Environmental Foundation), TT by the DFG (Deutsche Forschungsgemeinschaft) and CFD by the Helmholtz Association (VH-NG 247).

\section{REFERENCES}

Abdala-Roberts, L., Parra-Tabla, V. \& Navarro, J. (2007). Is floral longevity influenced by reproductive costs and pollination success in Cobniella ascendens (Orchidaceae)? Ann. Bot. - London, 100, 1367-1371.

Alarcón, R. (2010). Congruence between visitation and pollen-transport networks in a California plant - pollinator community. Oikos, 119, 35-44.

Alarcón, R., Waser, N.M. \& Ollerton, J. (2008). Year-to-year variation in the topology of a plant - pollinator interaction network. Oikos, 117, 17961807

Alexander, J.M., Naylor, B., Poll, M., Edwards, P.J. \& Dietz, H. (2009). Plant invasions along mountain roads: the altitudinal amplitude of alien Asteraceac forbs in their native and introduced ranges. Ecography, 32, 334-344.

Ashman, T.L. \& Schoen, D.J. (1994). How long should flowers live?. Nature, 371, 788-791.

Bascompte, J. \& Jordano, P. (2007). Plant-animal mutualistic networks: the architecture of biodiversity. Annu. Rev. Ecol. Evol. S., 38, 567-593.

Burgerstein, A.. (1901). A. v. Kerner's Beobachtungen über die Zeit des Oeffnens und Schliessens von Blüten. Plant Syst. Evol, 51, 185-193.

Burnham, K.P. \& Anderson, D.R. (2001). Kullback-Leibler information as a basis for strong inference in ecological studies. Wildl. Res., 28, 111-119.

Clark, M.J. \& Husband, B.C. (2007). Plasticity and timing of flower closure in response to pollination in Chamerion angustifolium (Onagraceae). Int. J. Plant Sci, $168,619-625$.

Collier, M.H. \& Rogstad, S.H. (2004). Clonal variation in floral stage timing in the common dandelion Taraxacum officinale (Asteraceae). Am. J. Bot., 91, 1828-1833. van Doorn, W.G. (1997). Effects of pollination on floral attraction and longevity J. Exp. Bot., 48, 1615-1622.

van Doorn, W. (2002). Does ethylene treatment mimic the effects of pollination on floral lifespan and attractiveness? Ann. Bot. - London, 89, 375-383.

van Doorn, W.G. \& van Meeteren, U. (2003). Flower opening and closure: a review. J. Exp. Bot., 54, 1801-1812.

Dormann, C.F., Fründ, J., Blüthgen, N. \& Gruber, B. (2009). Indices, graphs and null models: analyzing bipartite ecological networks. Open Ecol. J., 2, 7-24.

Ewusie, J.Y. \& Quaye, E.C. (1977). Diurnal periodicity in some common flowers. New Phytol., 78, 479-485.

Ferrer, M.M. \& Good-Avila, S.V. (2007). Macrophylogenetic analyses of the gain and loss of self-incompatibility in the Asteraceae. New Pbytol, 173, 401-414.

Fitting, H. (1909). Die Beeinflussung der Orchideenblüten durch die Bestäubung und durch andere Umstände. Zeitschrift für Botanik, 1, 1-86.

Fitting, H. (1911). Untersuchungen über die vorzeitige Entblätterung von Blüten. Jabrbücher für wissenschaftliche Botanik, 49, 187-263.

Fründ, J., Linsenmair, K. \& Blüthgen, N. (2010). Pollinator diversity and specialization in relation to flower diversity. Oik.os, 119, 1581-1590.

Fryxell, P.A. (1957). Mode of reproduction of higher plants. Bot. Rev., 23, 135233.
Ghazoul, J. (2006). Floral diversity and the facilitation of pollination. J. Ecol., 94, 295-304

Hao, J.H., Qiang, S., Chrobock, T., van Kleunen, M. \& Liu, Q.Q. (2010). A test of baker's law: breeding systems of invasive species of Asteraceae in China. Biol. Invasions, 13, 571-580

von Hase, A., Cowling, R. \& Ellis, A. (2006). Petal movement in cape wildflowers protects pollen from exposure to moisture. Plant Ecol., 184, 75-87.

He, Y., Duan, Y, Liu, J. \& Smith, W.K. (2005). Floral closure in response to temperature and pollination in Gentiana straminea Maxim. (Gentianaceae), an alpine perennial in the Qinghai-Tibetan Plateau. Plant Syst. Evol., 256, 17-33.

Hoehn, P., Tscharntke, T., Tylianakis, J.M. \& Steffan-Dewenter, I. (2008). Functional group diversity of bee pollinators increases crop yield. P. Roy. Soc. B: Biol. Sci., 275, 2283-2291.

Kevan, P.G. \& Baker, H.G. (1983). Insects as flower visitors and pollinators. Annu. Rev. Entomol., 28, 407-453.

Lázaro, A., Lundgren, R. \& Totland, O. (2009). Co-flowering neighbors influence the diversity and identity of pollinator groups visiting plant species. Oikos, 118, 691-702.

Lienhard, A., Mirwald, L., Hötzl, T., Kranner, I. \& Kastberger, G. (2010). Trade-off between foraging activity and infestation by nest parasites in the primitively eusocial bee Halictus scabiosae. Psyche: J. Entom., DOI: 10.1155/2010/707501.

Linnaeus, C. (1783). Pbilosopbia Botanica, 2nd edn. Vienna.

Memmott, J. (1999). The structure of a plant-pollinator food web. Ecol. Lett., 2, $276-280$.

Memmott, J., Waser, N.M. \& Price, M.V. (2004). Tolerance of pollination networks to species extinctions. P. Roy. Soc. B: Biol. Sci., 271, 2605-2611.

Mitchell, R.J., Flanagan, R.J., Brown, B.J., Waser, N.M. \& Karron, J.D. (2009). New frontiers in competition for pollination. Ann. Bot. - London, 103, 14031413.

Miyake, T. \& Yahara, T. (1999). Theoretical evaluation of pollen transfer by nocturnal and diurnal pollinators: when should a flower open? Oikos, 86, 233-240.

Mosquin, T. (1971). Competition for pollinators as a stimulus for the evolution of flowering time. Oikos, 22, 398-402.

Nitta, K., Yasumoto, A.A. \& Yahara, T. (2010). Variation of flower opening and closing times in F1 and F2 hybrids of daylily (Hemerocallis fulva; Hemerocallidaceae) and nightlily (H. citrina). Am. J. Bot., 97, 261-267.

Olesen, J.M., Bascompte, J., Elberling, H. \& Jordano, P. (2008). Temporal dynamics in a pollination network. Ecology, 89, 1573-1582.

Oltmanns, F. (1895). Ueber das Oeffnen und Schliessen der Blüthen. Botanische Zeitung, 2, 31-52.

O'Neill, S.D. (1997). Pollination regulation of flower development. Annu. Rev. Plant Biol., 48, 547-574.

Petanidou, T., Kallimanis, A.S., Tzanopoulos, J., Sgardelis, S.P. \& Pantis, J.D. (2008). Long-term observation of a pollination network: fluctuation in species and interactions, relative invariance of network structure and implications for estimates of specialization. Ecol. Lett., 11, 564-575.

Pleasants, J.M. \& Chaplin, S.J. (1983). Nectar production rates of Asclepias quadrifolia: causes and consequences of individual variation. Oecologia, 59, 232238.

R Development Core Team. (2010). R: A Language and Environment for Statistical Computing. R Foundation for Statistical Computing, Vienna, Austria

Sitte, P., Weiler, E.W., Kadereit, J.W., Bresinsky, A. \& Körner, C. (2002). Strasburger - Lebrbuch der Botanik, fur Hocbscbulen, 35th edn. Spektrum-Akademischer Vlg, Heidelberg, Berlin.

Stone, G., Willmer, P. \& Nee, S. (1996). Daily partitioning of pollinators in an African Acacia community. P. Roy. Soc. B: Biol. Sci., 263, 1389-1393.

Stone, G.N., Willmer, P. \& Rowe, J.A. (1998). Partitioning of pollinators during flowering in an African Acacia community. Ecology, 79, 2808-2827.

Stone, G.N., Gilbert, F., Willmer, P., Potts, S., Semida, F. \& Zalat, S. (1999). Windows of opportunity and the temporal structuring of foragin activity in a desert solitary bee. Ecol. Entomol., 24, 208-221.

Stoppel, R. (1910). Über den Einfluß des Lichtes auf das Öffnen und Schließen einiger Blüten. Zeitscbrift für Botanik, 2, 369-453.

Tanaka, O., Tanaka, Y. \& Wada, H. (1988). Photonastic and thermonastic opening of capitulum in dandelion, Taraxacum officinale and Taraxacum japonicum. J. Plant. Res., 101, 103-110. 
Todt, D. (1962). Untersuchungen über Öffnung und Anthocyangehaltsveränderungen der Blüten von Cichorium intrbus im Licht-Dunkel-Wechsel und unter konstanten Bedingungen. Zeitscbrift für Botanik, 50, 1-21.

Vázquez, D.P., Blüthgen, N., Cagnolo, L. \& Chacoff, N.P. (2009). Uniting pattern and process in plant - animal mutualistic networks: a review. Ann. Bot. - London, $103,1445-1457$

Westrich, P. (1989). Die Wildbienen Baden-Wirttembergs. Teil 1: Lebensräume, Verbalten, Ökologie und Scbutr. Teil 2: Die Gattungen und Arten. Ulmer, Stuttgart.

Willmer, P.G. \& Corbet, S.A. (1981). Temporal and microclimatic partitioning of the floral resources of Justicia aurea amongst a concourse of pollen vectors an nectar robbers. Oecologia, 51, 67-78.

\section{SUPPORTING INFORMATION}

Additional Supporting Information may be found in the online version of this article:

Table S1 Experimental details of hand pollination experiments.

Table S2 Fitted parameters for closure curves per flower head.

Table S3 Summary statistics for additional hand pollination controls.

Table S4 Summary statistics for number of seeds in experimental

Crepis biennis.

Table S5 Plant species codes for Figure S2.

Table S6 Pollinator codes for Figure S2.
Table S7 Prevalence of Cichorioideae in plant-pollinator network studies.

Figure S1 Circadian pattern of flower visitation in the networks dataset.

Figure S2 Network graphs with all species codes.

Figure S3 Alternative Figures to Fig. 6a-d, presenting uncorrected response variables including summary statistics.

Appendix S1 Explanation of randomization procedures for dissimilarity analyses.

As a service to our authors and readers, this journal provides Supporting Information supplied by the authors. Such materials are peer-reviewed and may be re-organised for online delivery, but are not copy edited or typeset. Technical support issues arising from Supporting Information (other than missing files) should be addressed to the authors.

Editor, Mark Vellend

Manuscript received 18 February 2011

First decision made 28 March 2011

Second decision made 4 June 2011

Manuscript accepted 8 June 2011 
Appendix of Fründ et al.: Flower closure in response to pollination

\section{Supporting Information for: Linné's floral clock is slow}

2 without pollinators - flower closure and plant-pollinator

3 interaction webs

Jochen Fründ ${ }^{1}$, Carsten F. Dormann ${ }^{2} \&$ Teja Tscharntke ${ }^{1}$

${ }^{1}$ Agroecology, Department of Crop Sciences, Georg-August-University Göttingen, Grisebachstr. 3, 37075 Göttingen, Germany

${ }^{2}$ Department of Computational Landscape Ecology, Helmholtz-Center for Environmental Research (UFZ), Leipzig, Germany

* Corresponding Author:

Email: jfruend@uni-goettingen.de

Phone: +49-551-3922359

Fax: +49-551-398806

Contents

Table S1 Experimental details of hand pollination experiments

Table S2 Fitted parameters for closure curves per flower head

Table S3 Summary statistics for additional hand pollination controls

Table S4 Summary statistics for number of seeds in experimental Crepis biennis

Table S5 Plant species codes for Fig S2

Table S6 Pollinator codes for Fig S2

Table S7 Prevalence of Cichorioideae in plant-pollinator network studies

Figure S1 Circadian pattern of flower visitation in the networks dataset

Figure S2 Network graphs with all species codes

Figure S3 Alternative Figures to Fig. 6a-d, presenting uncorrected response variables

including summary statistics

Appendix S1 Explanation of randomization procedures for dissimilarity analyses 
Appendix of Fründ et al.: Flower closure in response to pollination

32 Table S1: Experimental details of hand pollination experiments

\begin{tabular}{|c|c|c|c|c|c|}
\hline Species & Date & Time (start - end) ${ }^{1}$ & No. replicates $^{2}$ & No. times ${ }^{3}$ & No. donors ${ }^{4}$ \\
\hline Crepis biennis & 29 July 2009 & $10: 15 \mathrm{am}-7: 30 \mathrm{pm}$ & $5 / 5 / 0 / 3$ & 8 & 2 \\
\hline Crepis capillaris & 14 Aug 2008 & $11: 00 \mathrm{am}-7: 10 \mathrm{pm}$ & $12 / 12 / 0 / 0$ & 12 & 3 \\
\hline C. capillaris & 06 Aug 2009 & $11: 30 \mathrm{am}-8: 15 \mathrm{pm}$ & $5 / 5 / 6 / 0$ & 8 & 1 \\
\hline Leontodon autumnalis & 14 Aug 2008 & $1: 20 \mathrm{pm}-8: 05 \mathrm{pm}$ & $6 / 6 / 0 / 0$ & 10 & 2 \\
\hline Taraxacum officinale & 07 May 2009 & $12: 15 \mathrm{pm}-8: 50 \mathrm{pm}$ & $8 / 8 / 0 / 0$ & 11 & 2 \\
\hline
\end{tabular}

Table S2: Fitted parameters (mean $\pm \mathbf{s d}$ ) for closure curves of all flower heads in hand pollination experiments

47

48

\begin{tabular}{lllllll}
\hline & & \multicolumn{2}{l}{ Cross pollination } & & \multicolumn{2}{l}{ Control } \\
Species & Year & $\mathrm{b}$ & $\mathrm{t}_{0}$ & & $\mathrm{~b}$ & $\mathrm{t}_{0}$ \\
\hline Crepis biennis & 2009 & $0.041 \pm 0.022$ & $262 \pm 121$ & & $-{ }^{1}$ & $487 \pm 123^{1}$ \\
Crepis capillaris & 2008 & $0.065 \pm 0.018$ & $173 \pm 59$ & & $0.054 \pm 0.016$ & $349 \pm 74$ \\
C. capillaris & 2009 & $0.031 \pm 0.016$ & $335 \pm 114$ & & $0.016 \pm 0.004$ & $490 \pm 65$ \\
Leontodon autumnalis & 2008 & $0.053 \pm 0.025$ & $150 \pm 45$ & & $0.036 \pm 0.016$ & $243 \pm 103$ \\
Taraxacum officinale & 2009 & $0.077 \pm 0.064$ & $395 \pm 140$ & & $0.058 \pm 0.024$ & $376 \pm 138$
\end{tabular}

$54{ }^{1}$ in this group, some curves could not be fitted, but a conservative estimate of $\mathrm{t}_{0}$ was used (see 55 Methods) 
Appendix of Fründ et al.: Flower closure in response to pollination

57 Table S3: ANOVA contrast results for additional hand pollination

58 controls

\begin{tabular}{lllllll}
59 & Species & comparison $^{1}$ & $\mathrm{t}$ & $\mathrm{p}$ & \multicolumn{2}{c}{${\text { mean } \mathrm{t}_{0}(\mathrm{~min})}$} \\
60 & & & & & groupA & groupB \\
61 & C. biennis $_{62}$ & hetero $^{2}$ vs. cross & -4.23 & 0.002 & 600 & 262 \\
63 & & hetero vs. none & -1.41 & 0.18 & 600 & 487 \\
64 & ${\text { C. } \text { capillaris }^{3}}^{3}$ & self vs. cross & -2.64 & 0.021 & 468 & 335 \\
65 & & self vs. none & 0.43 & 0.64 & 468 & 447 \\
\hline
\end{tabular}

$66{ }^{1}$ refers to the type of flower head used for hand pollination

$67 \quad{ }^{2}$ hetero-specific hand pollination with flower heads of Picris hieracioides

$68{ }^{3}$ Plant set tested in 2009

70 Table S4: Number of seeds produced by flower heads of Crepis biennis

71 of different flower closure after pollination treatments

$\begin{array}{llll}72 & \text { Group of flower heads } & \text { Closure time }\left(\mathrm{t}_{0}\right) & \text { No. of seeds } \\ 73 & \text { (treatments) } & {[\text { mean } \pm 1 \mathrm{sd}]} & 41.0 \pm 7.6 \\ 74 & \text { all cross-pollinated and one non-pollinated } & 269 \pm 110 & 4.1 \pm 4.6 \\ 75 & & 561 \pm 66 & \\ 76 & \text { all "hetero" and all but one "none" } & \text { 1mean } \pm 1 \mathrm{sd}] \\ 77 & \text { 1 flower heads could be clearly grouped into two groups with either mostly fertile seeds or mostly } \\ 78 & \text { sterile seeds; the one non-pollinated flower head in the first group was probably unintentionally } \\ 79 & \text { pollinated by the observer or insects in the exclusion cage } \\ 80 & & \\ 81 & & \\ 82 & & \end{array}$


Appendix of Fründ et al.: Flower closure in response to pollination

83 Table S5: Plant species codes for Fig S2

\begin{tabular}{|c|c|c|}
\hline Code & Plant Species & Family \\
\hline$\overline{A s g l}$ & Astragalus glycyphyllosL. & Fabaceae \\
\hline Cia & Cirsium arvense (L.) Scop. & Asteraceae \\
\hline Con & Convolvulus arvensis $\mathrm{L}$. & Convolvulaceae \\
\hline Cor & Securigera varia (L.) Lassen & Fabaceae \\
\hline $\mathrm{Crb}$ & Crepis biennis L. & Asteraceae: Cichorioideae \\
\hline Dau & Daucus carota L. & Apiaceae \\
\hline Falc & Falcaria vulgaris Bernh. & Apiaceae \\
\hline Gv & Galium verum $\mathrm{L}$. & Rubiaceae \\
\hline Her & Heracleum sphondylium L. & Apiaceae \\
\hline $\mathrm{Kn}$ & Knautia arvensis (L.) Coult. & Dipsacaceae \\
\hline Ltub & Lathyrus tuberosus L. & Fabaceae \\
\hline Melial & Melilotus albus Med. & Fabaceae \\
\hline Mlup & Medicago lupulina $\mathrm{L}$. & Fabaceae \\
\hline Myo & Myosotis cf. arvensis (L.) Hill. & Boraginaceae \\
\hline Pas & Pastinaca sativa $\mathrm{L}$. & Apiaceae \\
\hline Pic & Picris hieracioides L. & Asteraceae: Cichorioideae \\
\hline $\mathrm{Pl}$ & Plantago lanceolata L. & Plantaginaceae \\
\hline Pru & Prunella vulgaris L. & Lamiaceae \\
\hline Sen & Senecio jacobea L. & Asteraceae \\
\hline Tdu & Trifolium dubium Sibth. & Fabaceae \\
\hline $\mathrm{Tp}$ & Trifolium pratense $\mathrm{L}$. & Fabaceae \\
\hline Trep & Trifolium repens $\mathrm{L}$. & Fabaceae \\
\hline
\end{tabular}

107

108

109

110 
Appendix of Fründ et al.: Flower closure in response to pollination

111 Table S6: Pollinator species codes for Fig S2

112

113

114

115

Code Pollinator Species

Abys Anthidium byssinum (Panzer 1804)

Afla Andrena flavipes Panzer 1799

Amla Andrena minutula (Kirby 1802)

Amloi Andrena minutuloides Perkins 1914

Bhum Bombus humilis Illiger 1806

119 Bhyp Bombus hypnorum (Linnaeus 1758)

120 Blap Bombus lapidarius (Linnaeus 1758)

121 Bluc Bombus cf. lucorum s.l. (Linnaeus 1758)

122 Bpas Bombus pascuorum (Scopoli 1763)

123 Bsyl Bombus sylvarum (Linnaeus 1761)

124 Bter Bombus cf. terrestris (Linnaeus 1758)

125 Clatif Cheilosia latifrons (Zetterstedt 1843)

126 Csor Cheilosia soror (Zetterstedt 1843)

127 Cvul Cheilosia vulpina(Meigen 1822)

128 Ebal Episyrphus balteatus(Degeer 1776)

129 Eten Eristalis tenax (Linnaeus 1758)

130 Hdif Hylaeus difformis (Eversmann 1852)

131 Hgre Hylaeus cf. gredleri Förster 1871

132 Hpen Helophilus pendulus (Linnaeus 1758)

133 Hsim Halictus cf. simplex Blüthgen 1923

134 Htum Halictus tumulorum (Linnaeus 1758)

135 Hvar Hylaeus variegatus (Fabricius 1798)

136 Lcal Lasioglossum calceatum (Scopoli 1763)

137 Lglab Lasioglossum glabriusculum (Morawitz 1872)

138 Llatic Lasioglossum laticeps (Schenck 1868)

139 Llativ Lasioglossum lativentre (Schenck 1853)

140 Lleu Lasioglossum leucozonium (Schrank 1781)

141 Lmal Lasioglossum malachurum (Kirby 1802)

142 Lmor Lasioglossum morio (Fabricius 1793)

143 Lpaux Lasioglossum pauxillum (Schenck 1853)

144 Lpol Lasioglossum politum (Schenck 1853)

145 Lspec

146 Lvil

147 Mflo

Lasioglossum sp.

148 Mlep

149 Mmel

150 Mver

$151 \quad$ Mwil

152 Nfla

Lasioglossum villosulum (Kirby 1802)

Myathropa florea(Linnaeus 1758)

Melitta leporina (Panzer 1799)

Melanostoma mellinum (Linnaeus 1758)

Megachile versicolor Smith 1844

Megachile willughbiella (Kirby 1802)

153 Oleu

154 Ospi

Nomada flavopicta (Kirby 1802)

Osmia leucomelana (Kirby 1802)

Osmia spinulosa (Kirby 1802)

155 Pcal

Panurgus calcaratus (Scopoli 1763)

156 Phaem Paragushaemorrhous Meigen 1822

157 Pvid Pipizella viduata (Linnaeus 1758)

158 Spyr Scaeva pyrastri (Linnaeus 1758)

159 Sscr Sphaerophoria scripta (Linnaeus 1758)

160 Svit Syrphus vitripennis Meigen 1822

Family

Megachilidae

Andrenidae

Andrenidae

Andrenidae

Apidae

Apidae

Apidae

Apidae

Apidae

Apidae

Apidae

Syrphidae

Syrphidae

Syrphidae

Syrphidae

Syrphidae

Colletidae

Colletidae

Syrphidae

Halictidae

Halictidae

Colletidae

Halictidae

Halictidae

Halictidae

Halictidae

Halictidae

Halictidae

Halictidae

Halictidae

Halictidae

Halictidae

Halictidae

Syrphidae

Melittidae

Syrphidae

Megachilidae

Megachilidae

Anthophoridae

Megachilidae

Megachilidae

Andrenidae

Syrphidae

Syrphidae

Syrphidae

Syrphidae

Syrphidae

161

162

163 
Appendix of Fründ et al.: Flower closure in response to pollination

164 Table S7: Prevalence of Cichorioideae in published plant-pollinator

165 interaction network studies

\begin{tabular}{|c|c|c|c|c|}
\hline Continent & Country & Citation & $\begin{array}{l}\text { \# Cichorieae } \\
\text { species }\end{array}$ & $\begin{array}{l}\% \text { of } \\
\text { species }\end{array}$ \\
\hline \multirow[t]{14}{*}{ Europe } & Azores & Olesen et al. 2002 Divers. Distrib. 8: 181-192 & 0 & 0 \\
\hline & Canary Islands & Dupont et al. 2003 Ecography 26: 301-310 & 1 & 9 \\
\hline & England & Memmott 1999 Ecol. Lett. 2: 276-280 & 5 & 15 \\
\hline & England & Carvalheiro et al. 2008 J. Appl. Ecol. 45: 1419-1427 & 5 & 6 \\
\hline & England & Dicks et al. 2002 J. Animal. Ecol. 71: 32-43 & 3 & 9 \\
\hline & England & Forup \& Memmott 2005 Restoration Ecol. 13:265-274 & 4 & 10 \\
\hline & Germany & this study & 11 & 7 \\
\hline & Germany & Weiner et al. Basic Appl. Ecol. doi:10.1016/j.baae.2010.08.006 & 5 & 6 \\
\hline & Germany & Kratochwil et al. 2009 Apidologie 40: 634-650 & 4 & 10 \\
\hline & Norway & Hegland \& Totland 2005 Oecologia 145: 586-594 & 0 & 0 \\
\hline & Norway & Lázaro et al. 2009 Oikos 118: 691-702 & 5 & 16 \\
\hline & Spain & Stang et al. 2006 Oikos 112: 111-121 & 2 & 8 \\
\hline & Spain & Bosch et al. 1996 Oecologia 109:583-591 & 3 & 18 \\
\hline & Switzerland & Albrecht et al. 2010 Oikos 119: 1610-1624 & 4 & 7 \\
\hline \multirow[t]{16}{*}{ America } & Argentina & Morales \& Aizen 2006 J. Ecol. $94: 171-180$ & 1 & 3 \\
\hline & Argentina & Medan et al. 2002 Arc. Antarct. Alp. Res. 34:233-241 & 1 & 2 \\
\hline & Argentina & Vazquez \& Simberloff 2002 Am. Nat. 159:606-623 & 0 & 0 \\
\hline & Canada & Barrett \& Helenurm 1987 Can. J. Bot. 65:2036-2046 & 0 & 0 \\
\hline & Canada & Hocking 1968 Oikos 19:359-388 & 1 & 3 \\
\hline & Canada & Kevan 1970 Ph.D. thesis, University of Alberta & 1 & 3 \\
\hline & Canada & Mosquin \& Martin 1967 Can. Field Nat. 81:201-205 & 1 & 9 \\
\hline & Canada & Small 1976 Can. Field Nat. 90:22-28 & 0 & 0 \\
\hline & Chile & Arroyo et al. 1982 Am. J. Bot. 69:82-97 & 0 & 0 \\
\hline & Chile & Smith-Ramirez et al. 2005 Bot. J. Linn. Soc. 147: 399-416 & 0 & 0 \\
\hline & USA & $\begin{array}{l}\text { Clements \& Long } 1923 \text { Washington, D.C., USA, Carnegie } \\
\text { Institute of Washington }\end{array}$ & 1 & 1 \\
\hline & USA & Motten 1986 Ecol. Monogr. 56:21-42 & 0 & 0 \\
\hline & USA & Robertson 1929 Carlinville, IL, USA, C. Robertson & 5 & 1 \\
\hline & USA & Schemske et al. 1978 Ecology 59: 351-366 & 0 & 0 \\
\hline & USA & Alarcon et al. 2008 Oikos 117: 1796-1807 & 0 & 0 \\
\hline & Venezuela & Ramirez \& Brito 1992 Bot. J. Linn. Soc. 110:277-302 & 0 & 0 \\
\hline \multirow[t]{8}{*}{ others } & Australia & Inouye \& Pyke 1988 Aust. J. Ecol. 13:191-210 & 2 & 5 \\
\hline & Galapagos & McCullen 1993 Pan-Pac. Entomol. 69:95-106 & 1 & 1 \\
\hline & Greenland & Olesen et al. 2008 Ecology 89: 1573-1582 & 1 & 3 \\
\hline & Japan & Kato et al. 1990 Contr. Biol. Lab. Kyoto Univ. 27:309-375 & 0 & 0 \\
\hline & Kenya & Hagen \& Kraemer 2010 Biol. Cons. 143: 1654-1663 & 0 & 0 \\
\hline & Mauritius & $\begin{array}{l}\text { Kaiser-Bunbury et al. } 2009 \text { Perspect. Plant Ecol. Evol. Syst. 11: } \\
\text { 241-254 }\end{array}$ & 0 & 0 \\
\hline & Mauritius & Olesen et al. 2002 Divers. Distrib. 8: 181-192 & 0 & 0 \\
\hline & Mongolia & Yoshihara et al. 2008 Biol. Cons. 141: 2376-2386 & 2 & 5 \\
\hline
\end{tabular}

${ }^{1}$ Studies on plant-pollinator communities compiled by an extensive literature search (all studies included for which data of

sufficient resolution were available, excluding studies restricted to small taxonomic subsets of the whole network, avoiding 
Appendix of Fründ et al.: Flower closure in response to pollination

168 multiple studies of the same network). Thanks to the interaction web database (http://www.nceas.ucsb.edu/interactionweb/)

169 for providing access to some of the data.

$170{ }^{2}$ The number of plant species of the tribe Cichorieae within the family Asteraceae being part of the interactions analysed 171 
Appendix of Fründ et al.: Flower closure in response to pollination

172

(a)

Visits to Cichorioidae

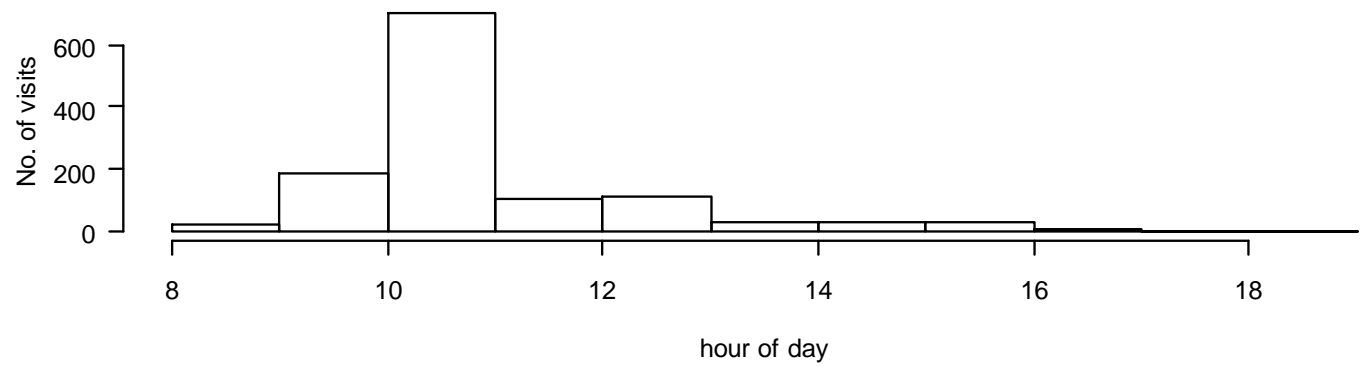

(b)

Visits to all plants

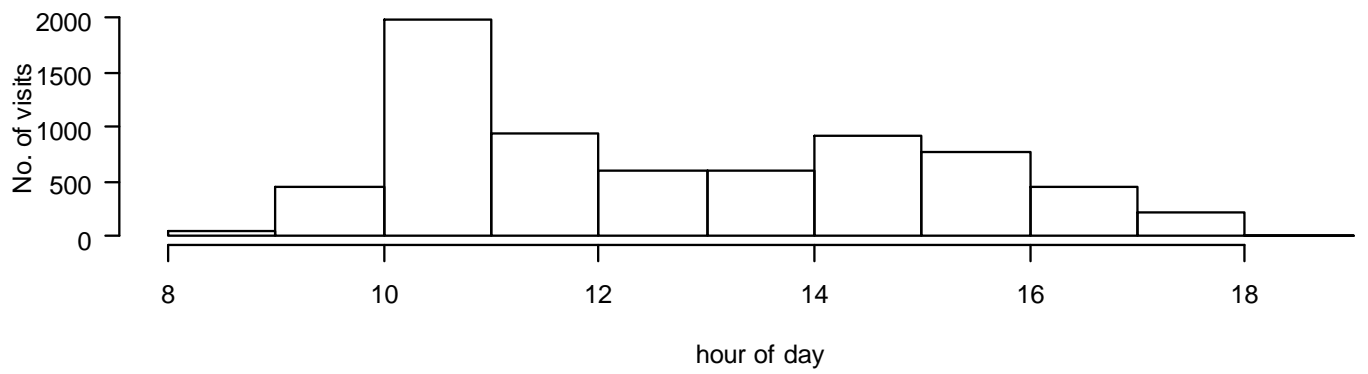

(c) Estimated sampling effort
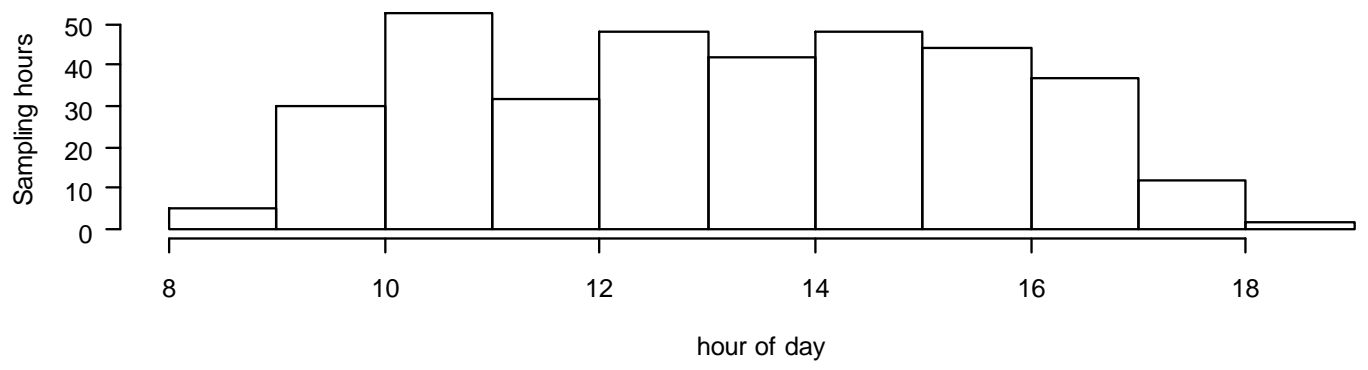

174 Fig. S1. Circadian pattern of flower visitation to (a) Cichorioideae and (b) all plants, in a set 175 of 32 single-day networks from different meadow sites. (c) shows the sampling effort in hours 176 (estimated from average times of transect and plot observations). Most visits to Cichoriods 177 occurred well before 13:00. This small-scale temporal pattern reflects early flower closure and 178 is not caused by the temporal distribution of sampling nor is it a consequence of overall 179 pollinator activity or nectar availability (as many plants were also visited in the afternoon). 
Chapter 3: Flower closure and plant-pollinator interactions

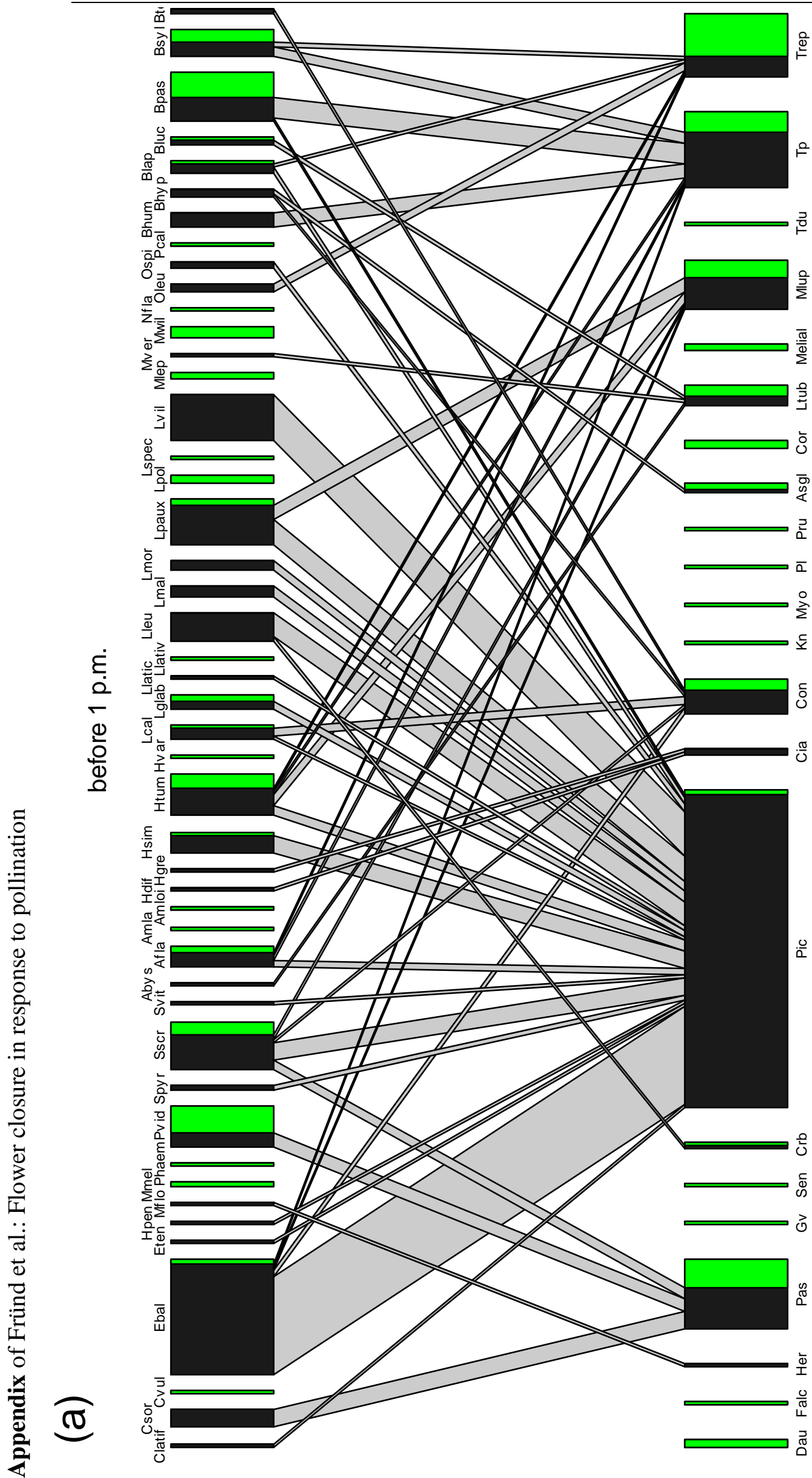




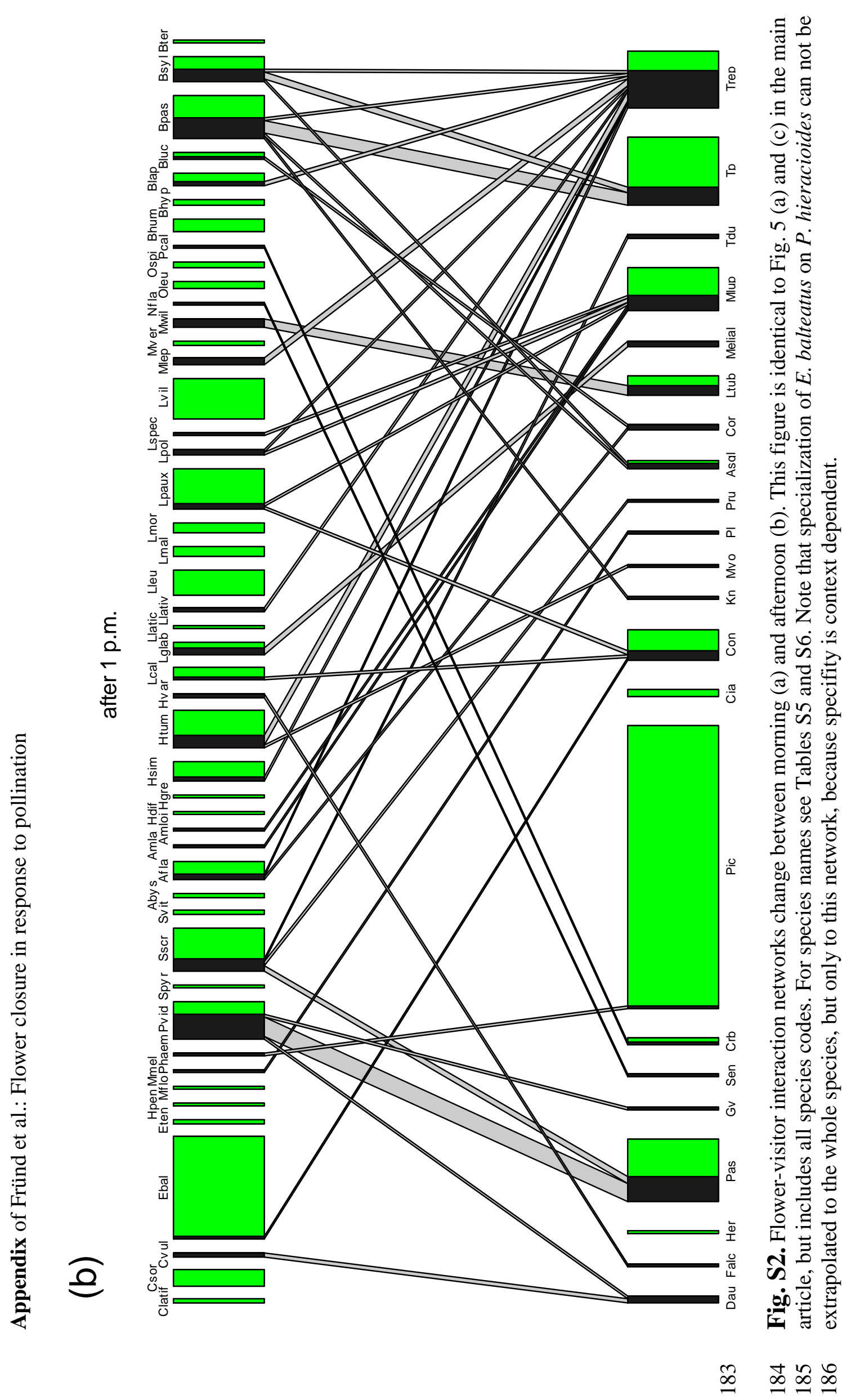

Dissertation J Fründ 
Appendix of Fründ et al.: Flower closure in response to pollination

187

188 a
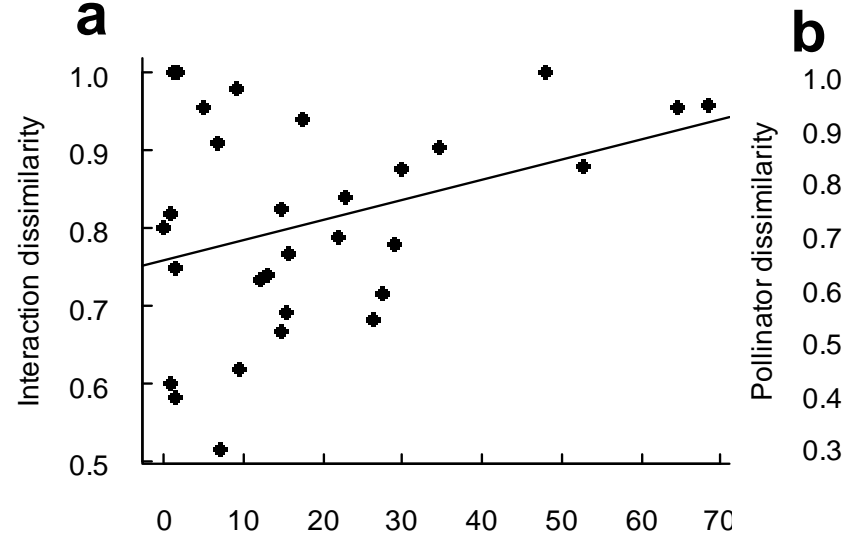

Dominance of Cichorioids (\% of visits)

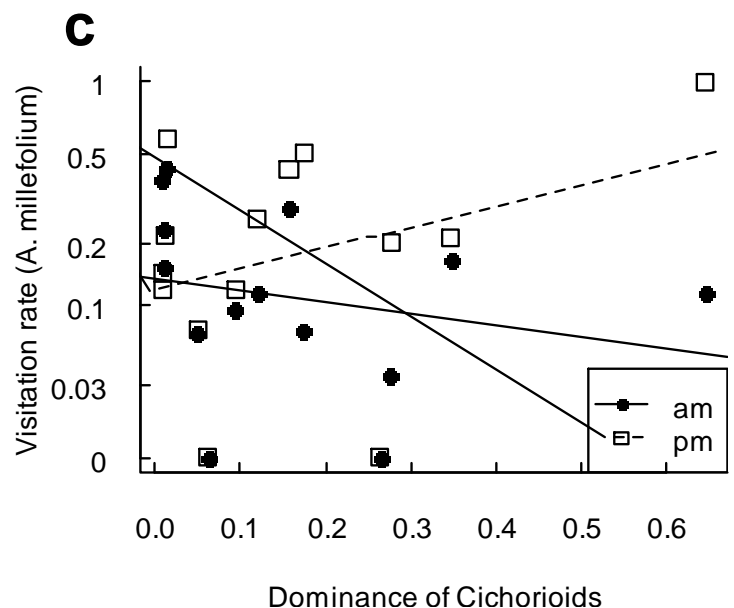
$\mathrm{F}_{1,16}=52.9, \mathrm{p}<0.001$.

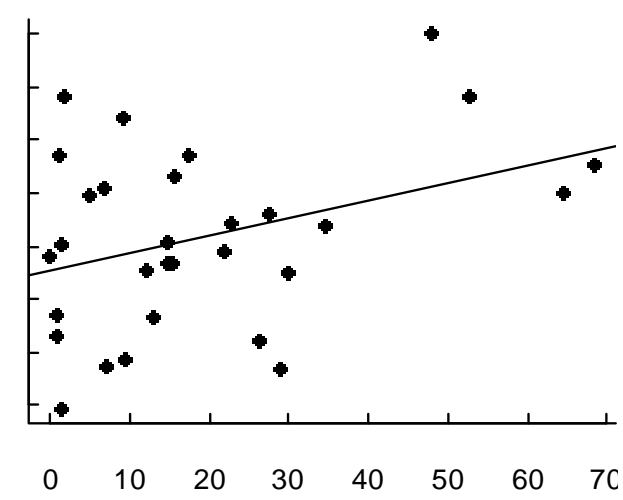

Dominance of Cichorioids (\% of visits)

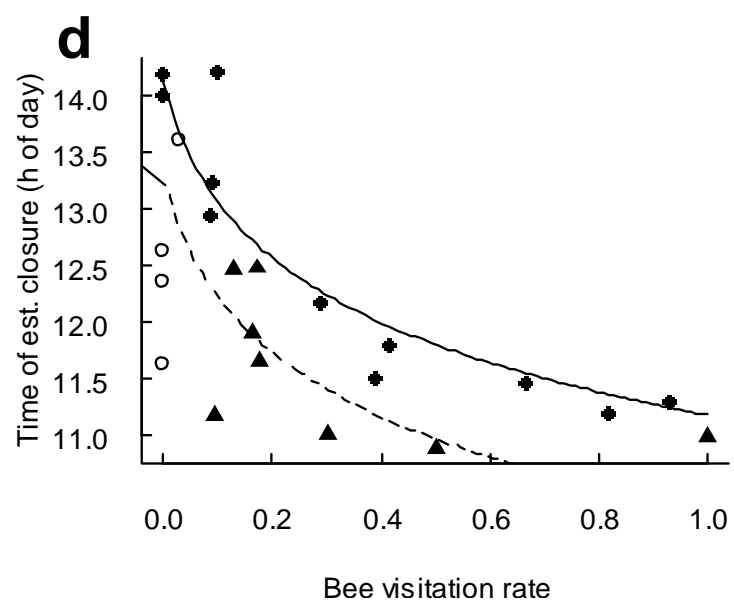

Fig. S3. Plots showing alternative (raw) response variables for the relationships shown in Fig. 6 (a-d)of the main article presenting patterns in plant-pollinator interaction webs from grasslands. In all cases, the same trends can be found. (a) Interaction dissimilarities (BrayCurtis) without controlling for null model, $\mathrm{F}_{1,28}=4.1, \mathrm{p}=0$. 053. (b) Pollinator community dissimilarities (Bray-Curtis) without controlling for null model, $F_{1,28}=4.2, p=0$. 049. (c) Visitation rate (visits per inflorescence and $15 \mathrm{~min}$ ) of morning and afternoon, showing the shift to afternoon visitation in webs with a high percentage of early closing Cichorioideae. This was indicated by a significant interaction between time of day and proportion of Cichorioideae $\left(\mathrm{F}_{1,12}=11.1, \mathrm{p}=0.006\right)$ in a linear mixed effects model with "web" as random grouping factor. Note the log-sclae of the y-axis. (d) Time of day when $>90 \%$ of visits received, here without controlling for differences in day length / time of year. Times are given according to the $24 \mathrm{~h}$-clock. Weather: $\mathrm{F}_{1,16}=17.0, \mathrm{p}<0.001$; $\log [$ bee visitation rate +0.05$]$ : 
Appendix of Fründ et al.: Flower closure in response to pollination

\section{Appendix S1: Additional information about randomization procedures} used for dissimilarity analyses

Dissimilarity indices are sensitive to sample size and do not reach the theoretical minimum of zero with discrete samples of identical communities (Wolda 1981; Fig. S1.1). We tried to account for this problem by substracting the expected value estimated by a randomization (null model) procedure that redistributes observations among the two community (or network) subsets (i.e., times-of-day) keeping total frequencies per species (or link) and subset by using function $r 2 \mathrm{dtab}$ le, an implementation of Patefield's (1981) algorithm (see Fig. S1.2 a-b for expected values). This simulates sampling from identical communities (or networks, respectively). Note that the null model approach applied here did not randomize the interaction web matrices, but only re-assigned observations among the two subwebs.

To evaluate the robustness of our results and conclusions to the choice of randomization procedure, we also performed an alternative null model analysis in addition to the one presented in the main article. In this alternative approach, total frequencies per species (or link) were not fixed per network, but used as probability for the sampling of communitysubsets of the same size (number of observations) as the original subsets. Here we sampled with replacement, therefore it is a 'bootstrap' approach (similar to Fig. S1.1; see Fig. S1.2 c-d for expected values). This alternative procedure produced very similar results (Fig. S1.3), but expected values were slightly lower than for the preferred randomization approach, which keeps the same number of species as in the observed sample. 
Appendix of Fründ et al.: Flower closure in response to pollination

\section{Bray-Curtis (of proportions)}

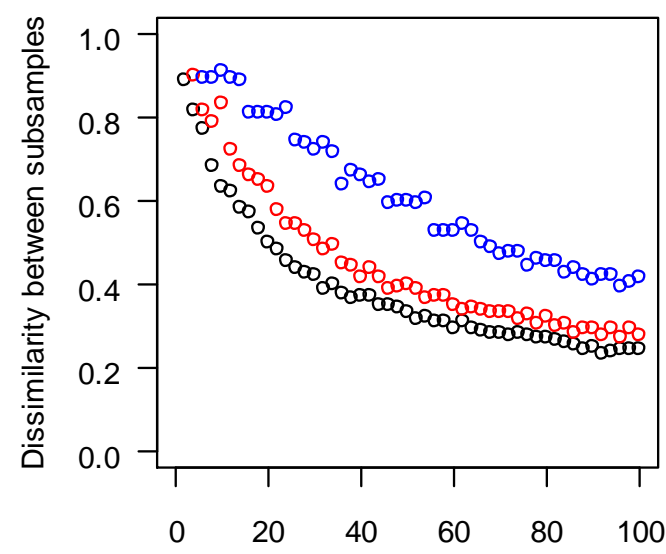

total No. of indiv. sampled

\section{Chao}

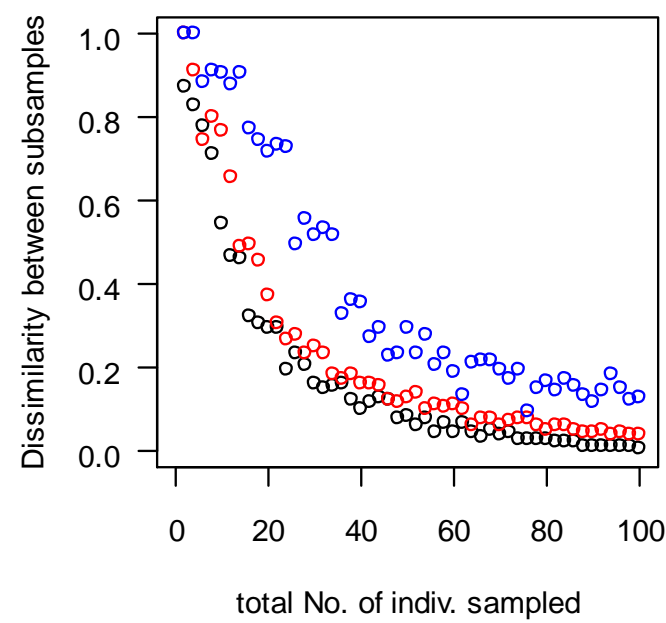

Horn-Morisita

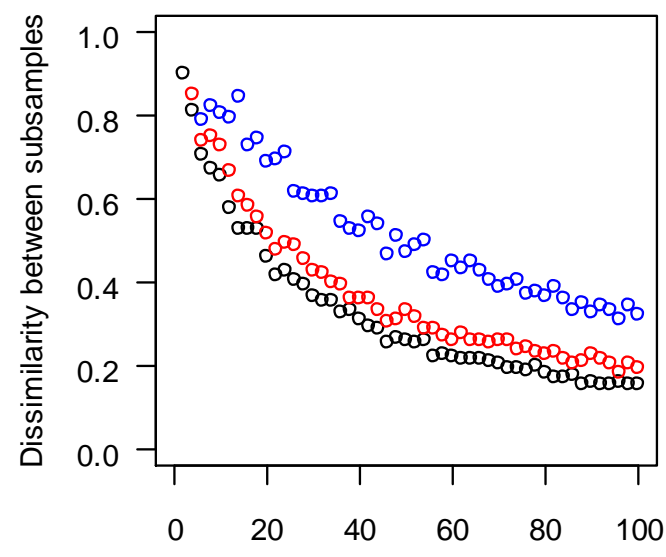

total No. of indiv. sampled

\section{Binomial}

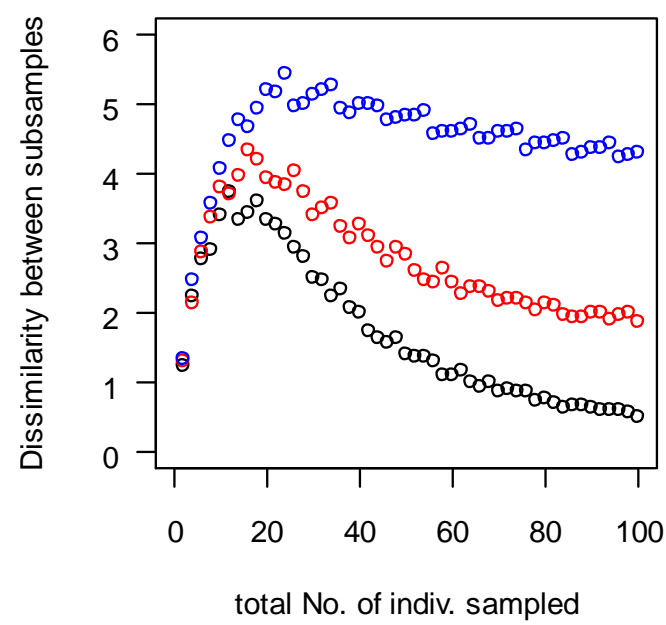

Fig. S1.1. Sampling from a virtual community of 10 species with equal abundance (sampling probability), showing the dissimilarity between two samples estimated by different indices. Points represent the mean index value of 100 random draws for a given sample size, and different colors indicate different sample size ratios between the different subsamples: for the black dots, both subsamples had the same number of individuals, the red dots represent a sample size ratio of 3:1 and the blue dots a ratio of 9:1 - i.e., in the case of 100 total individuals, one subsample had $50(25,10)$ and the other $50(75,90)$ individuals. This figure shows that all these indices, including those said to be insensitive to sampling effects, indicate larger than zero dissimilarity even though samples from the same community are compared. The bias depends nonlinearly on sample size, has a different relationship for each index, and is stronger with unequal sizes of subsamples. Method: Ten 'species' were sampled with replacement (function sample in $\mathrm{R}$ ), and the dissimilarity between two resulting 'communities' (frequency tables) for each sample size was calculated using the function vegdist in the 'vegan' R package (Oksanen et al. 2010) for all indices except Bray-Curtis. The

240 package documentation should also be consulted for further information on the different 241 indices. 
Appendix of Fründ et al.: Flower closure in response to pollination

a) interactions - r2dtable

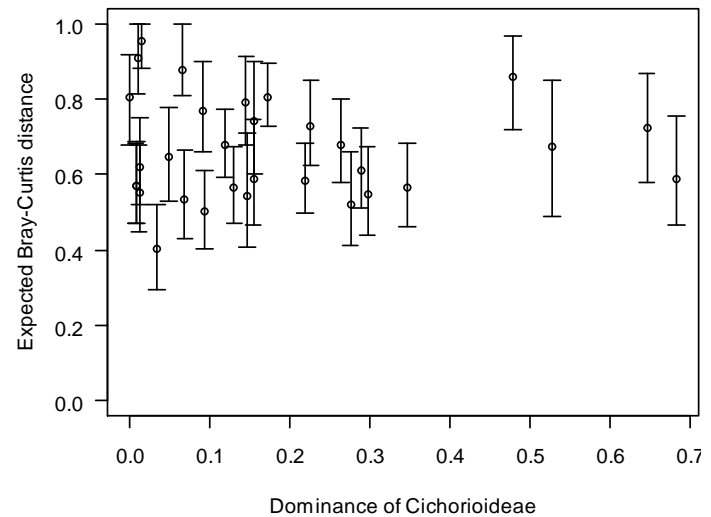

243

244

c) interactions - bootstrap

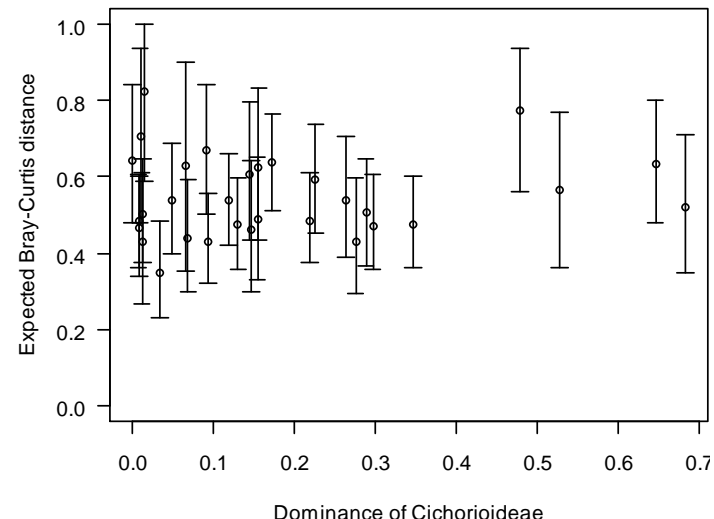

b) pollinator communities $-\mathrm{r} 2 \mathrm{dtable}$

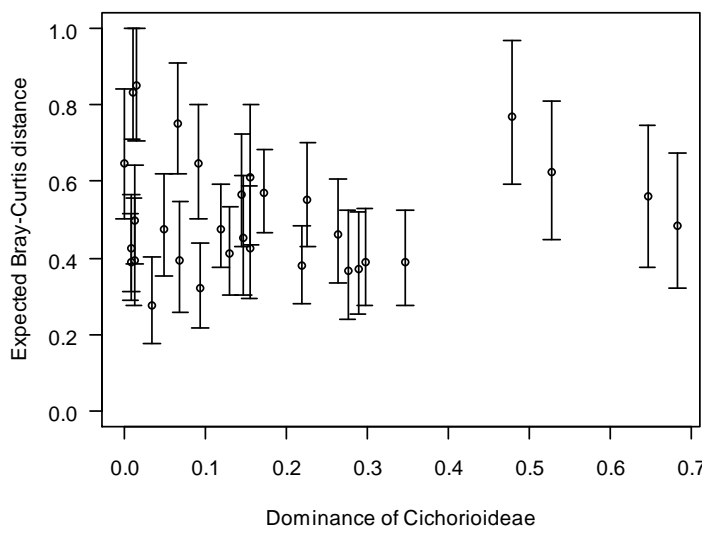

d) pollinator communities - bootstrap

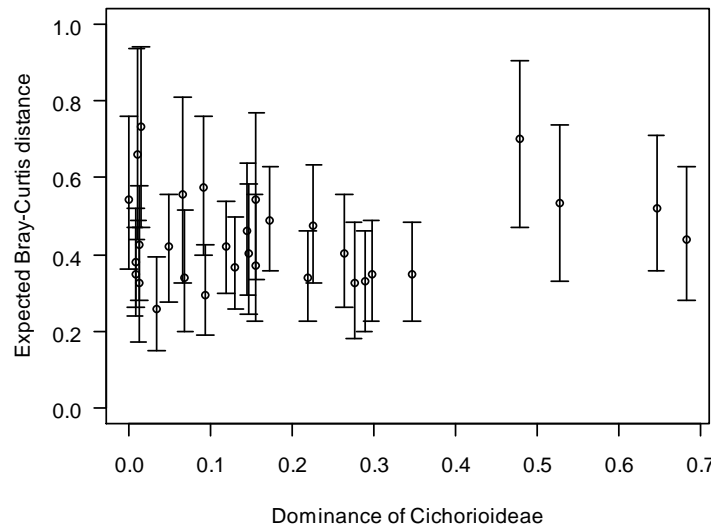

Fig. S1.2. Expected dissimilarity values for randomization of the data according to the null hypothesis of no difference between a.m.- and p.m.-subweb, mean and 95\%-confidence interval of 1000 replicates of the null model. (a) and (b) show expected values for the null model used in the main manuscript (fixing marginal totals), and (c) and (d) show expected values for an alternative randomization procedure (see Fig. S1.3). Confidence limits for the slopes of the regression lines of null model values are a) -0.154 to +0.128 , and b) -0.145 to +0.167 , compared to slopes of observed values of +0.258 and +0.327 , respectively. This confirms that the increase of dissimilarity with \% Cichoirioideae visits can not be expected by the null model. 
Appendix of Fründ et al.: Flower closure in response to pollination
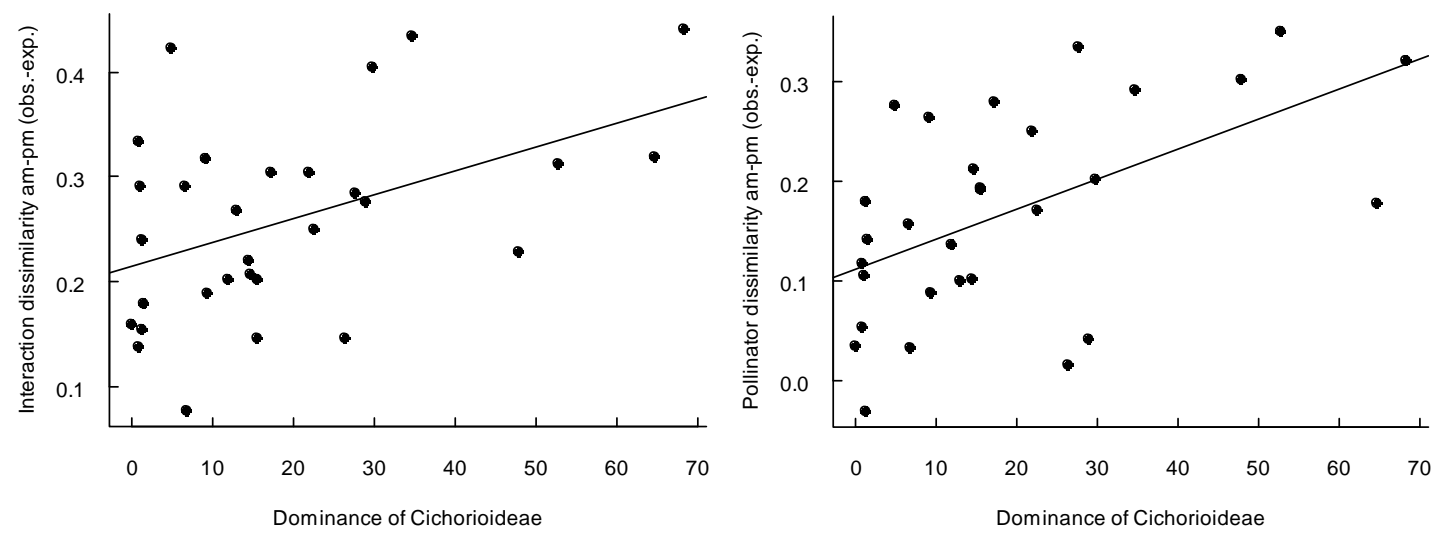

Fig. S1.3. Alternative versions of the relationships shown in Fig. 6 of the main article, but here the expected values are estimated by a bootstrap approach. Showing the relationship between within-day turnover of interactions or pollinator assemblies and the proportion of early-closing Cichorioideae plants in a network. obs.-exp. indicates that expected values

261 (mean of 1000 replicates) were substracted from the observed dissimilarity values to get the 262 response variable. (a) Dissimilarity of interactions between morning and afternoon subwebs, 263 regression line: $p=0.011$. (b) Dissimilarity in pollinator species composition between

264 morning and afternoon subwebs, regression line: $\mathrm{p}=0.002$.

\section{References}

Oksanen, Jari; F. Guillaume Blanchet; Roeland Kindt; Pierre Legendre; R. B. O'Hara; Gavin

\section{2 http://CRAN.R-project.org/package=vegan}

273 Patefield, W.M. (1981). An efficient method of generating random RxC tables with given row 274 and column totals. Applied Statistics, 30, 91-97.

275 Wolda, Henk (1981). Similarity indices, sample size and diversity. Oecologia 50: 296-302 


\section{Chapter 4}

\section{Specialization of mutualistic interaction networks decreases towards tropical latitudes}

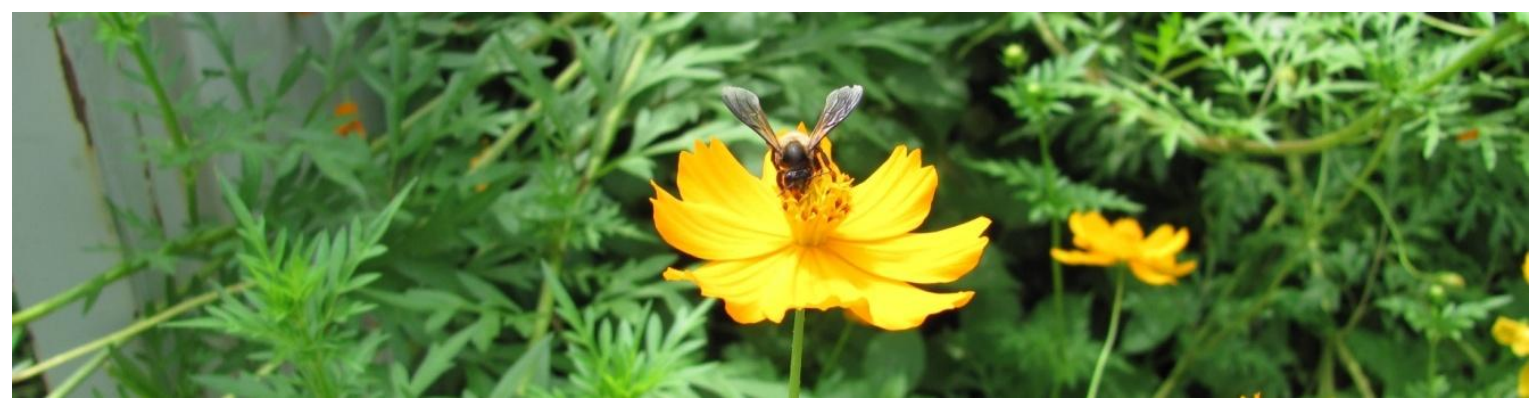

Authors: Matthias Schleuning*, Jochen Fründ*, Alexandra-Maria Klein, Stefan Abrahamczyk, Ruben Alarcón, Matthias Albrecht, Georg Andersson, Simone Bazarian, Katrin Böhning-Gaese, Riccardo Bommarco, Bo Dalsgaard, Matthias Dehling, Ariella Gotlieb, Melanie Hagen, Thomas Hickler, Andrea Holzschuh, Christopher KaiserBunbury, Holger Kreft, Rebecca J Morris, Brody Sandel, William J Sutherland, JensChristian Svenning, Mathias Templin, Teja Tscharntke, Stella Watts, Christiane N Weiner, Michael Werner, Neal M Williams, Camilla Winqvist, Carsten F Dormann \& Nico Blüthgen

* MS and JF contributed equally to this work.

This chapter is published in:

Current Biology (2012), vol. 22, pages 1925 - 1931

Please access by doi: 10.1016/j.cub.2012.08.015

(C) Elsevier 2012 


\section{Abstract}

Species-rich tropical communities are expected to be more specialized than their temperate counterparts. Several studies have reported increasing biotic specialization toward the tropics, whereas others have not found latitudinal trends once accounting for sampling bias or differences in plant diversity. Thus, the direction of the latitudinal specialization gradient remains contentious. With an unprecedented global data set, we investigated how biotic specialization between plants and animal pollinators or seed dispersers is associated with latitude, past and contemporary climate, and plant diversity. We show that in contrast to expectation, biotic specialization of mutualistic networks is significantly lower at tropical than at temperate latitudes. Specialization was more closely related to contemporary climate than to past climate stability, suggesting that current conditions have a stronger effect on biotic specialization than historical community stability. Biotic specialization decreased with increasing local and regional plant diversity. This suggests that high specialization of mutualistic interactions is a response of pollinators and seed dispersers to low plant diversity. This could explain why the latitudinal specialization gradient is reversed relative to the latitudinal diversity gradient. Low mutualistic network specialization in the tropics suggests higher tolerance against extinctions in tropical than in temperate communities. 


\section{Specialization of Mutualistic Interaction Networks Decreases toward Tropical Latitudes}

Matthias Schleuning,,$^{1,28,{ }^{*}}$ Jochen Fründ, ${ }^{2,28}$ Alexandra-Maria Klein, ${ }^{3}$ Stefan Abrahamczyk, ${ }^{4,5}$ Ruben Alarcón, ${ }^{6}$ Matthias Albrecht, ${ }^{7,8}$

Georg K.S. Andersson, ${ }^{9,10}$ Simone Bazarian, ${ }^{11}$ Katrin Böhning-Gaese, ${ }^{1,12}$ Riccardo Bommarco, ${ }^{13}$ Bo Dalsgaard, ${ }^{14,15}$ D. Matthias Dehling, ${ }^{1}$ Ariella Gotlieb, ${ }^{16}$ Melanie Hagen, ${ }^{17}$ Thomas Hickler, ${ }^{1,18}$ Andrea Holzschuh, ${ }^{19}$ Christopher N. Kaiser-Bunbury, ${ }^{17}$ Holger Kreft, ${ }^{20}$ Rebecca J. Morris, ${ }^{21}$ Brody Sandel, ${ }^{22,23}$

William J. Sutherland, ${ }^{14}$ Jens-Christian Svenning, ${ }^{22}$ Teja Tscharntke, ${ }^{2}$ Stella Watts, ${ }^{24}$ Christiane N. Weiner, ${ }^{19}$ Michael Werner, ${ }^{19}$ Neal M. Williams, ${ }^{25}$ Camilla Winqvist, ${ }^{13}$ Carsten F. Dormann, ${ }^{26}$ and Nico Blüthgen ${ }^{19,27}$

${ }^{1}$ Biodiversity and Climate Research Centre (BiK-F) and Senckenberg Gesellschaft für Naturforschung, 60325 Frankfurt am Main, Germany

${ }^{2}$ Agroecology, Department of Crop Sciences, Georg-August University of Göttingen, 37077 Göttingen, Germany IInstitute of Ecology, Ecosystem Functions, Leuphana University of Lüneburg, 21335 Lüneburg, Germany ${ }^{4}$ Institute for Systematic Botany, University of Zurich, 8008 Zurich, Switzerland

Institute for Systematic Botany and Mycology, Ludwig Maximilian University of Munich, 80638 Munich, Germany ${ }^{6}$ Biology Program, California State University Channel Islands, Camarillo, CA 93012, USA

7Terrestrial Ecology Group, Mediterranean Institute for Advanced Studies (CSIC-UIB), 07190 Esporles, Mallorca, Spain

${ }^{8}$ Agricultural Landscapes and Biodiversity, Research Station Agroscope Reckenholz-Tanikon ART, Reckenholzstrasse 191, 8046 Zurich, Switzerland

${ }^{9}$ Centre for Environmental and Climate Research

10 Department of Biology

Lund University, 22362 Lund, Sweden

${ }^{11}$ Associação ProScience, CEP 05451-030, São Paulo - SP Brazil

12Department of Biological Sciences, Johann Wolfgang Goethe University of Frankfurt, 60438 Frankfurt am Main, Germany

13Department of Ecology, Swedish University of Agricultural Sciences, 75007 Uppsala, Sweden

${ }^{14}$ Conservation Science Group, Department of Zoology, University of Cambridge, Cambridge CB2 3EJ, UK

${ }^{15}$ Center for Macroecology, Evolution and Climate,

Department of Biology, University of Copenhagen, 2100 Copenhagen $\varnothing$, Denmark

${ }^{16}$ Department of Zoology, Tel Aviv University, Tel Aviv 69978, Israel

17Ecology and Genetics Group, Department of Bioscience, Aarhus University, 8000 Aarhus C, Denmark

${ }^{18}$ Department of Physical Geography, Johann Wolfgang Goethe University of Frankfurt, 60323 Frankfurt am Main, Germany
19Department of Animal Ecology and Tropical Biology, University of Würzburg, 97074 Würzburg, Germany ${ }^{20}$ Free Floater Research Group "Biodiversity, Macroecology and Conservation Biogeography," Georg-August University of Göttingen, 37077 Göttingen, Germany

21Department of Zoology, University of Oxford, Oxford OX1 3PS, UK

${ }^{22}$ Ecoinformatics and Biodiversity Group, Department of Bioscience, Aarhus University, 8000 Aarhus C, Denmark ${ }^{23}$ Center for Massive Data Algorithmics (MADALGO), Department of Computer Science, Aarhus University, 8200 Aarhus N, Denmark

${ }^{24}$ Natural Environment Research Group, School of Science and Technology, University of Northampton, Northampton NN2 6JE, UK

${ }^{25}$ Department of Entomology, University of California, Davis, Davis, CA 95616, USA

${ }^{26}$ Biometry and Environmental System Analysis, Faculty of Forest and Environmental Science, University of Freiburg, 79106 Freiburg, Germany

${ }^{27}$ Ecological Networks, Department of Biology, Technical University of Darmstadt, 64287 Darmstadt, Germany

\section{Summary}

Species-rich tropical communities are expected to be more specialized than their temperate counterparts [1-3]. Several studies have reported increasing biotic specialization toward the tropics [4-7], whereas others have not found latitudinal trends once accounting for sampling bias [8, 9] or differences in plant diversity $[10,11]$. Thus, the direction of the latitudinal specialization gradient remains contentious. With an unprecedented global data set, we investigated how biotic specialization between plants and animal pollinators or seed dispersers is associated with latitude, past and contemporary climate, and plant diversity. We show that in contrast to expectation, biotic specialization of mutualistic networks is significantly lower at tropical than at temperate latitudes. Specialization was more closely related to contemporary climate than to past climate stability, suggesting that current conditions have a stronger effect on biotic specialization than historical community stability. Biotic specialization decreased with increasing local and regional plant diversity. This suggests that high specialization of mutualistic interactions is a response of pollinators and seed dispersers to low plant diversity. This could explain why the latitudinal specialization gradient is reversed relative to the latitudinal diversity gradient. Low mutualistic network specialization in the tropics suggests higher tolerance against extinctions in tropical than in temperate communities.

Results and Discussion

Latitudinal Specialization Gradient

In order to test the direction of the latitudinal specialization gradient, we gathered a global data set comprising a total of 


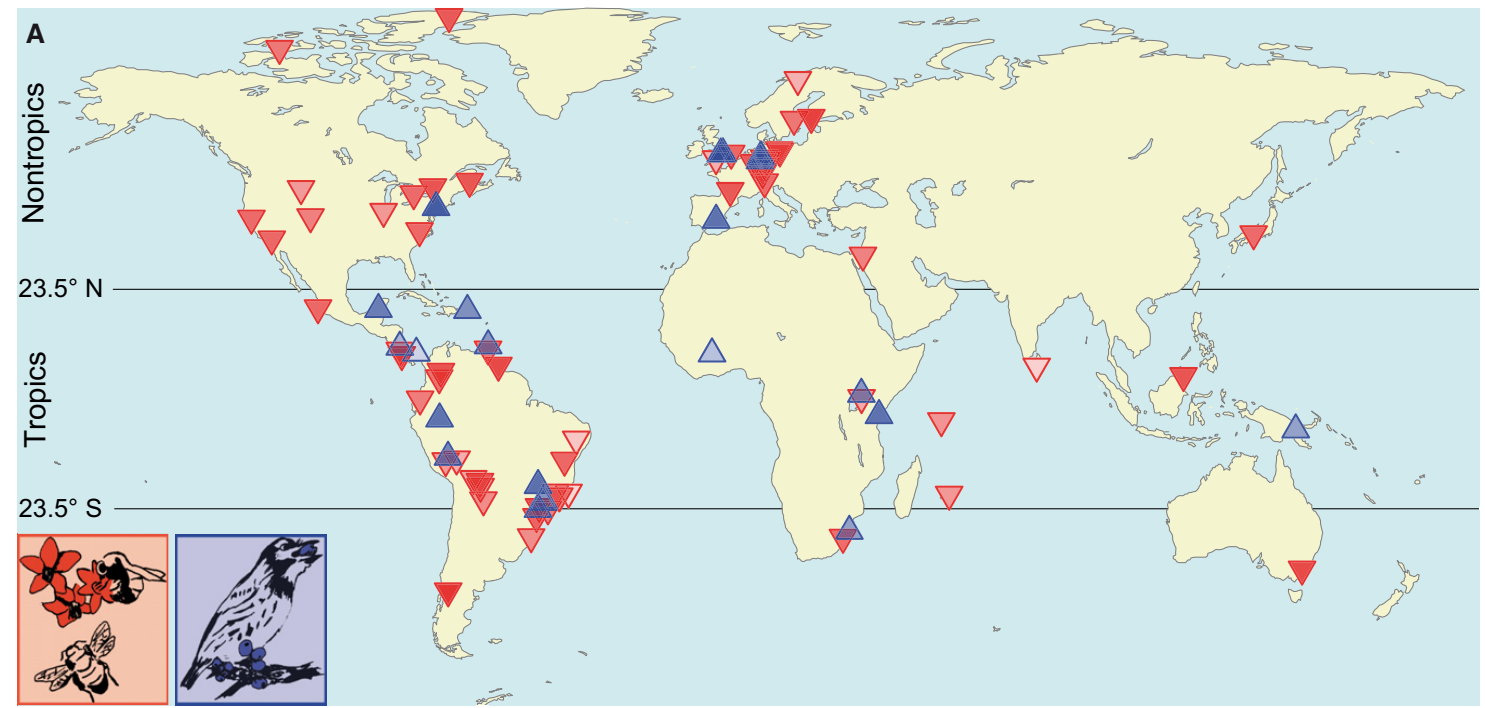

B

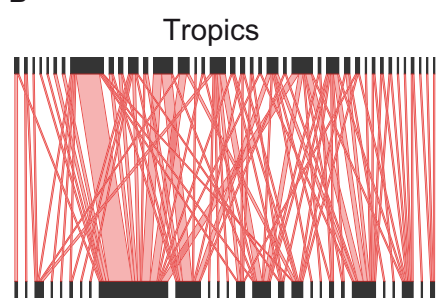

Nontropics

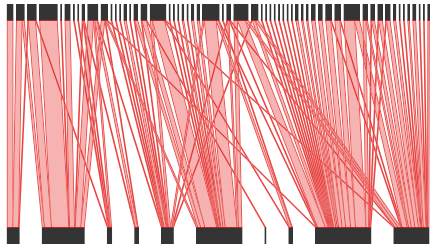

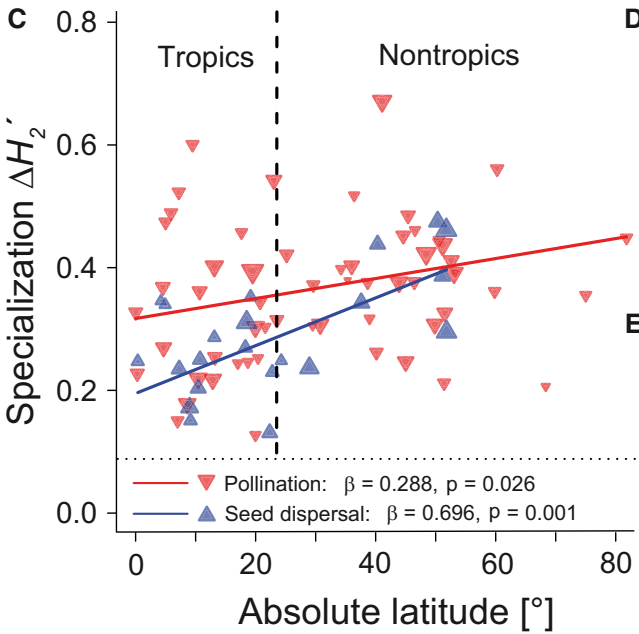

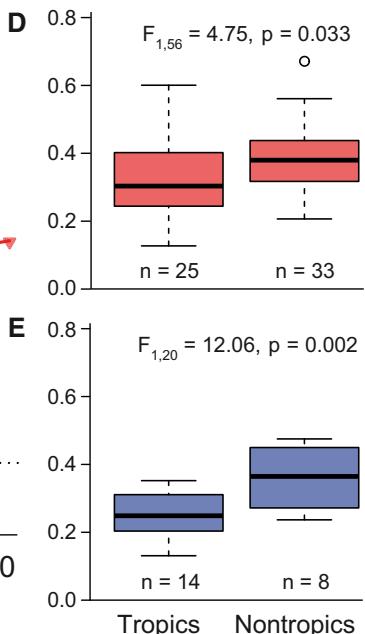

Figure 1. Latitudinal Trends in Specialization of Pollination and Seed Dispersal Networks

(A) Global distribution of pollination (red) and seed dispersal (blue) networks. Color intensities of triangles reflect mean network specialization $\left(\Delta \mathrm{H}_{2}{ }^{\prime}\right)$ in each study region: color intensity increases with $\Delta H_{2}{ }^{\prime}$.

(B) Examples of a generalized pollination network with functionally redundant pollinators (top: $\Delta H_{2}{ }^{\prime}=0.18,13^{\circ} \mathrm{S}$ ) and a specialized network with functionally distinct pollinators (bottom: $\Delta H_{2}{ }^{\prime}=0.51,51^{\circ} \mathrm{N}$ ). Pollinators are shown at top and plants at bottom of the networks.

(C) The relationship between $\Delta H_{2}^{\prime}$ and latitude. Symbol size corresponds to weights by sampling intensity in each region.

(D and E) The difference in $\Delta H_{2}^{\prime}$ between tropical $\left(\leq 23.5^{\circ}\right)$ and nontropical $\left(>23.5^{\circ}\right)$ regions. Thick horizontal lines are medians, boxes indicate $25^{\text {th }}$ and $75^{\text {th }}$ percentiles, whiskers indicate the data range, and the circle is an outlier. See Figure $\mathrm{S} 1$ for consistent latitudinal trends in alternative indices of biotic specialization and Table $\mathrm{S} 1$ for an overview of the data set.

282 quantitative pollination and seed dispersal networks from 80 sampling regions ( 58 for pollination, 22 for seed dispersal) ranging in absolute latitude from $0^{\circ}$ to $82^{\circ}$ (Figures $1 \mathrm{~A}$ and 1B; see also Table $S 1$ available online). Original studies reported the number of pollinator or seed disperser individuals feeding on a plant species or the number of individuals of a consumer species carrying pollen or seeds of a plant species. Although pollinator and seed disperser species differ in the efficiency of mutualistic services provided to plant species
$[12,13]$, because original studies did not report interaction efficiencies, we relied on estimates of interaction strength as a surrogate for the mutualistic importance of a consumer species for a plant species [12].

We estimated specialization of the interacting species by assessing patterns of niche partitioning and resource overlap among pollinator or seed disperser species [14-16]. We exploited recent advances in the analysis of quantitative interaction networks that facilitate the comparison of network-wide 
Latitudinal Trends in Biotic Specialization 1927
Table 1. Minimal Adequate Linear Models for Relationships between Network Specialization $\Delta H_{2}^{\prime}$ and Predictor Variables

\begin{tabular}{lrrr}
\hline Predictor & $\beta$ & $\mathrm{t}$ & $\mathrm{p}$ \\
\hline Absolute Latitude ( $\mathrm{n}=80, \mathrm{R}^{2}=0.24, \mathrm{p}<0.001$ ) & & & \\
\hline Network type (pollination) & 0.122 & 2.70 & 0.009 \\
Absolute latitude & 0.696 & 3.40 & 0.001 \\
Network type (pollination) $\times$ absolute latitude & -0.408 & -1.67 & 0.098 \\
\hline Past Climate Stability $\left(\mathrm{n}=80, \mathrm{R}^{2}=0.19, \mathrm{p}=0.003\right.$ ) & & \\
\hline Network type (pollination) & 0.160 & 3.09 & 0.003 \\
Glaciated during LGM & 0.072 & 1.95 & 0.055 \\
Climate-change velocity & 0.555 & 2.59 & 0.012 \\
Network type (pollination) $\times$ climate-change & -0.564 & -2.36 & 0.021 \\
velocity & & & \\
\hline Contemporary Climate $\left(\mathrm{n}=80, \mathrm{R}^{2}=0.27, \mathrm{p}<0.001\right)$ & & \\
\hline Network type (pollination) & 0.464 & 1.93 & 0.057 \\
Growing degree days & -0.456 & -4.54 & $<0.001$ \\
\hline Regional Plant Diversity $\left(\mathrm{n}=78, \mathrm{R}^{2}=0.13, \mathrm{p}=0.004\right)$ & & \\
\hline Network type (pollination) & 0.065 & 2.50 & 0.015 \\
Regional plant diversity & -0.250 & -2.13 & 0.036 \\
\hline
\end{tabular}

$\begin{array}{lll}-0.250 & -2.13 & 0.036\end{array}$

Local Plant Diversity $\left(n=232, R^{2}\right.$ and $p$ values not applicable for mixed effects models)

\begin{tabular}{lrrr}
\hline Network type (pollination) & 0.058 & 1.96 & 0.052 \\
\hline
\end{tabular}

Models correspond to relationships in Figures 1C, 2, and 3. See Figure S4 for spatial autocorrelation in model residuals and Table $\mathrm{S} 3$ for independence of $\Delta H_{2}{ }^{\prime}$ from sampling effort and network size. For analyses of latitude, past climate stability, contemporary climate, and regional plant diversity, least squares of linear models were weighted according to the sampling intensity within a region. For analysis of local plant diversity, we accounted for the spatial structure in the data by fitting mixed-effects models with region as random effect. For analyses of latitude, contemporary climate, and regional and local plant diversity, we compared five models (including main and interaction effects of the respective predictor variable and network type), and for analysis of past climate stability, we compared nine models (including main and interaction effects of climate-change velocity and network type plus the additional covariate glaciated during last glacial maximum [LGM]). Minimal adequate models were those with the lowest Akaike information criterion, corrected for small sample size, AICc.

specialization among communities differing in species richness [16]. This approach aims at integrating specialization across individual species to the community level, providing information about functional complementarity and redundancy among species [17]. The specialization metric gives more weight to frequently observed rather than rarely observed species and is weighted by interaction frequencies [16]. This mitigates potential biases in estimates of specialization by giving low weights to accidental observations of consumers on plants with which they are rarely associated.

We found that specialization of both pollination and seed dispersal networks decreased significantly toward tropical latitudes (Figure 1C; Table 1). The same pattern was found in a categorical approach: specialization of both network types was significantly lower in the tropics than in temperate regions (Figures 1D and 1E); this pattern was also found when we restricted the analysis to the New World $\left(F_{1,44}=\right.$ 4.2, $\mathrm{p}=0.047)$ or the Old World $\left(\mathrm{F}_{1,29}=11.0, \mathrm{p}=0.002\right)$. We emphasize that alternative indices of biotic specialization (i.e., connectance, unweighted and weighted generality), as well as guild-specific analyses for plants and animals, showed corresponding latitudinal trends, all confirming a lower degree of specialization in the tropics (Figure S1). This finding contradicts the long-standing assumption that biotic interactions are more specialized in species-rich tropical communities [1-7], which appears to be reversed for mutualistic interactions involving mobile pollinators and seed dispersers.

\section{Effects of Climate and Plant Diversity}

In order to identify climatic factors that may determine the latitudinal specialization gradient, we tested for effects of past climate stability (i.e., climate-change velocity [18]) and contemporary climate on network specialization. To describe the latitudinal gradient in contemporary climate, we focused on cumulative annual temperature [19], which was closely associated with potential and actual evapotranspiration (Figure S2). Both past climate stability and contemporary climate have been postulated to influence biotic specialization $[3,5]$. Past climate stability reflects the temporal stability of local communities and the available time for coevolution [20]. Effects of contemporary climate on network specialization might be mediated by an increase in plant diversity in warm climates [21] because high plant diversity reduces relative abundances and densities of resource species. Consistent with optimal foraging theory, reduced densities of resource plants lead to longer search times [22] and constrain the specialization of consumer species [23].

Specialization of seed dispersal networks increased with increasing climate-change velocity (Figure 2A), suggesting that coevolutionary processes have led to more generalized seed dispersal systems in regions with stable climates. This is in line with recent ideas that diffuse coevolutionary processes in mutualistic networks favor trait convergence [24]. On the other hand, specialization of pollination networks was unaffected by climate-change velocity (Figure 2A), possibly due to multiple trade-offs between the benefits of low and high degrees of specialization for the fitness of plants and pollinators that preclude general specialization trends over evolutionary timescales [25]. In contrast, increasing specialization with increasing past climate stability has been shown for plant-hummingbird networks [5]. Reasons for these divergent findings may include strong direct competition between hummingbirds [26] and tight coadaptations between hummingbirds and their food plants [27], leading to increased network specialization where species composition is relatively stable. Effects of past climate fluctuations on hummingbird range-size dynamics may have caused the breakup of coadapting plant-hummingbird species pairs in areas with low past climate stability $[5,20]$. Other types of pollinators may be more flexibly linked to their resource plants [28], resulting in weak effects of community stability on network specialization.

Specialization of both pollination and seed dispersal networks consistently decreased with increasing cumulative annual temperature (Figure 2B; Table 1). The effect of contemporary climate on network specialization was much stronger than that of past climate stability (cf. $R^{2}$ values in Table 1 and Akaike weights from multipredictor models in Table S2), showing that current conditions, rather than historical processes, have influenced associations among consumer and resource species in mutualistic networks. Consistent with the effect of contemporary climate, network specialization also decreased with increasing plant diversity both regionally and locally (Figures $3 \mathrm{~A}$ and 3B; Table 1). Differences in plant diversity and associated changes in relative resource abundances provide a generic explanation for decreasing network specialization with decreasing latitude because both regional 

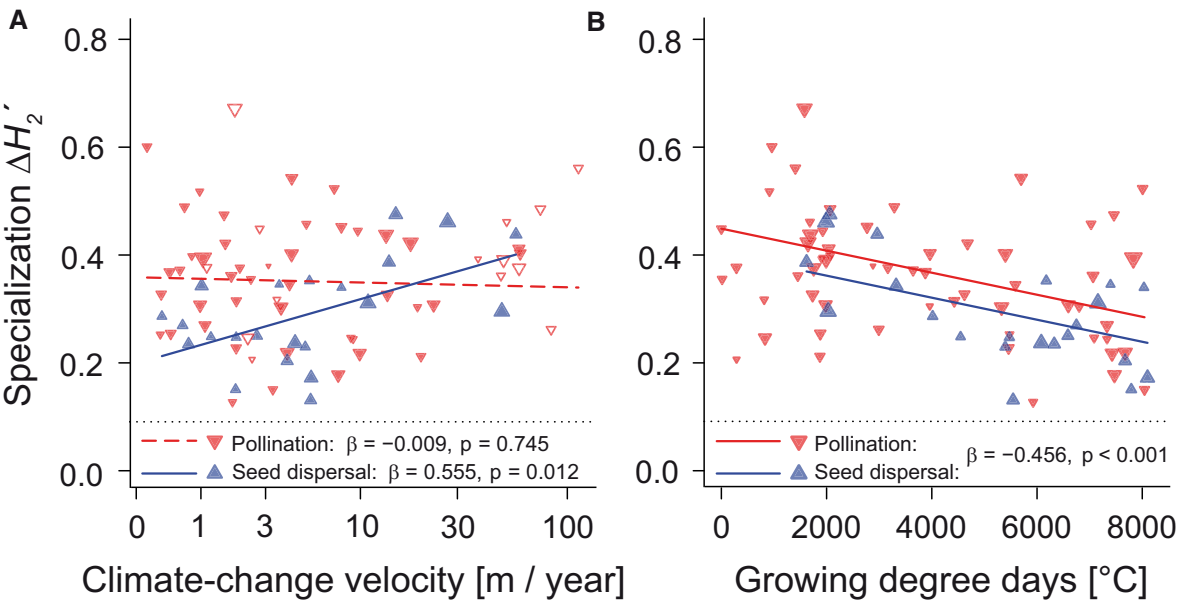

Figure 2. Effects of Past Climate Stability and Contemporary Climate on Specialization of Pollination and Seed Dispersal Networks

(A) Relationship between network specialization $\Delta H_{2}^{\prime}$ and climate-change velocity (m/year; log scale), i.e., climate stability from the LGM to contemporary climate. Open triangles indicate glaciated regions during the LGM.

(B) Relationship between network specialization $\Delta \mathrm{H}_{2}{ }^{\prime}$ and growing degree days ( ${ }^{\circ} \mathrm{C}$ ), i.e., current cumulative annual temperature.

See Figure S2 for correlations between cumulative annual temperature and other climatic predictor variables and Table S2 for multiple predictor models including past climate stability and contemporary climate.

and local plant species richness decreased with latitude (Figure S3). The latitudinal gradient in the diversity of animal-pollinated flowers and animal-dispersed fruits is even stronger than the overall plant diversity gradient [29]. Previous studies have shown that increasing plant diversity in the tropics is also associated with both a wider range of resource traits $[4,30]$ and a larger number of distinct pollination systems [11]. In response to high functional resource diversity, generalist consumer species may evolve traits $[28,30]$ that enable them to use resources from a wide trait spectrum [24], whereas consumer species associated with a specific pollination or seed dispersal syndrome may utilize various plant species within that syndrome $[28,30]$. Consistent with previous work at the local scale [23], our findings suggest that high resource diversity may represent a key driver of generalization of consumer species in mutualistic networks.

\section{Influence of Guild Structure and Network Sampling}

Latitudinal trends in guild structure could also influence latitudinal differences in specialization. Whereas most tropical seed dispersers feed on fruits throughout the year, most seed dispersers in temperate systems switch diet between fruits and invertebrates [31]. Frugivore species appear to be more generalized than omnivores in seed dispersal networks [32]. In our data set, frugivores were more numerous in tropical than in temperate systems (ANOVA: $F_{1,20}=7.0, p=0.015$ ), and network specialization was negatively associated with their proportion in the network (Pearson correlation: $r=-0.60$, $p=0.003)$. Pollinator communities also differed between tropical and temperate latitudes: the proportion of long-lived pollinator species (vertebrate pollinators and social insects with perennial colonies, such as honeybees, stingless bees, and ants) was higher in tropical than in temperate systems (ANOVA: $F_{1,51}=79.7, p<0.001$ ). Long-lived species might use more different resources during their life span than shortlived species. The latitudinal difference in longevity, however, could not be assigned unequivocally to network specialization (Pearson correlation: $r=-0.26, p=0.056$ ). Differences in guild structure among tropical and temperate consumer communities may supplement effects of climate and plant diversity on network specialization, and future studies should aim at separating the relative role of changes in consumer communities from that of climate and plant diversity.

Despite the fact that we compiled the most comprehensive global database of quantitative mutualistic networks thus far, we are aware that the data set is heterogeneous, combining interaction data from different studies. We assessed the sensitivity of our results to potentially confounding latitudinal differences in network sampling. Specifically, we tested the effects of time span of observation (number of observation days), habitat type (forest versus nonforest habitats), and taxonomic completeness of sampling (entire species community versus single plant and/or animal family) together with the effects of past climate stability and contemporary climate on network specialization. This multipredictor analysis supported our conclusion that contemporary climate was the best predictor to explain the latitudinal specialization gradient (Table S2).

\section{Conclusions}

We found that specialization of pollination and seed dispersa networks decreases toward tropical latitudes. This finding calls for a careful rethinking of the role of specialized biotic interactions as a cause of high tropical diversity. Furthermore, we showed that past climate stability is related to specialization only in seed dispersal networks, whereas specialization in both pollination and seed dispersal networks is associated with contemporary climate and plant diversity. We propose that the latitudinal specialization gradient is to a large extent mediated by the latitudinal gradient in plant diversity because high resource diversity requires consumer species to generalize their diet. 

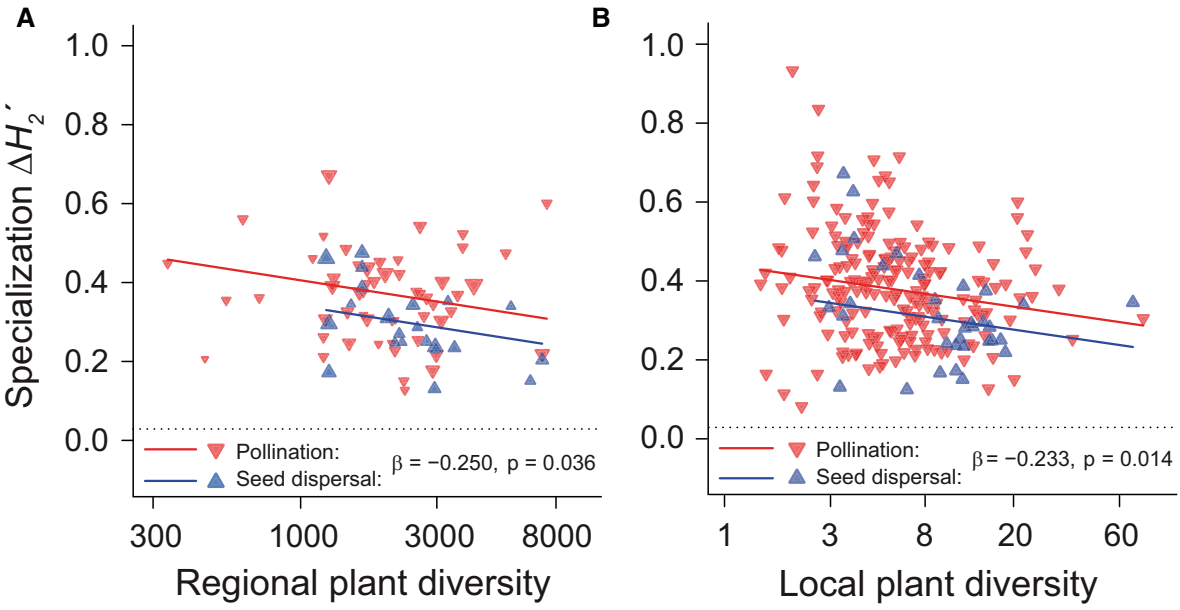

Figure 3. Effects of Regional and Local Plant Diversity on Specialization of Pollination and Seed Dispersal Networks

(A) Relationship between network specialization $\Delta H_{2}{ }^{\prime}$ and regional plant diversity, i.e., the number of vascular plant species (log scale) in equal-area grids of $\approx 12,100 \mathrm{~km}^{2}$.

(B) Relationship between network specialization $\Delta \boldsymbol{H}_{2}{ }^{\prime}$ and local plant diversity, i.e., the effective number of plant species (log scale) in each network (e to the power of Shannon diversity of plant species interaction frequencies)

Regional diversity of vascular plant species and average local plant diversity were not correlated $(n=78, r=0.077, p=0.505)$. Regional plant diversity could not be derived for small islands $\left(<2,000 \mathrm{~km}^{2}\right.$, i.e., Seychelles and Mauritius were excluded from this part of the analysis) and was set to the species pool of the entire Canadian Arctic Archipelago (340 species) for the northernmost point (Ellesmere Island). See Figure S3 for negative latitudinal trends in regional and local plant diversity.

Our findings also have important implications for the robustness of pollination and seed dispersal functions to disturbance in tropical and temperate ecosystems. Low specialization of tropical plant-animal communities is likely to increase their functional redundancy and resistance against secondary extinctions [33], whereas high diversity and functional complementarity of consumer species may be crucial for maintaining ecosystem functions in the more specialized temperate communities [17].

\section{Experimental Procedures}

Network Metrics

For each of the $\mathbf{2 8 2}$ networks, interactions among animal and plant species were summarized in a bipartite interaction matrix between $I$ animal species in rows and $J$ plant species in columns (data collection is described in the Supplemental Experimental Procedures). Species represent the nodes of the network, and interaction strength per link is given by the number of interaction events between an animal and a plant species. All network analyses were performed with the software $R$ [34] and the bipartite 1.17 package [35]. To quantify specialization for a weighted network, we first calculated interaction diversity (Shannon entropy) $H_{2}$ across all $I$ animal and $J$ plant species [36]. In order to disentangle different degrees of specialization from differences in species frequencies, a standardized network specialization metric has been proposed, in which the actual $H_{2}$ value is compared with the range $\left(H_{2 \min }\right.$ to $\left.H_{2 \max }\right)$ of possible $H_{2}$ from any distribution of interaction events with the same number of events per species [36]. $H_{2}^{\prime}$ ranges from 0.0 for the most generalized (i.e., maximum niche overlap) to 1.0 for the most specialized network (i.e., maximum niche divergence). In poorly sampled networks, higher values of $H_{2}^{\prime}$ can be reached by chance as expected values of nonselective foraging deviate more strongly from 0 and may get closer to 1 [36]. Because we aimed at comparing the most unbiased estimates of network specialization, we used a modified specialization index $\Delta H_{2}{ }^{\prime}=H_{2}{ }^{\prime}-H_{2 r a n}$, where $H_{2 r a n}$ represents the mean $\mathrm{H}_{2}{ }^{\prime}$ from 1,000 randomized networks. Randomizations were performed with the Patefield algorithm, which randomly redistributes interaction events among all cells of the network while constraining total interaction strength per species. $\Delta H_{2}{ }^{\prime}$ differs only slightly from $H_{2}{ }^{\prime}$, and the latitudinal trends in both metrics were qualitatively identical (compare Figures $1 \mathrm{C}$ and $\mathrm{S} 1 \mathrm{~A})$.

We also examined latitudinal trends in biotic specialization with other specialization indices. We calculated two alternative indices for binary networks: connectance, i.e., the realized proportion of possible links, and unweighted generality, i.e., the average number of links (species degree) per consumer species. We also determined weighted generality, i.e., the average effective number of links per consumer species, accounting for interaction strength [35]. Furthermore, we tested specialization trends separately for plants and animals by calculating weighted and unweighted means of species-level specialization $d^{\prime}$ [36]. Because network asymmetry, i.e., the balance between plant and animal diversity in a network, strongly affects guild-level specialization [16], we accounted for differences in network asymmetry, i.e., we included network asymmetry as a covariate in guild-level analyses. In the main manuscript, we focus on $\Delta \boldsymbol{H}_{2}^{\prime}$ because it integrates specialization across the entire community [16] and was the only metric that was affected by neither the number of interaction events nor the number of species in the network (Table S3).

\section{Predictor Variables}

For each network location, we obtained climate-change velocity since the last glacial maximum (LGM, 21,000 years ago) as an estimate of past climate stability [18]. The measure describes the rate at which temperature conditions have moved over the Earth's surface since the LGM (here in $\mathrm{m} / \mathrm{year}$ ), based on 2.5 min resolution maps of contemporary climate [37] and paleoclimate projections (CCSM3 model in [38]). The spatial pattern of climatechange velocity since the LGM is representative of the last several hundred thousand years [39]. We also identified locations that were glaciated at the LGM with maps of glacial extent [40]. We additionally obtained information on contemporary climate (monthly temperatures, annual precipitation) for each network location at a $2.5 \mathrm{~min}$ resolution [37]. We calculated estimates of the cumulative annual temperature above $5^{\circ} \mathrm{C}$ (i.e., growing degree days) as a measure of available thermal energy during the growing season [19]. The regional plant diversity for each network location was derived from spatial interpolation of global plant richness data at a spatial resolution of $\approx 12,100 \mathrm{~km}^{2}$ [21]. The local plant diversity was derived from each network as the Shannon index of the plant species marginal totals. This takes into account the number of observed plant species in a network 
and the evenness of their abundance distribution. Local plant diversity was averaged over networks from the same location ( $n=232$ locations).

Statistical Analyses

Each of the 282 networks was assigned to a sampling region $(n=80$ regions). Regions were defined by the original studies that focused on a particular habitat type in a given area (see Supplemental Experimental Procedures). Region-level analyses were conservative because they prevented pseudoreplication of networks with almost identical climatic conditions and overrepresentation of regions with many replicate networks.

At the global scale, we related network specialization $\Delta H_{2}^{\prime}$ to absolute latitude, past climate stability, contemporary climate, and regional plant diversity in linear models. We used the sampling region as the unit of replication and calculated mean $\Delta H_{2}^{\prime}$ of all networks within a region. At the local scale, we tested the effect of local plant diversity on $\Delta \boldsymbol{H}_{2}{ }^{\prime}$ with a randomintercept model with sampling region as random factor. For each predictor, we fitted reduced and full models (including main effects and interaction effects with network type) and identified the minimal adequate model according to the lowest Akaike information criterion, corrected for small sample size, AICc (Table 1).

In analyses at the global scale, we accounted for differences in sampling intensities among regions with least squares weighted by sampling intensity,

$$
\begin{gathered}
\text { Intensity }_{\text {web }}=\frac{\sqrt{N_{i}}}{\sqrt{\text { size }_{i}}} ; \\
\text { Intensity }_{\text {region }}=\log _{10}\left(\text { Intensity }_{\text {web_mean }} \times \sqrt{n}+1\right),
\end{gathered}
$$

where $N_{i}$ is the number of interactions in network $i$ and size is the product of the number of plant species and the number of animal species in network $i$. Intensity $_{\text {web }}$ reflects the number of interactions observed per species.

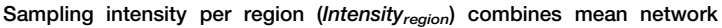
sampling intensity in a region (Intensity web mean) with the number of networks sampled per region $(n)$. Analyses of the relationship between $\Delta H_{2}^{\prime}$ and latitude with each network as a replicate $(\beta=0.262, p<0.001)$ and with unweighted least squares at the regional scale $(\beta=0.326$, $p=0.003$ ) resulted in the same latitudinal trend as the weighted regional analysis. We visually examined spatial dependences (Moran's $n$ in the residuals of all minimal adequate models. Spatial autocorrelation was negligibly small in all cases (Figure S4)

\section{Supplemental Information}

Supplemental Information includes four figures, three tables, and Supplemental Experimental Procedures and can be found with this article online at http://dx.doi.org/10.1016/j.cub.2012.08.015.

\section{Acknowledgments}

We thank M. Templin, E.L. Neuschulz, and E.-M. Gerstner for support with data compilation and figure design. J. Ollerton and anonymous reviewers provided valuable comments on an earlier manuscript version. Funding information and author contributions are provided in the Supplemental Information.

Received: June 1, 2012

Revised: July 24, 2012

Accepted: August 6, 2012

Published online: September 13, 2012

\section{References}

1. Jocque, M., Field, R., Brendonck, L., and De Meester, L. (2010). Climatic control of dispersal-ecological specialization trade-offs: a metacommunity process at the heart of the latitudinal diversity gradient? Glob. Ecol. Biogeogr. 19, 244-252.

2. MacArthur, R.H. (1972). Geographical Ecology: Patterns in the Distribution of Species (New York: Harper \& Row).

3. Schemske, D.W. (2009). Biotic interactions and speciation in the tropics. In Speciation and Patterns of Diversity, R. Butlin, J. Bridle, and D. Schluter, eds. (Cambridge: Cambridge University Press), pp. 219-239.
4. Armbruster, W.S. (2006). Evolutionary and ecological aspects of specialized pollination: Views from the arctics to the tropics. In PlantPollinator Interactions: From Specialization to Generalization, N.M. Waser and J. Ollerton, eds. (Chicago: University of Chicago Press), pp. 260-282.

5. Dalsgaard, B., Magård, E., Fjeldså, J., Martín González, A.M., Rahbek, C., Olesen, J.M., Ollerton, J., Alarcón, R., Cardoso Araujo, A., Cotton, P.A., et al. (2011). Specialization in plant-hummingbird networks is associated with species richness, contemporary precipitation and quaternary climate-change velocity. PLoS ONE 6, e25891.

6. Dyer, L.A., Singer, M.S., Lill, J.T., Stireman, J.O., Gentry, G.L., Marquis, R.J., Ricklefs, R.E., Greeney, H.F., Wagner, D.L., Morais, H.C., et al. (2007). Host specificity of Lepidoptera in tropical and temperate forests. Nature 448, 696-699.

7. Olesen, J.M., and Jordano, P. (2002). Geographic patterns in plant-pollinator mutualistic networks. Ecology 83, 2416-2424.

8. Ollerton, J., and Cranmer, L. (2002). Latitudinal trends in plant-pollinato interactions: are tropical plants more specialised? Oikos 98, 340-350.

9. Vázquez, D.P., and Stevens, R.D. (2004). The latitudinal gradient in niche breadth: concepts and evidence. Am. Nat. 164, E1-E19.

10. Novotny, V., Drozd, P., Miller, S.E., Kulfan, M., Janda, M., Basset, Y., and Weiblen, G.D. (2006). Why are there so many species of herbivorous insects in tropical rainforests? Science 313, 1115-1118.

11. Ollerton, J., Johnson, S.D., and Hingston, A.B. (2006). Geographica variation in diversity and specificity of pollination systems. In PlantPollinator Interactions: From Specialization to Generalization, N.M. Waser and J. Ollerton, eds. (Chicago: University of Chicago Press), pp. 283-308.

12. Vázquez, D.P., Morris, W.F., and Jordano, P. (2005). Interaction frequency as a surrogate for the total effect of animal mutualists on plants. Ecol. Lett. 8, 1088-1094.

13. Watts, S., Huamán Ovalle, D., Moreno Herrera, M., and Ollerton, J. (2012). Pollinator effectiveness of native and non-native flower visitors to an apparently generalist Andean shrub, Duranta mandoni (Verbenaceae). Plant Species Biol. 27, 147-158.

14. Devictor, V., Clavel, J., Julliard, R., Lavergne, S., Mouillot, D., Thuiller, W., Venail, P., Villéger, S., and Mouquet, N. (2010). Defining and measuring ecological specialization. J. Appl. Ecol. 47, 15-25.

15. Blüthgen, N., Fründ, J., Vázquez, D.P., and Menzel, F. (2008). What do interaction network metrics tell us about specialization and biological traits? Ecology 89, 3387-3399.

16. Blüthgen, N., Menzel, F., Hovestadt, T., Fiala, B., and Blüthgen, N. (2007). Specialization, constraints, and conflicting interests in mutualistic networks. Curr. Biol. 17, 341-346.

17. Blüthgen, N., and Klein, A.M. (2011). Functional complementarity and specialisation: the role of biodiversity in plant-pollinator interactions. Basic Appl. Ecol. 12, 282-291.

18. Sandel, B., Arge, L., Dalsgaard, B., Davies, R.G., Gaston, K.J., Sutherland, W.J., and Svenning, J.-C. (2011). The influence of Late Quaternary climate-change velocity on species endemism. Science 334, 660-664.

19. Woodward, F.I. (1987). Climate and Plant Distribution (Cambridge: Cambridge University Press)

20. Jansson, R., and Dynesius, M. (2002). The fate of clades in a world of recurrent climatic change: Milankovitch oscillations and evolution. Annu. Rev. Ecol. Syst. 33, 741-777.

21. Kreft, H., and Jetz, W. (2007). Global patterns and determinants of vascular plant diversity. Proc. Natl. Acad. Sci. USA 104, 5925-5930.

22. MacArthur, R.H., and Pianka, E.R. (1966). On optimal use of a patchy environment. Am. Nat. 100, 603-609.

23. Albrecht, M., Riesen, M., and Schmid, B. (2010). Plant-pollinator network assembly along the chronosequence of a glacier foreland. Oikos 119, 1610-1624.

24. Guimarães, P.R., Jr., Jordano, P., and Thompson, J.N. (2011). Evolution and coevolution in mutualistic networks. Ecol. Lett. 14, 877-885.

25. Johnson, S.D., and Steiner, K.E. (2000). Generalization versus specialization in plant pollination systems. Trends Ecol. Evol. 15, 140-143.

26. Graham, C.H., Parra, J.L., Rahbek, C., and McGuire, J.A. (2009) Phylogenetic structure in tropical hummingbird communities. Proc. Natl. Acad. Sci. USA 106 (Suppl 2), 19673-19678.

27. Temeles, E.J., and Kress, W.J. (2003). Adaptation in a plant-hummingbird association. Science 300, 630-633. 
28. Waser, N.M., Chittka, L., Price, M.V., Williams, N.M., and Ollerton, J. (1996). Generalization in pollination systems, and why it matters. Ecology 77, 1043-1060.

29. Schemske, D.W., Mittelbach, G.G., Cornell, H.V., Sobel, J.M., and Roy, K. (2009). Is there a latitudinal gradient in the importance of biotic interactions? Annu. Rev. Ecol. Syst. 40, 245-269.

30. Wheelwright, N.T. (1988). Fruit-eating birds and bird-dispersed plants in the tropics and temperate zone. Trends Ecol. Evol. 3, 270-274.

31. Kissling, W.D., Böhning-Gaese, K., and Jetz, W. (2009). The global distribution of frugivory in birds. Glob. Ecol. Biogeogr. 18, 150-162.

32. Schleuning, M., Blüthgen, N., Flörchinger, M., Braun, J., Schaefer, H.M., and Böhning-Gaese, K. (2011). Specialization and interaction strength in a tropical plant-frugivore network differ among forest strata. Ecology 92, 26-36.

33. Jordano, P., Bascompte, J., and Olesen, J.M. (2006). The ecological consequences of complex topology and nested structure in pollination webs. In Plant-Pollinator Interactions: From Specialization to Generalization, N.M. Waser and J. Ollerton, eds. (Chicago: University of Chicago Press), pp. 173-199.

34. R Development Core Team (2010). R: A language and environment for statistical computing. R Foundation for Statistical Computing, Vienna. http://www.r-project.org.

35. Dormann, C.F., Fründ, J., Blüthgen, N., and Gruber, B. (2009). Indices, graphs and null models: analysing bipartite ecological networks. Open Ecol. J. 2, 7-24.

36. Blüthgen, N., Menzel, F., and Blüthgen, N. (2006). Measuring specialization in species interaction networks. BMC Ecol. 6, 9.

37. Hijmans, R.J., Cameron, S.E., Parra, J.L., Jones, P.G., and Jarvis, A. (2005). Very high resolution interpolated climate surfaces for global land areas. Int. J. Climatol. 25, 1965-1978.

38. Braconnot, P., Otto-Bliesner, B., Harrison, S., Joussaume, S. Peterchmitt, J.-Y., Abe-Ouchi, A., Crucifix, M., Driesschaert, E., Fichefet, T., Hewitt, C.D., et al. (2007). Results of PMIP2 coupled simulations of the Mid-Holocene and Last Glacial Maximum-Part 1 : experiments and large-scale features. Clim. Past 3, 261-277.

39. Siegenthaler, U., Stocker, T.F., Monnin, E., Lüthi, D., Schwander, J. Stauffer, B., Raynaud, D., Barnola, J.-M., Fischer, H., MassonDelmotte, V., and Jouzel, J. (2005). Stable carbon cycle-climate relationship during the Late Pleistocene. Science 310, 1313-1317.

40. Ehlers, J., and Gibbard, P.L. (2004). Quaternary Glaciations-Extent and Chronology, Parts I-III (Developments in Quaternary Science 2) (Amsterdam: Elsevier). 
Current Biology, Volume 22

\section{Supplemental Information}

\section{Specialization of Mutualistic}

\section{Interaction Networks Decreases}

\section{toward Tropical Latitudes}

Matthias Schleuning, Jochen Fründ, Alexandra-Maria Klein, Stefan Abrahamczyk, Ruben Alarcón, Matthias Albrecht, Georg K.S. Andersson, Simone Bazarian, Katrin Böhning-Gaese, Riccardo Bommarco, Bo Dalsgaard, D. Matthias Dehling, Ariella Gotlieb, Melanie Hagen, Thomas Hickler, Andrea Holzschuh, Christopher N. Kaiser-Bunbury, Holger Kreft, Rebecca J. Morris, Brody Sandel, William J. Sutherland, Jens-Christian Svenning, Teja Tscharntke, Stella Watts, Christiane N. Weiner, Michael Werner, Neal M. Williams, Camilla Winqvist, Carsten F. Dormann, and Nico Blüthgen

\section{Supplemental Inventory}

\section{Supplemental Data}

Figure S1, related to Figure 1. Latitudinal specialization trends in standardized and unstandardized network metrics.

Figure S2, related to Figure 2. Relationships between cumulative annual temperature (growing degree days) and other climatic variables.

Figure S3, related to Figure 3. Relationship between plant diversity and latitude in the 80 study regions.

Figure S4, related to Table 1. Spatial autocorrelation in the residuals of minimal adequate linear models.

Table S1, related to Figure 1. Detailed information about location and sampling intensity for each of the 80 sampling regions.

Table S2, related to Figure 2. Minimal adequate linear models of the effects of multiple predictor variables on network specialization $\left(\mathrm{\Delta H}_{2}^{\prime}\right)$ in 80 study regions.

Table S3, related to Table 1. Correlations between different specialization metrics and sampling effort and network size.

\section{Supplemental Experimental Procedures}

Data set description

Author contributions

Extended acknowledgments

\section{Supplemental References}




\section{Supplemental Data}
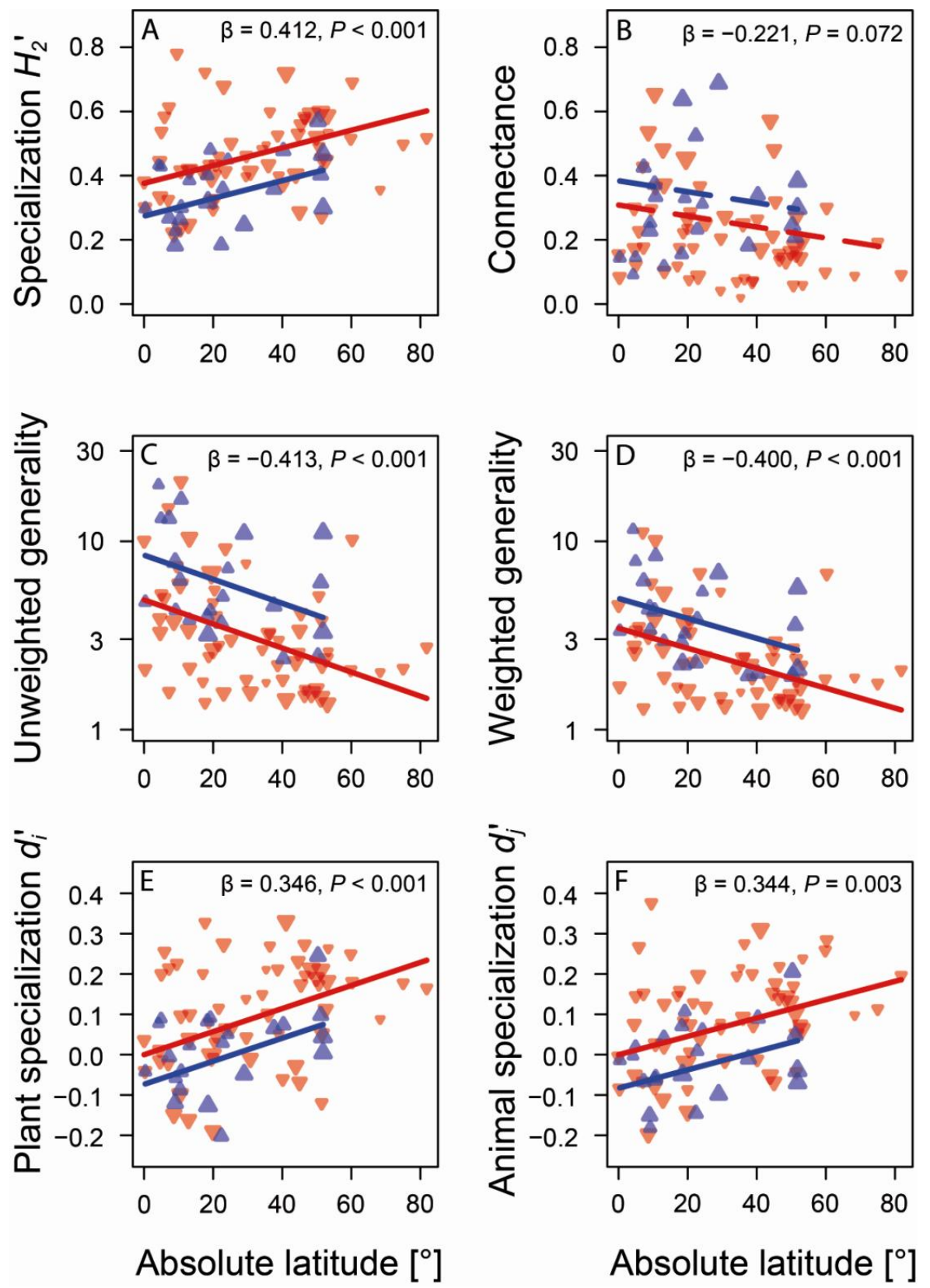

Figure S1. 
Figure S1, Related to Figure 1. Latitudinal Specialization Trends in Standardized and Unstandardized Network Metrics

(A) Network specialization $H_{2}$ ', i.e., standardized Shannon entropy, (B) connectance, i.e., the realized proportion of possible links, (C) unweighted generality, i.e., the average number of links (the number of observed resource plant species) per consumer species, (D) weighted generality, i.e., the average effective number of links per consumer species (accounting for interaction strength), (E) plant specialization $d_{i}^{\prime}$, and (F) animal specialization $d_{j}^{\prime}$. For (E) and (F) partial residuals are shown because regression models were adjusted for the effects of mean web asymmetry on plant and animal specialization in each region; web asymmetry was given as the difference between the effective number of plant and animal species standardized by the sum of the effective number of plant and animal species. Results for (E) and (F) were qualitatively identical for weighted and unweighted means of $d$, shown are weighted means across species. Symbol size corresponds to weights by sampling intensity in each region. We focus on a nullmodel adjusted version of (A) in the main text because it was the only metric that was independent of sampling effort and network size (Table S3). All network metrics showed the same trend: Tropical communities were more generalized than temperate communities. 

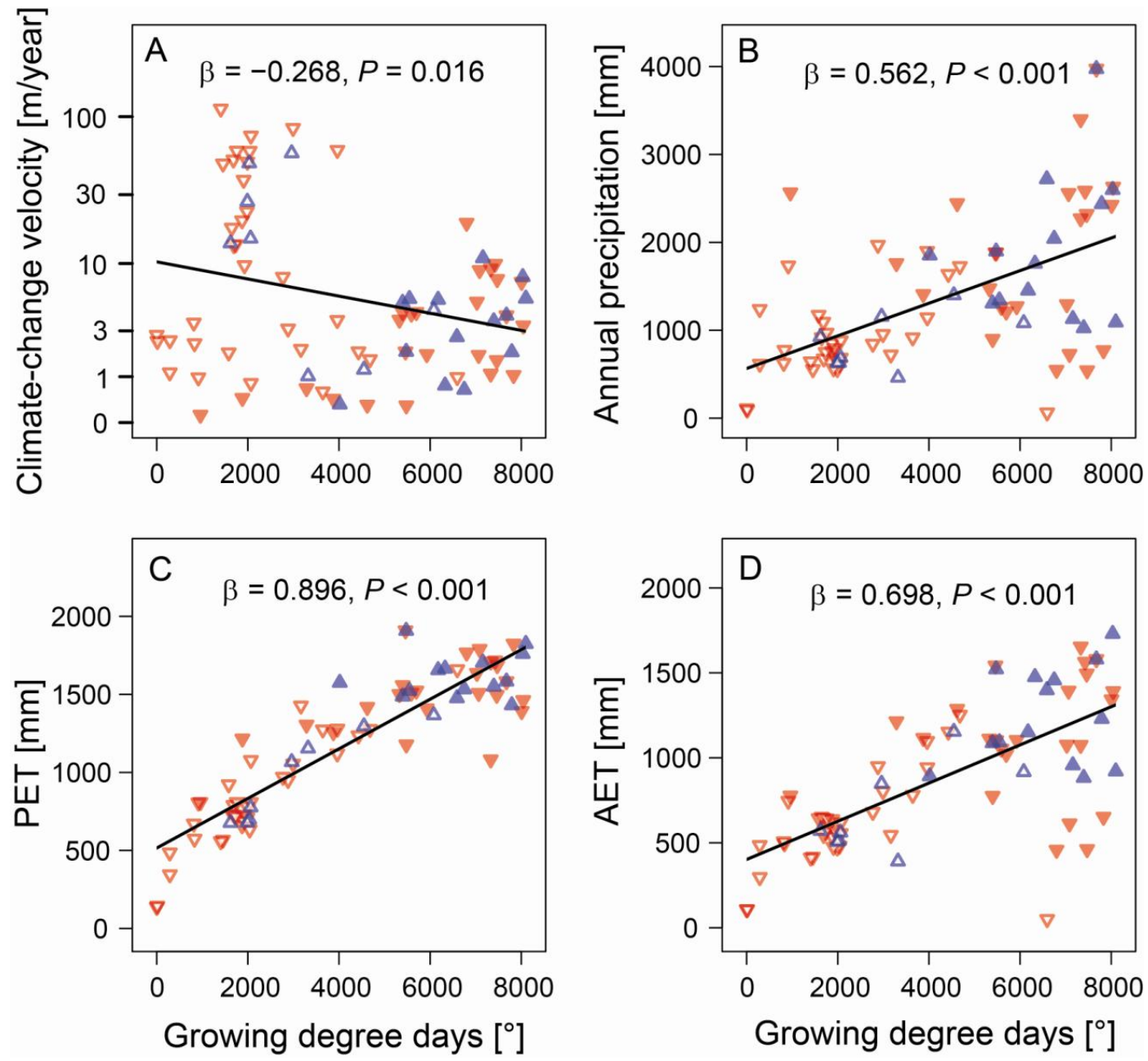

Figure S2, Related to Figure 2. Relationships between Cumulative Annual Temperature (Growing Degree Days) and Other Climatic Variables

(A) Climate-change velocity $(\log 10$-scale), (B) annual precipitation, (C) potential evapotranspiration (PET) and (D) actual evapotranspiration (AET). Red triangles indicate regions with pollination networks, blue triangles regions with seed dispersal networks. Filled triangles indicate tropical regions, open triangles indicate non-tropical regions. Cumulative annual temperature is closely related to gradients in annual precipitation, AET and PET, probably because climates in most study regions were not limited by water availability. Values for potential (PET) and actual evapotranspiration (AET) were taken from a global aridity database (http://www.cgiar-csi.org/data/item/51-global-aridity-and-pet-database). 

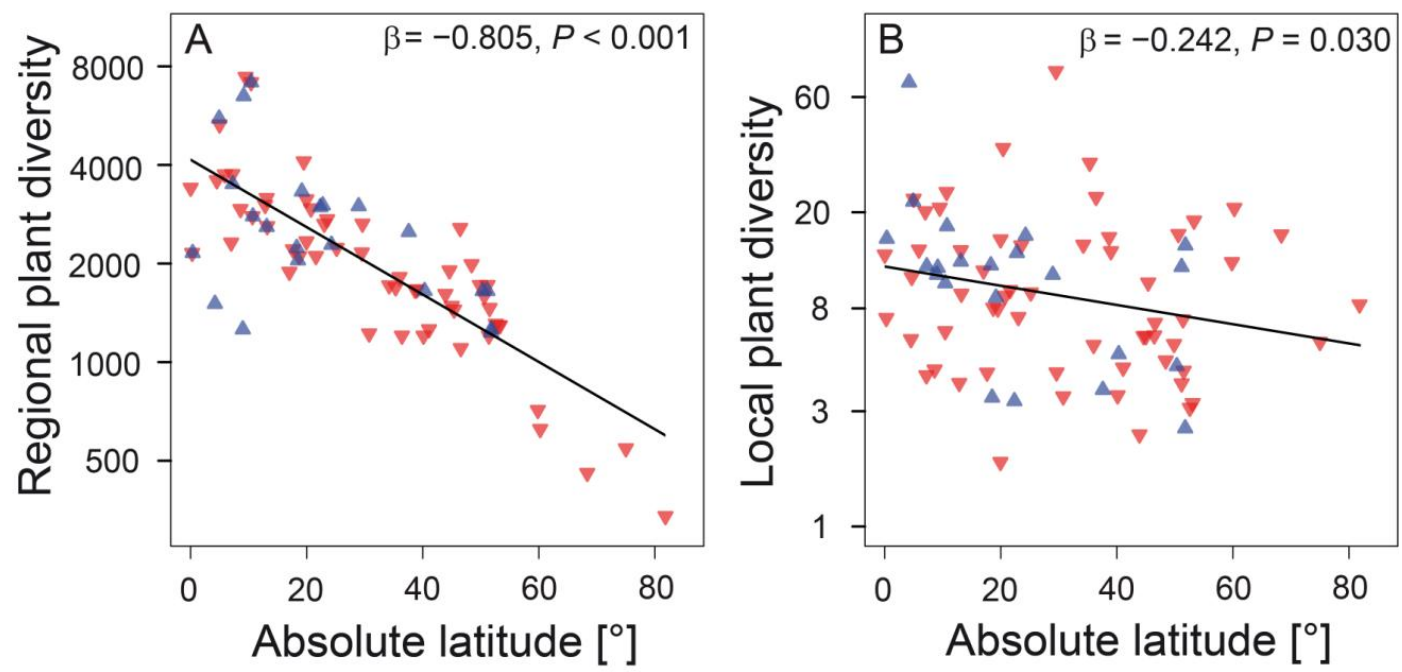

Figure S3, Related to Figure 3. Relationship between Plant Diversity and Latitude in the 80 Study Regions

(A) Regional plant diversity, i.e., the number of vascular plant species $(\log 10$-scale) in equal area grids of $\approx 12,100 \mathrm{~km}^{2}$.

(B) Mean local plant diversity, i.e., the effective number of plant species in each network ( $e$ to the power of Shannon diversity of plant species interaction frequencies), averaged over multiple networks from the same region. Red triangles indicate regions with pollination networks, blue triangles those with seed dispersal networks. Note that the estimates of regional plant species richness are likely to underestimate the latitudinal gradient in the diversity of animal-pollinated and animal-dispersed plants: while the proportions of animal-pollinated and animal-dispersed plants increase in the tropics [29], we relied on overall estimates of vascular plant species richness for this analysis. Regional and average local plant diversity were not correlated $(n=78$, $\mathrm{r}=0.077, \mathrm{p}=0.505)$. 

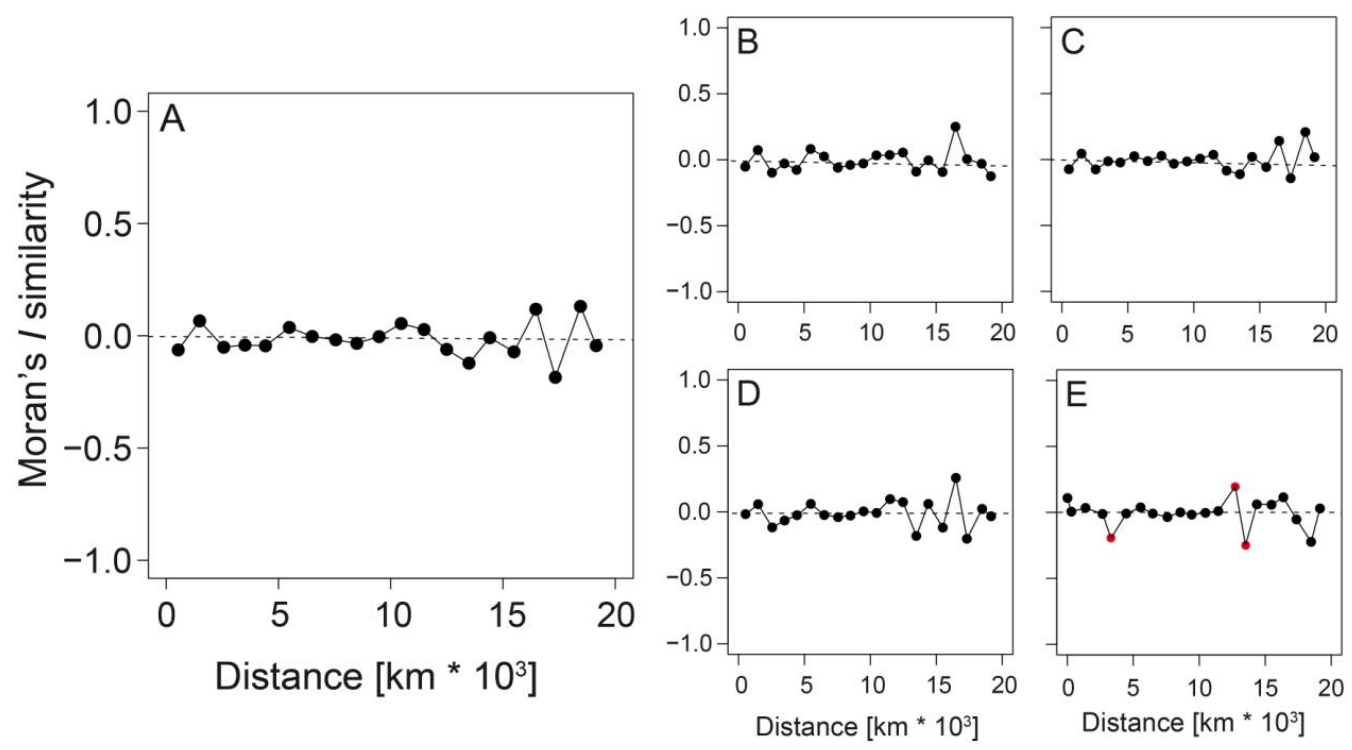

Figure S4, Related to Table 1. Spatial Autocorrelation in the Residuals of Minimal Adequate Linear Models

(A) Absolute latitude, (B) past climate stability, (C) contemporary climate, (D) regional plant diversity, and (E) local plant diversity. Minimal adequate linear models are provided in Table 1. Note that similarity in the residuals of all models did not decrease with increasing distance of discrete distance classes of $500 \mathrm{~km}$, i.e., spatial autocorrelation was negligibly small in all minimal adequate models. Red dots indicate Moran's $I$ similarities significantly different from 0 (two-sided permutation test, $\mathrm{p}<0.025$ ). 
Table S1, Related to Figure 1. Detailed Information about Location and Sampling Intensity for Each of the 80 Sampling Regions

For each sampling region, we provide the name of the data holders, network type (pollination or seed dispersal), latitude and longitude [decimal degrees], country, altitude [m above sea level], glaciation at last glacial maximum $(21,000$ years ago), predominant habitat type (forest or nonforest), completeness of sampling (full species communities or restricted to specific plant and/or animal families), sampling focus (plant or animal) and sampling design (sampling time representative for species abundance or standardized per species). We further provide the number of networks per region and means across all networks from a region for sampling duration [observation days], number of animal and plant species, number of observed interaction events as well as network specialization $\Delta H_{2}{ }^{\prime}$. 


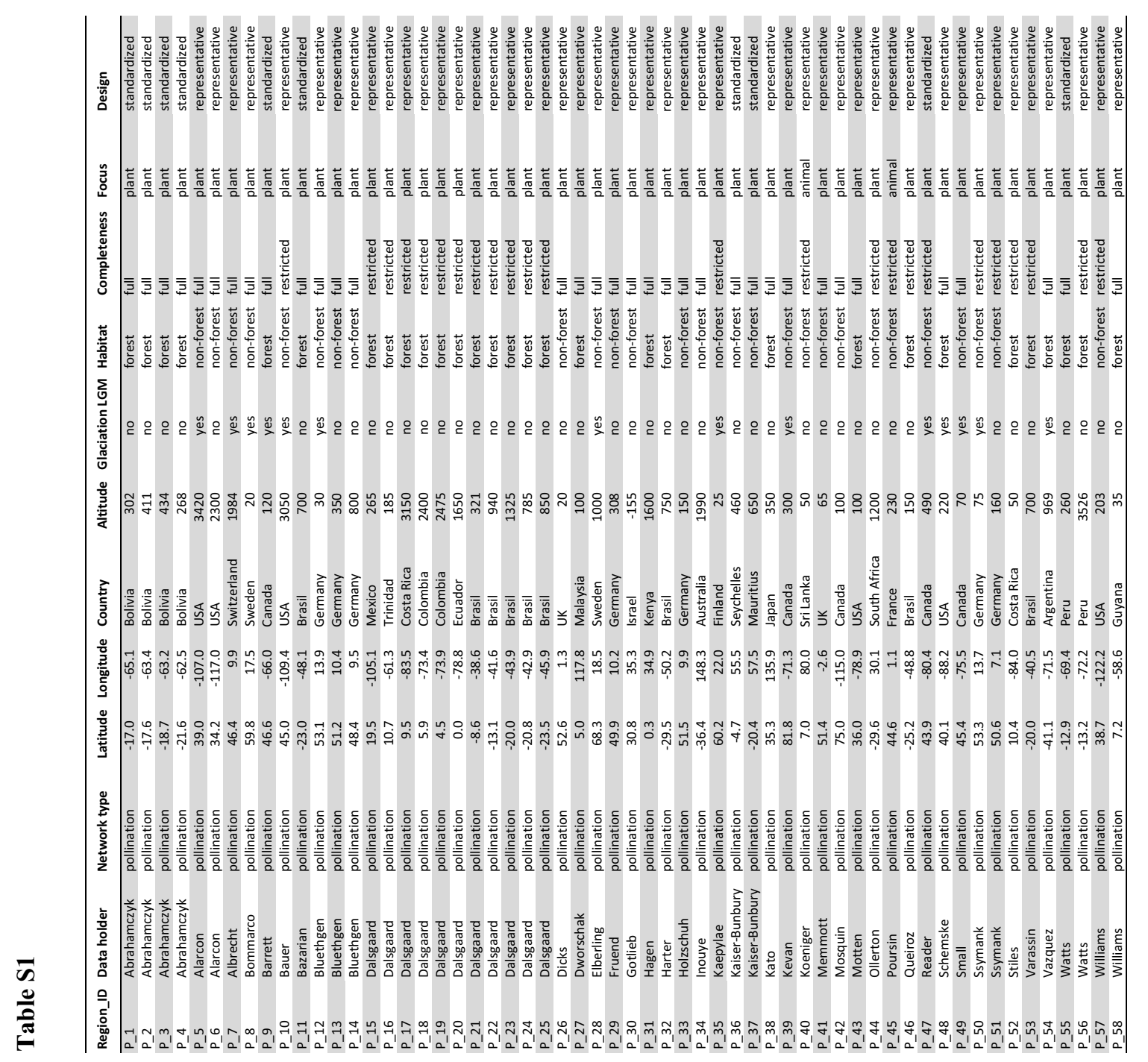




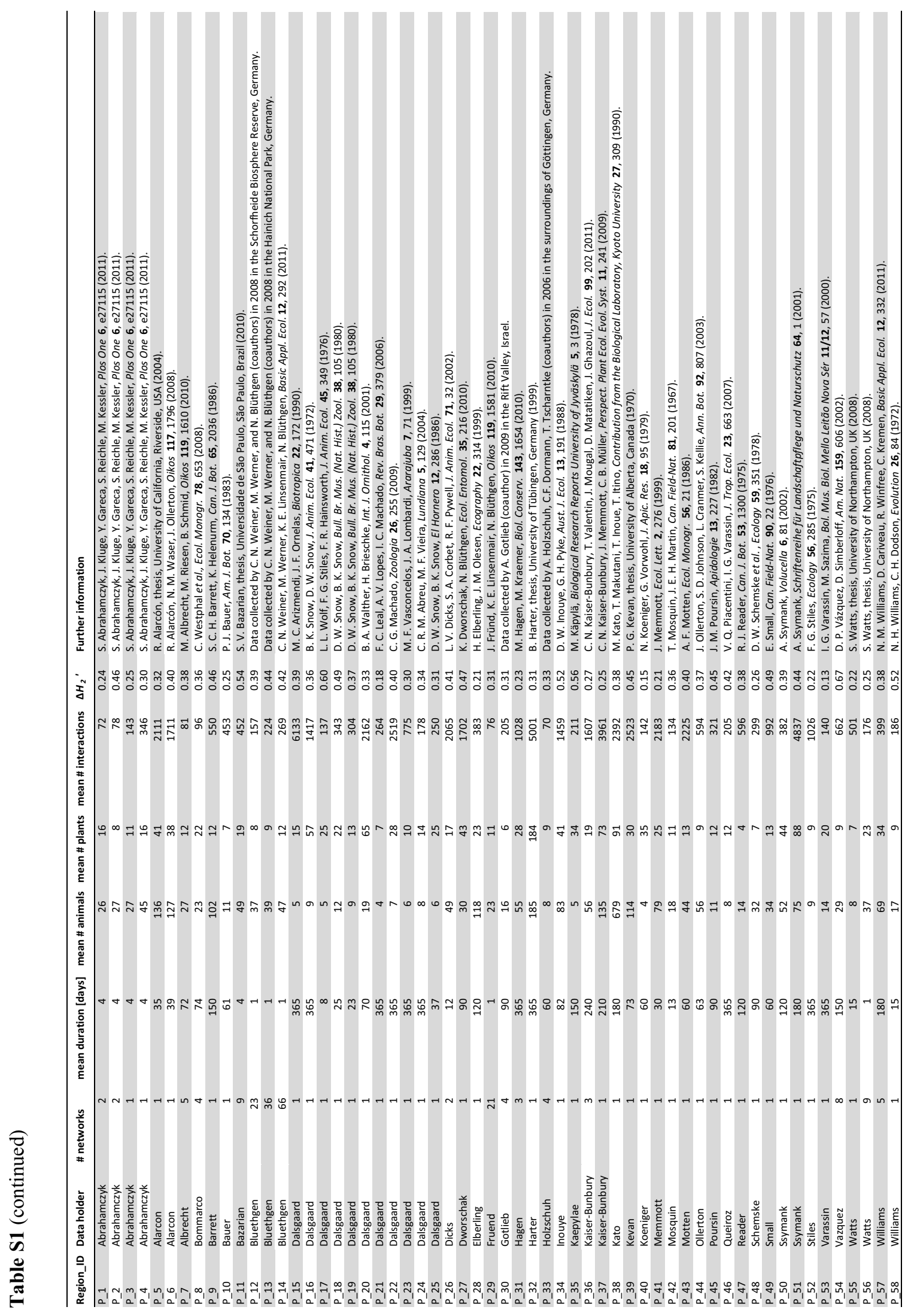




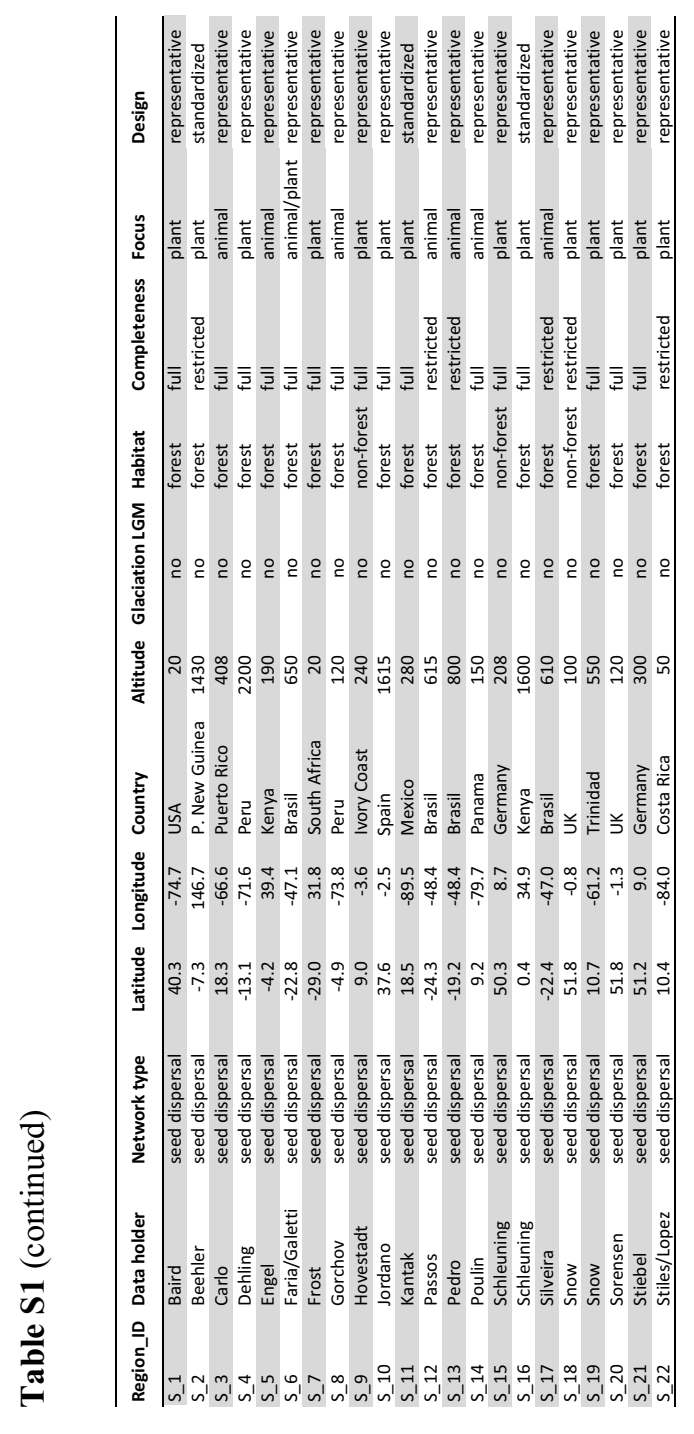




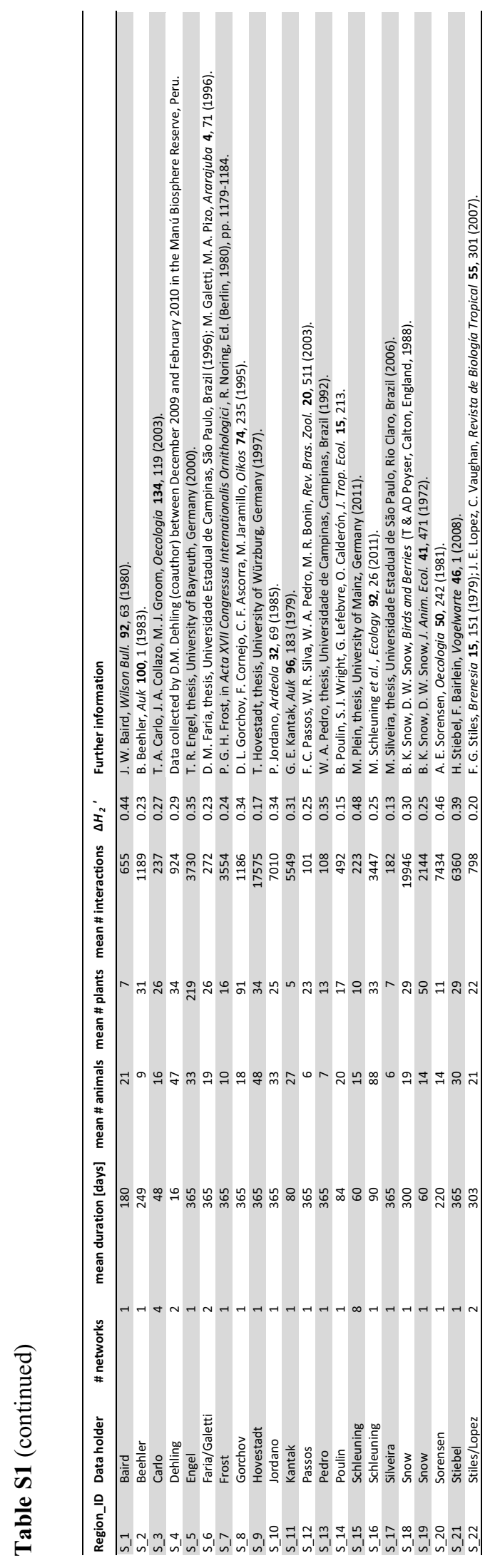


Table S2, Related to Figure 2. Minimal Adequate Linear Models of the Effects of Multiple Predictor Variables on Network Specialization $\left(\mathrm{\Delta H}_{2}{ }^{\prime}\right)$ in 80 Study Regions

(A) All minimal adequate linear models with $\triangle \mathrm{AICc}<2$

\begin{tabular}{lcrr} 
Predictor & $\beta$ & $\mathrm{t}$ & $\mathrm{p}$ \\
\hline Best model, $\mathrm{R}^{2}=0.32, \mathrm{p}<0.001$ & & & \\
Network type (pollination) & 0.058 & 2.46 & 0.016 \\
Growing degree days & -0.594 & -5.29 & $<0.001$ \\
Habitat type (forest) & 0.065 & 2.47 & 0.016 \\
Alternative model, $\Delta \mathrm{AICc}=0.94, \mathrm{R}^{2}=0.34, \mathrm{p}<0.001$ & & & \\
Network type (pollination) & & & \\
Growing degree days & 0.068 & 2.71 & 0.008 \\
Habitat type (forest) & -0.563 & -4.89 & $<0.001$ \\
Taxonomic focus (full) & 0.071 & 2.65 & 0.010
\end{tabular}

Alternative model, $\triangle \mathrm{AICc}=1.62, \mathrm{R}^{2}=0.35, \mathrm{p}<0.001$

$\begin{array}{lccr}\text { Network type (pollination) } & 0.127 & 2.66 & 0.010 \\ \text { Growing degree days } & -0.552 & -4.74 & <0.001 \\ \text { Habitat type (forest) } & 0.067 & 2.50 & 0.015 \\ \text { Climate-change velocity } & 0.331 & 1.69 & 0.096 \\ \text { Network type x Climate-change velocity } & -0.351 & -1.60 & 0.113 \\ \text { Alternative model, } \Delta \text { AICc }=1.63, \mathrm{R}^{2}=0.33, \mathrm{p}<0.001 & & & \\ \text { Network type (pollination) } & 0.052 & 2.09 & 0.040 \\ \text { Growing degree days } & -0.572 & -4.96 & <0.001 \\ \text { Habitat type (forest) } & 0.068 & 2.56 & 0.013 \\ \text { Observation time span } & -0.087 & -0.82 & 0.418\end{array}$


Predictors were past climate stability (glaciation during LGM, climate-change velocity), contemporary climate (growing degree days), and potential confounding factors (time span of observation, habitat type, taxonomic sampling focus); network type (pollination, seed dispersal) was included in all models. Based on the results of univariate models, we included the interaction term between climate-change velocity and network type (pollination, seed dispersal) in all models with climate-change velocity.

(B) Akaike weights for all predictor variables across all 63 model combinations.

\begin{tabular}{ll} 
Predictor variable & Akaike weight \\
\hline Growing degree days & 0.999 \\
Habitat type & 0.898 \\
Taxonomic focus & 0.343 \\
Climate-change velocity & 0.323 \\
Sampling period & 0.308 \\
Glaciated during LGM & 0.245
\end{tabular}

We fitted linear models for all combinations of predictor variables $(n=63$ models) and calculated the Akaike weights for each fitted model. The Akaike weight gives the likelihood that a model is the best available model, and thus the summed Akaike weight for each predictor variable measures the relative importance of each variable in contributing to the best model. Note that none of the potentially confounding variables (habitat type, taxonomic focus, sampling period) significantly affected $\Delta H_{2}{ }^{\prime}$ in univariate models ( $p>0.05$ in all cases). 
Table S3, Related to Table 1. Correlations between Different Specialization Metrics and Sampling Effort and Network Size

\begin{tabular}{|c|c|c|c|c|}
\hline & \multicolumn{2}{|c|}{ (A) Sampling effort } & \multicolumn{2}{|c|}{ (B) Network size } \\
\hline & $\mathrm{r}$ & $\mathrm{p}$ & $\mathrm{r}$ & $\mathrm{p}$ \\
\hline Specialization $\Delta H_{2}^{\prime}$ & -0.015 & 0.898 & 0.075 & 0.507 \\
\hline Specialization $H_{2}{ }^{\prime}$ & -0.361 & 0.001 & 0.093 & 0.413 \\
\hline Connectance & 0.027 & 0.810 & -0.700 & $<0.001$ \\
\hline Unweighted Generality & 0.446 & $<0.001$ & 0.088 & 0.438 \\
\hline Weighted Generality & 0.313 & 0.005 & 0.076 & 0.501 \\
\hline Plant specialization $d_{i}^{\prime}$ & -0.237 & 0.035 & 0.320 & 0.004 \\
\hline Animal specialization $d_{j}^{\prime}$ & -0.268 & 0.017 & 0.167 & 0.138 \\
\hline
\end{tabular}

(A) Sampling effort is estimated by the number of observed interactions events (log10-scale), and (B) network size equals the sum of plant and animal species in a network (log 10 -scale). Pearson correlation coefficients $r$ and $p$-values are given; significant correlations are printed bold. Pearson correlations $\mathrm{r}$ were calculated with region as the unit of replication $(\mathrm{n}=80$ in all cases). $\Delta H_{2}^{\prime}$ is the only index that is neither related to sampling effort nor to network size and was therefore the preferred metric in the main manuscript. 


\section{Supplemental Experimental Procedures}

\section{Data Set Description}

We compiled a dataset of quantitative interaction networks between plants and their animal pollinators or seed dispersers from original sources, accessible databases [41, 42] and co-authors. Each network matrix in the dataset describes the community-wide pattern of interactions among plants and flower visitors (called 'pollination networks') or plants and fruit-eating animals (called 'seed dispersal networks'). Most networks were recorded by observing consumer visits to plant individuals, either in transect walks or in focal plant observations. Studies based on pollen or fecal samples from consumer species were also included but were less numerous (cf. 'sampling focus' in Table S1). Most network studies used representative sampling designs, i.e., distributed observation times per plant species proportional to their abundance, while few studies standardized observation times per species ('sampling design' in Table S1). All network studies provided an estimate of the number of interaction events (interaction strength) between a plant and an animal species, e.g., the number of pollinator or seed-disperser individuals observed feeding on a plant species or the number of individuals of a consumer species carrying pollen or seeds of a particular plant species. Estimates of interaction strength are a meaningful surrogate for the mutualistic importance of a consumer species for a plant species and vice versa because interaction frequencies have a stronger effect on mutualist species than interaction efficiencies per visit $[12,43]$.

We only included networks in our meta-analysis that comprised at least 50 interaction events and more than four plant and four consumer species (i.e., adequately sampled networks), that were limited to a single community, and that were dominated by native plants or animals (threshold: $>80 \%$ of interactions from native species). We excluded 71 networks that did not meet these criteria, and the final dataset comprised 282 quantitative networks. For each of these networks, we recorded the location of sampling (latitude, longitude, altitude), the predominant habitat type (forest vs. non-forest habitats), the taxonomic completeness of sampling (entire species community vs. single plant and/or animal family) and the duration of sampling (the maximum duration was defined to be an entire year, i.e., 365 days).

The number of networks strongly varied among the original studies. To avoid overrepresentation of particular studies in the analysis, we assigned each network to a sampling region. These regions were defined by the original studies that focused on a particular type of habitat in a given area. However, networks from the same study that were more than $100 \mathrm{~km}$ apart were assigned to distinct regions; this criterion applied to four of the original studies. Moreover, different studies that were conducted at the same location were assigned to belong to the same sampling region; this was the case for two regions: La Selva (Costa Rica) and Santa Genebra Reserve (Brazil).

\section{Author Contributions}

The project was developed by MS, JF, AMK, DMD, RJM, CFD and NB. Network data were collected and provided by MS, JF, SA, RA, MA, GKSA, SB, KBG, RB, BD, DMD, AG, MH, AH, CNKB, TT, SW, CNW, MW, NMW, CW, CFD and NB. Climate and plant-richness variables were compiled by DMD, TH, HK, BS, WJS and JCS. Analyses and presentation of results were conducted by MS, JF, CFD and NB. All co-authors contributed to the interpretation of the results. The manuscript was written by MS and JF in collaboration with all co-authors. 


\section{Extended Acknowledgments}

MS, KBG, DMD and TH thank the research funding programme "LOEWE-Landes-Offensive zur Entwicklung Wissenschaftlich-ökonomischer Exzellenz" of Hesse's Ministry of Higher Education, Research, and the Arts. MS, KBG and MH acknowledge funds by the German Ministry of Education and Research (Biota East Africa). JF received a doctoral fellowship by the DBU (German Federal Environmental Foundation) and funding by DFG. AMK received funding by the German Science foundation, DFG Forschergruppe 456 (KL 1849/5-1). SA is grateful to Konrad-Adenauer Stiftung and DFG. RA thanks the National Science Foundation's Predoctoral Fellowship Program and The California Alliance for Minority Participation for funding. MA was supported by a fellowship from the Swiss National Science Foundation. GKSA was partly funded by The Swedish Research Council for Environment, Agricultural Sciences and Spatial Planning (FORMAS).RB received funding by the European Union as part of the FP6-project ALARM (GOCE-CT-2003-506675) and the FP7-project STEP (244090). BD was supported by Weis-Fogh Fund at Department of Zoology, University of Cambridge, The Danish Council for Independent Research | Natural Sciences, and The Carlsberg Foundation. DMD was supported by the German Academic Exchange Service (DAAD). AH received funding from the Helmholtz Association (VH-NG-247). CNKB was funded by the Swiss National Science Foundation (PA00P3 131495/1). HK acknowledges funding from the German Research Council (DFG) in the scope of the Excellence Initiative at the University of Göttingen. RJM was funded by a Royal Society University Research Fellowship. BS was supported by the Aarhus University Research Foundation and MADALGO - Center for Massive Data Algorithmics, a Center of the Danish National Research Foundation. SW thanks the Peruvian National Institute of Natural Resources (INRENA) for research permits (permit numbers: 008799 and 0001982). CNW, MW and NB acknowledge funds by the DFG Priority Program 1374 "Infrastructure-BiodiversityExploratories" (LI 150/20-1); field work permits in this project were given by the responsible state environmental offices of Baden-Württemberg, Thüringen, and Brandenburg (according to $\S$ $72 \mathrm{BbgNatSchG).} \mathrm{CW} \mathrm{was} \mathrm{funded} \mathrm{by} \mathrm{the} \mathrm{European} \mathrm{Science} \mathrm{Foundation} \mathrm{and} \mathrm{Swedish} \mathrm{Research}$ Council through the EuroDiversity AgriPopes programme.

\section{Supplemental References}

41. Supplemental information provided by Rezende, E.L., Lavabre, J.E., Guimarães Jr, P.R., Jordano, P., and Bascompte, J. (2007). Non-random coextinctions in phylogenetically structured mutualistic networks. Nature 448, 925-929.

42. Interaction Web Database. http://www.nceas.ucsb.edu/interactionweb (accessed March 2011).

43. Vázquez, D.P., Lomáscolo, S.B., Belén Maldonado, M., Chacoff, N.P., Dorado, J., Stevani, E.L., and Vitale, N.L. (2012). The strength of plant-pollinator interactions. Ecology 93, $719-725$. 


\section{Chapter 5}

\section{Experimental environmental change and mutualistic vs. antagonistic plant flower-visitor interactions}

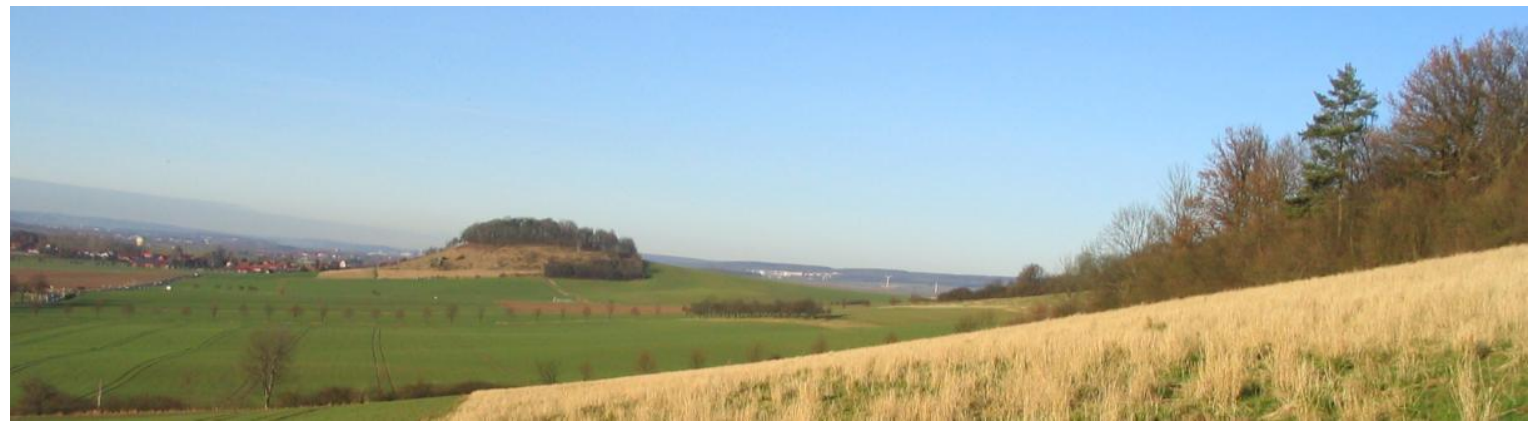

Authors: Susann Parsche, Jochen Fründ* and Teja Tscharntke

*Corresponding author

This chapter is published in:

Perspectives in Plant Ecology, Evolution and Systematics (2011), vol. 13, pages 27-35

Please access by doi: 10.1016/j.ppees.2010.12.001

(C) Elsevier 2011 


\section{Abstract}

Habitat modification and human-induced climate change are having a severe impact on ecosystems. Plant-insect interactions in particular might become disrupted due to speciesspecific responses of plants and insects towards these changes. We investigated how environmental change affects flower visitation and pollination with a field study simulating pollinator habitat loss (distance to semi-natural habitat), phenological shift (anticipated flowering) and environmentally induced growth (enhanced flower height). We established 16 habitat islands of potted plants of Sinapis arvensis L., recorded all flower visitors (mainly bees, flies and pollen beetles) and quantified the seed set. Experimentally elevated flowers were less often visited by flies, while visitation by bees was not affected. Further, plants distant from calcareous grassland were less often visited by bees but visitation by flies did not decrease. Anticipated flowering reduced the number of both pollinators and herbivorous pollen beetles and increased the reproductive success (seeds per plant) of S. arvensis, showing that the loss of mutualists was compensated by an escape from antagonists. During the natural flowering period more seeds were produced close to grasslands, especially by plants of natural height, presumably due to the higher bee visitation rate. However, seed production appeared to be relatively tolerant to multiple environmental changes due to complementary patterns among the different flower visitor guilds. Our results suggest complex interactions of environmental change with responses of mutualists and antagonists, making general predictions difficult. 
Research article

\title{
Experimental environmental change and mutualistic vs. antagonistic plant flower-visitor interactions
}

\author{
Susann Parsche ${ }^{1}$, Jochen Fründ*, Teja Tscharntke \\ Agroecology, Department of Crop Sciences, Georg-August University of Göttingen, Grisebachstraße 6, 37077 Göttingen, Germany
}

\section{A R T I C L E I N F O}

\section{Article history:}

Received 7 June 2010

Received in revised form 5 November 2010 Accepted 30 December 2010

\section{Keywords:}

Global change

Pollination

Herbivory

Bees

Flies

Functional complementarity

\begin{abstract}
A B S T R A C T
Habitat modification and human-induced climate change are having a severe impact on ecosystems. Plant-insect interactions in particular might become disrupted due to species-specific responses of plants and insects towards these changes. We investigated how environmental change affects flower visitation and pollination with a field study simulating pollinator habitat loss (distance to semi-natural habitat), phenological shift (anticipated flowering) and environmentally induced growth (enhanced flower height). We established 16 habitat islands of potted plants of Sinapis arvensis L., recorded all flower visitors (mainly bees, flies and pollen beetles) and quantified the seed set. Experimentally elevated flowers were less often visited by flies, while visitation by bees was not affected. Further, plants distant from calcareous grassland were less often visited by bees but visitation by flies did not decrease. Anticipated flowering reduced the number of both pollinators and herbivorous pollen beetles and increased the reproductive success (seeds per plant) of S. arvensis, showing that the loss of mutualists was compensated by an escape from antagonists. During the natural flowering period more seeds were produced close to grasslands, especially by plants of natural height, presumably due to the higher bee visitation rate. However, seed production appeared to be relatively tolerant to multiple environmental changes due to complementary patterns among the different flower visitor guilds. Our results suggest complex interactions of environmental change with responses of mutualists and antagonists, making general predictions difficult.
\end{abstract}

(c) 2011 Elsevier GmbH. All rights reserved.

\section{Introduction}

Earth's current state is characterized by an unprecedented overexploitation of natural resources (Vitousek, 1994; Baur and Erhardt, 1995; Luck, 2007; IPCC, 2008) and associated decrease in global biodiversity (e.g. Foley et al., 2005; IPCC, 2008). The main drivers of biodiversity loss are land use change, climate change, nitrogen deposition, biotic exchange and an increasing concentration of carbon dioxide with habitat modification as a global key factor (Sala et al., 2000; Laurance and Cochrane, 2001; Foley et al., 2005). In spite of rising knowledge about the complexity of global environmental change, many recent studies and models still consider each driver separately, ignoring potential interactions (Laurance and Cochrane, 2001; Hare, 2003; Didham et al., 2007). Discontinuities and synergistic interactions among these drivers create huge uncertainty with regard to prospective conditions (Myers, 1996;

\footnotetext{
* Corresponding author. Tel.: +49 055139 22359; fax: +49 0551398806. E-mail address: jfruend@uni-goettingen.de (J. Fründ).

Present address: Molecular Ecology, Institute of Zoology, Martin-LutherUniversity Halle-Wittenberg, Hoher Weg 4, 06099 Halle (Saale), Germany.
}

Sala et al., 2000; Ewers and Didham, 2006; Darling and Côté, 2008; Tylianakis et al., 2008). For example, today's highly fragmented landscapes prevent habitat specialists from tracking climate change (Walther et al., 2002), potentially affecting mutualists and antagonists (Tylianakis et al., 2008). Hence, there is an urgent demand for more realistic approaches, as possible negative synergism is likely to be the most important but least understood issue of the ongoing environmental crisis (Laurance and Cochrane, 2001).

Animal-mediated pollination is a key ecosystem service crucial to human welfare (e.g. Daily, 1997). Bees and hoverflies are among the most important pollinators of both wild and cultivated plants (e.g. Kearns et al., 1998; Klein et al., 2007; Jauker and Wolters, 2008). Such mutualisms, but also antagonisms, are often affected by environmental change such as conversion and loss of natural or semi-natural habitats (Rathcke and Jules, 1993; Cane, 2001; Tylianakis et al., 2008; Winfree et al., 2009).

Habitat fragmentation is known to affect pollinator communities and to potentially disrupt plant-pollinator interactions, reducing seed set (e.g. Rathcke and Jules, 1993; Steffan-Dewenter and Tscharntke, 1999; Murren, 2002; Öckinger and Smith, 2007). In addition to such changes, different responses towards climate change may lead to an increasing asynchrony in the life cycles 


\section{Author's personal copy}

Table 1

Overview of the three aspects of global environmental change simulated in this study.

\begin{tabular}{lll}
\hline Global change driver & Disrupting process & Experimental simulation \\
\hline $\begin{array}{l}\text { Land use change } \\
\text { Climate change }\end{array}$ & $\begin{array}{l}\text { Habitat loss/fragmentation } \\
\text { Phenological shift causing asynchrony in life cycles } \\
\text { of interacting species }\end{array}$ & $\begin{array}{l}500-1000 \mathrm{~m} \text { distance from semi-natural habitat } \\
\text { Anticipation of flowering by greenhouse cultivation }\end{array}$ \\
Enhanced nutrients, temperature or $\mathrm{CO}_{2}$ & $\begin{array}{l}\text { Increasing flower height due to enhanced growth } \\
\text { Elevation via platforms (0.5 m) }\end{array}$ \\
\hline
\end{tabular}

of insect pollinators and flowering plants, potentially disrupting their interactions (Parmesan, 2006, 2007; Memmott et al., 2007). Simulating phenological shift of different magnitude for individual species within a plant-pollinator network, Memmott et al. (2007) predict a shortage in floral food supply for a substantial proportion of all pollinators. Another potential consequence of global change is enhanced plant growth, e.g. caused by increased nitrogen levels, enhanced temperature or higher $\mathrm{CO}_{2}$ partial pressure (Morecroft et al., 1994, Tylianakis et al., 2008). Some pollinators are known to prefer certain flower heights while foraging (Dafni and Potts, 2004; Engel and Irwin, 2003; Hoehn et al., 2008), so enhanced growth might influence the reproductive success of plants.

In order to test how three major global change drivers affect plant-pollinator interactions we carried out a field study using a full factorial design. Potted plants were established near calcareous grasslands which are among the most species-rich semi-natural habitats in Europe (Poschlod and WallisDeVries, 2002) but also particularly sensitive to environmental change (Baur and Erhardt 1995). Wild mustard (Sinapis arvensis L.) served as model plant because it is pollinator-dependent, attracting a variety of bee and hoverfly species, and its flowers can be heavily destroyed by pollen beetles (Kunin, 1993; Steffan-Dewenter and Tscharntke, 1999). We examined potential differences in flower visitation and reproductive success in response to three experimental treatments: (i) pollinator habitat loss (close to versus distant from calcareous grassland), (ii) phenological shift of plants (natural vs. experimentally anticipated flowering period) and (iii) environmentally enhanced plant growth (natural vs. experimentally enhanced height of flowers). We tested the hypothesis that the abundance and community composition of flower visitors differ between treatments, thereby changing reproductive success of S. arvensis. Further, interactions between different changes might lead to synergistic effects (as proposed by Laurance and Cochrane, 2001).

\section{Methods}

\section{Study sites and study plants}

The field study was carried out in proximity to calcareous grasslands in southern Lower Saxony (Germany), around Göttingen in 2008. This region is dominated by intensively managed agricultural landscapes but also comprises forest fragments and scattered remnants of semi-natural habitats like calcareous grasslands (Steffan-Dewenter and Tscharntke, 1999; Steffan-Dewenter et al., 2001; Meyer et al., 2009).

Eight calcareous grasslands within heterogeneous landscapes (>20\% non-crop habitat; Tscharntke et al., 2005) have been chosen. Calcareous grasslands have evolved by extensive grazing over a long period of time (Poschlod and WallisDeVries, 2002). They represent a retreat for thermophile and endangered specialists and harbour species-rich bee communities (Westrich, 1989; Steffan-Dewenter and Tscharntke, 2000; Meyer, 2007). Nowadays, the remaining fragments are highly endangered and therefore protected by law in Germany (Westrich, 1989). Bees inhabiting fragments of calcareous grassland may forage several hundred metres (Gathmann and Tscharntke, 2002) around these habitats and provide pollination service to plants of the agricultural matrix.
Wild mustard (Brassicaceae: Sinapis arvensis L.) is an annual, self-incompatible plant that is native to Europe (Kunin, 1993). It reaches a height of about $20-60 \mathrm{~cm}$ and flowering peaks in June/July (Jäger and Werner, 2000). Offering easily accessible floral resources it attracts a great variety of bees and hoverflies (Kunin, 1993; Steffan-Dewenter and Tscharntke, 1999). This plant species naturally occurs in the agricultural matrix and not on calcareous grassland, but profits from pollinator-rich habitats in the surrounding (Steffan-Dewenter and Tscharntke, 1999).

Seeds of wild mustard were sown in a greenhouse in Göttingen. For the first flowering period, seeds were sown on 4 March 2008 and plants were raised under artificial long-day conditions (15 h day length at $23 / 14{ }^{\circ} \mathrm{C}$ day/night temperature), thereby experimentally anticipating flowering. For the natural flowering period, seeds were sown on 14 April and plants were raised without heating or artificial light. Seedlings were planted into single 3.51 pots as soon as the first leaves emerged. All pots were filled with a mixture of commercial garden soil (Fruhstorfer Einheitserde T25, HAWITA, Vechta, Germany) with standardized high levels of nutrients and a water storing granulate (BROADLEAF ${ }^{\circledR}$ P4, BOSSE, Costa Mesa, USA) to prevent rapid dehydration of the plants. Afterwards $S$. arvensis was adapted to outdoor weather conditions and positioned at the field sites shortly before flowering.

\section{Experimental design}

To experimentally simulate environmental change (Table 1) we established 16 artificial flower patches of S. arvensis ("habitat islands") within eight landscapes. In each landscape, one habitat island was placed close to $(0-5 \mathrm{~m})$, and one at $500-1000 \mathrm{~m}$ distance from the calcareous grasslands (on a field margin), thereby exceeding the foraging ranges of most wild bees (Gathmann and Tscharntke, 2002; Westphal et al., 2006; Greenleaf et al., 2007). We selected heterogeneous landscapes to safeguard a certain level of flower visitors even at distant sites. Each of the 16 experimental habitat islands consisted of two plots, which were separated with a distance of $1 \mathrm{~m}$ : four plants were put at ground level (natural height) and four plants on wooden platforms of $0.5 \mathrm{~m}$ height, simulating environmentally enhanced growth caused by nutrient, temperature or $\mathrm{CO}_{2}$ levels (Fig. 1). Per habitat island, one additional plant covered with gauze ( $1.35 \mathrm{~mm}$ mesh size), was set up, again at a distance of $1 \mathrm{~m}$, to test the degree of pollinator dependence. The habitat islands were monitored during two different periods. A first set of plants was established in the field on 20 and 21 April, and a second set on 23 and 24 May 2008, representing anticipated and natural flowering respectively. In summary the simulated environmental change factors were proximity ( $n=16$ replicates), flowering period (32) and flower height (64). Including the controls, 288 potted plants were used. All plants were protected by wire netting boxes against herbivores and wind damage, and regularly watered during dry weather.

\section{Flower visitors and reproductive success}

Insects visiting flowers of $S$. arvensis were observed during both flowering periods. Four surveys per flowering period were conducted, between 26 April and 12 May, and between 6 and 


\section{Author's personal copy}
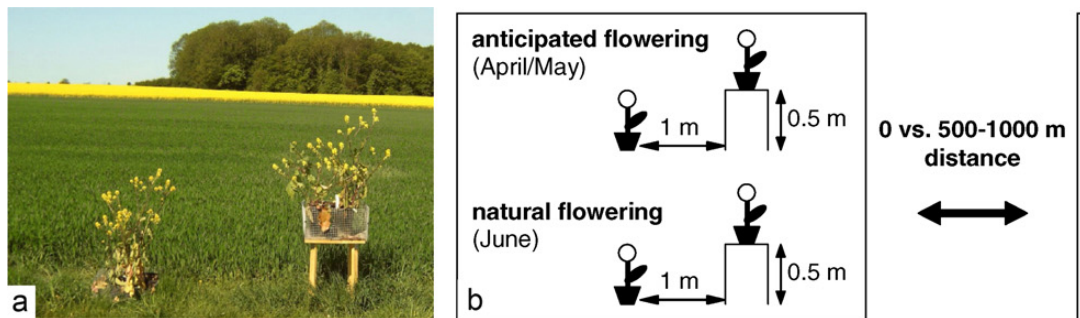

Calcareous grasslands

(pollinator source habitat)

Fig. 1. Design of the experimental habitat islands simulating three aspects of environmental change: (1) habitat loss (close to vs. distant from calcareous grassland within an agricultural matrix), (2) phenological shift (anticipated vs. natural flowering period), and (3) environmentally induced growth (natural vs. enhanced height of flowers). First observation of flower visitors was conducted in April/May, the second one in June. A different set of Sinapis arvensis plants was used in each observation period. (a) Example photo of an experimental habitat island including plots of enhanced and natural height, representing a distant site during anticipated flowering. (b) Schematic sketch.

24 June 2008, respectively. Monitoring of flower visitors took place mainly between 08.30 and 19.00 during sunny weather (max. $30 \%$ cloud cover), low wind and at least $16^{\circ} \mathrm{C}$. Observations were performed in random order and time of day to gain unbiased data. Matching pairs within a landscape (close to and distant from calcareous grassland) were surveyed directly one after the other on the same day. Each plot within a habitat island was observed for $15 \mathrm{~min}$ per survey, recording all flower-visiting insects (pollinators and herbivores) and collecting wild bees and hoverflies with a sweep net. These $15 \mathrm{~min}$ were subdivided into 5-min subunits alternating between the two plots of different flower height. Hence, each plot was monitored for one hour per flowering period. All captured bees and hoverflies were identified to species level. Non-syrphid flies were neither caught nor determined to species level but were included in the analyses due to their abundance and their potential contribution to pollination (see e.g. Escaravage and Wagner, 2004; Clement et al., 2007).

After pollinator surveys were finished, potted plants were removed from the field sites back to the cultivation site in Göttingen. There the plants were placed under gauze (cage of $8 \mathrm{~m}^{2}$ ) to prevent remaining flowers from being pollinated by local insects, allowing the fruits to ripen under standardized conditions. To quantify the fruit and seed set, all pods per plant were counted at full ripeness. Afterwards 30 pods per plant were taken randomly to count the number of seeds per fruit. The following measures of reproductive success of $S$. arvensis were calculated: (a) number of seeds per pod, (b) number of seeds per plant (the number of seeds per pod multiplied by the number of pods per plant and (c) dry weight per seed (calculated from the seeds of 30 pods per plant, dried for $24 \mathrm{~h}$ at $60^{\circ} \mathrm{C}$ ). In total, 61,458 seeds from 8521 pods were counted. A few plants (four in the first and 20 in the second flowering period) died due to weather conditions or herbivore attacks and could not be used for analysis, but in each flowering period at least two plants per plot survived.

\section{Statistics}

Statistical analyses were performed using R 2.11.1 for Windows (R Development Core Team, 2010). Linear mixed-effects models (with package "nlme"-Pinheiro et al., 2009) were used to test the effects of the simulated environmental change treatments on the frequency of flower visitors as well as on the reproductive success of S. arvensis. Full models, including treatment main effects and all interactions, were simplified by removing non-significant terms (according to a likelihood ratio test) to obtain the final model (Crawley, 2007).
A multiple-nested error structure was used, representing the experimental design and its spatial arrangement: factor height (enhanced vs. natural) was nested in flowering period (anticipated vs. natural), which was nested in proximity (close to vs. distant from calcareous grassland), which finally was nested in landscape (the eight study landscapes). Landscape was only modelled as random effect. Residuals were checked for the model assumptions (normality and homogeneity of variances). If required, response variables were transformed (Table 2) and variance functions were used to model heteroscedasticity.

Regarding the number of flower visitors, the visitation rate per plot (number of flower visitors per hour and per 100 flowers) was calculated to control for attraction effects of flower abundance on visitor abundance. There was no significant difference in the number of open flowers during monitoring between the two flowering periods $(t=-0.50, p=0.6180$, means: 308.7 and 325.8 during anticipated and natural flowering, respectively). Multiple visits by the same insect individual within one observation interval were not considered. Note that this measure of visitation rate is not directly proportional to the number of visits received by each individual flower. Only flower-visiting bees (Hymenoptera: Apoidea) and flies (Diptera: Brachycera; hoverflies and non-syrphid flies separately) were considered as pollinators in the analyses. Pollen beetles (Nitidulidae: Meligethes spp.) are major antagonists, reducing the reproductive success by destroying buds and flowers (Steffan-Dewenter and Tscharntke, 1999; Thies and Tscharntke, 1999) and were analysed in the same way as visitation by the three groups of potential pollinators. Other insect groups were only observed in very low numbers except for ants, which were excluded because they are usually regarded as inefficient pollinators (Beattie et al., 1984; Peakall and Beattie, 1991).

The reproductive success of wild mustard was analysed in two steps. First a comparison between open $(n=233)$ and enclosed $(n=30)$ plants was conducted to obtain information on the extent of pollinator dependence. Afterwards only the open plants were used for further analyses with mixed-effects models considering the environmental change simulations.

Species might react differently to environmental change, so it is particularly interesting to investigate the effects of simulated change on species diversity and community composition. This was analysed only including specimens identified to species level. Community composition could not be reliably measured on the plot level, because for several plots there were only a few observed individuals. Therefore we used a more reliable approach to compare pollinator communities between the different treatments, asking whether different species visit $S$. arvensis under different conditions: For each of the three treatments, we pooled all data for flower visitors to construct a commu- 


\section{Author's personal copy}

Table 2

Summary statistics of linear mixed-effects models testing the effect of the three simulation treatments on the number of pollinators visiting Sinapis arvensis, the number of pollen beetles visiting $S$. arvensis and the reproductive success of $S$. arvensis. Values from the minimal adequate models are shown.

\begin{tabular}{|c|c|c|c|c|c|c|c|c|c|c|c|c|c|c|c|}
\hline \multirow[t]{3}{*}{ Factor $^{\mathrm{a}}$} & \multicolumn{12}{|c|}{ Visitation rate of mutualistic and antagonistic flower visitors ${ }^{b}$} & \multirow{2}{*}{\multicolumn{3}{|c|}{$\begin{array}{l}\text { Reproductive success of } \\
\text { S. arvensis }{ }^{c} \\
\text { Seeds per plant }\end{array}$}} \\
\hline & \multicolumn{3}{|l|}{ Bees } & \multicolumn{3}{|c|}{ Hoverflies } & \multicolumn{3}{|c|}{ Non-syrphid flies } & \multicolumn{3}{|c|}{ Pollen beetles } & & & \\
\hline & $d f$ & $F$ & $p$ & $d f$ & $F$ & $p$ & $d f$ & $F$ & $p$ & $d f$ & $F$ & $p$ & $d f$ & $F$ & $p$ \\
\hline Proximity & 1,7 & 14.08 & $0.0071^{* *}$ & & & n.s. & & & n.s. & & & n.s. & 1,7 & 3.27 & 0.1136 \\
\hline Flowering & 1,14 & 7.25 & $0.0175^{*}$ & 1,15 & 24.66 & $0.0002^{* * *}$ & & & n.s. & 1,15 & 756.16 & $<0.0001^{* * *}$ & 1,14 & 92.36 & $<0.0001^{* * * *}$ \\
\hline Height & & & n.s. & & & n.s. & 1,31 & 8.47 & $0.0066^{* *}$ & & & n.s. & 1,28 & 5.58 & $0.0254^{*}$ \\
\hline Prox:Flow & 1,14 & 4.75 & $0.0469^{*}$ & & & n.s. & & & n.s. & & & n.s. & 1,14 & 2.19 & 0.1611 \\
\hline Prox:Height & & & n.s. & & & n.s. & & & n.s. & & & n.s. & 1,28 & 0.46 & 0.5048 \\
\hline Flow:Height & & & n.s. & & & n.s. & & & n.s. & & & n.s. & 1,28 & 1.82 & 0.1883 \\
\hline Prox:Flow:Height & & & n.s. & & & n.s. & & & n.s. & & & n.s. & 1,28 & 4.00 & $0.0553^{(*)}$ \\
\hline
\end{tabular}

Significance levels: ${ }^{* * *} p<0.001 ;{ }^{* *} p<0.01 ;{ }^{*} p<0.05 ;{ }^{(*)} p<0.1$; n.s.: not significant, terms removed according to likelihood ratio tests.

a Prox $($ imity $)=$ close vs. distant proximity to calcareous grassland; Flow $($ ering $)=$ anticipated vs. natural flowering period; Height $=$ natural vs. experimentally enhanced flower height.

b log-transformed, adding a small value $z$, which was chosen so that the assumptions of homogeneous variance and normally distributed residuals were met most accurately $(z=2.6$ for bees, 1.7 for hoverflies, 0.4 for non-syrphid flies and 1.5 for pollen beetles). For hoverflies, a variance function was used to model an exponential variance-mean relationship.

c Square-root transformed.

nity matrix with two rows, one for each factor level - the first row representing species abundances under "natural conditions", the second row "changed conditions" (experimentally enhanced height, anticipated flowering and distance to calcareous grassland, respectively). These two "communities" were compared by calculating the Bray-Curtis dissimilarity, indicating how strongly the flower visitor community changes with the respective factor. We then tested whether these dissimilarity values are larger than one could explain by chance, given the observed difference in abundance. This was done by constructing 10,000 replicates of contingency tables with the same marginal totals as the community matrix (command "r2dtable" in R), and using those to calculate the (expected) confidence intervals of Bray-Curtis distance for each factor, under the null hypothesis of no difference in species composition.

\section{Results}

Abundance and species richness of flower visitors

We recorded a great variety of flower visitors. Apart from the pollen beetles, bees (30\%), non-syrphid flies (22\%) and hoverflies (18\%) were most abundant (see Table A1 for a summary of all flower-visiting taxa). In total, 196 bees and 89 hoverflies (of 297 and 173 observed individuals, respectively) were caught. We identified 30 bee species of eight genera and 23 hoverfly species representing 14 genera (Tables $\mathrm{A} 2$ and $\mathrm{A} 3$, respectively). The most species-rich bee genera were Andrena (ten species), Lasioglossum (six) and Hylaeus (four). Eristalis (four species) represented the most species-rich genus among the hoverflies, followed by Syrphus and Platycheirus (three each). Twenty wild bee species were exclusively found close to, but two species only distant from calcareous grasslands. Hoverflies showed a different pattern: Six hoverfly species were exclusive to experimental habitat islands next to calcareous grasslands, while eight species were observed only in the distant sites.

\section{Effect of treatments on flower visitation}

Simulated habitat loss and phenological shift had a significant effect on the visitation by bees (Fig. 2a, Table 2). The number of bees visiting the model plants was significantly higher close to calcareous grassland as well as during the natural flowering period of
S. arvensis. A significant interaction term indicates that this increase in bee visitation during the natural flowering period mainly happened close to calcareous grasslands and that there was almost no effect for plots distant from the calcareous grassland.

Experimentally anticipated flowering also had a significant, strongly negative effect on the visitation by hoverflies (Fig. 2b, Table 2). Non-syrphid flies showed a preference for natural height of flowers (Fig. 2c, Table 2). In contrast to the bees, visitation by the two groups of flies was not reduced in the absence of calcareous grasslands, and no interactions between treatments could be identified for them. In summary, each pollinator group reacted differently towards the experimental treatments.

The number of pollen beetles observed on the flowers of $S$. arvensis increased by more than two orders of magnitude from the anticipated to the natural flowering period (Fig. 2d, Table 2). Only very few pollen beetles were observed during anticipated flowering. The other environmental change treatments did not have significant effects on the visitation by pollen beetles.

\section{Pollinator community composition}

The species composition of the pollinator community differed between our experimental treatments (Fig. 3). Striking differences occurred between the two flowering periods $(p<0.001)$ and between close and distant habitat islands $(p<0.001)$. In contrast, plants of varying flower height were visited by a more similar community $(p=0.089)$. Generally, dissimilarity measures can be influenced by differences in abundance. However, the comparison to the null model showed that the differences in community dissimilarity are not predominantly explained by abundance differences. During the anticipated flowering period many flower visitor species specific to spring and a high proportion of Andrena bees were recorded, while during natural flowering higher numbers of hoverflies (especially aphidophagous species) occurred, and plants close to calcareous grasslands attracted numerous bees of the genera Lasioglossum and Hylaeus (Tables A2 and A3). On average, the bees active in spring were larger than those most abundant in sum$\operatorname{mer}(t=2.53, p=0.0144$, means: $8.10 \mathrm{~mm}$ and $6.97 \mathrm{~mm}, n=36 / 147)$.

\section{Pollinator dependence}

Wild mustard covered with gauze to exclude pollinating insects differed significantly from those plants accessible to flower visitors in two of the three parameters of reproduc- 


\section{Author's personal copy}

$\mathrm{a}$
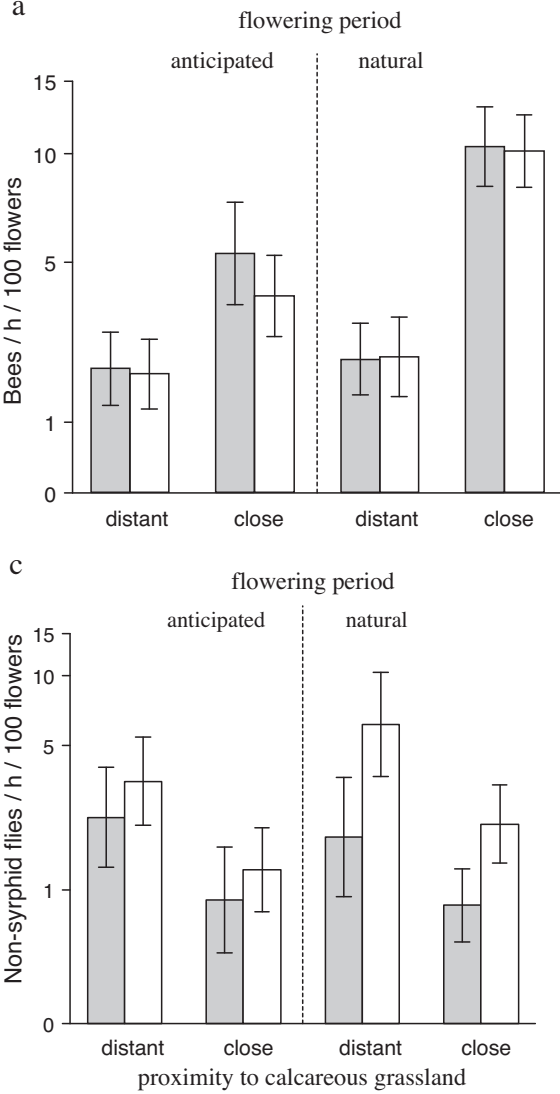

$\mathrm{b}$
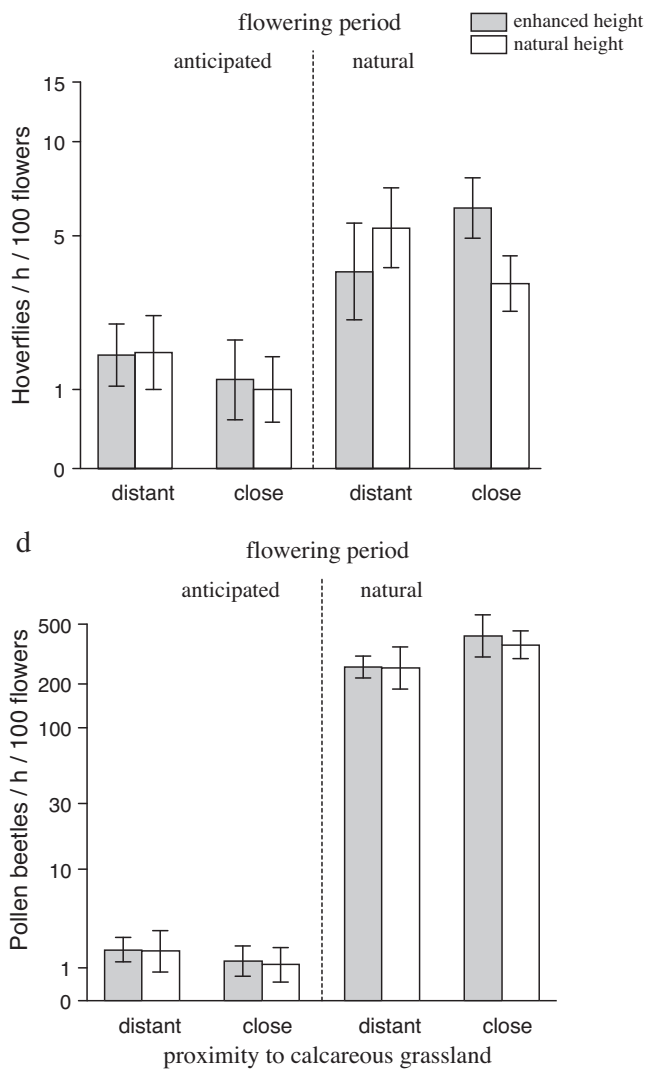

Fig. 2. Visitation rate (number of visitors/100 open flowers/hour) of (a) bees, (b) hoverflies, (c) non-syrphid flies and (d) pollen beetles visiting flowers of Sinapis arvensis. Means \pm SE are shown ( $n=64$ plots, not accounting for random effects). $y$-Axes are $\log (x+z)$-transformed (see Table 2 for $z$-values).

tive success. In detail, open plants produced 1448 seeds per plant and enclosed ones 573 (medians, Wilcoxon rank sum test: $W=1626, p<0.0001 ; n=233 / 30)$, and 7.34 vs. 3.83 seeds per pod have been found $(W=162, p<0.0001 ; n=233 / 30)$. In contrast, dry weight per seed did not differ significantly between open and control plants (medians: 1.93 and $1.98, W=3376, p=0.791$ $n=233 / 30$ ).

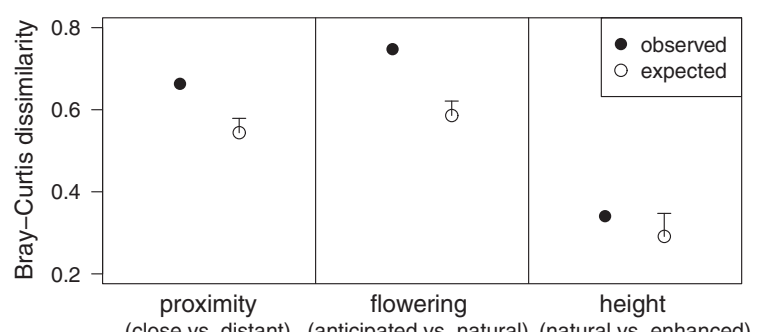

(close vs. distant) (anticipated vs. natural) (natural vs. enhanced)

Fig. 3. Changes in community composition (wild bee and hoverfly species combined) caused by the different simulation treatments. Filled circles represent the observed value, open circles show medians and upper confidence limits of community dissimilarity (due to the treatment) from a permutation test randomly redistributing individuals. See Methods for further details.

\section{Effect of treatments on the reproductive success}

Almost twice as many seeds were produced during anticipated flowering compared to the natural flowering period, indicating a significant response of S. arvensis towards phenological shift (Fig. 4, Table 2). Enhanced flower height had a negative impact on the number of seeds. The minimal adequate model for seed output included a three-way interaction between the environmental change treatments: Proximity to calcareous grassland had a positive effect on seed production only during the natural flowering period, and this was stronger for plants of natural height. Experimental elevation of $S$. arvensis had a stronger negative effect on the seed set during anticipated flowering. Both the number of seeds per pod and the dry weight per seed did not differ with respect to simulated environmental change.

When flowering periods were analysed separately, the total number of seeds per plant was higher in plants of natural flower height in the anticipated flowering period $\left(F_{1,15}=7.89, p=0.0132\right)$. During natural flowering more seeds were produced in those plots next to calcareous grasslands $\left(F_{1,7}=6.75, p=0.0356\right)$, with an interaction $\left(F_{1,14}=3.18, p=0.0960\right)$ indicating that the positive effect of calcareous grassland was mainly present for plants of natural height but not for plants of enhanced height. Plants of the first flowering period were also larger (mean final heights: $0.87 \mathrm{~m}$ in April/May and $0.54 \mathrm{~m}$ in June respectively, $t=17.56, p<0.0001$ ). When the number of seeds was divided by plant height to con- 


\section{Author's personal copy}

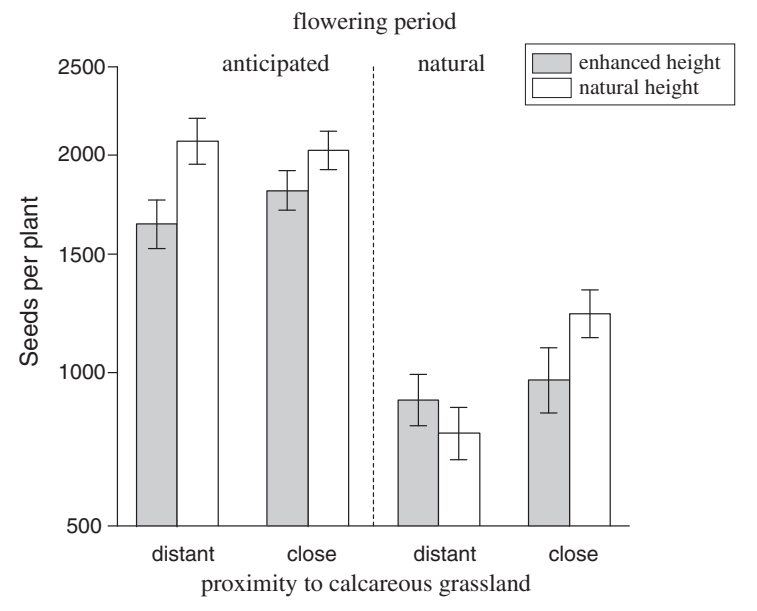

Fig. 4. Reproductive success of Sinapis arvensis (number of seeds per plant $=$ number of seeds per pod multiplied by the number of pods per plant) in relation to three treatments simulating environmental change. Means $\pm \operatorname{SE}$ are shown $(n=233$ plants, not accounting for random effects). $y$-Axis is square-root transformed.

trol for differences in plants' reproductive potential, the difference in seed production between the flowering periods was smaller but still significant, while the patterns within flowering periods remained similar (Fig. A1, Table A4).

\section{Discussion}

In this study we simulated three aspects of human-induced environmental change, investigating the impact on mutualistic and antagonistic flower visitation and reproductive success of Sinapis arvensis.

Simulated pollinator habitat loss resulted in a significant decline of wild bees, which is in accordance with the findings of a recently published meta-analysis: Winfree et al. (2009) also found a significant decline in the abundance and species richness of unmanaged bees due to habitat loss. Steffan-Dewenter and Tscharntke (1999) also demonstrated a decreasing number in both bee individuals and species with increasing habitat isolation, whereas the abundance of hoverflies did not change. In our study flower visitor communities were strongly different in close compared to distant sites, probably because several bee species depend on calcareous grasslands Most of the bees abundant in the vicinity of calcareous grasslands were not observed before the natural flowering time of S. arvensis (in June), the importance of these grasslands as a pollinator habitat was much lower in spring (April/May). Plants produced more seeds close to the grassland compared to distant habitat islands, but only during natural flowering. This supports the results of SteffanDewenter and Tscharntke (1999), who found a significant decline in the number of seeds with increasing isolation from calcareous grassland: The mean seed set per plant was twice as high close to grassland compared to a distance of $1000 \mathrm{~m}$. Our study confirmed that calcareous grasslands are an important source of bee pollinators, but their importance for plants in surrounding habitats may vary with environmental change.

Simulating phenological shift of $S$. arvensis, anticipated flowering entailed a significant decrease in the visitation by wild bees and hoverflies. According to a recent simulation, up to $50 \%$ of all pollinators will suffer from a shortage in floral food supply when the phenology of plants changes (Memmott et al., 2007). In turn, a considerable proportion of plants is supposed to lose all or some pollinators (Memmott et al., 2007), resulting in a decline of fruit and seed set, especially in bee-pollinated plants (Kudo et al., 2004). Another aspect is the avoidance of unfamiliar flowers, especially rare ones, observed in bumble bees (Forrest and Thomson, 2009). Nevertheless, in our study Sinapis-flowers were successfully pollinated several weeks before the natural flowering time and, although most of the original pollinators were not present at that time, some generalist pollinators visited the flowers even though they were rare and unfamiliar at the time. The fact that reproductive success (number of seeds per plant) was actually higher during anticipated flowering appeared to derive from counterbalancing effects of herbivory and pollination, while weather conditions (stress by alternating heavy rain and drought impaired plant performance during the natural flowering period) may have also played a role. Herbivorous pollen beetles can greatly reduce the reproductive success of wild mustard (SteffanDewenter and Tscharntke, 1999; Thies and Tscharntke, 1999). The anticipation of flowering released $S$. arvensis from pollen beetle pressure and appeared to compensate the bee pollinator losses. Similarly, Steffan-Dewenter et al. (2001) found counterbalancing effects of seed set and seed predation, which were both enhanced along a gradient of landscape complexity. Notably, the spring pollinator community provided sufficient pollination service to allow for a positive effect of enemy release. Despite their low numbers, spring pollinators may have been more efficient due to their larger body size (Kandori, 2002; Sahli and Conner, 2007). Seed production responded to phenological shift in an unexpected way because the interactions with the whole community of flower visitors were disrupted.

The elevation of flower height had a strong negative impact on the visitation by non-syrphid flies. However, we did not find preferences of flower heights in bees or hoverflies. In other published studies, bees responded strongly towards varying heights of flowers, for example offered by pumpkins (Cucurbita moschata) (Hoehn et al., 2008). Dafni and Potts (2004) found height preferences of pollinating beetles (Glaphyridae: Amphicoma): Model plants with elevated flowers obtained less visitors compared to those of natural and lowered flowers. In contrast, taller individuals of Ipomopsis aggregata (Polemoniaceae) experienced higher visitation rates of hummingbirds (Engel and Irwin, 2003). In our study, changes in plant height, which may be caused by increased nutrient levels, enhanced temperature or higher $\mathrm{CO}_{2}$ partial pressure (Tylianakis et al., 2008), appeared to have a limited effect on plant-pollinator interactions. Nonetheless, changes on larger scales may cause stronger effects than in our experiment. However, despite effects only on non-syrphid flies as flower visitors, plants of enhanced height produced fewer seeds, but only during anticipated flowering (when the difference to the surrounding vegetation height was largest). This suggests that there were more subtle differences in community composition or pollinator behaviour with respect to flower height.

When several drivers of global environmental change act simultaneously, their effects might be non-additive, making predictions more difficult. This is also highlighted by our study, one of the first studies considering the joint effects of three different global change aspects on a major ecosystem function. In two cases, we found significant interactions between treatments simulating environmental change (Table 2). However, combined effects in this study were usually smaller than the sum of single change effects, contrasting to our expectation of synergistic effects. While some species such as specialized bees appeared to be particularly vulnerable, other pollinators apparently provide baseline services or an insurance (e.g. McNaughton, 1977; Elmqvist et al., 2003) even under changing conditions - for example the complementary patterns of different flower visitor groups with respect to the three simulated changes. A similar pattern was found for seed produc- 


\section{Author's personal copy}

tion: The negative effect of habitat loss (absence of calcareous grassland) was strongest under the most natural conditions (natural height and natural flowering period), and no negative synergism occurred. These results suggest that generalist plants, such as $S$. arvensis, can be tolerant to moderate changes, because different pollinator groups with different habitat requirements, behaviour and phenology can step in to provide pollination. Other plant species might show similar responses, as many plant species in human-dominated landscapes share the same pollinators (e.g., Gibson et al., 2006). However, specialized plant species depending on specific pollinators might be much more vulnerable (but see Ashworth et al., 2004). Understanding the complexity of environmental change drivers affecting interspecific interactions and ecosystem functioning still remains a huge challenge for future research.

\section{Acknowledgements}

Péter Batáry, Juliane Parsche, Claire E. Fischbacher and four anonymous reviewers provided valuable comments on earlier drafts of this manuscript. We would like to thank C. Scherber for statistical advice, A. Holzschuh for additional support and B. Preuschhof (district of Göttingen) as well as M. Weitemeier (city of Göttingen) for the required permits. The staff of the Plant Breeding Unit (University of Göttingen) contributed to the successful cul- tivation of anticipated flowering mustard by procuring room in their heated greenhouse and watering service. Financial support for TT came from the German Ministry of Research and Education (BMBF) and the German Science Foundation (DFG).JF is funded by the German Federal Environmental Foundation (DBU).

\section{Appendix A.}

Table A1

Overall abundance and proportion of flower-visiting insects observed on Sinapis arvensis.

\begin{tabular}{lcc}
\hline Species group & $\begin{array}{c}\text { Number of } \\
\text { Individuals }\end{array}$ & Proportion $^{\text {a }} \%$ \\
\hline All bees (Hymenoptera: Apoidea) & 297 & 30.2 \\
Wild bees (except Bombus) & 283 & 28.8 \\
Bumble bees (Bombus spp.) & 9 & 0.9 \\
Honeybees (Apis mellifera) & 5 & 0.5 \\
Ants (Formicidae) & 198 & 20.2 \\
Stem sawflies (Cephidae) & 19 & 1.9 \\
Beetles (Coleoptera except M. spp.) & 15 & 1.5 \\
Meligethes spp. & 26,500 & \\
Flies (Diptera except Syrphidae) & 213 & 21.7 \\
Hoverflies (Syrphidae) & 173 & 17.6 \\
Bugs (Heteroptera) & 57 & 5.8 \\
Butterflies (Lepidoptera) & 10 & 1.0 \\
All flower visitors (except M. spp.) & 982 & \\
\hline
\end{tabular}

aEcept Meligethes spp.

Table A2

Captured wild bee species visiting S. arvensis. Frequency and breeding strategy. Proximity: $c=$ close to $/ d=$ distant from calcareous grassland, flowering: $n=$ natural $/$ $\mathrm{a}=$ anticipated flowering period, height: $n=$ natural $/ \mathrm{e}=$ enhanced flower height. ${ }^{\mathbf{0}}=$ oligolectic (Brassicaceae); red list-status: ${ }^{\mathbf{3}}=$ endangered, $^{\mathbf{6}}=$ threat of unknown magnitude (Westrich, 1989).

\begin{tabular}{|c|c|c|c|c|c|}
\hline \multirow[t]{2}{*}{ Bee species } & \multicolumn{5}{|l|}{ Frequency } \\
\hline & Total $\left(0^{\top} /\right.$ o $)$ & Proximity c/d & Flowering n/a & Height n/e & Breeding strategy \\
\hline Andrena agilissima (SCOPOLI 1770) o 3 & $6(2 / 4)$ & $2 / 4$ & $5 / 1$ & $4 / 2$ & Communal \\
\hline A. chrysosceles (KIRBY 1802) & $2(1 / 1)$ & $0 / 2$ & $1 / 1$ & $1 / 1$ & Solitary \\
\hline A. cineraria (LINNAEUS 1758) & $1(0 / 1)$ & $1 / 0$ & $0 / 1$ & $1 / 0$ & Solitary \\
\hline A. flavipes (PANZER 1799) & $2(2 / 0)$ & $2 / 0$ & $1 / 1$ & $1 / 1$ & Solitary \\
\hline A. fucata (SMITH 1847) & $1(1 / 0)$ & $0 / 1$ & $0 / 1$ & $1 / 0$ & Solitary \\
\hline A. haemorrhoa (FABRICIUS 1781) & $6(0 / 6)$ & $2 / 4$ & $1 / 5$ & $1 / 5$ & Solitary \\
\hline A. cf. minutula (KIRBY 1802) & $14(9 / 5)$ & $14 / 0$ & $13 / 1$ & $8 / 6$ & Solitary \\
\hline A. nigroaenea (KIRBY 1802) & $4(0 / 4)$ & $2 / 2$ & $4 / 0$ & $2 / 2$ & Solitary \\
\hline A. strohmella (E. STÖCKHERT 1928) & $1(0 / 1)$ & $1 / 0$ & $0 / 1$ & $0 / 1$ & Solitary \\
\hline A. subopaca (NYLANDER 1848) & $4(0 / 4)$ & $2 / 2$ & $4 / 0$ & $4 / 0$ & Solitary \\
\hline Andrena spp._sum & $41(15 / 26)$ & $26 / 15$ & $29 / 12$ & $23 / 18$ & \\
\hline Bombus hortorum (LINNAEUS 1761) & $1(0 / 1)$ & $1 / 0$ & $1 / 0$ & $0 / 1$ & Social \\
\hline B. pascuorum (SCOPOLI 1763) & $1(0 / 1)$ & $1 / 0$ & $1 / 0$ & $0 / 1$ & social \\
\hline B. pratorum (LINNAEUS 1761) & $1(0 / 1)$ & $1 / 0$ & $1 / 0$ & $0 / 1$ & Social \\
\hline Bombus spp._sum & $3(0 / 3)$ & $3 / 0$ & $3 / 0$ & $0 / 3$ & \\
\hline Chelostoma rapunculi (LEPELETIER 1841) & $1(1 / 0)$ & $1 / 0$ & $1 / 0$ & $1 / 0$ & Solitary \\
\hline Halictus tumulorum (LINNAEUS 1758) & $10(2 / 8)$ & $8 / 2$ & $6 / 4$ & $7 / 3$ & Social \\
\hline Hylaeus annularis (KIRBY 1802) & $1(1 / 0)$ & $1 / 0$ & $1 / 0$ & $1 / 0$ & Solitary \\
\hline H. communis (NYLANDER 1852) & $15(6 / 9)$ & $15 / 0$ & $15 / 0$ & $6 / 9$ & Solitary \\
\hline $\begin{array}{l}\text { H. confusus/gibbus } \\
\text { (Nylander } 1852 / \text { Saunders } 1850 \text { ) }\end{array}$ & $1(0 / 1)$ & $1 / 0$ & $1 / 0$ & $1 / 0$ & Solitary \\
\hline H. hyalinatus (SMITH 1842) & $1(1 / 0)$ & $1 / 0$ & $1 / 0$ & $1 / 0$ & No information \\
\hline Hylaeus spp._sum & $18(8 / 10)$ & $18 / 0$ & $18 / 0$ & $9 / 9$ & \\
\hline Lasioglossum calceatum (SCOPOLI 1763) & $7(1 / 6)$ & $5 / 2$ & $4 / 3$ & $3 / 4$ & Social \\
\hline L. fulvicorne (KIRBY 1802) & $3(2 / 1)$ & $3 / 0$ & $3 / 0$ & $3 / 0$ & Solitary \\
\hline L. laticeps (SCHENCK 1868) & $2(0 / 2)$ & $2 / 0$ & $2 / 0$ & $0 / 2$ & Social \\
\hline L. minutulum (SCHENCK 1853) ${ }^{3}$ & $1(0 / 1)$ & $1 / 0$ & $0 / 1$ & $0 / 1$ & Solitary \\
\hline L. morio (FABRICIUS 1793) & $36(14 / 22)$ & $36 / 0$ & $28 / 8$ & $13 / 23$ & Social \\
\hline L. pauxillum (SCHENCK 1853) & $50(14 / 36)$ & $45 / 5$ & $47 / 3$ & $23 / 27$ & Social \\
\hline Lasioglossum spp._sum & $99(31 / 68)$ & $92 / 7$ & $84 / 15$ & $42 / 57$ & \\
\hline Nomada flavoguttata (KIRBY 1802) & $2(0 / 2)$ & $2 / 0$ & $1 / 1$ & $1 / 1$ & Cuckoo \\
\hline N. melanopyga (SCHMIEDEKNECHT 1882) & $1(0 / 1)$ & $1 / 0$ & $0 / 1$ & $0 / 1$ & Cuckoo \\
\hline Osmia bicolor (SCHRANK 1781) & 19 (NA) & $12 / 7$ & $4 / 15$ & $11 / 8$ & Solitary \\
\hline O. brevicornis (FABRICIUS 1798) o G & $1(0 / 1)$ & $1 / 0$ & $1 / 0$ & $1 / 0$ & Solitary \\
\hline O. rufa (LINNAEUS 1758) & $1(0 / 1)$ & $1 / 0$ & $1 / 0$ & $0 / 1$ & Solitary \\
\hline Osmia spp._sum & 21 (NA) & $14 / 7$ & $6 / 15$ & $12 / 9$ & \\
\hline
\end{tabular}




\section{Author's personal copy}

Table A3

Captured hoverfly species visiting S. arvensis. Frequency and larval feeding group. Proximity: $\mathrm{c}=$ close to $/ \mathrm{d}=$ distant from calcareous grassland, Flowering: $n=$ natural $/$ $\mathrm{a}=$ anticipated flowering period, height: $n=$ natural $/ \mathrm{e}=$ enhanced flower height.

\begin{tabular}{|c|c|c|c|c|c|}
\hline \multirow[t]{2}{*}{ Hoverfly species } & \multicolumn{5}{|l|}{ Frequency } \\
\hline & Total $\left(\sigma^{\pi} / q\right)$ & Proximity c/d & Flowering $\mathrm{n} / \mathrm{a}$ & Height $n / e$ & Larval feeding group \\
\hline Chrysotoxum bicinctum (LINNAEUS 1758) & $2(1 / 1)$ & $2 / 0$ & $2 / 0$ & $2 / 0$ & Aphidophagous \\
\hline Epistrophe eligans (HARRIS 1780) & $1(1 / 0)$ & $1 / 0$ & $0 / 1$ & $0 / 1$ & Aphidophagous \\
\hline Episyrphus balteatus (DEGEER 1776) & $13(0 / 13)$ & $4 / 9$ & $13 / 0$ & $3 / 10$ & Aphidophagous \\
\hline Eristalis cf. arbustorum (LINNAEUS 1758) & $5(1 / 4)$ & $2 / 3$ & $3 / 2$ & $2 / 3$ & Saprophagous \\
\hline E. cf. interrupta (PODA 1761) & $2(1 / 1)$ & $2 / 0$ & $2 / 0$ & $1 / 1$ & Saprophagous \\
\hline E. pertinax (SCOPOLI 1763) & $2(1 / 1)$ & $1 / 1$ & $1 / 1$ & $0 / 2$ & Saprophagous \\
\hline E. tenax (LINNAEUS 1758) & $2(0 / 2)$ & $0 / 2$ & $2 / 0$ & $2 / 0$ & Saprophagous \\
\hline Eupeodes corollae (FABRICIUS 1794) & $2(1 / 1)$ & $0 / 2$ & $2 / 0$ & $2 / 0$ & Aphidophagous \\
\hline E. lapponicus (ZETTERSTEDT 1838) & $1(1 / 0)$ & $0 / 1$ & $1 / 0$ & $0 / 1$ & No information \\
\hline Ferdinandea cuprea (SCOPOLI 1763) & $2(0 / 2)$ & $2 / 0$ & $2 / 0$ & $1 / 1$ & Saprophagous \\
\hline Myathropa florea (LINNAEUS 1758) & $1(1 / 0)$ & $0 / 1$ & $1 / 0$ & $1 / 0$ & Saprophagous \\
\hline Neoascia podagrica (FABRICIUS 1775) & $2(1 / 1)$ & $2 / 0$ & $1 / 1$ & $1 / 1$ & No information \\
\hline Pipizella spec. (RONDANI 1856) & $1(0 / 1)$ & $0 / 1$ & $0 / 1$ & $1 / 0$ & No information \\
\hline Platycheirus albimanus (FABRICIUS 1781) & $10(2 / 8)$ & $6 / 4$ & $2 / 8$ & $8 / 2$ & No information \\
\hline P. angustatus (ZETTERSTEDT 1843) & $1(1 / 0)$ & $0 / 1$ & $0 / 1$ & $1 / 0$ & No information \\
\hline P. peltatus (MEIGEN 1822) & $1(1 / 0)$ & $0 / 1$ & $0 / 1$ & $0 / 1$ & Aphidophagous \\
\hline Sphaerophoria scripta (LINNAEUS 1758) & $10(2 / 8)$ & $5 / 5$ & $9 / 1$ & $3 / 7$ & Aphidophagous \\
\hline Scaeva pyrastri (LINNAEUS 1758) & $1(0 / 1)$ & $0 / 1$ & $1 / 0$ & $0 / 1$ & Aphidophagous \\
\hline S. selenitica (MEIGEN 1822) & $8(4 / 4)$ & $3 / 5$ & $8 / 0$ & $5 / 3$ & Aphidophagous \\
\hline Syritta pipiens (LINNAEUS 1758) & $2(2 / 0)$ & $2 / 0$ & $2 / 0$ & $0 / 2$ & Saprophagous \\
\hline Syrphus ribesii (LINNAEUS 1758) & $10(5 / 5)$ & $8 / 2$ & $9 / 1$ & $5 / 5$ & Aphidophagous \\
\hline S. torvus (OSTEN SACKEN 1875) & $8(6 / 2)$ & $6 / 2$ & $8 / 0$ & $5 / 3$ & Aphidophagous \\
\hline S. vitripennis (MEIGEN 1822) & $2(1 / 1)$ & $1 / 1$ & $2 / 0$ & $0 / 2$ & Aphidophagous \\
\hline Aphidophagous spp._sum & $58(22 / 36)$ & $30 / 28$ & $54 / 4$ & $25 / 33$ & \\
\hline Saprophagous spp._sum & $16(6 / 10)$ & $9 / 7$ & $13 / 3$ & $7 / 9$ & \\
\hline
\end{tabular}

\section{Table A4}

Summary statistics of linear mixed-effects models testing the effect of the three simulation treatments on the reproductive success of S. arvensis (number of seeds per plant divided by final plant height). This measure controls for differences in plants vegetative performance (reproductive potential, approximated by plant height) Values from the minimal adequate models are shown.

\begin{tabular}{llll}
\hline Factor $^{\mathrm{a}}$ & \multicolumn{3}{l}{ Reproductive success of S. arvensis } \\
\cline { 2 - 4 } & \multicolumn{2}{l}{ Seeds per plant/plant height } \\
\cline { 2 - 4 } & $d f$ & $F$ & $p$ \\
\hline Proximity & 1,7 & 1.01 & 0.3492 \\
Flowering & 1,14 & 8.54 & $0.0111^{*}$ \\
Height & 1,28 & 2.39 & 0.1332 \\
Prox:Flow & 1,14 & 3.43 & $0.0852^{(*)}$ \\
Prox:Height & 1,28 & 0.32 & 0.5782 \\
Flow:Height & 1,28 & 0.14 & 0.7104 \\
Prox:Flow:Height & 1,28 & 4.77 & $0.0374^{*}$ \\
\hline
\end{tabular}

Significance levels: ${ }^{* * *} p<0.001 ;{ }^{* *} p<0.01 ;{ }^{*} p<0.05 ;{ }^{(*)} p<0.1$; n.s. $=$ not significant, terms removed according to likelihood ratio tests.

a Prox (imity) $=$ close vs. distant proximity to calcareous grassland; Flow $($ ering $)=$ anticipated vs. natural flowering period; Height=natural vs experimentally enhanced flower height.

b Square-root transformed.

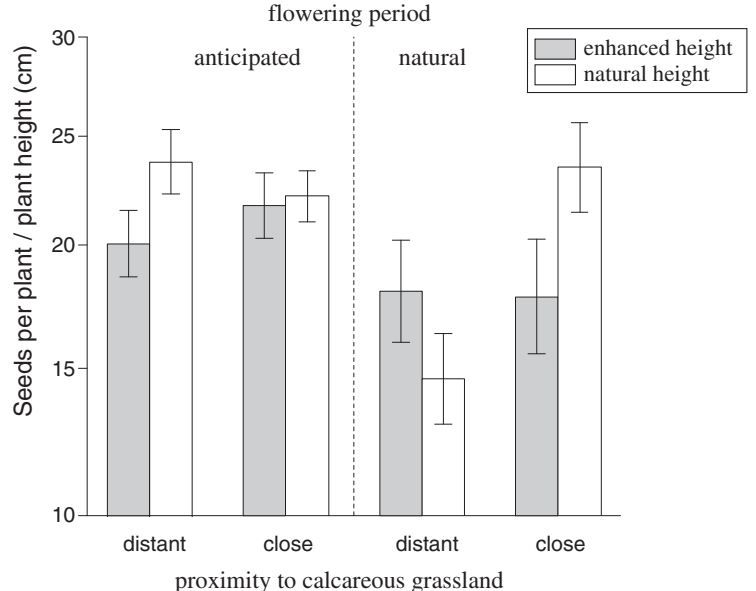

Fig. A1. Reproductive success of Sinapis arvensis (number of seeds per plant divided by final plant height) in relation to three treatments simulating environmental change. This measure controls for differences in plants' vegetative performance (reproductive potential, approximated by plant height). Means \pm SE are shown ( $n=233$ plants, not accounting for random effects). $y$-Axis is square-root transformed. 


\section{Author's personal copy}

\section{References}

Ashworth, L., Aguilar, R., Galetto, L., Aizen, M.A., 2004. Why do pollination generalis and specialist plant species show similar reproductive susceptibility to habitat fragmentation? J. Ecol 92 717-719.

Baur, B., Erhardt, A., 1995. Habitat fragmentation and habitat alterations: principal threats to most animal and plant species. Gaia 4, 221-226.

Beattie, A.J., Turnbull, C., Knox, R.B., Williams, E.G., 1984. Ant inhibition of pollen function: a possible reason why ant pollination is rare. Am. J. Bot. 71, 421-426.

Cane, J.H., 2001. Habitat fragmentation and native bees: a premature verdict? Conserv. Ecol. 5, 3.

Clement, S.L., Hellier, B.C., Elberson, L.R., Staska, R.T., Evans, M.A., 2007. Flies (Diptera:Muscidae:Calliphoridae) are efficient pollinators of Allium ampeloprasum L. (Alliaceae) in field cages. J. Econ. Entomol. 100, 131-135.

Crawley, MJ 2007. The R Book. John Wiley \& Sons Ltd. Chichester.

Dafni, A., Potts, S.G., 2004. The role of flower inclination, depth, and height in the preferences of a pollinating beetle (Coleoptera: Glaphyridae). J. Insect. Behav. $17,823-834$.

Daily, G.C., 1997. Nature's Services: Societal Dependance on Natural Ecosystems. Island Press, Washington.

Darling, E.S., Côté, I.M., 2008. Quantifying the evidence for ecological synergies. Ecol. Lett. 11, 1278-1286.

Didham, R.K., Tylianakis, J.M., Gemmell, N.J., Rand, T.A., Ewers, R.M., 2007. Interactive effects of habitat modification and species invasion on native species decline. Trends Ecol. Evol. 22, 489-496.

Elmqvist, T., Folke, C., Nyström, M., Peterson, G., Bengtsson, J., Walker, B., Norberg, J., 2003. Response diversity, ecosystem change, and resilience. Front. Ecol. Environ. $1,488-494$.

Engel, E.C., Irwin, R.E., 2003. Linking pollinator visitation rate and pollen receipt. Am. J. Bot. 90, 1612-1618

Escaravage, N., Wagner, J., 2004. Pollination Effectiveness and Pollen Dispersal in a Rhododendron ferrugineum (Ericacea) Population. Plant Biol. 6, 606-615.

Ewers, R.M., Didham, R.K., 2006. Confounding factors in the detection of species responses to habitat fragmentation. Biol. Rev. 81, 117-142.

Foley, J.A., DeFries, R., Asner, G.P., Barford, C., Bonan, G., Carpenter, S.R., Chapin, F.S Coe, M.T., Daily, G.C., Gibbs, H.K., Helkowski, J.H., Holloway, T., Howard, E.A., Kucharik, C.J., Monfreda, C. Patz, J.A., Prentice, I.C., Ramankutty, N., Snyder P.K., 2005. Global consequences of land use. Science 309, 570-574.

Forrest, J., Thomson, J.D., 2009. Pollinator experience, neophobia and the evolution of flowering time. Proc. R. Soc. B 276, 935-943.

Gathmann, A., Tscharntke, T., 2002. Foraging ranges of solitary bees. J. Anim. Ecol. 71, 757-764.

Gibson, R.H., Nelson, I.L., Hopkins, G.W., Memmott, J., 2006. Pollinator webs, plant communities and the conservation of rare plants: arable weeds as a case study. J. Appl. Ecol. 43, 246-257.

Greenleaf, S.S., Williams, N.M., Winfree, R., Kremen, C., 2007. Bee foraging ranges and their relationship to body size. Oecologia 153, 589-596.

Hare, W., 2003, Assessment of Knowledge on Impacts of Climate Change-Contribution to the Specification of Art 2 of the UNFCCC: Impacts Change-Contribution to the Specification of Art. 2 of the UNFCCC: Impacts on Ecosystems, Food Production, Water and Socio-economic Systems: Pots-
dam, Berlin, WBGU (Wissenschaftlicher Beirat der Bundesregierung Globale dam, Berlin, WBGU (Wissensch

Hoehn, P., Tscharntke, T., Tylianakis, J.M., Steffan-Dewenter, I., 2008. Functional group diversity of bee pollinators increases crop yield. Proc. R. Soc. B 275 2283-2291.

IPCC, 2008. Climate Change 2007: Synthesis Report. In: Core writing team, Pachauri, R.K. \& Reisinger, A. (Eds.), Contribution of working groups I, II and III to the Fourth Assessment of the Intergovernmental Panel on Climate Change. IPCC, Geneva, Switzerland.

Jäger, E.J., Werner, K., 2000. Rothmaler - Exkursionsflora von Deutschland. Band 3, Gefäßpflanzen: Atlasband. Spektrum Akademischer Verlag. Heidelberg/Berlin.

Jauker, F., Wolters, V., 2008. Hover flies are efficient pollinators of oilseed rape. Oecologia 156, 819-823.

Kandori, I., 2002. Diverse visitors with various pollinator importance and temporal change in the important pollinators of Geranium thunbergii (Geraniaceae). Ecol. Res. 17, 283-294.

Kearns, C.A., Inouye, D.W., Waser, N.M., 1998. Endangered mutualisms: the conservation of plant-pollinator interactions. Annu. Rev. Ecol. Syst. 29, 83-112.

Klein, A.M., Vaissiere, B.E., Cane, J.H., Steffan-Dewenter, I., Cunningham, S.A., Kremen, C., Tscharntke, T., 2007. Importance of pollinators in changing landscape for world crops. Proc. R. Soc. B 274, 303-313.

Kudo, G., Nishikawa, Y., Kasagi, T., Kosuge, S., 2004. Does seed production of spring ephemerals decrease when spring comes early? Ecol. Res. 19, 255-259.
Kunin, W.E., 1993. Sex and the single mustard-population-density and pollinator behavior effects on seed-set. Ecology 74, 2145-2160.

Laurance, W.F., Cochrane, M.A., 2001. Special section: synergistic effects in fragmented landscapes. Conserv. Biol. 15, 1488-1489.

Luck, G.W., 2007. A review of the relationships between human population density and biodiversity. Biol. Rev. 82, 607-645.

McNaughton, S.J., 1977. Diversity and stability of ecological communities: a comment on the role of empiricism in ecology. Am. Nat. 111, 515-525.

Memmott, J., Graze, P.G., Waser, N.M., Price, M.V., 2007. Global warming and the disruption of plant-pollinator interactions. Ecol. Lett. 10, 710-717.

Meyer, B., 2007. Pollinator communities and plant-pollinator interactions in fragmented calcareous grasslands: PhD thesis, Georg-August-University Göttingen. Meyer, B., Jauker, F., Steffan-Dewenter, I., 2009. Contrasting resource-dependent responses of hoverfly richness and density to landscape structure. Basic Appl. Ecol. 10, 178-186.

Morecroft, M.D., Sellers, E.K., Lee, J.A., 1994. An experimental investigation into the effects of atmospheric nitrogen deposition on two seminatural grasslands. J. Ecol. 82, 475-483.

Murren, C.J., 2002. Effects of habitat fragmentation on pollination: pollinators, pollinia viability and reproductive success. J. Ecol. 90, 100-107.

Myers, N., 1996. Two key challenges for biodiversity: discontinuities and synergisms. Biodivers. Conserv. 5, 1025-1034.

Öckinger, E., Smith, H.G., 2007. Semi-natural grasslands as population sources for pollinating insects in agricultural landscapes. J. Appl. Ecol. 44, 50-59.

Parmesan, C., 2006. Ecological and evolutionary responses to recent climate change. Annu. Rev. Ecol. Evol. S 37, 637-669.

Parmesan, C., 2007. Influences of species, latitudes and methodologies on estimates of phenological response to global warming. Global Change Biol. 13, 1860-1872.

Peakall, R., Beattie, A.J., 1991. The genetic consequences of worker ant pollination in a self-compatible, clonal orchid. Evolution 45, 1837-1848.

Pinheiro, J., Bates, D., DebRoy, S., Sarkar, D., the R Development Core team, 2009. nlme: Linear and Nonlinear Mixed Effects Models. R package version 3, pp. 1-96.

Poschlod, P., WallisDeVries, M.F., 2002. The historical and socioeconomic perspective of calcareous grasslands-lessons from the distant and recent past. Biol. Conserv. 104, 361-376.

Rathcke, B.J., Jules, E.S., 1993. Habitat fragmentation and plant pollinator interactions. Curr. Sci. India. 65, 273-277.

R Development Core Team, 2010. R: A Language and Environment for Statistical Computing. R Foundation for Statistical Computing, Vienna.

Sala, O.E., Chapin, F.S., Armesto, J.J., Berlow, E., Bloomfield, J., Dirzo, R., HuberSanwald, E., Huenneke, L.F., Jackson, R.B., Kinzig, A., Leemans, R., Lodge, D.M Mooney, H.A., Oesterheld, M., Poff, N.L., Sykes, M.T., Walker, B.H., Walker, M. Wall, D.H., 2000. Biodiversity-global biodiversity scenarios for the year 2100 . Science 287, 1770-1774

Sahli, H.F., Conner, J.K., 2007. Visitation, effectiveness, and efficiency of 15 genera of visitors to wild radish, Raphanus raphanistrum (Brassicaceae). Am. J. Bot. 94 203-209.

Steffan-Dewenter, I., Münzenberg, U., Tscharntke, T., 2001. Pollination, seed set and seed predation on a landscape scale. Proc. R. Soc. Lond. B 268, 1685-1690.

Steffan-Dewenter, I., Tscharntke, T., 1999. Effects of habitat isolation on pollinato communities and seed set. Oecologia 121, 432-440.

Steffan-Dewenter, I., Tscharntke, T., 2000. Resource overlap and possible competition between honey bees and wild bees in central Europe. Oecologia 122, 288-296.

Thies, C., Tscharntke, T., 1999. Landscape structure and biological control in agroecosystems. Science 285, 893-895.

Tscharntke, T., Klein, A.M., Kruess, A., Steffan-Dewenter, I., Thies, C., 2005. Landscape perspectives on agricultural intensification and biodiversity-ecosystem service management. Ecol. Lett. 8, 857-874.

Tylianakis, J.M., Didham, R.K., Bascompte, J., Wardle, D.A., 2008. Global change and species interactions in terrestrial ecosystems. Ecol. Lett. 11, 1351-1363.

Vitousek, P.M., 1994. Beyond Global Warming - Ecology and Global Change. Ecology $75,1861-1876$.

Walther, G.R., Post, E., Convey, P., Menzel, A., Parmesan, C., Beebee, T.J.C., Fromentin, J.-M., Hoegh-Guldberg, O., Bairlain, F., 2002. Ecological responses to recent climate change. Nature 416, 389-395.

Westphal, C., Steffan-Dewenter, I., Tscharntke, T., 2006. Bumblebees experience landscapes at different spatial scales: possible implications for coexistence. Oecologia 149, 289-300

Westrich, P., 1989. Die Wildbienen Baden Württembergs. In: Allgemeiner Teil Lebensräume, Verhalten, Ökologie und Schutz. Verlag Eugen Ulmer, Stuttgart.

Winfree, R., Aguilar, R., Vázquez, D.P., LeBuhn, G., Aizen, M.A., 2009. A meta-analysis of bees' responses to anthropogenic disturbance. Ecology 90, 2068-2076. 


\section{Chapter 6}

\section{Response diversity of solitary bees to overwintering temperatures}

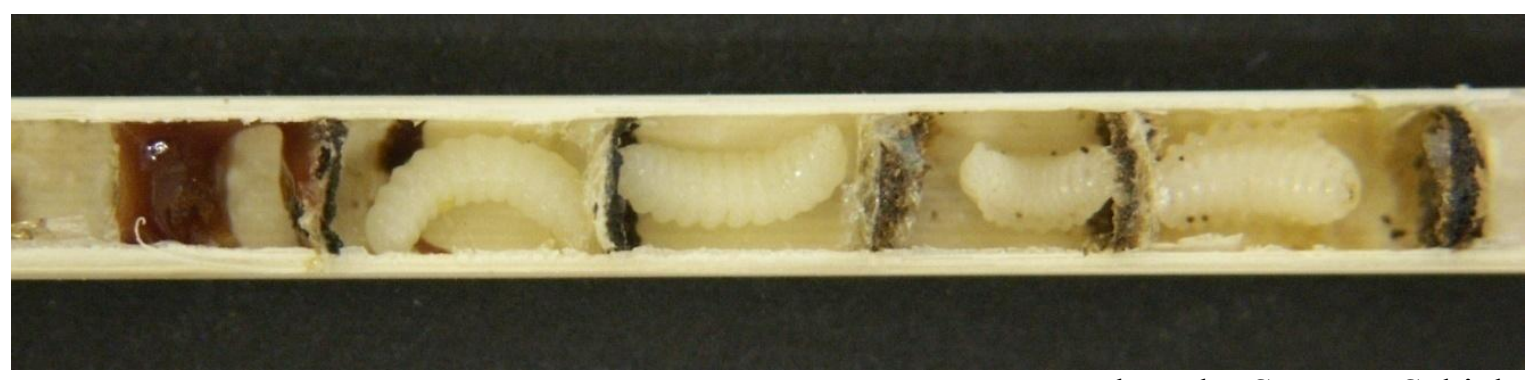

Photo by Susanne Schiele

Authors: Jochen Fründ, Sarah Zieger \& Teja Tscharntke

This chapter has been submitted for publication to Oecologia. 


\section{Abstract}

Biodiversity can provide insurance against environmental change, but only if species differ in their response to environmental conditions (response diversity). Wild bees provide pollination services to wild and crop plants, and response diversity might insure this function against changing climate. To experimentally test the hypothesis that bee species differ in their response to increasing winter temperature, we stored cocoons of nine bee species at different temperatures during the winter $\left(1.5^{\circ} \mathrm{C}\right.$ to $\left.9.5^{\circ} \mathrm{C}\right)$. Bee species differed significantly in their responses (weight loss, weight at emergence and emergence date). The developmental stage during the winter explained some of these differences. Bee species overwintering as adults generally showed decreased weight and earlier emergence with increasing temperature, whereas bee species overwintering in pre-imaginal stages showed weaker or even opposite responses. This means that winter warming will likely affect some bee species negatively by increasing energy expenditure, while others are less sensitive presumably due to different physiology. Likewise, species phenologies will respond differently to winter warming, potentially affecting plant-pollinator interactions. Responses are not independent of current flight periods: bees active in spring will likely show the strongest phenological advances. Taken together, wild bee diversity provides response diversity and potential insurance against climate change. 


\section{Introduction}

The consequences of global climate change for natural ecosystems can be severe (Sala et al. 2000; Parmesan 2006) and may affect their functioning and services (Geyer et al. 2011). Biodiversity is threatened by climate change (Thomas et al. 2004), but it may also provide an insurance against environmental variation (Naeem and Li 1997; Yachi and Loreau 1999) including climate change: if species respond differently to climate, the function performed by diverse communities should be more persistent across different climatic conditions than the function performed by species-poor communities. This property is generally called 'response diversity' (Elmqvist et al. 2003; Hooper et al. 2005; Laliberte et al. 2010), but it has been rarely tested whether species within functional groups really differ in their response to environmental change. In contrast, many studies on insect physiology rely on single model species (but see Addo-Bediako et al. 2002; Janion et al. 2009; Diamond et al. 2012). Pollination is an essential component of both ecosystem functioning and services (Kearns et al. 1998; Klein et al. 2007), and bees are the most important taxon contributing to this process (Kearns et al. 1998).

The phenology of many organisms is influenced by temperature. Increased temperature advances several phenological events (Fitter and Fitter 2002; Visser and Both 2005; Parmesan 2006), but the extent and direction of phenological shifts may vary between species (Fitter and Fitter 2002), potentially disrupting species interactions by phenological mismatch. While there are concerns about the integrity of plant-pollinator interactions (Memmott et al. 2007), field experiments show limited effects of phenological shifts on flower visitation (Parsche et al. 2011; Rafferty and Ives 2011).

Temperatures are predicted to increase disproportionately during the winter at least in Europe (Christensen et al. 2007). Effects of temperature during hibernation are less studied than effects of temperature during periods of activity. Generally, metabolic rate increases with temperature (Brown et al. 2004), which might lead to increased loss of stored energy in overwintering animals. Negative effects of increasing winter temperature have been shown for a few insect groups (e.g. flies: Irwin and Lee 2003; butterflies: Fartmann and Hermann 2006). While dependence of bee activity on temperature during the vegetation period is well known (Corbet et al. 1993; Stone 1994; Vicens and Bosch 2000), responses to winter temperature have only been studied in a few bee species with a focus on improving commercial management (Krunic and Hinks 1972; Richards et al. 1987; Bosch et al. 2000; Bosch and Kemp 2004; Sgolastra et al. 2010; Pitts-Singer and Cane 2011). These studies have shown that overwintering temperature influences the time 
of adult emergence and possibly survival and weight loss. Bee emergence time is also influenced by temperature during spring (Kemp and Bosch 2000; White et al. 2009; Forrest and Thomson 2011; Bartomeus et al. 2011). However, previous studies tested only a few contrasts of overwintering temperature, mostly outside the range of likely environmental change or natural interannual variation, and none of them tested multiple species within a single study.

In this study, we experimentally investigated the effect of overwintering temperatures on different wild bee species, focusing on the potential effects on energy or weight loss and changes in phenology (date of emergence). Using a finely resolved temperature gradient, we test the hypothesis that there is response diversity in the reaction to temperature among bee species.

\section{Materials and methods}

\section{Experiment}

We performed an experiment with overwintering cocoons or brood cells of nine species of solitary wild bees (Hymenoptera: Apiformes: Megachilidae and Colletidae) in climate chambers with a temperature gradient from $1.5^{\circ} \mathrm{C}$ to $9.5^{\circ} \mathrm{C}$. This gradient spans the whole range of temperature increases predicted by the IPCC (model projections for winter temperature increases in Northern Europe range between 2.6 to $8.2^{\circ} \mathrm{C}$ under the $\mathrm{A} 1 \mathrm{~B}$ scenario; Christensen et al. 2007). Given that the recent average temperature in Göttingen for November to February is $2.5^{\circ} \mathrm{C}$, our experimental gradient mainly simulated different degrees of warming and only limited cooling.

We used 17 climate chambers situated in different departments of the University of Göttingen. Climate chambers included true climatic chambers (or cabinets) of different types (12), but also cold storage rooms (2) and refrigerators (3); all cooling devices are considered as 'climate chambers' in this paper. All were set to a constant mean temperature between 1.5 and $9.5{ }^{\circ} \mathrm{C}$. To avoid bias by the different types of climate chambers, we choose temperature settings to create a temperature gradient also within each type and location of climate chamber. Apart from this constraint, temperatures were randomly assigned to climate chambers. One control set of bees was kept under outside conditions in Göttingen, Germany. Temperatures in each climate chamber were measured with iButton ${ }^{\circledR}$ data loggers every 90 minutes throughout the overwintering period. Mean temperatures across all measurements were used as explanatory variable in all analyses (= 
"overwintering temperature"). The range of realized temperatures within a climate chamber was generally low, with slightly higher fluctuations in refrigerators.

Bee nests were acquired from trap nests placed in 2009 in the field, mostly at the experimental field of the Agroecology group in Göttingen, Germany, and at an apple orchard close to Leipzig, Germany (see Gruber et al. 2011 for details of the study site). Before start of overwintering treatments, nests were stored in an unheated shed. Bee brood cells were isolated from the reed or bamboo internodes of the trap nests. Apparently intact brood cells were distributed in equal proportions to the different climate chambers. The same number of individuals and species proportion was used for all climate chambers (as far as possible). Individuals from the same nest were assigned to different climate chambers. Additionally, cocoons of two species (Osmia bicornis and Osmia cornuta) were purchased from the open rearing facilities of WAB Mauerbienenzucht in Konstanz, Germany. These cocoons were treated identically to the brood cells isolated from trap nests. Brood cells were individually placed in ID-labelled glass test tubes and sealed with cotton wool. Cocoons of Osmia were weighed before overwintering. Pre-winter weight could not be reliably measured for the other species, in which cocoons were not present or could not be feasibly separated from other nesting material.

Overwintering was started on 5 November 2009, locating trays with bee test tubes in the climate chambers, and lasted until 1 March 2010, when all trays were brought to an incubation room with a temperature of $12-17{ }^{\circ} \mathrm{C}$ and $42 \%$ relative humidity. Test tubes were checked at least daily for emerged bees. During the first five days from the start of incubation, cocoons of Osmia were weighed again on the same scales, successively taking sets of bees from all climate chambers to avoid imbalance or bias. Emerged bees were killed with ethyl acetate and stored at $-18{ }^{\circ} \mathrm{C}$. On 20 April 2010, remaining bees were moved to a different incubation room with a temperature of $17-23{ }^{\circ} \mathrm{C}$ until all bees had emerged (22 June 2010).

In total, nine bee species were represented by at least 10 emerged individuals and considered in the analyses. They can be broadly separated in two groups according to the developmental stage during the winter: Osmia bicornis (Linnaeus 1758), Osmia cornuta (Latreille 1805) and Chelostoma florisomne (Linnaeus 1758) enter diapause after metamorphosis (incomplete in C. florisomne) and emerged earlier than 50 days after termination of wintering treatments, whereas Heriades truncorum (Linnaeus 1758), Megachile ligniseca (Kirby 1802), Megachile centuncularis (Linnaeus 1758), Megachile versicolor Smith 1844, Hylaeus communis Nylander 1852 and Coelioxys mandibularis 
Nylander 1848 overwinter as larva or prepupa and emerged later than 50 days after end of wintering. The adult-overwintering species are naturally active in spring ('spring bees'), while the species that finish metamorphosis after winter are naturally active later in the year (late spring or summer, 'summer bees').

Dry weight was determined by drying specimens for $48 \mathrm{~h}\left(60^{\circ} \mathrm{C}\right)$ and immediately weighing dried specimens (within 20 minutes after taking them from the drying oven, avoiding water absorption). Body size was measured for all specimens as maximum head width in $\mathrm{mm}$, as this measure has been previously shown to be the best correlate of body mass among a number of morphometric variables (Bosch and Vicens 2002).

Mortality during the winter was generally very low (less than $5 \%$ in Osmia bicornis and Osmia cornuta, see Electronic Supplement), or it was difficult to separate from prewinter mortality (including damage caused by handling). This applied especially to species overwintering in pre-imaginal stages, which had the additional problem that only developed specimens (i.e. survivors) could be assigned unequivocally to a species in most cases. Therefore, we consider only surviving individuals in all analyses.

\section{Analyses}

Statistical analyses were performed using the statistical software R version 2.11.1 ( $\mathrm{R}$ Development Core Team 2010) and the 'nlme' package (Pinheiro et al. 2011). We used linear mixed effects models including a random effect of "chamber ID" to be able to test for the interaction between species and temperature without pseudoreplication for the temperature treatment. This approach is similar to the test for response diversity used in Winfree and Kremen (2009). A variance function (different standard deviation per species) was used to assure homogeneity of variances (Pinheiro et al. 2011).

We used mean temperature as explanatory variable in all linear models. For more accurately predicting the metabolic effects of temperature, it might be argued that the nonlinear relationship between temperature and metabolism should be considered. To explore whether this nonlinearity might influence our results, we calculated the sum of estimated metabolic rate for each measured temperature (based on exponents given in Brown et al. 2004). This measure was highly correlated to mean temperature $(r=0.995)$ showing that the temperature-metabolism relationship is approximately linear for the range of temperatures explored here, so we stick to mean temperature in the rest of the paper.

All explanatory variables of the respective models (one for each response variable, i.e. weight loss, weight at emergence and time to emergence) are presented in Table 1. To 
control for effects of body size on body weight, we used head width as a covariable in the models explaining dry weight. Body size might still change in bee species that have not completed metamorphosis before the winter. However, head width was not affected by temperature in our experiment $(p>0.5$ for both the main effect of temperature and for the temperature by species interaction; mixed effects model with head width as explanatory variable, including only bees overwintering in pre-imaginal stages). In the dry weight model, we also included the factor "faeces", indicating whether a bee had defecated after hatching and thereby lost some weight.

In weight loss models (fresh weight) for Osmia species, relative humidity (not significantly correlated with temperature, $r=-0.26, p=0.31$ ) and the number of days from beginning of incubation to weighing of cocoons were used as covariables. The response variable was the logarithm of weight loss during winter as per cent of pre-winter weight. No variance function was used in this model.

\section{Results}

Overwintering temperature did not influence mortality during winter, which was generally low (see Electronic Supplement). However, overwintering temperatures affected both the weight after winter and the date of emergence. Differences among bee species were found for both responses, indicated by the significant interactions between temperature and species (Table 1).

The two species in which weight loss over the winter could be directly measured lost significantly more weight at higher overwintering temperatures (Fig. 1, Table 1). This effect was significantly stronger in Osmia cornuta, in which weight loss doubled over a temperature increase from $1.5^{\circ} \mathrm{C}$ to $9.5^{\circ} \mathrm{C}$, reaching a mean of $8 \%$ for the highest overwintering temperature. As weight loss could not be accurately measured for most species, we used post-winter weight as an indirect measure of weight loss, controlling for body size and concentrating on dry weight to isolate metabolic effects (decreasing energy storage) from water loss. For effects on post-winter weight there was a significant temperature by species interaction (Table 1). Negative effects of higher temperatures on weight at emergence were found predominantly for species flying in spring and overwintering as adults (Fig. 2, Table 1), but in different strength. For species flying in summer and overwintering in pre-imaginal stages, winter temperature had positive, negative or no effects on final dry weight (Fig. 2, Table 1). 
Table 1: ANOVA tables of the linear mixed effects models of overwintering treatment effects on different bee species. Interactions among variables are indicated by ' $:$ '.

\begin{tabular}{|c|c|c|c|c|}
\hline & num. DF & den. DF & F-value & $\mathrm{p}$-value \\
\hline \multicolumn{5}{|c|}{$\begin{array}{l}\text { a) response variable: bee weight loss. i.e. } \log (\text { fresh weight change pre- to post-winter in \%); data were } \\
\text { available only for Osmia bicornis and Osmia cornuta. }\end{array}$} \\
\hline species & 1 & 550 & 12.3 & $<0.001$ \\
\hline temperature & 1 & 14 & 51.9 & $<0.001$ \\
\hline relative humidity & 1 & 14 & 14.4 & 0.002 \\
\hline incubation days & 1 & 550 & 49.5 & $<0.001$ \\
\hline species:temperature & 1 & 550 & 4.9 & 0.027 \\
\hline \multicolumn{5}{|c|}{ b) response variable: bee dry-weight after winter. i.e. $\log$ (weight in $\mathrm{mg}$ ); includes nine bee species. } \\
\hline species & 8 & 775 & 4775.8 & $<0.001$ \\
\hline $\log$ (head width) & 1 & 775 & 12203.2 & $<0.001$ \\
\hline $\operatorname{sex}$ & 1 & 775 & 82.8 & $<0.001$ \\
\hline faeces & 1 & 775 & 192.0 & $<0.001$ \\
\hline temperature & 1 & 15 & 5.8 & 0.030 \\
\hline species: $\log ($ head width) & 8 & 775 & 4.6 & $<0.001$ \\
\hline species:sex & 8 & 775 & 6.4 & $<0.001$ \\
\hline species:temperature & 8 & 775 & 5.2 & $<0.001$ \\
\hline \multicolumn{5}{|c|}{ c) response variable: bee phenology. i.e. days to adult emergence after winter; includes nine bee species } \\
\hline species & 8 & 1050 & 15788.7 & $<0.001$ \\
\hline $\operatorname{sex}$ & 1 & 1050 & 1429.8 & $<0.001$ \\
\hline temperature & 1 & 15 & 163.1 & $<0.001$ \\
\hline species:sex & 8 & 1050 & 81.1 & $<0.001$ \\
\hline species:temperature & 8 & 1050 & 50.2 & $<0.001$ \\
\hline sex:temperature & 1 & 1050 & 27.9 & $<0.001$ \\
\hline species:sex:temperature & 8 & 1050 & 5.9 & $<0.001$ \\
\hline
\end{tabular}

Osmia bicornis

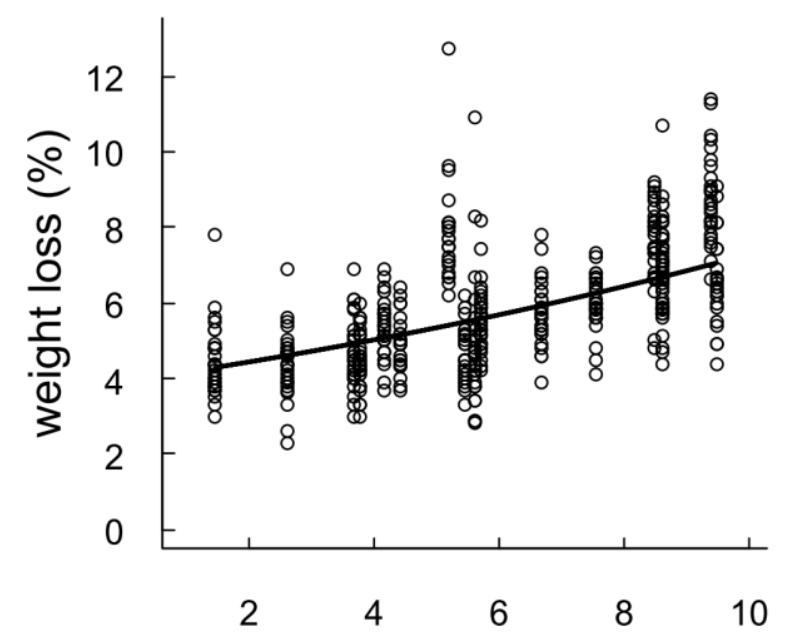

Osmia cornuta

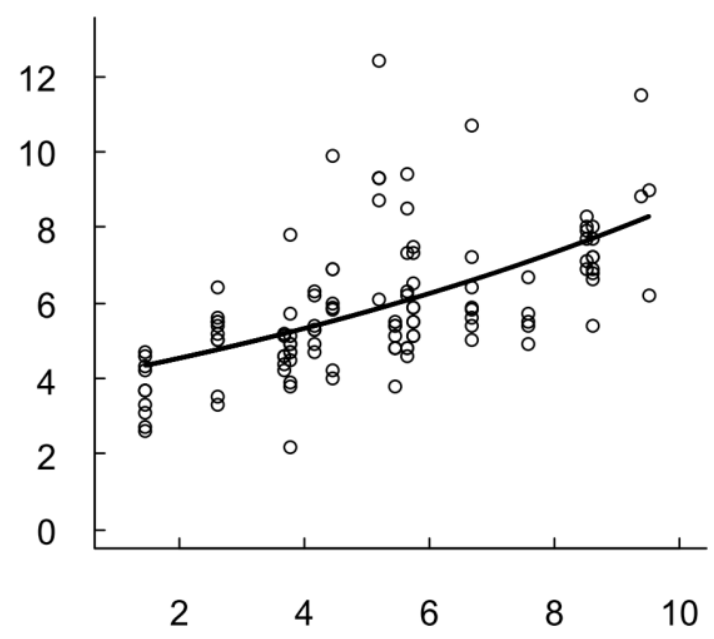

winter temperature $\left({ }^{\circ} \mathrm{C}\right)$

Figure 1: Loss of fresh cocoon weight (relative to pre-winter weight) in relation to mean overwintering temperature for the two bee species for which it could be measured directly. Solid lines show regression predictions from the mixed effects model, controlling for confounding factors (see Table 1). In difference to Fig. 2, points show the raw data here. 


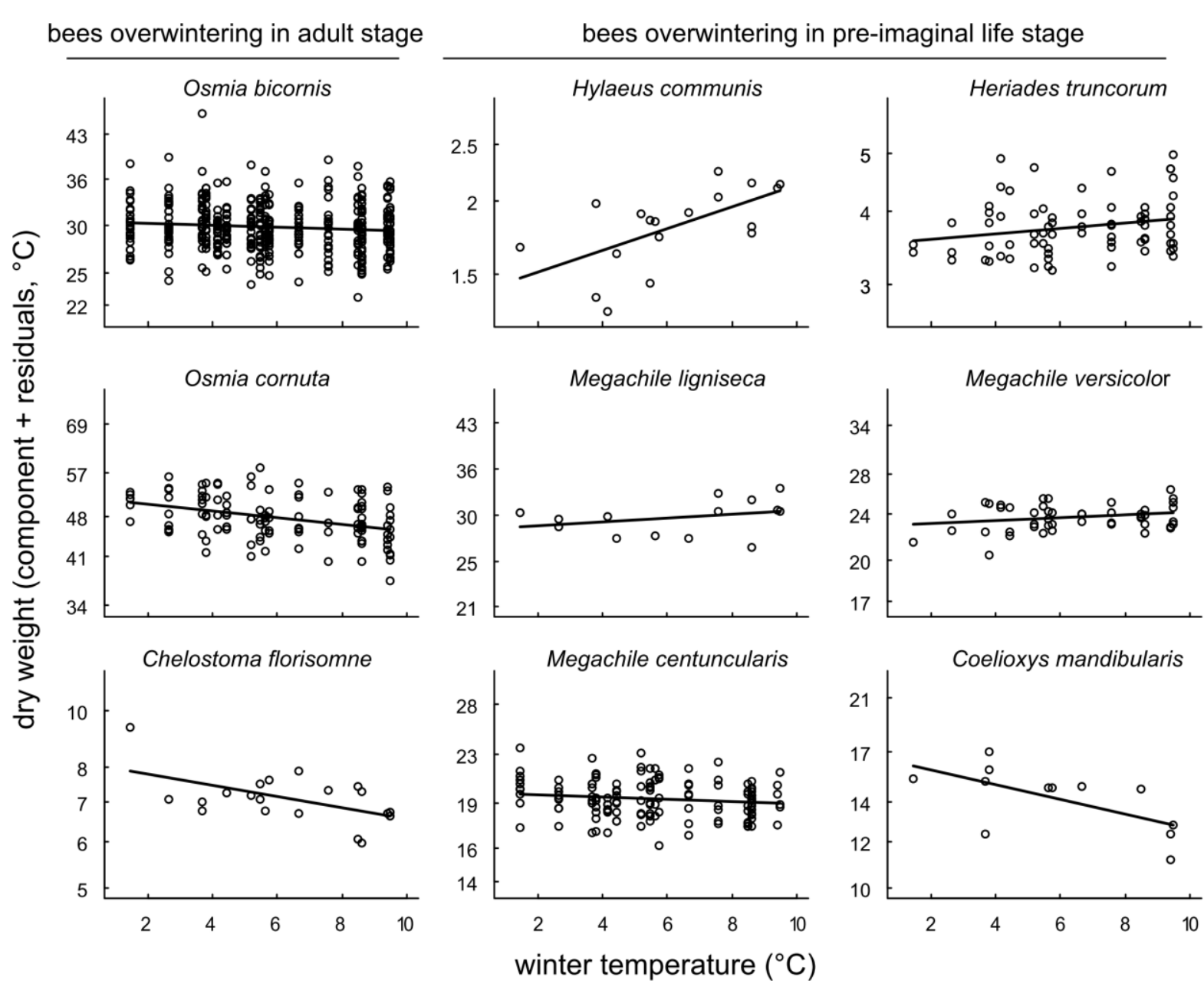

Figure 2: Dry weight of bees after emergence in relation to overwintering temperature (in climate chambers). Confounding effects of other factors are controlled for in this plot: the y-axis shows partial residuals of a linear mixed-effects model including the additional factors sex, defecation and $\log$ (head width) [within species]. One model was fit for all species, including differences among species and other factors (see Table 1), and this was also used for the regression lines. Note the log-scale of y-axes.

High overwintering temperature also had an effect on bee phenology (date of emergence), and this response differed significantly among species (Table 1): in some species, adults emerged earlier when they had been exposed to higher temperatures (Fig. 3 , Table 1). This also applied predominantly to 'spring bees' (advance by $\sim 1$ to 2 days per ${ }^{\circ} \mathrm{C}$ ), while 'summer bees' showed delayed emergence or no response (shift by $\sim-1$ to $<+$ 2 days per ${ }^{\circ} \mathrm{C}$ ). There was also variation in the phenological response to temperature among species within a phenological group. Sexes also responded differently, to a different extent in different species (significant three-way interaction, Table 1). When emergence date responses to temperature differed between sexes within a species, males tended to show less pronounced advance or more pronounced delay than females. The control set of bees that overwintered under outside conditions (temperature: mean $0.76{ }^{\circ} \mathrm{C}$, 
range -18 to $+16{ }^{\circ} \mathrm{C}$, sd $=5.6{ }^{\circ} \mathrm{C}$; humidity: mean $96 \%$, range 25 to $100 \%$ ) responded similarly to those under experimental conditions (Osmia bicornis and Osmia cornuta: weight loss slightly higher and emergence slightly earlier than predicted by our models).
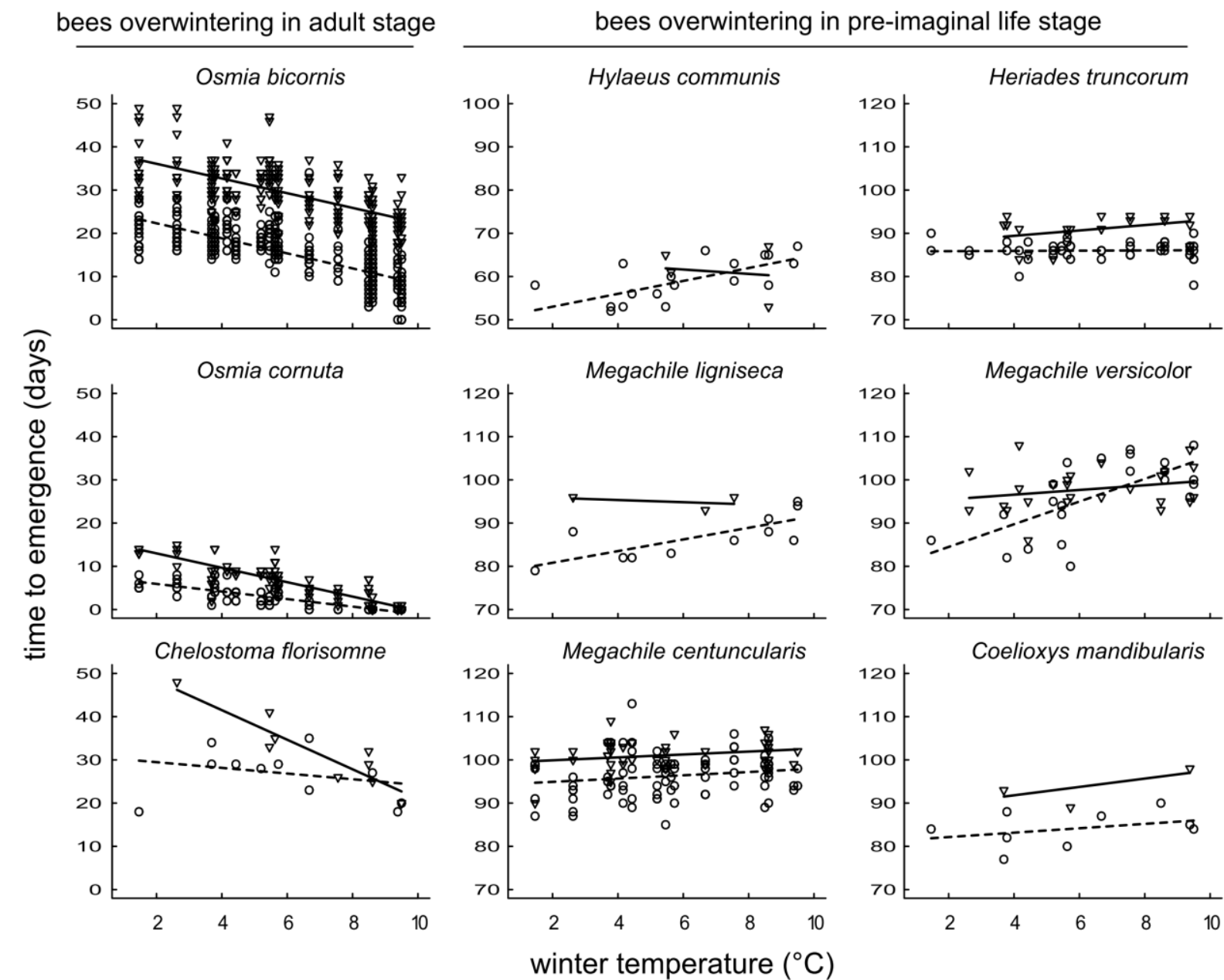

Figure 3: Effect of overwintering temperature on the time of emergence for nine bee species. Regression lines are shown for sexes separately (males: circles and dashed line, females: triangles and solid line) from a model fit for all species. Y-axis refers to the number of days from the beginning of incubation (1 March 2010). Points show the raw data.

\section{Discussion}

In this study, we found that temperature during overwintering affects weight at emergence and the time of emergence in a number of solitary bee species, and that these species differ in their responses to overwintering temperatures. Interspecific differences in temperature response could be explained partly, but not entirely, by the life history stage during overwintering. 
The increase in weight loss found in a majority of bee species presumably reflects higher metabolic rates and loss of energy. There is a direct effect of temperature on metabolic rates in most organisms (Brown et al. 2004), although the relationship may be weaker in insects during diapause. Effects of overwintering temperature on respiration rate in a solitary bee have been found in a recent study (Sgolastra et al. 2010). This effect may vary with diapause intensity, which, in turn, is influenced by many factors including ontogeny and pre-wintering conditions (Kemp and Bosch 2000; Bosch et al. 2010; PittsSinger and Cane 2011; Sgolastra et al. 2011). Differences in diapause intensity and resulting respiration rate could also explain some of the differences among species including differences in the response to temperature. While Megachile rotundata, a bee overwintering as prepupa and active in summer, decreases respiration to a minimum during winter, adult wintering bees probably have a less intensive diapause and increase respiration already by the end of winter (Kemp et al. 2004). This differential temperature sensitivity could explain the generally weaker response in 'summer bees' and the strong effect in Osmia cornuta, the earliest emerging species in our data set. For this species, negative effects of higher overwintering temperatures have been suggested in a previous study (Bosch and Kemp 2004). Even without lethal effects of higher winter temperatures, weight loss during winter probably affects fitness and vigour (Leather et al. 1993). Bosch et al. (2010) have shown that weight loss and fat body depletion entails decreased bee longevity.

It is surprising that the increase of weight loss with increasing temperature not only differently affected different bee species, but post-winter weight even appeared to be positively related to temperature in some species (e.g. Hylaeus communis and Heriades truncorum). This might be explained by adaptations to warmer winters, temperatureinduced changes in diapause intensity or up-regulation of cold-tolerance processes. For example, the production of metabolically costly cryoprotectants such as glycerol is independent of temperature in some insects, while it is a response to low temperatures in others (Leather et al. 1993). Although these issues cannot be resolved without better knowledge of the physiology of the species studied, it became clear that some bee species are more tolerant to increasing temperature than others and thus bee diversity provides response diversity to winter climate warming.

High overwintering temperature also had an effect on bee phenology - in some species, bees emerged earlier when they had been exposed to higher temperatures, as generally predicted (Gordo and Sanz 2005; Memmott et al. 2007; Hegland et al. 2009), and reported 
for a few bee species in experimental studies mainly focusing on post-wintering temperatures (Kemp and Bosch 2000; White et al. 2009; Sgolastra et al. 2011). As for weight loss, the generally predicted effect was predominantly found in 'spring bees' (consistent with Bosch et al. 2000; Bosch and Kemp 2004; Sgolastra et al. 2010), while 'summer bees' showed delayed emergence or no response. The importance of overwintering life-history stage for species' response to climate change has been stressed for other holometabolous insects such as butterflies (Wallisdevries and Van Swaay 2006), but previous studies on bees' response to climate change have barely considered species overwintering as larvae (Willmer 2012), which we found to respond differently than adult overwinterers. However, also species within each group responded differently to temperature treatments. Again, while the overall stronger effect on 'spring bees' can be explained by their less pronounced diapause (Kemp et al. 2004), the tendency to delayed emergence in 'summer bees' is difficult to explain. Although advanced mathematical models of emergence-response to temperature have been developed and the accumulation of degree-days is a useful concept to predict the time of emergence (White et al. 2009; Forrest and Thomson 2011), the underlying biological mechanisms are not really known. The degree-day concept implying that the time to completion of development depends on the temperature-dependent metabolic rate is less applicable for low temperatures and when diapause is involved. A possible, but unstudied, mechanism for delayed emergence after higher winter temperature in some species might be that stronger temperature contrasts at the end of winter cause accelerated diapause termination. This underscores the findings that the timing of climate warming is very relevant for phenological consequences (see also Fitter and Fitter 2002; Visser and Both 2005).

Phenological shifts caused by climate change may have multiple effects on organisms. Interestingly, the degree of protandry (i.e. males emerging before females) was reduced for several bee species in our experiment. Effects of temperature on synchrony of emergence have been reported by previous studies (Krunic and Hinks 1972; Richards et al. 1987). While in Osmia cornuta, the observed effect might be influenced by some males emerging already during the winter under warmer treatments and thus being missed in our data, the effect was found also in other species. This change in the relative appearance of the different sexes might influence mating behaviour, which is related to territoriality, nesting behaviour and reproductive fitness in bees (Eickwort and Ginsberg 1980).

Our findings also complicate the predictions about climate change consequences for plant-pollinator interaction networks and potential temporal mismatches (Memmott et al. 
2007; Hegland et al. 2009; but see Bartomeus et al. 2011). While species responded differently in our study, species with a similar phenology showed also more similar phenological shifts in response to warming. This might lead to a temporal gap in bee activity. Phenological mismatches might be limited if early blooming plants also show stronger advances in flowering than late blooming species, which was found in some plant studies (Miller-Rushing and Primack 2008; Rafferty and Ives 2011; Bartomeus et al. 2011).

For accurate predictions, the timing of warming is important, and temperatures will probably change to different extents in different seasons (Christensen et al. 2007). This could also change winter duration, which can have severe consequences for bees (Bosch and Kemp 2004) aside from effects of winter temperature. Variable temperatures or realistic temperature curves might have different effects than constant temperatures (Leather et al. 1993). In this study, we focus on differences in mean temperatures in order to have a feasible number of replicates and to avoid confounding thresholds with variability or specific temperature histories. Weight loss and time of emergence of bees in the outside control did not deviate strongly from predictions based on mean temperature, suggesting that overwintering under experimental constant temperature can be used as a reasonable estimate of responses under natural conditions. A recent study by Bartomeus et al. (2011) used observational data and found larger phenological advances of spring bees per degree of temperature increase than our study. While they considered recent climate change across all seasons and found the strongest effects for April temperatures, we isolated the effect of winter temperature change. Our experimental approach has the further advantage that it is independent of field observations focusing on flowers, which might underestimate the degree of temporal mismatches (see also Forrest and Thomson 2011). Compared to previous experimental studies considering temperature effects on bees, we used a more realistic temperature gradient within the range of climate change predictions.

Our results show that bee diversity represents response diversity with respect to overwintering temperatures, confirming the precondition for an insurance effect (Thomas et al. 2004) of bee biodiversity for pollination (Winfree et al. 2007; Winfree and Kremen 2009). These differences are obviously partly (but not completely) determined by the life stage during winter and likely corresponding differences in diapause intensity, which mediates differential temperature sensitivity. Therefore, future studies focusing on the relationship between temperature sensitivity and functional redundancy of different bee 
species (including soil-nesting species, for which overwintering has not been studied yet) are needed to fully evaluate the insurance potential of bee diversity for pollination. The results on how winter temperature affects the time of emergence are also important for estimating the consequences of phenological shifts caused by warming. Future studies on this topic should consider that bee phenologies respond to (winter) warming, but these responses cannot be assumed to be independent of a species' original phenology. Our study shows that climate warming may affect bees also during the season when they are inactive and it highlights the need for deeper biological knowledge for predicting consequences of climate change.

\section{Acknowledgements}

We kindly thank all departments of the University of Göttingen who helped by providing climate chambers, and Heinz Coners, Barbara Hohlmann, Evelyn Vorbeck, Hans-Otto Heise for technical assistance. We thank Bernd Gruber, Carsten Dormann, Maximilian von Fragstein and Mike Hermann for providing bees and Susanne Schiele for practical advice. Funding was provided to JF by a scholarship of the DBU (German Federal Environmental Foundation), and to TT by DFG (Deutsche Forschungsgemeinschaft).

\section{References}

Addo-Bediako A, Chown SL, Gaston KJ (2002) Metabolic cold adaptation in insects: a large-scale perspective. Funct. Ecol. 16:332-338.

Bartomeus I, Ascher JS, Wagner D, Danforth BN, Colla S, Kornbluth S, Winfree R (2011) Climate-associated phenological advances in bee pollinators and bee-pollinated plants. Proc. Natl. Acad. Sci. U. S. A. 108:20645-20649.

Bosch J, Kemp WP (2004) Effect of pre-wintering and wintering temperature regimes on weight loss, survival, and emergence time in the mason bee Osmia cornuta (Hymenoptera: Megachilidae). Apidologie 35:469-479.

Bosch J, Kemp WP, Peterson SS (2000) Management of Osmia lignaria (Hymenoptera: Megachilidae) populations for almond pollination: methods to advance bee emergence. Environ. Entomol. 29:874-883.

Bosch J, Sgolastra F, Kemp WP (2010) Timing of eclosion affects diapause development, fat body consumption and longevity in Osmia lignaria, a univoltine, adult-wintering 
solitary bee. J. Insect Physiol. 56:1949-1957.

Bosch J, Vicens N (2002) Body size as an estimator of production costs in a solitary bee. Ecol. Entomol. 27:129-137.

Brown JH, Gillooly JF, Allen AP, Savage VM, West GB (2004) Toward a metabolic theory of ecology. Ecology 85:1771-1789.

Christensen J, Hewitson B, Busuioc A, Chen A, Gao X, Held R, Jones R, Kolli R, Kwon W, Laprise R, Magaña Rueda V, Mearns L, Menéndez CG, Räisänen J, Rinke A, Sarr. A, Angelstam P (2007) Regional climate projections. In: Solomon S, Quin D, Manning M, Chen Z, Marquis M, Averyt KB, Tignor M, Miller HL (eds) Climate change 2007: the physical science basis. Contribution of working group I to the fourth assessment report of the Intergovernmental Panel on Climate Change. Cambridge University Press, Cambridge, United Kingdom and New York, NY, USA,

Corbet S, Fussell M, Ake R, Fraser A, Gunson C, Savage A, Smith K (1993) Temperature and the pollinating activity of social bees. Ecol. Entomol. 18:17-30.

Diamond SE, Sorger DM, Hulcr J, Pelini SL, Toro ID, Hirsch C, Oberg E, Dunn RR (2012) Who likes it hot? A global analysis of the climatic, ecological, and evolutionary determinants of warming tolerance in ants. Glob. Change Biol. 18:448-456.

Eickwort GC, Ginsberg HS (1980) Foraging and mating behavior in Apoidea. Annu. Rev. Entomol. 25:421-446.

Elmqvist T, Folke C, Nyström M, Peterson G, Bengtsson J, Walker B, Norberg J (2003) Response diversity, ecosystem change, and resilience. Front. Ecol. Environ. 1:488-494. Fartmann T, Hermann G (2006) Larvalökologie von Tagfaltern und Widderchen in Mitteleuropa. Abhandlungen aus dem Westfälischen Museum für Naturkunde 68:1157.

Fitter AH, Fitter RSR (2002) Rapid changes in flowering time in British plants. Science 296:1689-1691.

Forrest JRK, Thomson JD (2011) An examination of synchrony between insect emergence and flowering in Rocky Mountain meadows. Ecol. Monogr. 81:469-491.

Geyer J, Kiefer I, Kreft S, Chavez V, Salafsky N, Jeltsch F, Ibisch PL (2011) Classification of climate-change-induced stresses on biological diversity. Conserv. Biol. 25:708-715.

Gordo O, Sanz JJ (2005) Phenology and climate change: a long-term study in a Mediterranean locality. Oecologia 146:484-495.

Gruber B, Eckel K, Everaars J, Dormann CF (2011) On managing the red mason bee 
(Osmia bicornis) in apple orchards. Apidologie 42:564-576.

Hegland SJ, Nielsen A, Lázaro A, Bjerknes AL, Totland U (2009) How does climate warming affect plant-pollinator interactions? Ecol. Lett. 12:184-195.

Hooper DU, Chapin FS, Ewel JJ, Hector A, Inchausti P, Lavorel S, Lawton JH, Lodge DM, Loreau M, Naeem S, Schmid B, Setälä H, Symstad AJ, Vandermeer J, Wardle DA (2005) Effects of biodiversity on ecosystem functioning: a consensus of current knowledge. Ecol. Monogr. 75:3-35.

Irwin JT, Lee REJ (2003) Cold winter microenvironments conserve energy and improve overwintering survival and potential fecundity of the goldenrod gall fly, Eurosta solidaginis. Oikos 100:71-78.

Janion C, Worland MR, Chown SL (2009) Assemblage level variation in springtail lower lethal temperature: the role of invasive species on sub-Antarctic Marion Island. Physiol. Entomol. 34:284-291.

Kearns CA, Inouye DW, Waser NM (1998) Endangered mutualisms: The conservation of plant-pollinator interactions. Annu. Rev. Ecol. Syst. 29:83-112.

Kemp W, Bosch J (2000) Development and emergence of the alfalfa pollinator Megachile rotundata (Hymenoptera: Megachilidae). Ann. Entomol. Soc. Am. 93:904-911.

Kemp W, Bosch J, Dennis B (2004) Oxygen consumption during the life cycles of the prepupa-wintering bee Megachile rotundata and the adult-wintering bee Osmia lignaria (Hymenoptera: Megachilidae). Ann. Entomol. Soc. Am. 97:161-170.

Klein AM, Vaissiere BE, Cane JH, Steffan-Dewenter I, Cunningham SA, Kremen C, Tscharntke T (2007) Importance of pollinators in changing landscapes for world crops. Proc. R. Soc. Lond. B 274:303-313.

Krunic MD, Hinks CF (1972) The effect of temperature and of temperature pretreatment on diapause and on the synchronization of adult emergence in Megachile rotundata (Hymenoptera: Megachilidae). Can. Entomol. 104:889-893.

Laliberte E, Wells JA, DeClerck F, Metcalfe DJ, Catterall CP, Queiroz C, Aubin I, Bonser SP, Ding Y, Fraterrigo JM, others (2010) Land-use intensification reduces functional redundancy and response diversity in plant communities. Ecol. Lett. 13:76-86.

Leather SR, Walters KFA, Bale JS (1993) The ecology of insect overwintering. Cambridge University Press.

Memmott J, Craze PG, Waser NM, Price MV (2007) Global warming and the disruption of plant-pollinator interactions. Ecol. Lett. 10:710-717.

Miller-Rushing AJ, Primack RB (2008) Global warming and flowering times in Thoreau's 
Concord: a community perspective. Ecology 89:332-341.

Naeem S, Li S (1997) Biodiversity enhances ecosystem reliability. Nature 390:507-509.

Parmesan C (2006) Ecological and evolutionary responses to recent climate change. Annu. Rev. Ecol. Evol. Syst. 37:637-669.

Parsche S, Fründ J, Tscharntke T (2011) Experimental environmental change and mutualistic vs. antagonistic plant flower-visitor interactions. Perspect. Plant Ecol. Evol. Syst. 13:27-35.

Pinheiro J, Bates D, DebRoy S, Sarkar D, R Development Core Team (2011) nlme: Linear and nonlinear mixed effects models. R package version 3.1-98.

Pitts-Singer TL, Cane JH (2011) The alfalfa leafcutting bee, Megachile rotundata: the world's most intensively managed solitary bee. Annu. Rev. Entomol. 56:221-237.

R Development Core Team (2010) R: A language and environment for statistical computing. R Foundation for Statistical Computing, Vienna, Austria.

Rafferty NE, Ives AR (2011) Effects of experimental shifts in flowering phenology on plant-pollinator interactions. Ecol. Lett. 14:69-74.

Richards KW, Whitfield GH, Schaalje GB (1987) Effects of temperature and duration of winter storage on survival and period of emergence for the alfalfa leafcutter bee (Hymenoptera: Megachilidae). J. Kans. Entomol. Soc. 60:70-76.

Sala OE, Chapin FS, Armesto JJ, Berlow E, Bloomfield J, Dirzo R, Huber-Sanwald E, Huenneke LF, Jackson RB, Kinzig A, Leemans R, Lodge DM, Mooney HA, Oesterheld M, Poff NL, Sykes MT, Walker BH, Walker M, Wall DH (2000) Global biodiversity scenarios for the year 2100. Science 287:1770-1774.

Sgolastra F, Bosch J, Molowny-Horas R, Maini S, Kemp W (2010) Effect of temperature regime on diapause intensity in an adult-wintering Hymenopteran with obligate diapause. J. Insect Physiol. 56:185-194.

Sgolastra F, Kemp WP, Buckner JS, Pitts-Singer TL, Maini S, Bosch J (2011) The long summer: Pre-wintering temperatures affect metabolic expenditure and winter survival in a solitary bee. J. Insect Physiol. 57:1651-1659.

Stone GN (1994) Activity patterns of females of the solitary bee Anthophora plumipes in relation to temperature, nectar supplies and body size. Ecol. Entomol. 19:177-189.

Thomas CD, Cameron A, Green RE, Bakkenes M, Beaumont LJ, Collingham YC, Erasmus BFN, de Siqueira MF, Grainger A, Hannah L, Hughes L, Huntley B, van Jaarsveld AS, Midgley GF, Miles L, Ortega-Huerta MA, Townsend Peterson A, Phillips OL, Williams SE (2004) Extinction risk from climate change. Nature 427:145- 
148.

Vicens N, Bosch J (2000) Weather-dependent pollinator activity in an apple orchard, with special reference to Osmia cornuta and Apis mellifera (Hymenoptera: Megachilidae and Apidae). Environ. Entomol. 29:413-420.

Visser ME, Both C (2005) Shifts in phenology due to global climate change: the need for a yardstick. Proc. R. Soc. Lond. B 272:2561-2569.

Wallisdevries MF, Van Swaay CAM (2006) Global warming and excess nitrogen may induce butterfly decline by microclimatic cooling. Glob. Change Biol. 12:1620-1626.

White J, Son Y, Park YL (2009) Temperature-dependent emergence of Osmia cornifrons (Hymenoptera: Megachilidae) adults. J. Econ. Entomol. 102:2026-2032.

Willmer P (2012) Ecology: pollinator-plant synchrony tested by climate change. Curr. Biol. 22:R131-R132.

Winfree R, Kremen C (2009) Are ecosystem services stabilized by differences among species? A test using crop pollination. Proc. R. Soc. Lond. B 276:229-237.

Winfree R, Williams NM, Dushoff J, Kremen C (2007) Native bees provide insurance against ongoing honey bee losses. Ecol. Lett. 10:1105-1113.

Yachi S, Loreau M (1999) Biodiversity and ecosystem productivity in a fluctuating environment: the insurance hypothesis. Proc. Natl. Acad. Sci. U. S. A. 96:1463-1468. 


\section{Supplemental Material for Chapter 6}

Table S1a: number of individuals (brood cells / cocoons) per bee taxon

\begin{tabular}{lrr}
\hline Taxon $^{(1)}$ & pre-winter $^{(2)}$ & survivors \\
\hline Osmia bicornis & 644 & 619 \\
Osmia cornuta & 175 & 173 \\
Chelostoma & 37 & 24 \\
Heriades & 165 & 105 \\
Hylaeus & 35 & 30 \\
Megachile & 242 & 209 \\
\hline
\end{tabular}

(1) including parasitoids and cuckoo bees, but excl. Melittobia

(2) individuals potentially alive before winter

Table S1b: number of surviving individuals per bee taxon separated by sex

\begin{tabular}{lrr}
\hline Species $^{(3)}$ & males & females \\
\hline O. bicornis & 362 & 251 \\
O. cornuta & 80 & 91 \\
C. florisomne & 11 & 9 \\
H. truncorum & 52 & 20 \\
H. communis & 18 & 4 \\
M. centuncularis & 85 & 45 \\
M. ligniseca & 11 & 3 \\
M. versicolor & 22 & 25 \\
C. mandibularis & 9 & 3 \\
\hline
\end{tabular}

(3) species with fewer individuals and parasitoids not included

Survival rate was not significantly related to winter temperature for any of these taxa (glmm with binomial errors, neither a main effect of temperature nor a significant temperature by taxon interaction, $\mathrm{p}>0.1$ ). For the small bee species (Heriades, Chelostoma, Hylaeus), some mortality was probably related to handling. 


\section{Chapter 7}

\section{Synthesis}

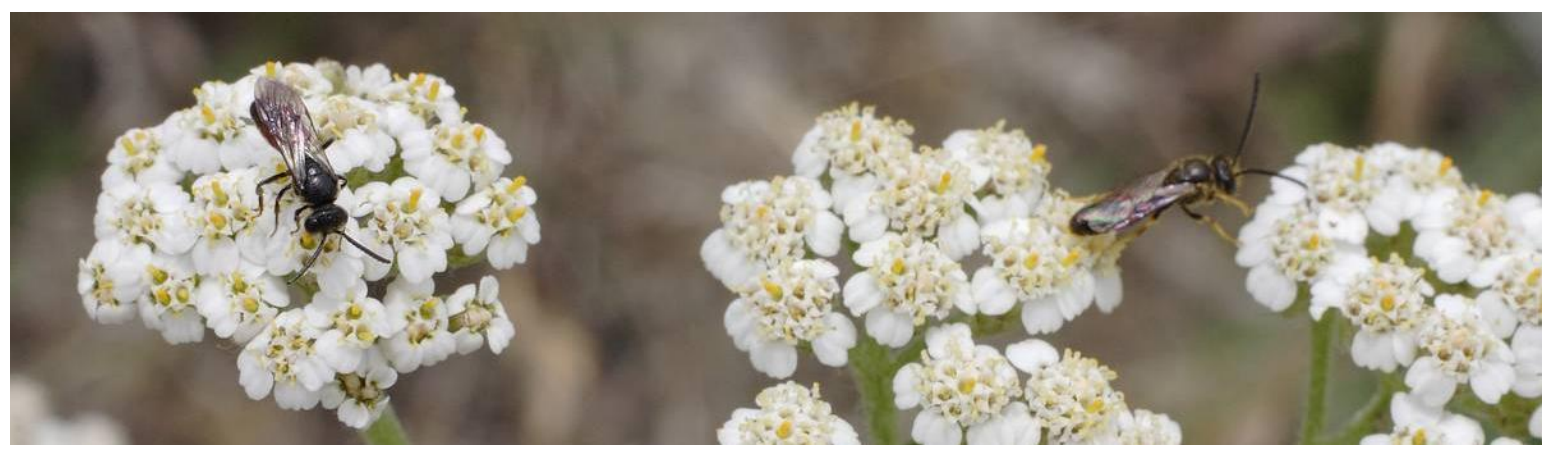

Photo by Jeroen Everaars 


\section{General Discussion}

In this thesis, I used different approaches to study pollination of wild plants and the importance of pollinator diversity for this ecosystem process. Most of my studies involved experimental treatments (chapters 2, 3, 5 and 6) and null model analyses of community and network patterns (chapters 2, 3, 4 and 5). With both I tried to minimize the influence of confounding factors, which are a pervasive problem in many ecological studies.

Declines in pollinator biodiversity, which have been observed around the globe (Brown \& Paxton 2009; Potts et al. 2010), may affect pollination and reproduction of plants. This might be the most important ecosystem process for which biodiversity-function relationships are poorly studied, as most biodiversity-ecosystem functioning research has primarily focused on primary productivity and consumptive interactions. Bees are among the most important and most declining groups of pollinators (Kearns et al. 1998; Biesmeijer et al. 2006; Westrich et al. 2008). Plant-pollinator interactions typically involve many different species, therefore a network approach is often most appropriate for understanding patterns and processes.

Based on my results, I will try to answer the main questions (research objectives) being addressed in this thesis:

\section{a) Does pollinator diversity have a positive effect on pollination of wild plants?}

Yes, but the number of bee species has only limited predictive power for plant community seed set (chapter 2). This is consistent with the few previous studies trying to answer the question (Klein et al. 2003; Hoehn et al. 2008; but see Perfectti et al. 2009). Future studies are needed to assess the generality of this effect. Knowledge of functional traits and the underlying mechanisms (e.g. functional niche coverage) strongly improves predictions about pollination effects of specific bee communities (chapter 2). More species will probably be needed at larger scales and under multiple conditions (Bengtsson et al. 2002; Isbell et al. 2011). Positive effects of pollinator diversity on larger spatio-temporal scales will likely also be found when environmental change is taken into account (chapters 5 and 6).

\section{b) Are different pollinator species functionally complementary, i.e. do they have different functional niches in which they provide pollination?}

Yes, on average. This could be confirmed to some degree in all chapters (2-6) and it is in agreement also with previous studies (Hoehn et al. 2008; Tylianakis et al. 2008b) and 
predictions (Blüthgen \& Klein 2011). Functional niche coverage, a measure of functional diversity which incorporates the effects of niche breadth and complementarity, predicts plant community seed set very well (chapter 2). However, not all species combinations exhibit the same degree of functional complementarity: for some species combinations, there is a considerable degree of redundancy in temperature sensitivity (chapters 2 and 6), in the plant species visited (chapters 3 and 4) and in the dependence on certain habitats (calcareous grasslands, chapter 5). Pollinator species can be complementary in many different dimensions (Blüthgen \& Klein 2011), not all of which could be considered in this thesis. Most importantly, parts of the realized complementarity effects are generated by interspecific interactions (probably competition) among bee species (chapter 2).

\section{c) How strong are daily temporal dynamics in plant-pollinator interactions and how are they related to daily patterns of flower opening and closure?}

In plant-pollinator networks, the identity of links among interacting species, flower availability and pollinator assemblies can drastically change between morning and afternoon (chapter 3), in line with findings from African savanna ecosystems (Stone et al. 1996; Baldock et al. 2011). However, the strength of temporal dynamics can differ between sites or networks depending on community context. In a set of meadows, withinday temporal patterns were mainly driven by rapid flower closure of the subfamily Cichorioideae within the Asteraceae. In a set of experiments, I showed for several species of this group that rapid closure of flower head is caused by successful pollination, while the timing of closure of flower heads had previously been attributed to abiotic or endogenous factors only (van Doorn \& van Meeteren 2003). This finding gives new insights in how communities of plants and pollinators are structured, providing a mechanism enhancing plant species coexistence and temporal specialization. Regarding pollinator diversity effects on pollination of plant communities, new concepts should be developed to incorporate these complexities: for example, pollinator complementarity with regard to morning vs. afternoon activity might be less important for the plants already closing at noon, but this would first require to identify how much pollinator circadian patterns are driven by patterns of flower opening and closure. 
d) Do tropical and temperate mutualistic interaction networks differ in the degree of functional complementarity, i.e. specialization of pollinators and seed dispersers?

Yes. In contrast to traditional assumptions (Hutchinson 1959), our study (chapter 4) shows that mutualistic interactions in tropical latitudes are less specialized than those in temperate regions. Niche specialization has been put forward as an explanation of the well-studied latitudinal gradient in species richness, but this study shows that this is not plausible for plant-pollinator and plant-seed disperser networks. Strong complementary specialization, which is a precondition for strong complementarity effects of pollinator diversity on pollinationof plant communities, is probably more constrained in tropical regions in consequence of high plant diversity, and favoured in regions with colder climate. In seed-dispersal networks, the differences were even stronger and probably additionally driven by the high generalization of tropical obligate frugivores and a tendency towards generalization in stable climates (see also Blüthgen et al. 2007).

\section{e) Can pollinator diversity provide an insurance against environmental change, including climate change and habitat destruction?}

Probably yes. Different pollinator groups, such as bees and flies, responded differently to environmental change simulations in a factorial field experiment (chapter 5: the presence of calcareous grasslands, changing plant height and changing flowering time). In contrast to the expectation of possible synergistic effects (Tylianakis et al. 2008a), effects of environmental change interacted in the opposite way: despite its positive effect on pollination, the high bee diversity of calcareous grasslands did not provide insurance for pollination. Rather, generalist pollinators with different phenology and habitat preferences ensured pollination also when multiple changes occurred simultaneously. In combination with a positive effect of enemy-release, phenological shift did not have a negative effect on plant reproductive success despite decreased bee visitation rate and changes in community composition. However, the effectiveness of various flies as pollinators requires further study (chapter 2, cf. Jauker \& Wolters 2008). Chapter 6 shows that bee diversity provides response diversity with respect to overwintering temperatures, confirming this precondition for an insurance effect of biodiversity. Winter temperature affected weight loss during diapause and the time of emergence of bees. These studies support the views that there is moderate potential for disruption of plant-pollinator interactions due to phenological shift (Hegland et al. 2009) and strong support for response diversity among pollinator species (Winfree \& Kremen 2009). 


\section{General Conclusions}

Taken together, the five studies advance the understanding of community-wide interactions among plants and pollinators and confirm that bee diversity is relevant for pollination. They stress the complex dynamics and flexible nature of these interactions, and these dynamics are only beginning to be understood. The need for more detailed biological trait information of multiple species is shown, as a prerequisite for reliably estimating the pollination function of bee communities. The intermediate and variable degree of specialization of plant-pollinator interactions and of individual pollinator species is important in mediating pollinator diversity effects on various scales. The pollination effect of bee communities is determined by functional complementarity, response diversity and species identity.

Wild bee diversity provides functional diversity on different scales, representing both a mechanism of direct pollinator biodiversity effects and an insurance against environmental change. However, there is some degree of redundancy both in response and effect traits of bee species, highlighting that diversity effects cannot be assumed for all cases with differing species composition. Rather, knowledge about biological traits (including life history, foraging behavior and temperature sensitivity) strongly improves the accuracy of predictions about the functional performance of bee communities (with respect to their role as pollinators).

Plant-pollinator interactions were shown to be highly dynamic, stressing the need to improve current approaches to the analysis and modelling of pollination networks. Pollination network dynamics include the sensitivity of realized flower preferences to the presence of co-occurring species, daily temporal dynamics depending on the reactivity of the local plant community to successful pollination, and dependence of network specialization on plant diversity. 


\section{References}

Baldock, K.C.R., Memmott, J., Ruiz-Guajardo, J.C., Roze, D. \& Stone, G.N. (2011). Daily temporal structure in African savanna flower visitation networks and consequences for network sampling. Ecology, 92, 687-698.

Bengtsson, J., Engelhardt, K., Giller, P., Hobbie, S., Lawrence, D., Levine, J., Vilà, M. \& Wolters, V. (2002). Slippin' and slidin' between the scales: the scaling components of biodiversity-ecosystem functioning relations. In: Biodiversity and ecosystem functioning: synthesis and perspectives. Oxford University Press, Oxford, New York, pp. $209-220$.

Biesmeijer, J.C., Roberts, S.P.M., Reemer, M., Ohlemüller, R., Edwards, M., Peeters, T., Schaffers, A.P., Potts, S.G., Kleukers, R., Thomas, C.D., Settele, J. \& Kunin, W.E. (2006). Parallel declines in pollinators and insect-pollinated plants in Britain and the Netherlands. Science, 313, 351-354.

Blüthgen, N. \& Klein, A.-M. (2011). Functional complementarity and specialisation: The role of biodiversity in plant-pollinator interactions. Basic and Applied Ecology, 12, 282-291.

Blüthgen, N., Menzel, F., Hovestadt, T., Fiala, B. \& Blüthgen, N. (2007). Specialization, constraints, and conflicting interests in mutualistic networks. Current Biology, 17, 341346.

Brown, M.J.F. \& Paxton, R.J. (2009). The conservation of bees: a global perspective. Apidologie, 40, 410-416.

van Doorn, W.G. \& van Meeteren, U. (2003). Flower opening and closure: a review. Journal of Experimental Botany, 54, 1801-1812.

Hegland, S.J., Nielsen, A., Lázaro, A., Bjerknes, A.L. \& Totland, U. (2009). How does climate warming affect plant-pollinator interactions? Ecology Letters, 12, 184-195.

Hoehn, P., Tscharntke, T., Tylianakis, J.M. \& Steffan-Dewenter, I. (2008). Functional group diversity of bee pollinators increases crop yield. Proceedings of the Royal Society B: Biological Sciences, 275, 2283-2291.

Hutchinson, G.E. (1959). Homage to Santa Rosalia or why are there so many kinds of animals? The American Naturalist, 93, 145-159.

Isbell, F., Calcagno, V., Hector, A., Connolly, J., Harpole, W.S., Reich, P.B., SchererLorenzen, M., Schmid, B., Tilman, D., van Ruijven, J., Weigelt, A., Wilsey, B.J., Zavaleta, E.S. \& Loreau, M. (2011). High plant diversity is needed to maintain ecosystem services. Nature, 477, 199-202. 
Jauker, F. \& Wolters, V. (2008). Hover flies are efficient pollinators of oilseed rape. Oecologia, 156, 819-823.

Kearns, C.A., Inouye, D.W. \& Waser, N.M. (1998). Endangered mutualisms: The conservation of plant-pollinator interactions. Annual Review of Ecology and Systematics, 29, 83-112.

Klein, A.M., Steffan-Dewenter, I. \& Tscharntke, T. (2003). Fruit set of highland coffee increases with the diversity of pollinating bees. Proceedings of the Royal Society of London Series B-Biological Sciences, 270, 955-961.

Perfectti, F., Gómez, J.M. \& Bosch, J. (2009). The functional consequences of diversity in plant-pollinator interactions. Oikos, 118, 1430-1440.

Potts, S.G., Biesmeijer, J.C., Kremen, C., Neumann, P., Schweiger, O. \& Kunin, W.E. (2010). Global pollinator declines: trends, impacts and drivers. Trends in Ecology \& Evolution, 25, 345-353.

Stone, G., Willmer, P. \& Nee, S. (1996). Daily partitioning of pollinators in an African Acacia community. Proceedings of the Royal Society of London Series B-Biological Sciences, 263, 1389-1393.

Tylianakis, J.M., Didham, R.K., Bascompte, J. \& Wardle, D.A. (2008a). Global change and species interactions in terrestrial ecosystems. Ecology Letters, 11, 1351-1363.

Tylianakis, J.M., Rand, T.A., Kahmen, A., Klein, A.-M., Buchmann, N., Perner, J. \& Tscharntke, T. (2008b). Resource heterogeneity moderates the biodiversity-function relationship in real world ecosystems. Plos Biol, 6, e122.

Westrich, P., Ulrich Frommer, Klaus Mandery, Helmut Riemann, Haike Ruhnke, Christoph Saure \& Johannes Voith. (2008). Rote Liste der Bienen Deutschlands (Hymenoptera, Apidae) (4. Fassung, Dezember 2007). Eucera, 1.

Winfree, R. \& Kremen, C. (2009). Are ecosystem services stabilized by differences among species? A test using crop pollination. Proceedings of the Royal Society B: Biological Sciences, 276, 229. 


\section{Acknowledgments}

This thesis would not have been possible with the help of many, many people. I owe deep thanks to my supervisor Teja Tscharntke for his continuous support and encouragement and always seeing the essentials and positive sides of new ideas and results. I deeply thank Carsten Dormann and Andrea Holzschuh for perfectly complementing my team of supervisors, with theoretical and practical expertise and your personalities. You three provided the optimal 'functional diversity of supervisors' and 'degrees of freedom' to allow for a strongly positive 'thesis effect'.

The Agroecology group provided a really nice environment for my $\mathrm{PhD}$ time. Thank you all for being one family and not a bunch of egoists! Thanks to the fellows of the Center for Applied Chaos Theory and Advanced Fish Nutrition - perhaps this is where the real progress was made... In fact, most current and former members of the group also helped me practically, in particular during the busy field season of 2008, be it soil shiveling, weeding, fruit harvesting, bumblebee permuting, carrying of heavy material, applying netting, providing trap nests, watering, or other things: Max von Fragstein, Christina Fischer, Andreas Flohre, David Gladbach, Sebastian Hänke, Björn Klatt, Kristin Krewenka, Christoph Rothenwöhrer, Barbara Scheid, Ines Vollhardt, Birte Waßmuth and Arno Wielgoss.

To manage the practical tasks mainly of the cage experiment and the entailed sample processing, I relied on the assistance of Susanne Jahn, Brigitte Jünemann and Bianca Tappe, who not only did excellent work but also improved experimental details by their ideas: thank you! I also thank Elisabeth Eilers, Vincent Karwath and Susi Parsche for assistance and suggestions, and Carola Fessel for technical assistance. Suse Schiele earns gratitude for all the tips and help with trap nest handling, and for keeping the lab organized. Thanks to the IT-team Thomas Österreich, Jan Tönjes and Siggi Opolka for responding to my special needs and queries. Jutta Gilles helped enormously leading me through the jungle of university bureaucracy.

During the preparation of the bee biodiversity experiment and later during the interpretation, I received a lot of valuable advice and good ideas by numerous people (in no particular order): Matthias Albrecht, Cathrin Westphal, Yann Clough, Christoph Scherber, Alex Klein, Ingolf Steffan-Dewenter, Carsten Thies, Andreas Bettin, Andreas Müller, Andreas Block, Rüdiger Schwenk, Ernst Rieger, Peter Batary, Birte Waßmuth, Wolfgang Link, Nico Blüthgen, Matthias Schäfer, Steve Hanlin, Neal Williams, Claire 
Kremen, Karen Goodell, Wolfgang Weißer, Jochen Krauss, Birgit Jauker, Frank Jauker, T'ai Roulston and definitely many more (e. g. for the comments I received in conferences and seminars). I thank Matthias Weitemeier, Björn Klatt, Reinhard Urner and Heinrich Klingelhöfer for support in the field season 2009.

It was nice to get help by other institutions within the university: the Division of Agricultural Engineering and the Division of Agronomy provided help in the preparation of the experimental field site, the Division of Agronomy and the Division of Plant Breeding provided greenhouse space, drying cabinets, and climate chambers, the Division of Crop Production Systems in the Tropics, the Division of Plant Pathology and Crop Protection and the Department of Plant Ecology and Ecosystem Research also provided climate chambers. I further thank Stefan Vidal for being an excellent committee-member and Klaus Hövemeyer for lending luxmeters.

I want to thank the two students I have supervised, Susann Parsche and Sarah Zieger, who perfectly mastered their masters' theses and thereby contributed enormously to chapters 5 and 6 . Thanks to Matthias Schleuning for taking over the lead of the latitudinal project and considering all my thoughts on this complex topic, and to the people in the YoMo network, including Florian Hartig, for the chance to also develop my understanding of ecological theory and simulation. For allowing to use their photos, I thank Henning Schnellen, Suse Schiele, Jeroen Everaars and René Capell, whom I also thank for help with cage preparation. Bee nests from the Sachsenobst project were provided by Bernd Gruber, Katharina Eckel and Jeroen Everaars.

The DBU (German Federal Environmental Foundation) supported this thesis with a three-year-scholarship. I want to thank the DBU for the financial and non-financial support, especially Hedda Schlegel-Starmann for mentoring and Volker Wachendörfer and fellow students for suggestions during the seminars.

My parents of course gave me support throughout my life for which I am grateful, but they also actively helped out in the hard times of the cage experiment when this help was most needed. Additional thanks to my father for suggestions for improving some of the texts.

Last, but not least, I thank Jana from the bottom of my heart for insisting on clear reasoning and true experimental tests, endless discussions on (circadian) science and allround support around-the-clock. 


\section{Declaration: contribution of the author to multi-authored manuscripts}

I did not use any other sources as those indicated. This thesis has not been submitted previously in any form for another degree at any university or institution. I have developed and written chapters 1 and 7 without co-authors. Chapters 2-6 are manuscripts in preparation or published journal articles, to which I made major contributions. In all these studies, I contributed substantially to the development of the study design, the main ideas, the analyses and interpretation of data and the writing of the manuscript.

Chapter 2 is based on a study that was mainly developed, performed and presented by me, with the co-authors being involved in the conception of the study, discussion and interpretation of analyses, results and their presentation, and in writing the final version of the text.

Chapter 3 describes a study primarily developed, performed and presented by me, coauthors providing guidance in data analyses and interpretation and being involved in writing the final version of the text.

Chapter 4 is a joint work of many co-authors who contributed with data, ideas, interpretation and writing. The project idea was initiated by me and others in a discussion group on a workshop organized by A-M. Klein, N. Blüthgen and C. F. Dormann. The project concept was mainly developed by M. Schleuning, me and the workshop organizers. I initiated the realization of the project idea, chiefly contributed to data collection, analyses, interpretation and presentation of the results. The manuscript was written in close collaboration by M. Schleuning and me.

Chapter 5 is based on a study conceived by me together with T. Tscharntke. S. Parsche contributed to the study design and performed the experiment under my guidance and collected the data. Data analyses were performed by me with contributions of S. Parsche, results were interpreted by me together with co-authors. The manuscript was written by $\mathrm{S}$. Parsche and me in close collaboration, with contributions by T. Tscharntke.

Chapter 6 is based on a study conceived by me and performed by S. Zieger with my help. S. Zieger collected and organized the data. I performed the analyses and wrote the manuscript. The co-authors contributed to the study design, development of ideas and interpretation of the results. 